University of Tennessee Health Science Center

UTHSC Digital Commons

\title{
The Value of Online Medication Rating Systems to Older Adults and Their Association with Self-Reported Outcomes
}

\author{
Yazed Sulaiman AlRuthia \\ University of Tennessee Health Science Center
}

Follow this and additional works at: https://dc.uthsc.edu/dissertations

Part of the Health and Medical Administration Commons, Health Information Technology Commons, and the Pharmacoeconomics and Pharmaceutical Economics Commons

\section{Recommended Citation}

AlRuthia, Yazed Sulaiman, "The Value of Online Medication Rating Systems to Older Adults and Their Association with Self-Reported Outcomes" (2015). Theses and Dissertations (ETD). Paper 11. http://dx.doi.org/10.21007/etd.cghs.2015.0011. 


\title{
The Value of Online Medication Rating Systems to Older Adults and Their Association with Self-Reported Outcomes
}

\begin{abstract}
The Internet is a powerful and very popular vehicle for distributing judgment-free health information to patients. Multiple studies have examined the role of online health information as well as physician-rating websites in health care. Studies have examined the value of online drug information for patients and the value of the online drug information for patients. However, no study has examined the usefulness or value of online medication rating websites in facilitating physician-patient communication or participantreported outcomes. In this study, the value of online medication rating websites to older adults in facilitating communication with their physicians using a newly developed tool was assessed. Additionally, the participant-reported outcomes of quality of life, satisfaction with physician communication, beliefs about medications, and medication adherence plus the relationship between the older adults' actual ratings of their antihypertensive medications and their self-reported outcomes were examined. Older adults with poor quality of life were more likely to view the online medication rating websites more favorably than participants who enjoy good quality of life. Participants who liked to share health decisions with their physicians were also more likely to have favorable views of the online websites. In addition, older adults with hypertension, who highly rated their antihypertensive medication regimens, were more likely to have good physical quality of life, high satisfaction with physician communication, positive beliefs about medications, and high medication adherence. Older adults with poor quality of life were more likely to be unsatisfied with their antihypertensive medications, have multiple comorbidities, limited health literacy, low satisfaction with their communication with their physicians, take multiple medications, and were more likely to view online medication rating websites favorably compared to their counterparts with good quality of life. Online medication rating websites may play an important role in enhancing physician-patient communication particularly among this segment of the patient population.
\end{abstract}

\section{Document Type \\ Dissertation}

\section{Degree Name}

Doctor of Philosophy (PhD)

\section{Program}

Health Outcomes and Policy Research

\section{Research Advisor}

Song Hee Hong, Ph.D.

\section{Keywords}

Medication, Older Adults, Online, Outcomes, Rating, Self-Reported

\section{Subject Categories}

Health and Medical Administration | Health Information Technology | Medicine and Health Sciences | Pharmacoeconomics and Pharmaceutical Economics 


\title{
The Value of Online Medication Rating Systems to Older Adults and Their Association with Self-Reported Outcomes
}

\author{
A Dissertation \\ Presented for \\ The Graduate Studies Council \\ The University of Tennessee \\ Health Science Center
}

\author{
In Partial Fulfillment \\ Of the Requirements for the Degree \\ Doctor of Philosophy \\ From The University of Tennessee
}

By

Yazed Sulaiman AlRuthia

May 2015 
Copyright $(\mathcal{C} 2015$ by Yazed Sulaiman AlRuthia. All rights reserved. 


\section{DEDICATION}

This dissertation is dedicated to my parents, Sulaiman Al-Ruthia and Mona AlAmari, who always believed in me and helped me believe more in myself. I also dedicate this dissertation to my wife, Nuha Al-Jadeed whose encouragement has meant so much to me during the pursuit of my graduate degree. Without their love, patience, and support this process would have been harder, longer, and very lonely. Thank you so much for travelling along this dissertation journey with me. 


\section{ACKNOWLEDGEMENTS}

First, I would like to thank my research adviser, Dr. Song Hee Hong for his support and help throughout this dissertation process. I would also like to thank my other committee members Drs. Carolyn Graff, David Solomon, Mehmet Kocak, and Robert Nolly. Without their help and support, this dissertation would not have been possible. Finally, I would like to thank Drs. Donald Morisky and Robert Horne for granting me the permission to use the Morisky Medication Adherence Scale (MMAS-8) ${ }^{\circledR}$ and the Beliefs about Medicine Questionnaire (BMQ) C), respectively. 


\begin{abstract}
The Internet is a powerful and very popular vehicle for distributing judgment-free health information to patients. Multiple studies have examined the role of online health information as well as physician-rating websites in health care. Studies have examined the value of online drug information for patients and the value of the online drug information for patients. However, no study has examined the usefulness or value of online medication rating websites in facilitating physician-patient communication or participant-reported outcomes. In this study, the value of online medication rating websites to older adults in facilitating communication with their physicians using a newly developed tool was assessed. Additionally, the participant-reported outcomes of quality of life, satisfaction with physician communication, beliefs about medications, and medication adherence plus the relationship between the older adults' actual ratings of their antihypertensive medications and their self-reported outcomes were examined.

Older adults with poor quality of life were more likely to view the online medication rating websites more favorably than participants who enjoy good quality of life. Participants who liked to share health decisions with their physicians were also more likely to have favorable views of the online websites. In addition, older adults with hypertension, who highly rated their antihypertensive medication regimens, were more likely to have good physical quality of life, high satisfaction with physician communication, positive beliefs about medications, and high medication adherence. Older adults with poor quality of life were more likely to be unsatisfied with their antihypertensive medications, have multiple comorbidities, limited health literacy, low satisfaction with their communication with their physicians, take multiple medications, and were more likely to view online medication rating websites favorably compared to their counterparts with good quality of life. Online medication rating websites may play an important role in enhancing physician-patient communication particularly among this segment of the patient population.
\end{abstract}




\section{TABLE OF CONTENTS}

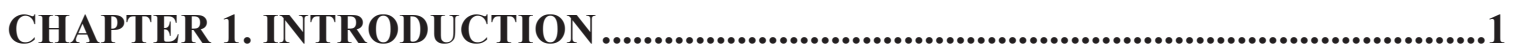

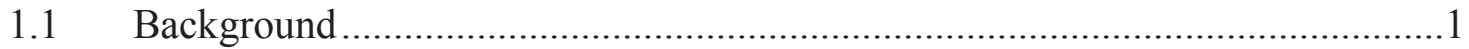

1.1.1 Online Health Rating Websites.................................................................

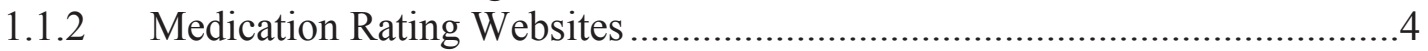

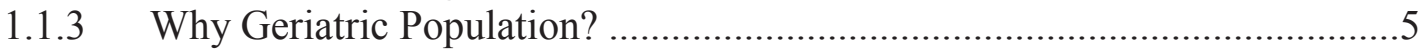

1.1.4 Physicians' Communication and Interpersonal Skills ...............................6

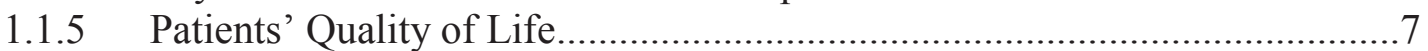

1.1.6 Patients' Beliefs about Medications......................................................... 9

1.1.7 Medication Adherence ........................................................................ 10

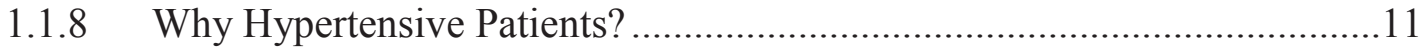

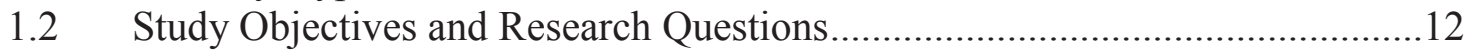

1.3 Theoretical Framework ...................................................................... 13

CHAPTER 2. LITERATURE REVIEW .................................................................16

2.1 Physician-Patient Communication................................................................ 16

2.1.1 Theoretical Models of Physician-Patient Relationship ..............................17

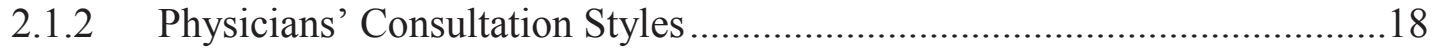

2.1.3 Communication with Older Adults ......................................................... 19

2.1.4 Factors Influencing Physician-Patient Communication..............................20

2.2 Linking Patient-Centered Care to Health Outcomes ......................................23

2.3 Assessing the Physician-Patient Relationship .................................................25

$2.4 \quad$ Health-Related Quality of Life (HRQoL) ....................................................26

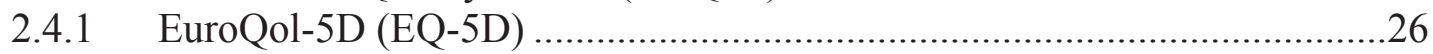

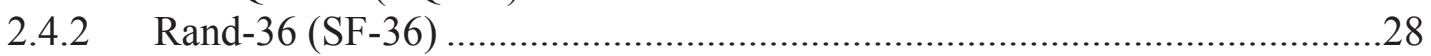

2.4.3 Nottingham Health Profile (NHP) ........................................................28

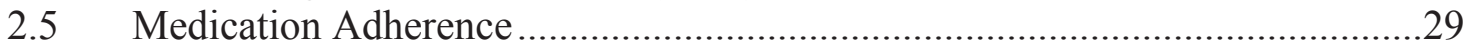

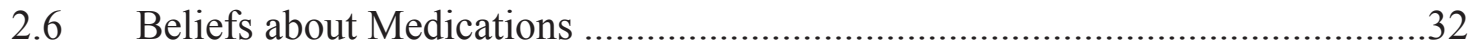

2.7 The Value and Influence of Media Outlets on Patients' Health Beliefs and

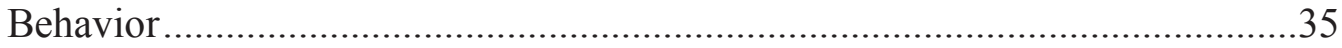

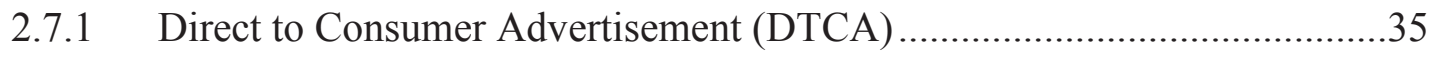

2.7.2 Online Search for Health Information .....................................................

CHAPTER 3. METHODOLOGY .......................................................................41

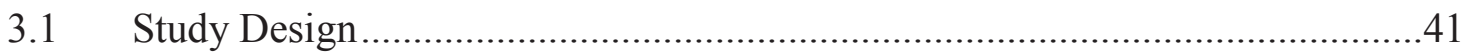

3.2 Settings and Subjects .............................................................................. 41

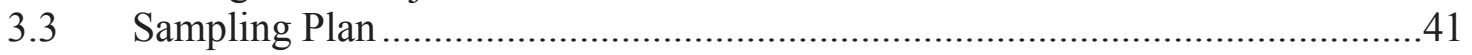

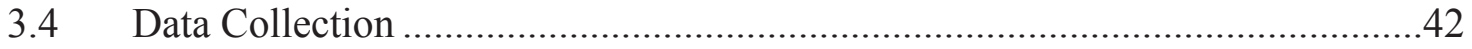

3.5 Participant-Reported Outcome Measures .......................................................42

3.5.1 Older Adults' Opinions of the Online Medication Rating Websites ...........42

3.5.2 Patient-Centered Practice Attributes.......................................................43

3.5.3 Health-Related Quality of Life ................................................................44

3.5.4 Patients' Beliefs about Medications.........................................................44

3.5.5 Medication Adherence .......................................................................45 
3.5.6 Older Adults' Evaluation of Their Antihypertensive Medication

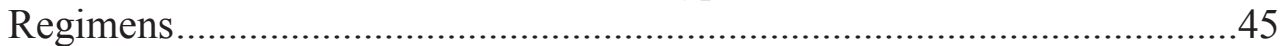

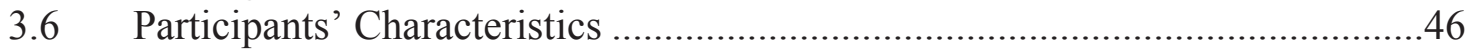

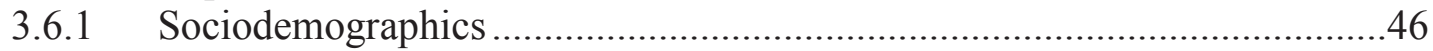

3.6.2 Health Decision Sharing Preference ......................................................46

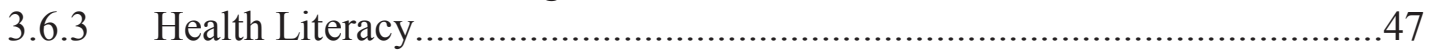

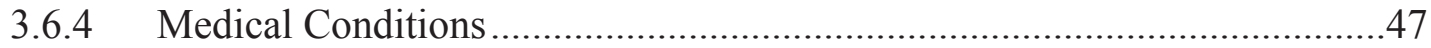

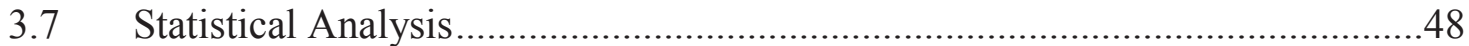

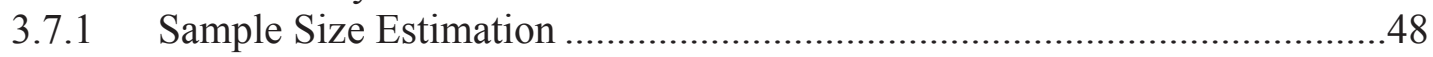

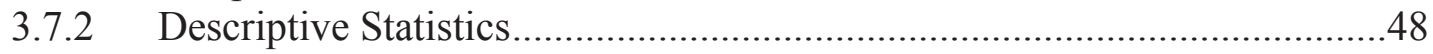

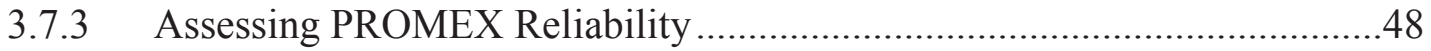

3.7.4 Principal Component Analysis ...........................................................49

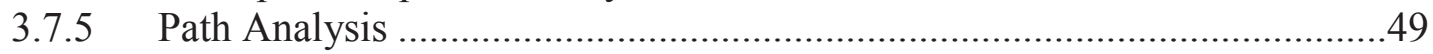

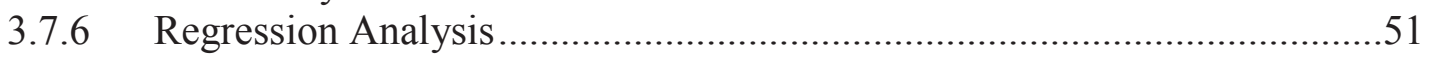

3.7.7 The Association between Participants' Rating of Their Antihypertensive Medication Regimens and Participant-Reported Outcomes (PROs) ...........52

3.8 Consideration of Human Subjects ................................................................54

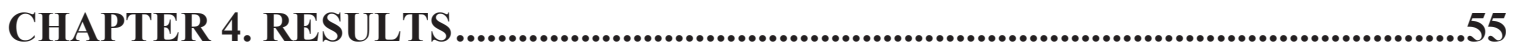

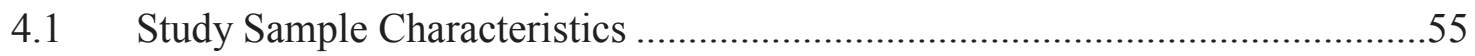

4.2 Item Analysis and Reliability of Patient Reviews of Medication

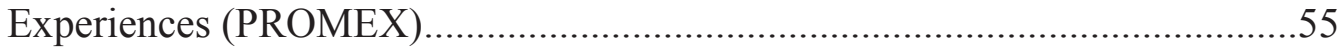

4.3 Patient Reviews of Medication Experiences (PROMEX) ..............................61

4.4 The Health-Related Quality of Life (HRQoL) ...............................................68

4.4.1 The SF-12v2 Physical Component Summary (PCS-12) ............................68

4.4.2 The SF-12v2 Mental Component Summary (MCS-12)............................68

4.5 Satisfaction with Physician Communication and Interpersonal Treatment.......73

4.5.1 The Primary Care Assessment Survey-Communication Scale (PCASCommunication) ................................................................................ 73

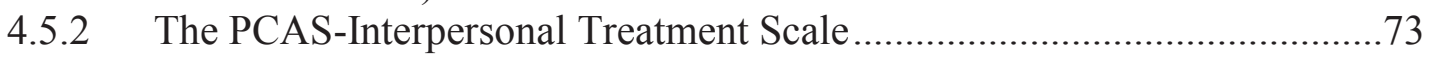

4.6 The General Domains of Beliefs about Medicines Questionnaire (BMQ) ........78

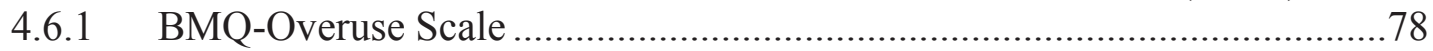

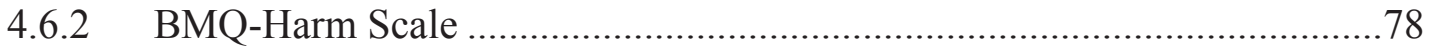

4.7 The Hypertensive Study Sample Characteristics .........................................83

4.8 Medication Adherence Levels among the Hypertensive Sample .....................83

4.9 Participant Rating of Antihypertensive Medication Regimens .......................89

4.10 Pearson Correlation Coefficients between Participant-Reported Outcomes

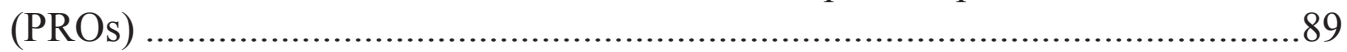

4.11 Pearson Correlation Coefficients between the Participant-Specific Ratings of Antihypertensive Medication Regimens and PROs ..................................101

4.12 Older Adult Participants' Views of Online Medication Rating Websites and Their Satisfaction with Physician Communication ......................................101

4.12.1 Path Model for the Association between PROMEX and PCASCommunication.................................................................................101

4.12.2 Multiple Linear Regression for the Association between PROMEX and

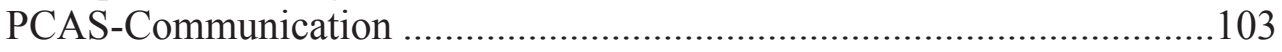


4.13 Older Adult Participants' Satisfaction with Physician Communication and

Overall Rating of Their Antihypertensive Medication Regimens

4.14 Older Adults' Views of Online Medication Rating Websites and Their

Quality of Life

4.14.1 Path Model for the Association between PROMEX and MCS-12 ............108

4.14.2 Path Model for the Association between PROMEX and PCS-12 .............108

4.14.3 Multiple Linear Regression for the Association between PROMEX and Both PCS-12 and MCS-12 ....................................................................108

4.15 The Health-Related Quality of Life and the Overall Rating of

Antihypertensive Regimens

4.15.1 The Association between the MCS-12 and the Overall Rating of Antihypertensive Regimens .....

4.15.2 The Association between the PCS-12 and the Overall Rating of Antihypertensive Regimens ....

4.16 Older Adult Participants' Views of Online Medication Rating Websites and

Their Beliefs about Medications

4.16.1 Path Model for the Association between PROMEX and BMQ-Overuse Scale

4.16.2 Path Model for the Association between PROMEX and BMQ-Harm Scale.

4.16.3 Multiple Linear Regression for the Association between PROMEX and Both BMQ-Overuse and BMQ-Harm...

4.17 Beliefs about Medications and the Overall Rating of Antihypertensive Regimens

4.17.1 The Association between BMQ-Overuse and the Overall Rating of Antihypertensive Regimens .....

4.17.2 The Association between BMQ-Harm and the Overall Rating of Antihypertensive Regimens ....

4.18 Older Adult Participants' Views of Online Medication Rating Websites and

Adherence to Antihypertensive Medication Regimens . .128

4.18.1 Path Model for the Association between PROMEX and Morisky Medication Adherence Scale (MMAS-8) 128

4.18.2 Regression Model for the Association between PROMEX and Morisky Medication Adherence Scale ( MMAS-8)

4.19 Medication Adherence and the Overall Rating of Antihypertensive Regimens

4.20 An Overarching Path Model of the Association between Older Adults' Views of Online Medication Rating Websites and Participant-Reported Outcomes

CHAPTER 5. DISCUSSION

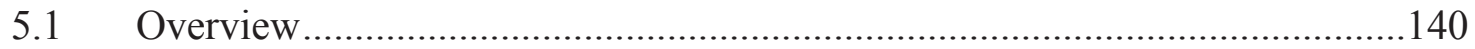

5.2 Patient Reviews of Medication Experiences (PROMEX) ..............................141

5.3 PROMEX and Participant-Reported Outcomes (PROs) .................................141

5.4 Participants' Rating of Their Antihypertensive Medications and ParticipantReported Outcomes (PROs)..................................................................... 146 


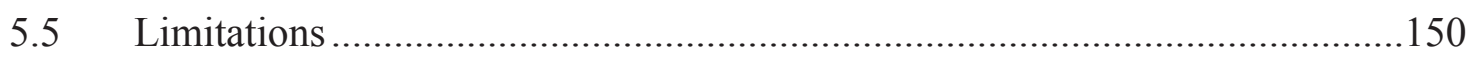

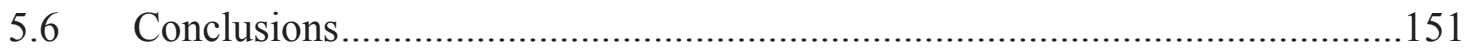

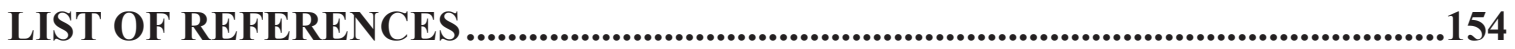

APPENDIX A. QUESTIONNAIRES AND COPYRIGHT PERMISSIONS............175

APPENDIX B. INSTITUTIONAL REVIEW BOARD DOCUMENTS .....................190

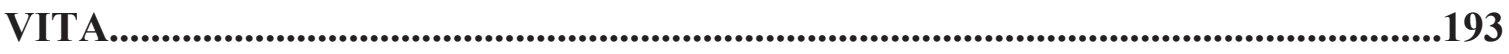




\section{LIST OF TABLES}

Table 2-1. $\quad$ Model of treatment decision-making........................................................24

Table 2-2. Comparison of quality of life instruments. ...................................................27

Table 4-1. Baseline characteristics of the participants across the senior centers. ...........56

Table 4-2. Item means, standard deviations, and minimum and maximum scores for

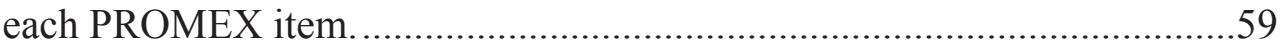

Table 4-3. Pearson correlation coefficients between PROMEX items and p-values.....60

Table 4-4. Cronbach coefficient alpha with deleted PROMEX item.............................62

Table 4-5. Eigenvalues of the correlation matrix........................................................63

Table 4-6. Loading of each item of PROMEX on the extracted factor...........................65

Table 4-7. Patient Reviews of Medication Experiences (PROMEX) scores of different sociodemographic subgroups $(\mathrm{n}=298)$........................................66

Table 4-8. SF-12v2 Physical Component Summary (PCS-12) scores of different sociodemographic subgroups $(\mathrm{n}=298)$.

Table 4-9. SF-12v2 Mental Component Summary (MCS-12) scores of different sociodemographic subgroups $(\mathrm{n}=298)$.

Table 4-10. Primary Care Assessment Survey (PCAS-Communication) scale

$(\mathrm{n}=300)$.

Table 4-11. Primary Care Assessment Survey (PCAS-Interpersonal Treatment) scale $(\mathrm{n}=300)$.

Table 4-12. Beliefs about Medicines Questionnaire-Overuse (BMQ-Overuse) scale scores of different sociodemographic subgroups $(n=297)$.

Table 4-13. Beliefs about Medicines Questionnaire-Harm (BMQ-Harm) scale scores of different sociodemographic subgroups $(\mathrm{n}=298)$.

Table 4-14. Baseline characteristics of the hypertensive participants $(\mathrm{n}=218)$.

Table 4-15. Morisky Medication Adherence Scale (MMAS-8) levels among the hypertensive sample $(\mathrm{n}=218)$.

Table 4-16. Morisky Medication Adherence Scale (MMAS-8) levels across the hypertensive subgroups. 
Table 4-17. Participants' evaluations of their antihypertensive medications ( $\mathrm{n}=193) \ldots . . .90$

Table 4-18. Pearson correlation coefficients between the participants' rated antihypertensive medication use aspects and their $\mathrm{p}$-values $(\mathrm{n}=193) \ldots \ldots . . .91$

Table 4-19. Antihypertensive medication rating (medication-specific) $(\mathrm{n}=148)$.............92

Table 4-20. Pearson correlation coefficients between the participant-reported outcomes (PROs) and their p-values $(\mathrm{n}=298)$.

Table 4-21. Pearson correlation coefficients between the participant-specific rating of antihypertensive medication regimens and participant-reported outcomes (PROs) variables.

Table 4-22. Path analysis: Standardized direct, indirect, and total effects of the variables evaluated on PROMEX and PCAS-Communication $(n=286) \ldots .105$

Table 4-23. Multiple linear regression: The association between PROMEX and PCAS-Communication $(\mathrm{n}=286)$. 106

Table 4-24. Multiple linear regression: The association between hypertensive participants' PCAS-Communication scale scores and overall ratings of their antihypertensive medication regimens $(n=193)$.

Table 4-25. Path analysis: Standardized direct, indirect, and total effects of the variables evaluated on PROMEX and MCS-12 $(\mathrm{n}=286)$.

Table 4-26. Path analysis: Standardized direct, indirect, and total effects of the variables evaluated on PROMEX and PCS-12 ( $\mathrm{n}=286)$.

Table 4-27. Multiple linear regression: The association between PROMEX and HRQoL (MCS-12) $(\mathrm{n}=286)$.

Table 4-28. Multiple linear regression: The association between PROMEX and HRQoL (PCS-12) $(\mathrm{n}=286)$.

Table 4-29. Multiple linear regression: The association between PROMEX and HRQoL (PCS-12 and MCS-12) ( $\mathrm{n}=286)$.

Table 4-30. Multiple linear regression: The association between hypertensive participants' MCS-12 scores and overall ratings of their antihypertensive medication regimens $(\mathrm{n}=193)$.

Table 4-31. Multiple linear regression: The association between hypertensive participants' PCS-12 scores and overall ratings of their antihypertensive medication regimens $(\mathrm{n}=193)$. 
Table 4-32. Path analysis: Standardized direct, indirect, and total effects of the variables evaluated on PROMEX and BMQ-Overuse $(n=286)$.

Table 4-33. Path analysis: Standardized direct, indirect, and total effects of the variables evaluated on PROMEX and BMQ-Harm $(n=286)$.

Table 4-34. Multiple linear regression: The association between PROMEX and BMQ-Overuse and BMQ-Harm $(\mathrm{n}=286)$.

Table 4-35. Multiple linear regression: The association between hypertensive participants' overall ratings of their antihypertensive medication regimens and BMQ-Overuse $(n=193)$.

Table 4-36. Multiple linear regression: The association between hypertensive participants' overall ratings of their antihypertensive medication regimens and BMQ-Harm $(\mathrm{n}=193)$.

Table 4-37. Path analysis: Standardized direct, indirect, and total effects of the variables evaluated on PROMEX and MMAS-8 $(n=286)$.

Table 4-38. Multiple linear regression: The association between participants' medication adherence (MMAS-8 Score) and PROMEX ( $\mathrm{n}=286)$.

Table 4-39. Multiple linear regression: The association between overall ratings of antihypertensive medication regimens and MMAS-8 score $(n=193)$.

Table 4-40. Standardized direct, indirect, and total effects of the variables evaluated on PROMEX, PCS-12, MCS-12, BMQ-Harm and BMQ-Overuse, and PCAS-Communication scales $(n=286)$. 


\section{LIST OF FIGURES}

Figure 1-1. The potential effect of online reviews of medications on physicianpatient communication.

Figure 1-2. Factors that may influence patient views of online medication reviews. .....15

Figure 2-1. Factors influencing physician-patient communication................................21

Figure 2-2. Factors influencing medication adherence....................................................30

Figure 2-3. Depiction of the self-regulation behavioral model. .......................................33

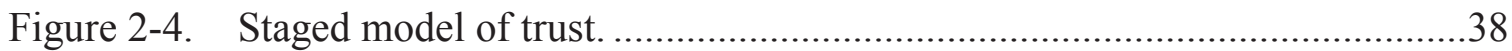

Figure 4-1. Scree plot of the possible number of factors that can be extracted from the 6-items PROMEX questionnaire...........................................................64

Figure 4-2. Antihypertensive medication ratings. ........................................................93

Figure 4-3. Rating of antihypertensive medications' effectiveness.................................94

Figure 4-4. Rating of antihypertensive medications' ease of use..................................95

Figure 4-5. Rating of antihypertensive medications' cost..............................................96

Figure 4-6. Rating of antihypertensive medications' food interactions. .........................97

Figure 4-7. Rating of antihypertensive medications' side effects. ..................................98

Figure 4-8. Overall rating of antihypertensive medications............................................99

Figure 4-9. Path analysis: Association between PROMEX and PCASCommunication. ...................................................................................104

Figure 4-10. Path analysis: The association between PROMEX and MCS-12...............109

Figure 4-11. Path analysis: The association between PROMEX and PCS-12 ...............111

Figure 4-12. Path analysis: The association between PROMEX and BMQ-Overuse.....120

Figure 4-13. Path analysis: The association between PROMEX and BMQ-Harm.........122

Figure 4-14. Path analysis: The association between PROMEX and MMAS-8 (adherence).

Figure 4-15. Path analysis: The association between PROMEX and PROs. 


\section{LIST OF ABBREVIATIONS}

$\begin{array}{ll}\text { BMQ } & \text { Beliefs about Medicines Questionnaire } \\ \text { CAD } & \text { Coronary Artery Disease } \\ \text { CHF } & \text { Congestive Heart Failure } \\ \text { COPD } & \text { Chronic Obstructive Pulmonary Disease } \\ \text { EQ-5D } & \text { EuroQol Five Dimensions Questionnaire } \\ \text { EQ-VAS } & \text { EuroQol Visual Analogue Scale } \\ \text { HRQoL } & \text { Health-Related Quality of Life } \\ \text { HTN } & \text { Hypertension } \\ \text { IBS } & \text { Irritable Bowel Syndrome } \\ \text { MCS-12 } & \text { The 12-Item Mental Component Summary of the Short Form } \\ & \text { Health Survey } \\ \text { MI } & \text { Myocardial Infarction } \\ \text { MMAS-8 } & \text { The 8-Item Morisky Medication Adherence Scale } \\ \text { NHP } & \text { Nottingham Health Profile } \\ \text { PCAS } & \text { Primary Care Assessment Survey } \\ \text { PCS-12 } & \text { The 12-Item Physical Component Summary of the Short Form } \\ & \text { Health Survey } \\ \text { PROs } & \text { Participant-Reported Outcomes } \\ \text { PROMs } & \text { Patient-Reported Outcome Measures } \\ \text { PROMEX } & \text { Patient Reviews of Medication Experiences } \\ \text { QoL } & \text { Quality of Life } \\ \text { RX } & \text { Prescription Medication } \\ \text { SF-12 } & \text { The 12-Item Short Form Health Survey } \\ \text { SF-36 } & \text { The 36-Item Short Form Health Survey }\end{array}$




\section{CHAPTER 1. INTRODUCTION}

\subsection{Background}

As people age they become more prone to diseases in general and to the chronic health conditions (i.e., diabetes, hypertension, and osteoporosis) in particular. Thus, chronic diseases are more prevalent among this segment of the population. Further, an ever-greater proportion of this population survives with multiple health conditions. Hence, older adults take a greater number of prescription medications than any other segments of the population. This makes them more susceptible to adverse drug events given their diminished physiological reserve (Wasson, 2008). In addition, many studies have shown a correlation between increasing age and higher adverse drug events (ADEs) rate. Besides the frailty of the elderly, which makes them more predisposed to the side effects of the medications, they are usually on multiple prescription medications. Taking multiple medications increases the likelihood of developing adverse drug reactions or interactions since the toxicity of any medication can be potentiated by another medication in the patient's medication list (i.e., by inhibiting or inducing its metabolism). Therefore, effective communication between the physicians and their patients can address some of these issues by changing or removing certain medications from their medication lists, and by adopting a holistic approach in managing the elderly patients' health conditions rather than treating each condition separate from the other (Routledge, O'Mahony, \& Woodhouse, 2004).

Generally speaking, patients want their physicians to inform them about their health conditions, the treatment options, as well as the safety profile and cost of each medication if pharmacological options were chosen (Nair et al., 2002). The patients' desire to learn about their health conditions, and the available treatment options, suggests they want to participate in the prescribing decision with their physicians. Involving the patients in the prescribing decision-making process after providing them with needed information about treatment options could result in improved patient treatment experience and satisfaction. It also may result in improved treatment outcomes (Bond, Blenkinsopp, \& Raynor, 2012). This partnership between patients and their physicians regarding the prescribing decision is even more important among the elderly. Since the elderly are mostly excluded from the randomized clinical trials that investigate the benefits of preventive medications. These medications are usually prescribed to treat different chronic diseases, such as hypercholesterolemia and hypertension, that are prevalent among the elderly population (Garattini \& Chalmers, 2009; Wasson, 2008). Thus, they fail to address important aspects of drug use from the patients' perspective (i.e., side effects, drug-food interactions, medication costs, drug-drug interactions).

Many patients seek information about different drugs that they are taking or will probably be taking in the future from multiple sources including the Internet. Further, studies that assessed the quality of medication prescribing among the ambulatory elderly patients, have indicated many of the prescribed medications were considered inappropriate (Goulding, 2004; Schmader, Hanlon, Weinberger, \& Landsman, 1994). 
Although medication prescribing appropriateness was assessed among the elderly in several studies, the patients' perspective regarding their medications was not taken into account (Goulding, 2004; Spinewine et al., 2007). Exploring elderly patients' opinions about their prescription medications can be useful to explain the variation in the medication utilization and adherence among this important segment of the population. This can be attained by asking the patients' about their level of satisfaction with regard to important aspects of medication use (i.e., effectiveness, side effects, ease of use, cost, and drug interactions), and substantiates the need to engage the elderly patients in prescribing decisions.

Today, many federal and private health institutions provide online educational information about different medical conditions and their treatments (i.e., Centers for Disease Control and Prevention, MedlinePlus, Mayoclinic $\left.{ }^{\circledR}\right)$. However, the information presented on these websites about the different treatments whether invasive (i.e., surgery) or non-invasive (i.e., pharmacological) are merely the same information provided in the medications' leaflets in layman's terms. In an era of empowered consumers, many websites provide the feedback of consumers about different products and services. Hence, patients in multiple online websites evaluate medications and services provided by medical professionals. This gives the patients who are looking for physicians in special practice areas, or are likely to be on a certain medication, the opportunity to view the evaluations and the overall ratings by other patients who had already seen those physicians or are/were on that medication. The factors that influence the patients' opinions of the content and value of these websites have not been investigated. Although patients with higher socioeconomic status might have a favorable opinion of these websites, other factors might also influence patient perception. For instance, patients' quality of life (QOL), a subjective and overarching concept involving multiple dimensions of the patient's life could potentially influence the opinion and value of such websites. Further, in an era of patient-centered care that entails effective communication between the physicians and their clients (patients), it is worthwhile to examine the significance of the relationship between patients' satisfaction with their physicians' communication style and their opinion of such website. Websites browsing may encourage and facilitate the patients' engagement in effective dialogs with their physicians. Patients' beliefs about medications could also affect the value of such websites to patients, since it was found to influence patients' adherence to their medications (Horne \& Weinman, 1999).

This study examined the relationship between the older adults' views of online medication rating websites (i.e., Askapatient.com ${ }^{\circledR}$, Drugs.com ${ }^{\circledR}$ ) and:

1. Important aspects of patient-centered care (i.e. attentive listening, quality of conversation, respect, and friendliness).

2. Older adults' quality of life from both the physical and mental perspectives.

3. Older adults' beliefs about medications in general.

4. Older adults' adherence to antihypertensive medications. 


\subsubsection{Online Health Rating Websites}

The implementation of public reporting systems in the United States (U.S.) in the 1980s was mainly driven by the need to improve the quality of care provided by healthcare organizations. These systems generate reports that compare the quality of care provided by different healthcare practitioners. The New York State Cardiac Surgery Reporting System (CSRS), Nursing Home Compare, and the German Kinikfuhrer RheinRuhr are examples of such systems (Emmert, Meier, Pisch, \& Sander, 2013; Mukamel \& Mushlin, 1998; Mukamel, Weimer, Zwanziger, Gorthy, \& Mushlin, 2004; Stevenson, 2006). These systems play a very important role in informing the patients, physicians, and health policy makers about the quality of care of multiple health institutions and healthcare providers. Further, these reports intend to encourage patients to participate in their own care by making informed choices about their healthcare providers, health plans and services (Faber, Bosch, Wollersheim, Leatherman, \& Grol, 2009).

Based on the Public Reporting theory, it is generally assumed that patients make an effort to learn about a product, such as a medication, before buying it. This applies to patients who usually search for healthcare services with good quality such as health insurance plans, physicians, and medications (Emmert, Sander, \& Pisch, 2013). The advent of the Internet provides a great opportunity for health activists and non-profit consumer protection organizations to design and create information rich websites. These websites contain a wealth of information about a variety of products including healthcare services that customers can utilize to make informed choices (Chen \& Xie, 2008; Longo et al., 1997). Nonetheless, these websites along with the public reports provide quality of care evaluation and comparisons across different health institutions and physicians based on clinical and scientific criteria and not from patients' perspective (Emmert, Sander, et al., 2013).

Websites that evaluate physicians and services from patients' perspective are ubiquitous in the Internet. Physicians' rating websites (i.e., RateMDs ${ }^{\circledR}$, Healthgrades ${ }^{\circledR}$ ) are examples that have gained popularity among patients who look for physicians with positive feedbacks from patients. These websites convey important information to both physicians and patients alike. Patients can easily search for specific physicians near their residence with the highest rating. Further, physicians can read patients' reviews and comments about their practices, and try to improve the quality of provided care (Tara Lagu, Hannon, Rothberg, \& Lindenauer, 2010). However, critics of such websites list several limitations. First, they do not include all practicing physicians in their databases; merely including 30\% of them at best (Emmert, Maryschok, Eisenreich, \& Schöffski, 2009). Secondly, most physician rating websites rely only on few patient reviews with few physicians rated by more than five patients (Mostaghimi, Crotty, \& Landon, 2010). Thirdly, only a few use validated criteria to evaluate physicians (Reimann \& Strech, 2010). Fourth, male physicians, those with board certifications and certain subspecialties (i.e., primary care, obstetrics and gynecology) are more likely to be rated than other specialties such as general surgery (Black, Thompson, Saliba, Dawson, \& Paradise Black, 2009) and physicians with malpractice claims are likely to be evaluated and rated negatively (Segal, 2009). Fifth, most contain positive reviews of the listed physicians and 
rarely contain negative feedbacks of the rated physicians (Kadry, Chu, Kadry, Gammas, $\&$ Macario, 2011). This raises the question of the validity of such reviews since they are provided by anonymous people and the possibility of fraud cannot be excluded (i.e., some physicians can write positive reviews of themselves). Sixth, many physicians question the ability of patients to make sound judgment of their physicians' quality of care. Most patients according to some physicians are not knowledgeable about the clinical skills needed to evaluate the quality of the provided care (Emmert, Sander, Esslinger, Maryschok, \& Schöffski, 2012). Taken together, this limits the usefulness of such websites (Emmert, Sander, et al., 2013). However, proponents see in such websites that evaluate not only physicians, but also other healthcare services and products (i.e., psychologists, prescription medications, over-the-counter medications and herbal products) an opportunity to understand patients' views and preferences. Further, their availability may offer a channel for patients to express their opinions in an anonymous and confidential way about the quality of the received care (Trigg, 2011).

Although these websites have several shortcomings and limitations, they can be addressed by taking measures to improve their content and value. For example, a minimum number of ratings/reviews for any physician or product should be determined. Further, the reviews should cover several aspects of care (i.e., satisfaction with the overall care, description of the physicians' communication style). In addition, websites should run security checks to protect reviewers' privacy. Finally, validated quality standards should be followed and word filters should be applied to prevent vulgar words or defamation from being posted (Emmert, Sander, et al., 2013; Segal, 2009).

\subsubsection{Medication Rating Websites}

Medication rating websites are newly emerged online websites, which have not been researched or reported in the literature before. The information presented on these websites are variable and contingent upon the sponsors as well as the affiliations. For example, the National Library of Medicine provides a useful website (www.ncbi.nlm.nih.gov/pubmedhealth/) about different medications in terms of their routes of administration, dosage forms, indications, brand names, side effects, as well as warnings about drug-drug and drug-food interactions. Further, the major chain pharmacies in the United States (U.S.) like Walgreens ${ }^{\circledR}$ (www.walgreens.com) and CVS ${ }^{\circledR}$ (es.cvs.com/drug/overview) provide useful and valid online information about multiple prescription and over-the-counter (OTC) medications to patients with respect to several aspects of medication use (i.e., indications, dosages, dosage forms, side effects, and food and drug interactions). Some health insurance plan websites, such as Cigna ${ }^{\circledR}$ (www.cigna.com), also offer valid information about different prescription medications to their enrollees. Although, providing valid and detailed information in layman's terms to patients about different medications, they lack, with few exceptions, patient reviews of the medications. Therefore, several independent websites have recently emerged on the Internet offering patients the opportunity to rate their medications as well as to view the opinions of other patients about different medications. 
Most of these rely heavily on commercial advertisements, and vary in their content and layout. This can be ascribable to the website administrators or authors, as some are operated by healthcare practitioners or by professional editorial staff, while consumerreporting agencies manage others. The WebMD ${ }^{\circledR}$ (www.webmd.com) and Drugs.com ${ }^{\circledR}$ (www.drugs.com) are well-known examples of the professionally operated websites that include updated scientific information in both layman's and medical terms about the medications and the health conditions they are prescribed for. Also included are reviews and comparisons of different medications prescribed for similar health conditions by patients in terms of their effectiveness, side effects and patients' satisfaction. Patients can rate their medications on a scale from one to five where one means dissatisfied and five means highly satisfied. Further, they include the prices as well as coupons and patient assistance programs for prescription medications that patients can refer to in case they are needed. In addition, some websites include support groups, where patients can ask questions related to a particular medication that will be answered by a medical expert. On

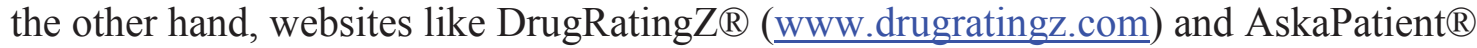
(www.askapatient.com) are operated by consumer reporting agencies that merely include patients' reviews and ratings of different prescription medications with regard to their effectiveness, convenience, side effects, and overall value. The main mission of these websites is to convey to physicians, pharmaceutical industry, and other patients the opinions of the websites users. However, these websites have limitations similar to the physicians rating websites. As with the physicians rating websites, these do not include important information about the reviewers such as sociodemographics, health conditions, number of medications, and prescriber specialties. These issues need to be addressed to improve their value to patients. Overall, medication-rating websites may empower patients to become more engaged in their health care.

\subsubsection{Why Geriatric Population?}

The growth of the older adult population in the U.S. over the next 50 years is expected to have a tremendous impact on the health care system. The number of older adults is projected to reach 55 million by 2020 as baby boomers age (McGinnis, March 2006). According to the Administration on Aging (AoA), the older population ( $\geq 65$ years) represented $12.9 \%$ in 2009, and is expected to reach 19\% in 2030 (Administration on Aging). In addition, more than $90 \%$ of older adults have at least one chronic medical condition, and $77 \%$ have multiple chronic conditions. Chronic diseases such hypertension and diabetes account for $75 \%$ of the total U.S. health care expenditure (Schwartz, 2011). The average number of office visits for older adults in 2012 according to the AoA is 7.1; which is twice that for adults between 45 and 65 years of age (U.S. Administration on Aging (AOA), 2012). Further, although seniors ( $\geq 65$ years) do not represent more than $13 \%$ of the US population; they consume approximately $34 \%$ of the total number of prescriptions per year (Control, 2004). This makes their utilization of the healthcare services higher than any other segments of the population. However, older adults are underrepresented in clinical trials and observational studies as well as in the clinical practice guidelines since they are mostly presented with multiple comorbidities that entail different treatment guidelines (Boult C, 2010; Boyd et al., 2005; Konrat et al., 2012; 
Lugtenberg, Burgers, Clancy, Westert, \& Schneider, 2011). The current elderly population is more diverse than a decade ago and is likely to be even more diverse in the next decades. It is projected that older adults of the minority population will increase by $217 \%$ by 2030 compared with $81 \%$ for Caucasian population (Administration on Aging, 2013).

The fact that many older adults are heterogeneous with regard to socio-demographics, medical conditions, severity of illness, personal experiences and preferences, and their quality of life demands flexible approaches in caring for this segment of the population. In addition, since many of the older adults with multiple comorbidities are on multiple medications to keep their chronic illnesses under control, they face "preference sensitive" decisions when their physicians decide to put them on a different medication or add another one. This comes as a result of their increased awareness of the adverse events as well as the possible drug interactions when a new medication is introduced in their medication lists (American Geriatrics Society Expert Panel on the Care of Older Adults with Multimorbidity, 2012). Further, the challenging task that faces almost every patient in general and particularly the elderly, is the adherence to their prescription medications. Medication adherence is more challenging for older adults compared to the younger populations due to their tendency to forget as well as their long medications lists (E. J. MacLaughlin et al., 2005). Thus, empowering elderly patients should be one of the utmost priorities of any physicians in general, and the primary care providers in particular since they are the gatekeepers in any successful health care system (American Geriatrics Society: American Geriatrics Society Expert Panel on the Care of Older Adults with Multimorbidity, 2012). The patients' empowerment would hopefully make the elderly patients feel that they are involved in their own care since their participation is pivotal in the success of any disease management plan (Schwartz, 2011).

\subsubsection{Physicians' Communication and Interpersonal Skills}

As the practice of medicine evolved over time, physicians felt that the success of any disease management plan depends on the patients themselves. Thus, a new principle in health care known as patient autonomy and patient-centered clinical practice was ushered in (Chin, 2002; Rodriguez-Osorio \& Dominguez-Cherit, 2008). This necessitates that the current and future physicians be equipped with new skills that enable them to address the needs of the patients in general and the elderly in particular since elderly patients are usually presenting with multiple health conditions. Hence, many physicians have started adopting a patient centered practice model instead of the traditional paternalistic practice model that prevailed for decades (R. Baker, 1999; American Geriatrics Society Expert Panel on the Care of Older Adults with Multimorbidity, 2012). This model takes into consideration the patients' experiences and insights that are believed to be relevant in the medical decision-making process (Charles, Gafni, \& Whelan, 1997). Understanding the patients' needs and concerns will likely have a positive impact on both the clinical outcomes as well as on the participant-reported outcomes (PROs) (Falkum \& Førde, 2001; Roumie et al., 2011). 
Elderly patients are not different from any other segment of the patient population in their desire to be involved in their own care. However, elderly patients are heterogeneous in their medical and personal characteristics. Further, their definition of involvement is different from the younger patient population who tend to participate more in the decision making process (Coulter, Parsons, \& Askham, 2008). The elderly patients' definition is more centered on "receiving information", "patient-centered approach", and "caring relationship" (Bastiaens, Van Royen, Pavlic, Raposo, \& Baker, 2007). Therefore, physicians need to have effective communication techniques in order to initiate constructive dialogs with their patients that enable them to elicit the patients' concerns and needs. Skills like attentive listening, speaking slowly, providing simplified medical information, being empathic, and making informed decision based on patients' needs and preferences are all important attributes of effective communication that physicians should possess (Duffy, Gordon, Whelan, Cole-Kelly, \& Frankel, 2004; Travaline, Ruchinskas, \& D'Alonzo, 2005). Effective communication and interpersonal treatment are integral in any therapeutic treatment plan, since it does not only address the physical aspect of the disease, but also addresses the psychological aspect of it (Travaline et al., 2005). Further, evidence suggests that effective patient-physician communication is correlated with improved patient health outcomes, lower health-related costs, reduction in the number of emergency department visits, improvement in the quality of life, medication adherence, and higher patient satisfaction (Stewart, 1995; Travaline et al., 2005).

However, in the real world many physicians are ineffective communicators, putting more pressure on patients to initiate constructive dialogs with their physicians that will ultimately serve both providers and patients. Thus, patients' empowerment tools such as educational television (TV) programs, public awareness programs, online patients' educational websites (i.e., Medline ${ }^{\circledR}$ ), and even TV and online drugs ads may encourage patients to discuss with their physicians the signs and symptoms of certain medical conditions they may have as well as exploring possible treatment options (Jacob, 2002; Van Woerkum, 2003). The advent of the Internet has revolutionized the provision of health information to the public. Today, patients can surf it and find hundreds if not thousands of health education websites that provide a wealth of information about almost any known disease. However, little is known about the value of such websites to patients in general and to elderly patients in particular in improving the patient-physician communication. Such websites may empower elderly patients who usually play a passive role when communicating with their physicians.

\subsubsection{Patients' Quality of Life}

Patients' health-related quality of life (HRQoL) is one of the patient-reported outcome measures (PROMs). Unlike the clinician-reported outcomes (ClinROs) that measure the effectiveness of the treatment (i.e. Hb1Ac, BP), the PROMs are mostly selfcompleted questionnaires, which can be completed by the patients themselves or by others on their behalf in structured interviews (Meadows, 2011). Quality of life (Qol) is a subjective multidimensional concept that involves several domains of life and assesses the impact of a treatment intervention, health conditions or employment status on the 
individual's life from their perspective. The physical, material, social, productive, emotional and civic well-being are the main domains of life that fall under the quality of life umbrella (Felce, 1997). This concept can also be concisely defined as "the satisfaction of an individual's values, goals and needs through the actualization of their abilities or lifestyle" (Emerson, 1985, p. 282). Hence, personal satisfaction, life conditions, and quality of life are inseparably intertwined concepts (Felce \& Perry, 1995).

The quality of life is variably defined across and within different groups of the population. For instance, the elderly people describe their quality of life differently compared to younger individuals. Multiple factors lead to this variation in the elderly's definition of this subjective concept. As people age, they face several physical and emotional limitations making their life experience very different. Further, due to the subjectivity of the quality of life concept, elderly people differ in their opinions of their quality of life even if their health and socioeconomic status are similar. Thus, some elderly people describe their lives as full of joy and happiness, whereas others feel their lives are depressing and miserable. The variability in describing quality of life among the elderly can be ascribable to the way elderly people interpret their losses, personality type, sets of belief, stress coping strategies, strength of family and social networks, economic status, health conditions, and functional ability (Wilhelmson, Andersson, Waern, \& Allebeck, 2005; Xavier, Ferraz, Marc, Escosteguy, \& Moriguchi, 2003).

Besides the subjective and objective factors considered as determinants of the individual's quality of life, other factors might also shape a person's perception of their quality of life. In an era of high technology, the Internet transformed many parts of our lives including the way we communicate with each other (i.e. Email, Facebook ${ }^{\circledR}$, and Twitter $\left.{ }^{\circledR}\right)$. The U.S. is one of the top countries in the world in terms of the number of the subscribers to Internet services, with a percentage over 70\% (Stats, 2012). This was found to have a significant impact on quality of life (Albarran \& Goff, 2000; Cairncross, 2001; DiMaggio, Hargittai, Neuman, \& Robinson, 2001). People with weak social ties and poor communication skills as well as the elderly can expand their acquaintances and gain a wealth of knowledge through online connection. Further, the use of online forums, counseling, and news can enhance self-sufficiency, psychological empowerment, and rehabilitation (Leung, 2010). Also, Internet use among older adults is associated with lower perceived life stress, improved psychological well-being, self-confidence, and higher personal satisfaction with social relations including family members and friends (Leung, 2010; Liang, 2011).

Today, many patients turn to the Internet to share their illness experiences with their illnesses with other patients through self-created personal blogs. Others use certain websites that facilitate communication with other patients who have the same health conditions. Such websites help reduce the feeling of depression and loneliness among patients in general and those with serious health conditions in particular (Klemm et al., 2003). However, little is known about the recently developed websites that ask patients to evaluate and rate their physicians or their treatment regimens and whether they have any impact on their personal quality of life. 
Finally, although several studies have investigated the effects of the Internet on the people's quality of life, studies that examined the effect of the Internet services on the quality of life are rare (Liang, 2011).

\subsubsection{Patients' Beliefs about Medications}

People vary in their beliefs about medications. Some have negative views of medications in general regardless of their origin. However, others have positive views of alternative medicine (i.e. medications from natural origins) and not of western medicine (i.e. prescription medications). Their views and beliefs about medications are influenced by multiple factors such as age, gender, race, cultural background, and experience with taking prescribed medications (Horne et al., 2004). For instance, Asians are more likely to believe in herbal medicine effectiveness in treating most of the common diseases compared to people from European descent.

The importance of the patients' beliefs about medications stems from the fact that the success of any disease management plan depends largely on the level of patients' adherence to their treatment regimens. Medications' adherence is significantly associated with medication beliefs. Thus, patients with negative views about medications were more likely to report low adherence levels to their medication regimens compared to those with positive views (Gatti, Jacobson, Gazmararian, Schmotzer, \& Kripalani, 2009). Further, research has shown that medication beliefs are more powerful predictors of patientreported medication adherence than clinical and sociodemographic factors (Horne \& Weinman, 1999). Medication beliefs affect patients' adherence to medications prescribed for many acute and chronic illnesses. Asthmatic, the renally compromised, oncology, and cardiac patients are some of patient subpopulations in which medication beliefs were found to affect patient adherence to prescribed medication regimens (Conn, Halterman, Lynch, \& Cabana, 2007; Horne \& Weinman, 1999). Patients tend to be more adherent to their prescribed medication regimens when the perceived necessity of these medications exceeds their perceived harmfulness (Aikens, Nease, Nau, Klinkman, \& Schwenk, 2005). Further, those with multiple comorbidities and functional limitations are more likely to believe that the benefits of taking medications to manage their health conditions outweigh their risks (Schüz et al., 2011). Older adults are more likely to have chronic health conditions as well as more physical limitations than their younger counterparts are. Therefore, older age was significantly associated with positive beliefs about medications (Aikens, Nease, \& Klinkman, 2008).

Another important factor that influences patients' beliefs about medications is the physicians' communication style. Patients who were satisfied about their physician's communication style held positive views about their own medication regimens and were more likely to be seen by their physicians for a follow-up visit (Bultman \& Svarstad, 2000). Although age, culture, health conditions, and physicians' communication style have shown to impact patients' beliefs about medications, the impact of other important factors on medication beliefs have not been investigated yet. For example, in an era where patients can access an immense amount of health information with the click of a 
mouse, no one knows if the information encountered online would change their beliefs about medications. Further, it is also unknown if the online-posted reviews and ratings of medications by patients would influence the physician-patient communication style of those who browsed such websites.

\subsubsection{Medication Adherence}

The prescribing of medications is the most common and effective healthcare intervention. However, even though most of the prescription medications are effective in managing many health conditions, $30-50 \%$ of these medications are not taken as recommended (Banning, 2009). Medication adherence is a complex and interesting psycho-behavioral issue which has been defined as "the extent to which the patients' behavior matches agreed recommendations for the prescriber" (Horne, 2005, p.27). Multiple factors can influence patient adherence. Patients' cultural background, social support, medical status, age, gender, and beliefs about illnesses and medications are some of these factors that might influence patient's adherence to prescription medications (Banning, 2009; Horne \& Weinman, 1999). Health and medication beliefs are considered one of the strongest predictors of medication adherence among patients in general and those on chronic or multiple medications in particular (Phatak \& Thomas, 2006). Therefore, understanding patients' beliefs about health and medications is of paramount significance to address medication non-adherence. Further, low patients' satisfaction with their treatment has a negative impact on their adherence to prescription medications (Sa'ed, Al-Jabi, Sweileh, \& Morisky, 2013). In addition, low patients' health-related quality of life is another barrier to achieving high medication adherence (Holt, Muntner, Joyce, Webber, \& Krousel-Wood, 2010).

Although medication non-adherence is prevalent among multiple patient populations, it is an increasing problem among older adults. This can mainly be attributable to multiple comorbidities that elderly patients usually suffer from as well as the complexity of their medication regimens. Further, the declining cognitive abilities, dexterity problems, poor physician-patient communication, and high risk of adverse drug events are additional factors that can lead to non-adherence and are common among elderly patients (Macías-Núñez et al., 2008). Thus, the elderly patients are at higher risk of adverse drug events, medication mismanagement, and poor health outcomes. This is particularly true in older adults with chronic health conditions such as hypertension and diabetes that require long-term management (Banning, 2009). For example, it was estimated that $10 \%$ of the unplanned admissions among older adults were related to adverse drug events (Pearson, Skelly, Wileman, \& Masud, 2002). Therefore, managing poor medication adherence among the elderly patients requires good communication between the patients and their physicians. Physicians need to form a therapeutic alliance with their patients whereby patients can share their concerns and beliefs about medications as well as their treatment preferences (Pound et al., 2005). Unfortunately, physicians tend to spend less time with the elderly patients despite the fact that they require additional time for giving and receiving information (Radecki, Kane, Solomon, Mendenhall, \& Beck, 1988). Hence, older adults should be empowered to start 
constructive conversations with their physicians where they can express their needs and concerns about the prescription medications as well as their preferences.

Education is power and a key approach in tackling the issue of non-adherence among patients. Thus, providing patients with information about their health conditions and the pros and cons of different available treatment options may improve their medications adherence. It also facilitates partnerships with their physicians in managing their health conditions (Banning, 2009). Nonetheless, given the short visit length, long medication lists, and the need to educate and follow up with elderly patients; new and creative ways of communication between physicians and patients should be developed. In an era of high technology, the Internet has become one of the new avenues that physicians use to communicate with their patients. Physician's communication with their patients through secure websites can help physicians understand patients' beliefs and adherence barriers. Further, physicians can use these websites to assess the patients' progress and update their treatment regimens accordingly. Such online interventions had a positive impact on patients' medication adherence levels (Linn, Vervloet, van Dijk, Smit, \& Van Weert, 2011). However, the use of Internet is not limited to the communication between physicians and their patients. Many health websites are competing in providing healthrelated information about multiple health services and medications in layman's term (Jenkins \& Dunn, 2004). These websites differ in their content, design, and affiliations. Some of these websites provide patients reviews of medical devices, physicians, and medications (Emmert, Sander, et al., 2013).

Online health information seeking was seen to help patients initiate constructive dialogs with their physicians, and improve their satisfaction with provided care (Bylund et al., 2007; Jacob, 2002). However, it is unknown whether the websites that provide patients' reviews of medications will enhance patient-physician communication, and eventually improve patients' medication adherence levels.

\subsubsection{Why Hypertensive Patients?}

As people age, they become more susceptible to chronic diseases such as hypertension and diabetes (Abrass, 1990). Essential hypertension is an asymptomatic chronic medical condition that is highly prevalent among the older adults especially among women and minorities. According to the latest report published by the Centers for Disease Control and Prevention, the prevalence of hypertension among older adults who are between 65 to 74 years of age approximates $65 \%$, and among those over 75 years approximates 75\% (Hamilton, 2003; Health, United States, 2012: With Special Feature on Emergency Care). It has been estimated that hypertensive patients are two times more likely to develop coronary artery diseases, three times more likely to have cerebrovascular diseases, and 3.5 times more likely to have heart failure at some point in their life when compared to the non-hypertensive population; and the likelihood of developing such serious illnesses increases with age (Kannel, 2003). Further, it is estimated that more than $60 \%$ of the older adults with hypertension had an incident of myocardial infarction, stroke, and/or heart failure (Lloyd-Jones et al., 2009). According 
to one study, the death rate attributable to hypertension among older adults ( $\geq 60$ years) is 735 cases per 100,000 people (Mensah, Mendis, Greenland, \& MacKay, 2004). Further, hypertension often represents a management dilemma to cardiovascular specialists because of the multiple physiological and behavioral factors that eventually determine the success of any treatment plan (Lionakis, Mendrinos, Sanidas, Favatas, \& Georgopoulou, 2012).

Although hypertension is considered a significant risk factor for cardiovascular diseases, the good news is that it is a modifiable risk factor. Patients who adhere to their antihypertensive medication regimens, which include both the pharmacological and the non-pharmacological measures, are likely to bring their blood pressure under control. Therefore, their risk of developing serious diseases such as myocardial infarction or stroke in the future will eventually be diminished (Sacco et al., 1997). To reach that goal, both patient and physician need to have a collaborative agreement where each one of them understands his/her roles and responsibilities. This agreement should also respect each party's expectations and values. Unfortunately, some evidence indicates that healthcare professionals treat their elderly patients in a condescending and impatient manner (Harwood, 2007; Nussbaum \& Coupland, 2004). Further, physicians seem to spend less time, provide less information, and often fail to stress the importance of the non-pharmacological preventive measures (Greene \& Adelman, 2001; Harwood, 2007). Finally, physicians should adopt effective communication strategies to build a constructive collaborative agreement with their hypertensive patients in order to achieve the desirable treatment outcomes and prevent future complications.

\subsection{Study Objectives and Research Questions}

The value and usefulness given to online patients' ratings of medication websites by older adults about the process of patient-physician communication (i.e., facilitating the communication, discussing the content of these websites with their physicians, asking their physicians to prescribe the top rated medications) can be associated with multiple factors. Thus, the following were studied:

1. Are the online medication reviews viewed more favorably by those who are satisfied with their communication with physicians and will the older adults' rating of their own treatment regimen influence their satisfaction with communication with physicians?

2. Do older adults with high quality of life scores have favorable views of the online medication reviews in comparison to those with lower quality of life scores and will the rating of their treatment regimens influence their quality of life?

3. Do older adults with positive beliefs about medications find the online medication reviews useful in comparison to those with negative beliefs and will the rating of their treatment regimens influence their medication beliefs? 
4. Do older adults' adherence to their antihypertensive treatment regimen influence their views of the online medication reviews and do older adults' rating of their antihypertensive medication regimens influence their medication adherence and their views of the online reviews of medications?

\subsection{Theoretical Framework}

In order to understand how the online medication reviews can affect certain indicators of health outcomes, such as the quality of life and medication adherence, the Donabedian model was used to evaluate how these factors are interrelated. The Donabedian model is a conceptual model proposed by Avedis Donabedian, a physician and health care services researcher at the University of Michigan, in 1966. The purpose of this model was to provide a framework to assess the quality of health care services and relate that to the ultimate outcomes such survival, blood pressure reduction, and $\mathrm{A} 1 \mathrm{C}$ improvement (Donabedian, 1966). According to the Donabedian model, the measurement of the health care quality should be based on three main components: Structure, Process, and Outcomes. Each of these components has a direct influence on the next one starting from the Structure, then the Process, and finally Outcomes (Donabedian, 2005). To apply this model to the study, physician education and training to communicate effectively and address the needs and concerns of the elderly patients represents a Structure component. Whereas, the appropriateness of the diagnosis and prescribing as well as the communication style and interpersonal aspect of the relationship between the physicians and their patients which can be influenced by their medical, cultural, and religious beliefs are Process components. Finally, patient's satisfaction with care, quality of life, and medication adherence considered indicators of health status are Outcome components, as is, patient beliefs about medications since effective communication can influence patient beliefs about medications and eventually affect patient adherence. However, to know the value of the online patients' medications reviews in facilitating patient-physician communication as well as its relationship with health status indicators; it is believed that the online patients' medication reviews can be considered as an intervention directed towards the Process component (i.e. facilitating the patient-physician communication)(Friedman et al., 2008) (Figure 1-1). Although, the online reviews of medications can influence patient-physician communication and indirectly affect outcomes (i.e. satisfaction with physicians, quality of life, beliefs about medications, and medication adherence), the same outcomes can also influence patients' opinions of such online websites (Figure 1-2). 


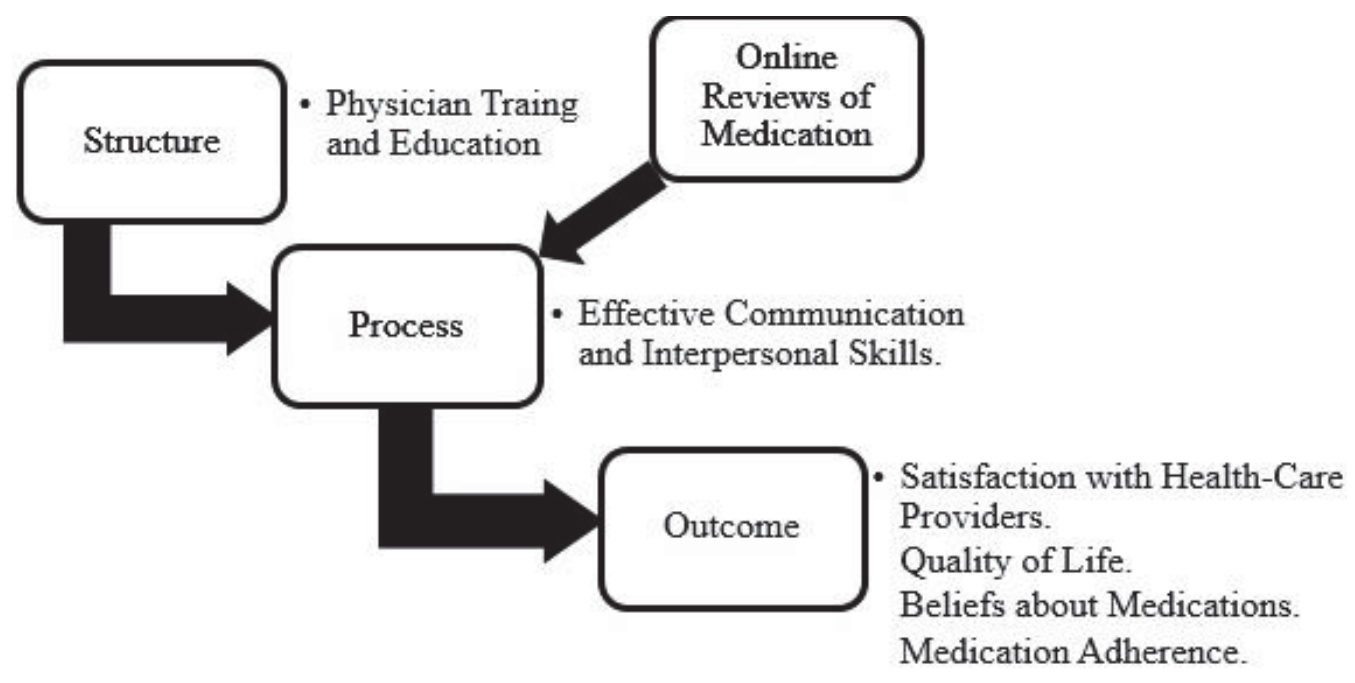

Figure 1-1. The potential effect of online reviews of medications on physicianpatient communication.

Source: Donabedian A, Evaluating the Quality of Medical Care. Milbank Quarterly 2005 December; 83(4): 691-729. 


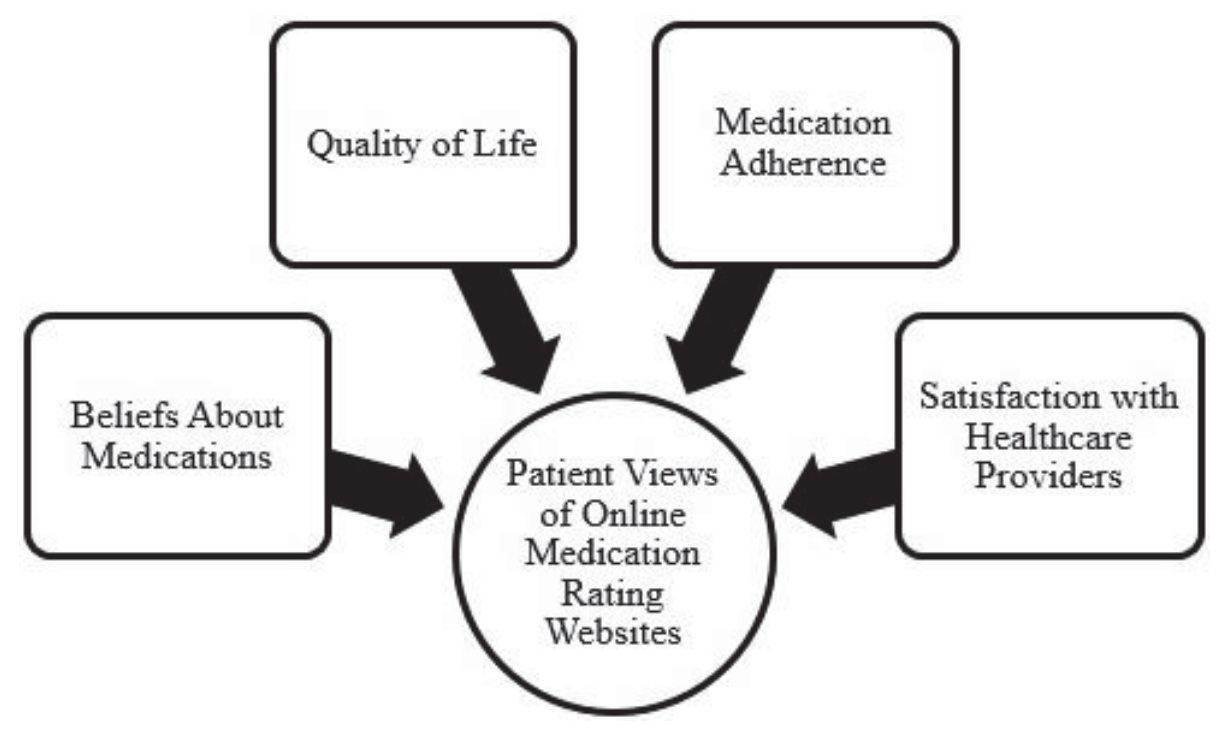

Figure 1-2. Factors that may influence patient views of online medication reviews. 


\section{CHAPTER 2. LITERATURE REVIEW}

\subsection{Physician-Patient Communication}

There is a belief that effective communication is both essential and lacking among physicians (Stein, 2006). A review of physician-patient communication by Persaud showed only $5 \%$ of the clinical consultations provided by physicians to patients were considered to be friendly or social (Persaud, 2005). Some argue that the deterioration in the physician-patient relationship or encounter probably came after the infiltration of corporate interests in the U.S. healthcare system, which resulted in diminished trust between the physicians and patients (Laugesen \& Rice, 2003). Furthermore, the main reason patients sue their physicians for malpractice is not because of their negligence, but for the lack of respect and ineffective communication from the physicians' side (Levinson, Roter, Mullooly, Dull, \& Frankel, 1997). The quality of physicians' communication skills has been found to be a positive predictor of patient adherence with medical advice (Robins \& Wolf, 1988). Hence, there seems to be a consensus among physicians and policy makers alike to adopt a patient-centered approach where patients are involved in their own care as partners with their physicians and not solely as receivers of care. Bensing (Bensing, 2000) and Mead, Bower, and Hann (Mead, Bower, \& Hann, 2002) summarized the basic elements of patient-centered practice as follows:

- Attending to patients' psychological and physical needs,

- Encouraging patients to disclose their concerns,

- Conveying a sense of partnership during the consultation sessions, and

- Actively facilitating the involvement of patients in the decision making process.

Thus, the provision of patient-centered care requires collaboration between all personal, professional, and organizational levels in healthcare. This can only be achieved through education and training of physicians that show friendliness and empathy in their conversations with patients and create a supportive environment and system that rewards those physicians who foster and provide patient-centered care for patients (Epstein \& Street, 2007; Epstein, Fiscella, Lesser, \& Stange, 2010; Epstein \& Street, 2011). Hence, structural changes need to be implemented in the healthcare system to strengthen the relationship between physicians and patients, and promote the communication between them in order to make the physician-patient encounter an enjoyable and informative experience that eventually leads to a constructive partnership between patients and physicians (Epstein \& Street, 2011).

To build that partnership both patients and physicians need to agree on the goals and tasks of the treatment plan and act upon them. By doing so, they form what is currently known as a "Working Alliance." This term has been studied extensively in the last few decades and it encompasses a wide array of cognitive and emotional factors that need to be included in this partnership (Boylan \& Fontanella, 2009). A good therapeutic working alliance consists of the following (Bordin, 1979): 
- Agreement on goals,

- Assignment of tasks, and

- Development of an effective bond between the physicians their patients.

This working alliance between the physicians and patients cannot succeed without a genuine effort made by the physicians to involve the patients in this partnership. Engaging patients in their own care is not by any means an easy task and only those with a good communication style and interpersonal skills can succeed (Brennan, Rivera-Tovar, Martin, Hepworth, \& Makoul, 2010). A sense of connection and mutual understanding has to exist between the physicians and patients in order to have an effective and meaningful communication. Otherwise, the physician-patient communication will merely be an exchange of medical information divorced from the context and complexities of the patient's life.

Empathy is regarded by most researchers in the domain of patient-centered care research as one of the most important interpersonal skills that healthcare professionals need to learn to effectively communicate with their patients (Boylan \& Fontanella, 2009). It has been variously defined by researchers in the field of psychotherapy; however, what is common between these definitions is that they all capture the importance of deep listening and objective understanding of patients' experiences (Davis, 1994). Empathy in the physician's communication with their patients was found to have a positive impact on overall patient care (Kim, Kaplowitz, \& Johnston, 2004; Larson \& Yao, 2005). Whereas, an indifferent physician-patient relationship was found as one of the factors behind poor medication adherence (Osterberg \& Blaschke, 2005). There are other verbal behaviors known to promote the physician-patient relationship especially among the elderly. Physicians' friendliness, attentive listening, and encouraging patients to ask questions are very important attributes of effective communication (Beck, Daughtridge, \& Sloane, 2002; Zachariae et al., 2003).

\subsubsection{Theoretical Models of Physician-Patient Relationship}

Parsons (1951); a sociologist, provided a description of the physician-patient relationship. His description was later called "Parsons' model of sick role and physician's role," whereby sick people are in need of care that is provided to them by specialized personnel. The specialized personnel are in most cases physicians, and because patients need that care they must cooperate with their physicians and forgo some of unhealthy activities, they were used to in order to recover quickly. According to Parsons' model, patients regardless of their medical conditions, gender, age, ethnicity, and culture, are expected to assume the sick role. Parsons also believed physicians should apply their clinical skills and knowledge for the benefit and welfare of patients and the whole community and not for their narrow financial interests (Parsons, 1951). However, this model has received a number of criticisms. The model assumes that the patients will voluntarily accept the sick role without any objections and will fully cooperate with their physicians. Further, it assumes a consistent physician-patient relationship whereby patients from different backgrounds and lifestyles will be treated the same. In addition, it puts most of the blame on patients who play the sick role for their illnesses. In reality, 
physicians' counseling and advice along with their treatment plan are highly important. Parsons' model may fit acute illnesses (i.e. measles, appendicitis, malaria); however, it does not fit chronic medical conditions such as hypertension, hypercholesterolemia, and diabetes where patients' participation in the treatment decision is very important (Jeffery, 1979; Macintyre, 1994; Morgan, 2003). Existing models that describe this relationship fall into one of the following (Charles et al., 1997; Clarke, Hall, \& Rosencrance, 2004; Emanuel \& Emanuel, 2000; Morgan, 2003):

- The Paternalistic (Parsonian) Model: A model in which physicians have the upper hand over patients when it comes to the decision making process regarding the treatment plan. Many consider this relationship similar to one between a parent and child.

- The Engineering (Informative or Consumerist) Model: In this model patients assume the active role, whereby physicians are hired by patients to relay the medical facts and information requested by the patient and then implement the treatment decision made by patients after explaining the variety of treatment options.

- Interpretive Model: A contractual model in which both patients and physicians forge an agreement whereby physicians work with patients as partners in the decision making process concerning their health and treatment plan provided that their moral integrity is kept intact. The principles of autonomy, fidelity, veracity, do no harm, and justice should form the basic elements in this contractual relationship. Physicians try to understand patients' values and behavior and come up with individualized treatment plans that fit patients' values and beliefs. This model assumes that patients usually are not clear about what would be the best diagnostic tests and/or treatment options for them. For this reason, discussions between physicians and patients will help patients decide which test or treatment would fit them best.

- Deliberative Model: Instead of trying to understand the patients' values and beliefs in order to devise an individualized treatment plan, physicians explain to patients the different diagnostic and treatment options; try to persuade the patients about the best options, and finally leave the decision to patients.

When it comes to clinical reality, none of these models will work all the time regardless of the medical condition, its urgency, and patients' backgrounds.

\subsubsection{Physicians' Consultation Styles}

- Physician-Centered Consultation: Represents the paternalistic (Parsonian) model whereby physicians have the upper hand in their relationships with their patients. According to this consultation style, patients should obey and cooperate with physicians in order to reach the desirable outcome. It focuses on the physical aspects of the disease and 
ignores the feelings and emotions of the patients (Mishler, 1984; Morgan, 2003).

- Patient-Centered Consultation: Physicians adopt a less controlling style and encourage patients to participate in the consultation. Physicians spend more time listening to patients and paying attention to the patients' feelings and emotions. This consultation approach can represent either the interpretive or the deliberative contractual (collaborative) models (Mishler, 1984; Morgan, 2003). The basic characteristics of this consultation style can be summarized in the following (Mead \& Bower, 2000):

- Biopsychosocial Perspective: Physicians are willing to become involved in all the difficulties patients are going through and not just their medical condition.

- Patient-as-a-Person: Physicians want to listen and understand patients' medical conditions from the patients' own perspective and use open-ended interview questions.

- Sharing Power and Responsibility: Patients are treated as a partner in this contractual or collaborative relationship with physicians; hence, they are encouraged to participate in the consultation.

- Therapeutic Alliance: Patients should be involved in the treatment decisions.

- Physician-as-a-Person: Physicians are human beings and not machines so they should recognize and respond to patients' cues.

\subsubsection{Communication with Older Adults}

Older adults mostly desire more information about their medical conditions and medications from their physicians, however, research has shown that they receive less information than younger patients (Beisecker, 1988). This can be partly due to the fact that older patients tend to communicate less effectively when they sense that physicians are rushed or uninterested (Robinson, White, \& Houchins, 2006). This becomes more complicated when it is known that the average consultation time is around six minutes with the actual length of time between 2 to 20 minutes. This can potentially lead to less attention paid to the psychosocial aspects of patients' disease and more attention to its physical nature. Eventually more medications are prescribed and fewer psychological problems are identified (Daschle, Domenici, Frist, \& Rivlin, 2013; Morgan, 2003).

Older patients revere their physicians and want to spend quality time with them to understand their health conditions better and verbalize their concerns. Hence they need an attentive physician who makes them feel they are important (Robinson et al., 2006). However, one of the most common complaints patients have about physicians is that they do not listen and frequently interrupt them (Meryn, 1998). Physicians sometimes avoid listening to patients not just because of the time constraints, but also because they do not 
want to distress themselves by listening to patients' concerns and do nothing about them (Ekdahl, Hellström, Andersson, \& Friedrichsen, 2012; Ha \& Longnecker, 2010). Older patients' non-adherence to physicians' advice and prescribed treatment can be greatly reduced by attentively listening and reducing the amount of distractions (Dreher, 2001). Besides the attentive listening, older patients appreciate the medical advice and information conveyed to them by physicians. Given the natural aging process that may involve sensory loss, decline of memory, and impaired hearing, physicians need to simplify their language by avoiding medical jargon and by talking slowly and loudly (Howard, Jacobson, \& Kripalani, 2013; Robinson et al., 2006).

\subsubsection{Factors Influencing Physician-Patient Communication}

Factors that can influence physician-patient communication are numerous, but little has been published about the potential factors that can be summarized into four domains: patient communication style, sociodemographic factors, health-related factors, and physician communication style (Morgan, 2003; Street Jr, Gordon, \& Haidet, 2007; Strull, Lo, \& Charles, 1984) (Figure 2-1). Each of these domains has the potential to shape the communication between physicians and patients.

\subsubsection{Patient Communication Style}

This domain covers how much information patients want to receive from and discuss with physicians about their medical conditions, their willingness to share and express

their concerns and feelings, and their decision-making preference. Patients with negative beliefs about healthcare (i.e., distrust in modern medicine or fear of the healthcare system) have a different communication style than those with positive beliefs (Ha \& Longnecker, 2010). For example, patients with positive views of healthcare tend to be more inquisitive and open (i.e., ask questions, assertive about getting answers, and express their fears and concerns to their physicians) than those with negative views of healthcare. Therefore, patients with positive are more likely to receive supportive, informative, and accommodating care (Ha \& Longnecker, 2010; Street Jr et al., 2007). Further, patients' preference towards the decision making process (i.e., whether they like their physicians to make the decision on their behalf, have a shared decision, or make the decision themselves) is another important factor that influences patients' communication style. Patients' preferences are dependent on factors that fall under the other domains such as health literacy, education, and age (Schneider et al., 2006).

\subsubsection{Patient Sociodemographic Factors}

Researchers have shown that as patients age, they become less interested in participating in the health decision-making as well as less inclined to engage in effective communication with their physicians (Garfield, Smith, Francis, \& Chalmers, 2007; 


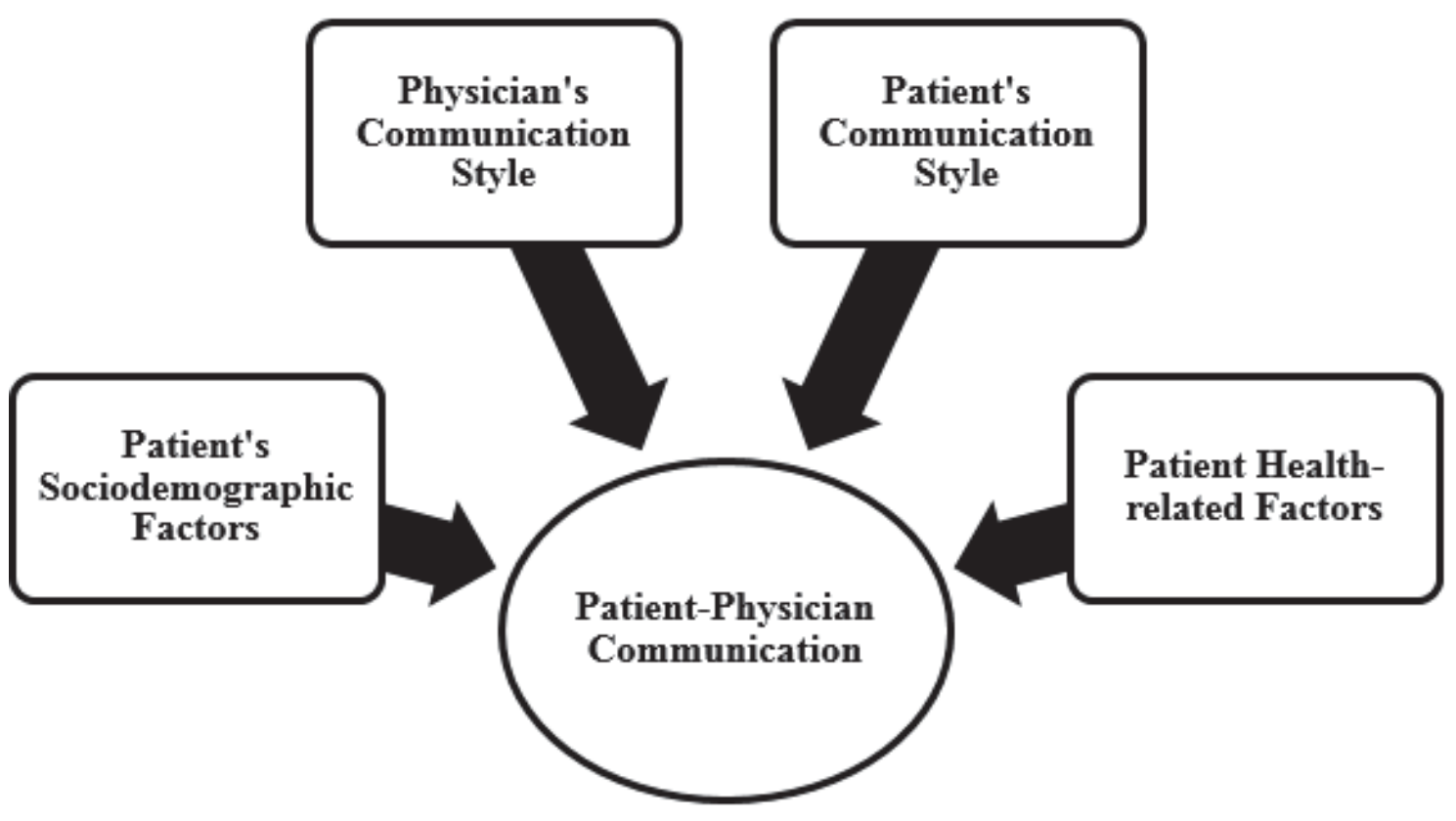

Figure 2-1. Factors influencing physician-patient communication.

Source: Reprinted from Social Science and Medicine, 65(3), Street Jr, Gordon \& Haidet, Physicians' communication and perceptions of patients: is it how they look, how they talk, or is it just the doctor?/Figure 1, 586-598, 2007 Jan, with permission from Elsevier. 
Morgan, 2003; Robinson et al., 2006; Schneider et al., 2006). Paradoxically, one study found that older patients are more likely to be satisfied with the care provided (Carlin, Christianson, Keenan, \& Finch, 2012). Patients of high educational and social status were more likely to engage in the consultation by asking questions and inquiring about other treatment options in comparison to patients with a lower socioeconomic status (Garfield et al., 2007; Morgan, 2003; Schneider et al., 2006). However, highly educated patients were also found to be less satisfied with care compared to patients with a lower educational status (Carlin et al., 2012). The association between gender and patients' preference for involvement in the decision-making process is variable (Garfield et al., 2007). Females are more interested than males in having a participatory role as well as more satisfied with the care provided (Arora \& McHorney, 2000; Carlin et al., 2012; Levinson, Kao, Kuby, \& Thisted, 2005; Nease Jr, 1995). Other studies show no significant association between gender and patients' preference for decision sharing with physicians (Florin, Ehrenberg, \& Ehnfors, 2006; McKinstry, 2000). Race is another potential factor that can play a major role in patient preference for decision sharing with physicians (Strull et al., 1984). Whites are more likely to believe in patients' autonomy than other minorities (Garfield et al., 2007). The role of patients' insurance status was not well described, however, patients enrolled in an HMO (Health Maintenance

Organization) were found to request more information from their physicians than patients with a different type of insurance coverage (Strull et al., 1984). In another study, insured patients were more likely to be satisfied with the provided care than those who are uninsured (Carlin et al., 2012).

\subsubsection{Patient Health Related Factors}

Patient disease severity was negatively associated with the desire to have an active role in both communication and decision sharing with few exceptions (Garfield et al., 2007). Patients with acute illnesses have been found to seek more information about their medical conditions from their physicians, but at the same time preferred a passive role when it comes to decision making (Wilkinson, Khanji, Cotter, Dunne, \& O'keeffe, 2008). Patients with more chronic illnesses report higher satisfaction with the health care provided and their physicians' communication style (Carlin et al., 2012). Further, patients

vary in their preference for the decision sharing based on their medical condition. Patients with heart failure were found to have a passive role in decision-making process, whereas older patients with serious mental illness were more likely to be involved in the decisionmaking than their younger counterparts (O'Neal et al., 2008; Rodriguez, Appelt, Switzer, Sonel, \& Arnold, 2008). Furthermore, patients with breast, prostate, colorectal, lung, gynecological and other cancers had a strong desire to be involved in the decisionmaking process regarding their treatment (Bruera, Sweeney, Calder, Palmer, \& BenischTolley, 2001; Tariman, Berry, Cochrane, Doorenbos, \& Schepp, 2010).

\subsubsection{Physicians' Communication Style}

Some physicians adopt a physician-centered approach where they control the direction of the communication during the physician-patient encounter and decide what 
treatment they deem appropriate with no patient involvement. This model referred to as the Parsonian or paternalistic model is widely practiced by many physicians. Others practice patient-centered care, where they listen attentively and involve patients in treatment decision. In this model, physicians share the treatment decisions with patients by explaining different treatment options, and letting the patients decide afterwards what treatment option would be the best for them (Morgan, 2003; F. A. Stevenson, Barry, Britten, Barber, \& Bradley, 2000) (Table 2-1). However, to understand why physicians choose to practice physician-centered or patient-centered care, one has to consider several factors that can influence physicians' communication style. For instance, physicians' prior experiences with patients may influence the physician communication style along with gender, cultural background and medical training (Street Jr et al., 2007; Zandbelt, Smets, Oort, Godfried, \& de Haes, 2006; I Gouni-Berthold MD \& Berthold, 2012).

\subsection{Linking Patient-Centered Care to Health Outcomes}

Patient experience with care is increasingly gaining ground to become an integral element or even one of the important pillars of the quality of healthcare along with patient safety and clinical effectiveness (Doyle, Lennox, \& Bell, 2013). Patient-centered care has been defined as "the experience (to the extent the informed, individual patient desires it) of transparency, individualization, recognition, respect, dignity, and choice in all matters, without exception, related to one's person, circumstances, and relationships in health care" (Berwick, 2009, p.560). Currently, there is a sort of consensus among the advocates of patient-centered care that a good outcome should be defined based on how meaningful and valuable this outcome will be to patients themselves, not solely to physicians or policy makers (Guyatt, Montori, Devereaux, Schünemann, \& Bhandari, 2004). Since the provision of patient-centered care encourages patients to participate in the discussion with physicians and get involved in their own care, it should be expected to see higher adherence, improved quality of life, and better clinical outcomes across a wide range of medical conditions (Berwick, 2009; Street Jr, Makoul, Arora, \& Epstein, 2009). However, past research shows inconsistent findings about the impact of patientcentered care on health outcomes (Lee \& Lin, 2010).

In a randomized control study that was conducted more than two decades ago in a range of settings in the U.S. and included 252 ulcer, hypertension, diabetes, and breast cancer patients, physician-patient communication was assessed by both audiotaping as well as questionnaire administration to see if communication style would influence any clinical parameters or self-reported health status. A positive association was found between an effective physician-patient communication and blood pressure control, blood glucose level, and self-reported health status (Kaplan, Greenfield, \& Ware Jr, 1989). Another study looked at the prevalence as well as the causes and implications for underuse of opioids medications among 191 veterans who received opioid medications for any pain. Under-users of opioids were identified using structured assessments that included detailed questions for the participants on how they use their opioid medications on a daily basis. Those who took less than the prescribed daily dose or reported having a pain that impaired their ability to function normally were considered under-users. Non-adherence 
Table 2-1. Model of treatment decision-making.

\begin{tabular}{|c|c|c|c|c|}
\hline $\begin{array}{l}\text { Analytical } \\
\text { Stages }\end{array}$ & & $\begin{array}{l}\text { Paternalistic } \\
\text { (Intermediate) }\end{array}$ & $\begin{array}{l}\text { Shared } \\
\text { (Intermediate) }\end{array}$ & Informed \\
\hline \multirow[t]{4}{*}{$\begin{array}{l}\text { Information } \\
\text { Exchange }\end{array}$} & Flow & One way (largely) & Two way & $\begin{array}{l}\text { One way } \\
\text { (largely) }\end{array}$ \\
\hline & Direction & Doctor $\rightarrow$ Patient & Doctor $\leftrightarrow$ Patient & $\begin{array}{l}\text { Doctor } \rightarrow \\
\text { Patient }\end{array}$ \\
\hline & Type & Medical & $\begin{array}{l}\text { Medical and } \\
\text { Personal }\end{array}$ & \\
\hline & Amount & $\begin{array}{l}\text { Minimum legally } \\
\text { required }\end{array}$ & $\begin{array}{l}\text { All relevant for } \\
\text { decision-making }\end{array}$ & $\begin{array}{l}\text { All relevant } \\
\text { for decision- } \\
\text { making }\end{array}$ \\
\hline Deliberation & & $\begin{array}{l}\text { Doctor alone or } \\
\text { with other doctors }\end{array}$ & $\begin{array}{l}\text { Doctor and patient } \\
\text { (plus potential } \\
\text { others) }\end{array}$ & $\begin{array}{l}\text { Patient (plus } \\
\text { potential } \\
\text { others) }\end{array}$ \\
\hline $\begin{array}{l}\text { Deciding on } \\
\text { treatment to } \\
\text { implement }\end{array}$ & & Doctors & Doctor and patient & Patient \\
\hline
\end{tabular}

Source: Reprinted from Sociology as applied to medicine (5th ed., p. 58), Scambler, G., \& Myfanwy, M., Models of treatment decision-making in a doctor-patient dyad/ Table 4.3, 49-65, 2003, with permission from Elsevier. 
to the prescribed opioids was not different from the non-adherence to any other medication regimens and was largely due to poor communication between patients and physicians (Lewis, Combs, \& Trafton, 2010). The provision of patient-centered care was associated with improved medication adherence among patients with breast cancer (Lee \& Lin, 2010). However, some studies have shown no association between patient experiences with care and health outcomes. In a large, multicenter, cross sectional study designed to investigate the relationship between clinical performance and patient experiences among adult patients (18-64 years) with continuous enrollment in one of five participating health plans in Massachusetts for at least a year, no association was found between patient experiences and clinical outcomes such as blood pressure, HbA1c, and LDL cholesterol level (Odigie \& Marshall, 2008). In another cross sectional study conducted in the United Kingdom, the relationship between older patients' ( $\geq 65$ years) assessment of primary care and the control of hypertension as well as vaccination against influenza was investigated. No significant association between the older patients' assessment of primary care and the aforementioned quality of care measures was found (Rao, Clarke, Sanderson, \& Hammersley, 2006). All in all, although some studies failed to show a significant association between patient-centered care and health outcomes, the preponderance of evidence supports a significant association between them (Doyle et al., 2013).

\subsection{Assessing the Physician-Patient Relationship}

The patient-physician relationship or encounter has been assessed using different methods including qualitatively by audiotaping or videotaping the physician-patient communication during patient visits. Recordings were analyzed using professional coders as well as several software systems to find repetitive themes than can be linked to certain communication styles (Hall, Roter, \& Katz, 1988; Levinson et al., 1997). The physicianpatient relationship has also been assessed by both audiotaping patient-physician encounter and then scoring the encounter using a patient-centered communication score tool (Oates, Weston, \& Jordan, 2000). Today, a myriad of self-administered questionnaires have been developed and validated across multiple patient populations. These questionnaires report the fulfillment of patients' expectations, needs, and wishes based on past physician-patient encounters. The Patient-Doctor Relationship Questionnaire [PDRQ-9], Health Care Relationship [HCR] Trust Scale, and Consultation and Relational Empathy [CARE] measure are a few examples of questionnaires used in the primary healthcare field (Eveleigh et al., 2012). These instruments address different important attributes of the physician-patient relationship such as patient-centeredness, interpersonal communication, cultural sensitivity, and respectfulness. However, some instruments were found to be more comprehensive in addressing these attributes of primary care in comparison to other instruments. The Primary Care Assessment Survey (PCAS) and the Primary Care Assessment Tool (PCAT) are two validated instruments with good coverage of the primary health care attributes. Both are available in the public domain (Lévesque et al., 2012). 


\subsection{Health-Related Quality of Life (HRQoL)}

In an era of patient-centered outcomes, patients' quality of life has become a more important outcome measure than proxy clinical parameters such as blood-pressure measurements, blood-glucose levels (Carr \& Higginson, 2001). The provision of patientcentered care is expected to improve the quality of life by increasing patients' independence (Poochikian-Sarkissian, Sidani, Ferguson-Pare, \& Doran, 2009). However, there is no consensus on the definition of patients' quality of life. It has been defined as "the extent to which hopes and ambitions are matched by experience"(Calman, 1984, p.124). Further, it has also been defined as the "individuals' perceptions of their position in life taken in the context of the culture and value systems where they live and in relation to their goals, expectations, standards, and concerns" (Orley, Kuyken, \& de la Santé, 1994, p.290). However, some lean towards defining the patients' quality of life as the patients' assessment of their own functioning against what is considered as being ideal functioning level (Carr \& Higginson, 2001; Cella \& Tulsky, 1990).

Elderliness is a starkly different and variable experience for each patient. Some elderly patients view this stage of their life as a relaxing and enjoyable experience; however, others describe it as a bad experience (Xavier et al., 2003). In a study that investigated the important items influencing elderly patients perception of the quality of life, 141 elderly patients were randomly selected, and interviewed in person using an open-ended interview structure. The study concluded that patients' social relations, functional ability and activities are the three most important items that influence elderly patients' quality of life as much as their health status (Wilhelmson et al., 2005).

For several generations, the dominant theory in economics and social research that describes people's quality of life is utilitarianism. According to this theory, quality of life involves the satisfaction of individuals' desires and preferences (Cobb, 2000; Torrance \& Drummond, 2005). There are many quality of life measurement questionnaires, but the most important fact to ponder is these instruments are only considered proxies or indirect indicators of quality of life. These instruments can never be treated as direct indicators of quality of life simply because people cannot observe their happiness or satisfaction directly. For example, people may report that they desire having something; however, when they have the means to get it, they get something else (Cobb, 2000). These instruments vary in their coverage of the quality life attributes (Torrance \& Drummond, 2005). The EuroQol-5D, SF-36 \& 12, and Nottingham health profile (NHP) are three commonly used and widely validated questionnaires across multiple medical conditions and have high reliability coefficient (Cronbach's Alpha $>0.7$ ) (Müller-Nordhorn, Roll, \& Willich, 2004; Torrance \& Drummond, 2005) (Table 2-2).

\subsubsection{EuroQol-5D (EQ-5D)}

The EuroQol-5D is a generic instrument for describing and valuing health, which was developed by a consortium of investigators in Western Europe. It includes five attributes of quality of life: mobility, self-care, usual activity, pain discomfort, and 
Table 2-2. Comparison of quality of life instruments.

\begin{tabular}{lccc}
\hline \multirow{2}{*}{ Domain } & \multicolumn{3}{c}{ QoL Questionnaires } \\
\cline { 2 - 4 } & SF-36 \& SF- & EuroQol (EQ- & NHP \\
\hline Pain & $\mathbf{1 2}$ & 5D) & \\
Energy or tiredness & Yes & Yes & Yes \\
Sleep & Yes & Not Covered & Yes \\
Physical functioning or & Not Covered & Not Covered & Yes \\
mobility & Yes & Yes & Yes \\
Daily living activities & & & Yes \\
Social interactions & Yes & Yes & Yes \\
Leisure activities & Yes & Not Covered & Not \\
& Yes & Yes & Covered \\
Work & & & Not Covered \\
Emotional wellbeing & Yes & & Covered \\
Dependence or independence & Not Covered & Not Covered & Yes \\
\hline
\end{tabular}

Source: Coons, Rao, Keininger, \& Hays, A Comparative Review of Generic Quality-ofLife instruments. Pharmacoeconomics 2000 Jan; 17(1): 13-35. 
anxiety/depression. Each attribute has three levels: no problems, some problems, and extreme problems. This instrument is self-administered and respondents can rate their overall utility of life on a $0-100$ hash-marked vertical visual analog scale (EQ-VAS). The EQ-5D has been widely used among the general population as well as patient samples and has been translated into more than 130 different languages (Herdman et al., 2011; Torrance \& Drummond, 2005). However, there is evidence that the EQ-5D can suffer from a ceiling effect especially when it is used among a general population with minor medical conditions. Thus, there might be issues with its ability to detect small changes in health (Bharmal \& Thomas III, 2006; Herdman et al., 2011; Huang et al., 2008).

\subsubsection{Rand-36 (SF-36)}

The Short Form Health Survey (SF-36) also known as, Rand-36 is one of the most widely used health related quality of life (HRQoL) survey instruments. It consists of 36 items that assess eight concepts in health: physical functioning, role limitations caused by physical health problems, role limitations caused by emotional problems, social functioning, emotional well-being, energy/fatigue, and general health perception. These concepts can be categorized into two component summaries (the Physical Component Summary [PCS-36] \& the Mental Component Summary [MCS-36]). Twenty of 36 items assess the respondent's health in the past four weeks. The last item assesses the change in the perceived health in the last 12 months, and every item is scored on a scale from 0-100 (Hays \& Morales, 2001). Owing to the length of time the SF-36 takes an individual to complete, a new and shorter version of the SF-36 was developed. The SF-12 is a succinct form of the SF-36 designed to assess the general self-reported health as well as the limitations in everyday activity owing to physical and mental health in the past four weeks and has the same two component summary scales (Ware Jr, Kosinski, \& Keller, 1996). The SF-12 was shown to be more sensitive to subtle changes in health than the EQ-5D in a relatively healthy population (Johnson \& Pickard, 2000).

\subsubsection{Nottingham Health Profile (NHP)}

The NHP was developed in the 1970s by a group of researchers in the Department of Community Health at Nottingham University. The instrument was designed to reflect lay people's perception of health as opposed to the medical professional assessment of patient health. It was created based on a pool of more than 2000 statements collected from in-person interviews that enabled the researchers to identify key concepts. Researchers reduced the number of statements to 38 for the first part and seven statements for the second part. Statements require a 'Yes' or 'No' response. The first part assesses perceived or subjective health, and statements fall into six domains: sleep, physical mobility, energy, pain, emotional reactions and social isolation. The first part is scored using weighted values, which results in scores ranging from 0 to 100 for each section. The higher the score on any section, the greater the severity of the perceived problems in that domain (Coons, Rao, Keininger, \& Hays, 2000; Hunt, McEwen, \& McKenna, 1985). The second part focuses on the domains of the daily life, which are 
mostly affected by health: paid employment, jobs around the house, social life, personal relationships, sex life, hobbies and interests, and holidays (Hunt et al., 1985). The developers of the NHP have recommended that the second part should no longer be used (Bowling, 1991; Coons et al., 2000).

\subsection{Medication Adherence}

According to the World Health Organization, adherence is defined as "the extent to which a person's behavior (i.e., taking medications, following a diet, or making healthy lifestyle changes) corresponds with agreed upon recommendations from a healthcare provider" (Sabaté, 2003, p.136). However, medication adherence can also be defined as the degree to which patients' or their caregivers' medications administration behavior coincides with their physicians' advice with regard to timing, dosage, and frequency of administration during the prescribed time window (Osterberg \& Blaschke, 2005). Adherence to prescribed medications is difficult for patients in general and particularly challenging for elderly. Multiple factors influence the elderly patients' adherence to their prescribed treatment regimens. Elderly patients' sociodemographic (age, race, sex, and education), medical (comorbidities, number of medications, and treatment of adverse events), psycho-behavioral (beliefs about medicine, understanding of the medical condition, and satisfaction with treatment), and economic (type of insurance, copayments and coinsurance) characteristics are potential factors that can influence the elderly patients' adherence to their prescribed medications (Gellad, Grenard, \& Marcum, 2011; MacLaughlin et al., 2005; Sa'ed et al., 2013) (Figure 2-2).

The relationship between each of these factors and medication adherence is far from being simple and clear. For instance, older adults are often assumed to have lower adherence to their prescribed medications compared to younger adults. However, this is not always the case. Some studies have shown that advanced age ( $\geq 65$ years) is positively associated with adherence to prescribed drug regimens (Billups, Malone, \& Carter, 2000). In addition, the number of medical conditions, the prescribed medications patients are receiving and their frequency of administration were positively associated with medication adherence (Billups et al., 2000; MacLaughlin et al., 2005). Furthermore, patient satisfaction with care may affect their adherence to medications (Dang, Westbrook, Black, Rodriguez-Barradas, \& Giordano, 2013; Krousel-Wood, Muntner, Islam, Morisky, \& Webber, 2009). Another important aspect of medication use, patients' satisfaction with their treatment regimens, was studied recently in a sample of patients with hypertension (HTN), and found to have a positive association with patients' adherence to their treatment regimens. Patients who were overall satisfied with their prescribed medications' effectiveness and convenience were more likely to be adherent to their treatment regimens (Sa'ed et al., 2013). In addition, health related quality of life (HRQoL) was also associated with medication adherence. Elderly patients with HTN and poor HRQoL scores have reported low adherence levels to their antihypertensive medications (Holt et al., 2010). 


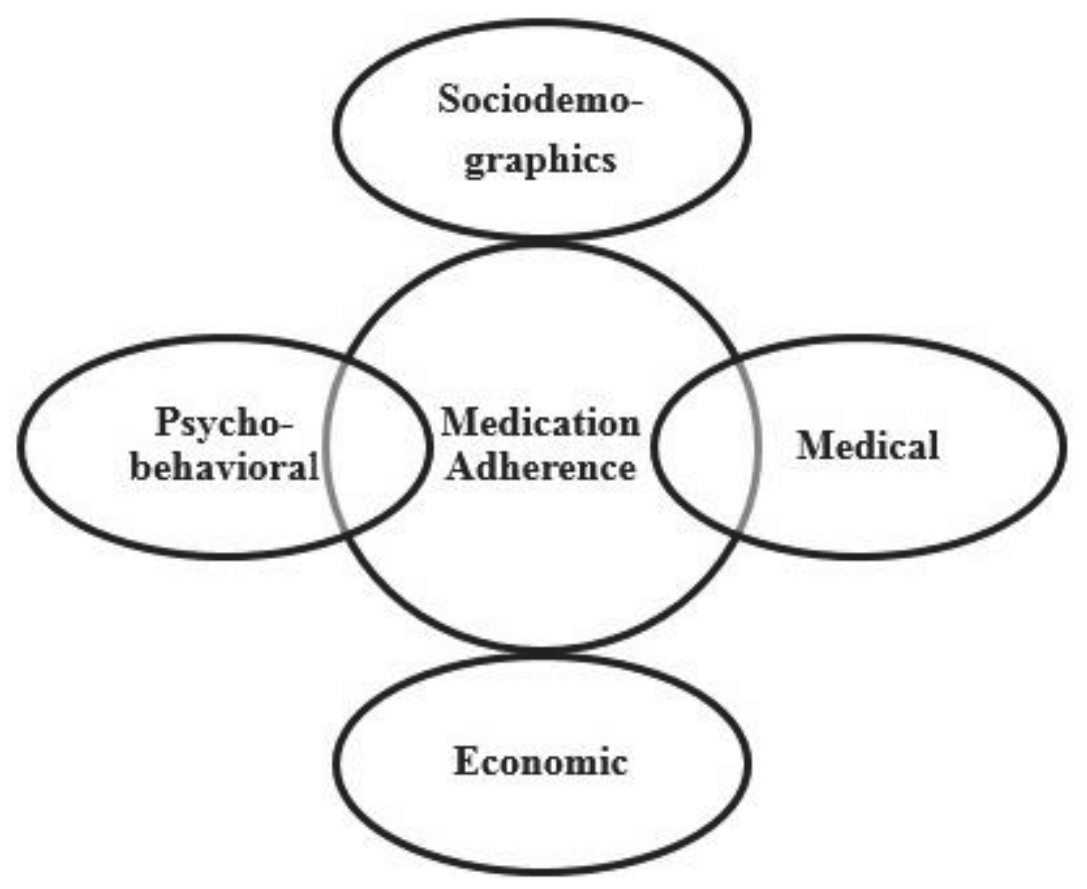

Figure 2-2. Factors influencing medication adherence.

Source(s): Gellad, Grenard, \& Marcum, A Systematic Review of Barriers to Medication adherence in the Elderly: Looking Beyond Cost and Regimen Complexity. The American Journal of Geriatric Pharmacotherapy 2011 Feb; 9(1): 11-23.

MacLaughlin et al, Assessing Medication Adherence in the Elderly: which Tools to Use in Clinical Practice? Drugs Aging 2005; 22(3):231-255.

Sa'ed, Al-Jabi, Sweileh, Morisky, Relationship of treatment satisfaction to medication adherence: findings from a cross-sectional survey among hypertensive patients in Palestine. Health and Quality of life Outcomes 2013 Nov; 11(1):191. 
The importance of medication adherence stems from the fact that poor medication adherence has been linked to high healthcare costs in comparison to higher levels of adherence which were associated with lower healthcare costs. This is particularly true among patients with chronic medical conditions that can lead to untoward consequences if left uncontrolled (Pittman, Tao, Chen, \& Stettin, 2010; Sokol, McGuigan, Verbrugge, $\&$ Epstein, 2005). HTN is one of the well-known preventable causes of cardiovascular disease morbidity and mortality. The utilization of antihypertensive medications has been found to reduce the risk of both coronary heart disease (CHD) and stroke by $34 \%$ and $21 \%$, respectively (Mazzaglia et al., 2009). Patients with poor adherence to antihypertensive medications were at higher risk of all-cause mortality, stroke, and acute myocardial infarction (Esposti et al., 2011). Only 51\% of the U.S. hypertensive population are considered adherent to their prescribed medications (WHO). Achieving an acceptable level of adherence $(>80 \%)$ entails an open and honest relationship between patients and their physicians.

Medication adherence measures can fall into two different categories: direct and indirect measurements (Fairman \& Matheral, 2000; Farmer, 1999). Direct measurement of medication adherence can be done through directly measuring the drug concentration in the patients' blood stream. It can also be done by observing patients and making sure that they swallow their pills and documenting that afterwards and by healthcare providers administering the medication to patients intravenously (IV), or intramuscularly (IM) and documenting the administration. Although direct measurement of adherence is considered the most reliable method of measuring adherence, this is impractical, uncommon, and rarely used. The indirect measurement of adherence are more commonly used and include medication monitoring (electronic monitoring, pills counts), self-report measures (diaries, surveys, and interviews), and prescription claims data (length of therapy, treatment gaps, medication possession ratio [MPR], and days of coverage) (Fairman \& Matheral, 2000; MacLaughlin et al., 2005).

Although there are several methods for measuring medication adherence and each one of them has its own advantages and limitations, no one measure of the aforementioned methods is perfect (Fairman \& Matheral, 2000). The advantage of selfreport measures over other medication adherence methods is that they provide the reason for non-adherence from patients' perspective (Fairman \& Matheral, 2000; Lavsa, Holzworth, \& Ansani, 2010). Self-report measures and scales have differing attributes such as the administration time, reliability, specificity and sensitivity, validity, and their ability to detect barriers to medication adherence. The new and commonly used selfreport medication adherence scale is the 8-item Morisky Medication Adherence Scale (MMAS-8). This scale was validated across a wide spectrum of clinical conditions with both high sensitivity (93\%) and specificity (53\%) towards detecting those with poor blood pressure control as well as high reliability ( $\alpha=0.8$ ) (Lavsa et al., 2010; Morisky, Ang, Krousel-Wood, \& Ward, 2008). The original 4-items of the Morisky Medication Adherence Scale (MMAS-4) is a validated shorter version of the MMAS-8, but has lower internal consistency reliability ( $\alpha=0.61$ ), sensitivity ( $81 \%$ ), and specificity ( $44 \%)$ in patients with HTN (Lavsa et al., 2010). Brief Medication Questionnaire (BMQ), Selfefficacy for Appropriate Medication Use Scale (SEAMS), and Medication Adherence 
Rating Scale (MARS) are widely used questionnaires that assess medication adherence in multiple patient populations. The BMQ, SEAMS, and MARS have limited generalizability and lower reliability in comparison with MMAS-8 (Lavsa et al., 2010).

\subsection{Beliefs about Medications}

The healthcare delivery in the U.S. and other industrialized countries has been following the biomedical model for a long time. This model assumes that illness is linked to diseases that results in disturbances in the physiological functions of the body and are separate from the psychosocial factors that may affect the disease severity and treatment outcome (Annandale, 1998; Horne, 2000). However, in reality these factors are crucial in determining the success of any treatment plan, and without considering them it is highly unlikely that any disease management strategy would result in favorable outcomes (Ogden, 2012). Hence, it is important to assess and understand people's beliefs and attitudes towards disease and medicine.

The self-regulatory model has been proposed as one of the best health behavior models to explain the relationship between health beliefs and illness behavior (i.e., medication taking behavior). According to this theory, the individual reacts to illness both cognitively and emotionally (Figure 2-3) (Cameron \& Leventhal, 2003). Understanding patients' beliefs and concerns about their newly diagnosed disease is important. However, equally important is patients' beliefs about the medications that treat these illnesses especially those medications that are used on a chronic basis (e.g., antihypertensives, antihyperlipidemics, and antiasthmatics). Some patients believe that taking medications to treat their medical conditions takes away their sense of control over their health. This eventually may affect their expectations of their prescribed medications which are also influenced by their past experiences (Dolovich et al., 2008).

Many of the published studies on health sociology focus on identifying barriers to healthcare access. However, fewer studies are investigating the patients' beliefs and concerns that may affect their compliance with physicians advice and recommendations (Horne, 2000). In an era of patient-centered care, patients are expected to take an active role with physicians in the decision making process (Lee \& Lin, 2010). Thus, physicians need to understand patients' needs and concerns. This understanding can only be achieved through physicians' candid and frank conversations with patients. To help physicians understand these beliefs and concerns, several qualitative and quantitative studies have been conducted to identify repeated themes and measure the impact of the cultural background on patients' beliefs about medications in general (Britten, 1994; Horne et al., 2004; Lorish, Richards, \& Brown, 1990) as well as about disease-specific medications (Emilsson et al., 2011; Farmer, Kinmonth, \& Sutton, 2006; Lennerling \& Forsberg, 2012; Paraskevi, 2012). 


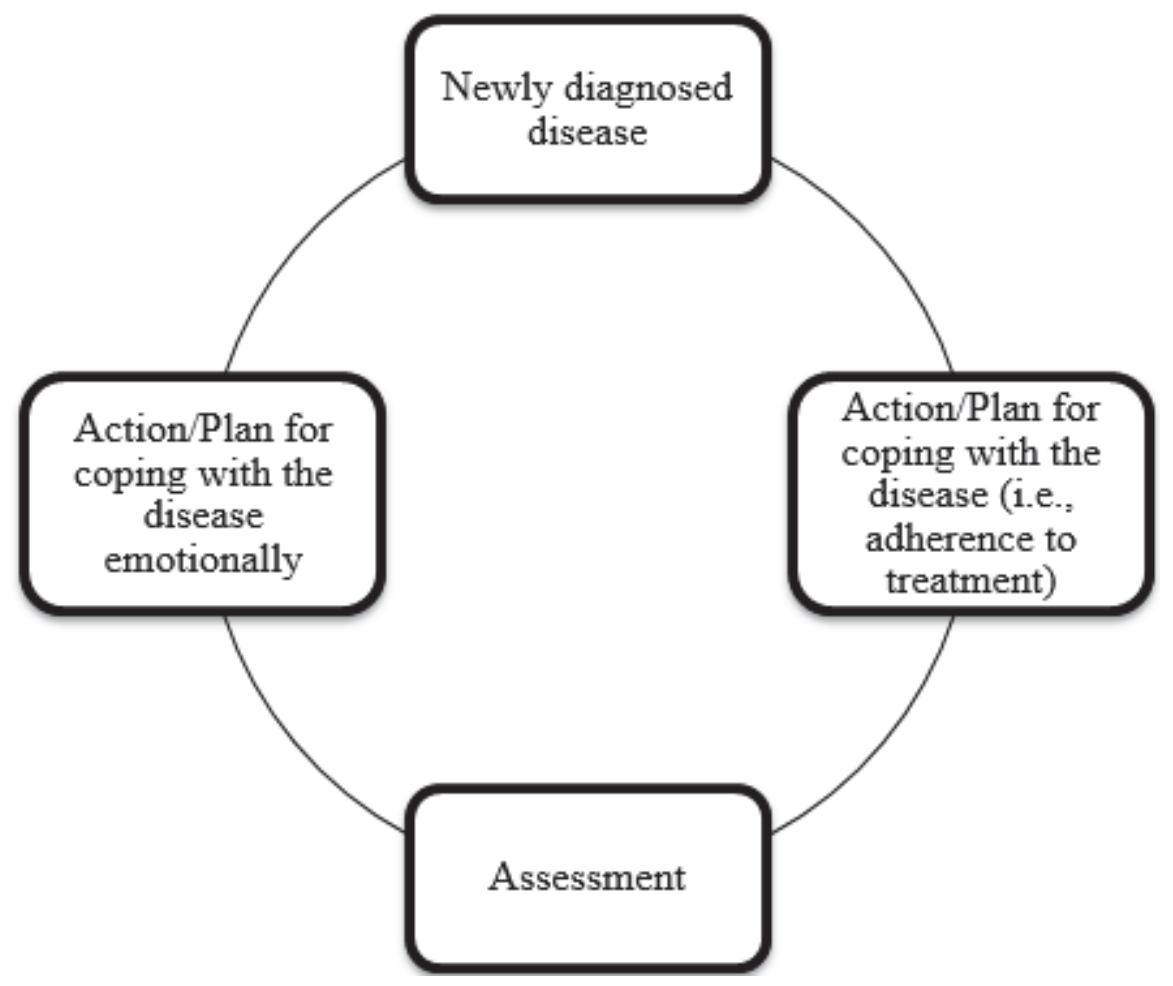

Figure 2-3. Depiction of the self-regulation behavioral model.

Source: Cameron \& Leventhal, Anxiety, Cognition, and Responses to Health Threats. The Self-regulation of Health and Illness Behavior. 2003 Jan; 157-183. 
Patients' beliefs about medications are dynamically changing and are potentially formed based on their past experiences, healthcare delivery system, culture, beliefs (Dolovich et al., 2008; Phatak \& Thomas, 2006). These beliefs are considered by some health sociologists as a hidden determinant of any treatment outcome (Horne, 1999). They can be classified under "central themes", such as people's perceptions about the inherent nature of the medications, the likelihood of the medications to do any harm or benefit, their tendency to cause addiction, and their likelihood to be overprescribed by physicians (Horne, 2000; Horne et al., 2004). The impact of these factors and other sociodemographic factors such as age on patient views and beliefs about medications are variable and controversial. For example, men were found in one study to have more negative beliefs about medications in general compared to women (Horne et al., 2004). In another study conducted in Sweden, women expressed negative views about medications and their harmful effects more than men (Isacson \& Bingefors, 2002). With regard to age, older adults were more likely to have positive views about medications than their younger counterparts were, and those with lower incomes were more likely to think of medications as something necessary but evil at the same time than those with higher incomes were. Patients with HTN considered their antihypertensive medications as necessary, but evil more than patients with other medical conditions. Patients with a psychiatric diagnosis had more positive views about medications than any other patient populations (Isacson \& Bingefors, 2002). Cultural background was also found to have a strong association with medication beliefs. For instance, patients of Asian descent have expressed negative views about medications more than those of European descent (Horne et al., 2004). Furthermore, in another study among Japanese patients, negative beliefs about medications were associated with non-adherence to medications (Iihara et al., 2004). Patients' educations were also associated with general beliefs about medications; those with lower levels of education were more likely to perceive medications as harmful compared to those with higher levels of education (Horne et al., 2004; Horne et al., 1999; Isacson \& Bingefors, 2002).

Health status also influences patient beliefs about medications. Those with chronic medical conditions such as hypertension and diabetes have stronger feelings regarding the necessity of medications than those with acute medical conditions (Horne \& Weinman, 1999). Patients who are currently on prescription medications have more positive beliefs about medications than those who are not (Ramstrom et al., 2006). Furthermore, believing in herbal/complementary medicine was associated with negative views about prescription medications in general. In addition, those who use herbal medicine have higher likelihood to think that physicians overprescribe (Horne et al., 2004; Isacson \& Bingefors, 2002; Mårdby, Åkerlind, \& Jörgensen, 2007). Another important and interesting factor that was found to influence patient beliefs about medications is the direct to consumer advertisement (DTCA) (Iosifescu, Halm, McGinn, Siu, \& Federman, 2008). Finally, physicians' communication style was found to have a positive impact on patients' beliefs about medications which in turn resulted in better adherence to drug regimens (Bultman \& Svarstad, 2000). Overall, patient beliefs about medications was shown to influence treatment outcomes in different patient populations. Patients who had negative views about medications were found to be less likely to adhere to their treatment regimens (Gatti et al., 2009; Iihara et al., 2004; Mårdby et al., 2007). 
Patients' beliefs and concerns about medications were identified qualitatively in several studies (Britten, 1994;Conrad, 1985; Lorish et al., 1990). However, to measure medications beliefs quantitatively Horne, Weinman, and Haskins developed the Beliefs about Medicines Questionnaire (BMQ) based on extensive qualitative research that identified common themes in medication beliefs (Horne et al., 1999). The BMQ was tested for psychometric properties and has been found to be valid and reliable across multiple chronic medical conditions including but not limited to asthma, cancer, diabetes, and hypertension. The BMQ has two sections (Horne et al., 1999):

- The BMQ-Specific, which assesses patients' beliefs about medications, prescribed for a particular illness from two aspects. The first aspect is the necessity of use. The second aspect is concerns about the potential side effects that patients may experience upon the use of these medications.

- The BMQ-General, which assesses the personal views about the medications in general, and has two 4-items scales. The first scale is the general-overuse scale, which assesses whether patients feel that physicians put too much trust in medications and hence overprescribe them. The second scale is the general-harm scale, which assesses patients' beliefs about whether they regard medications in general as inherently harmful with limited usefulness.

\subsection{The Value and Influence of Media Outlets on Patients' Health Beliefs and Behavior}

\subsubsection{Direct to Consumer Advertisement (DTCA)}

Multiple media outlets (i.e., TV, Internet, newspapers) that advertise as well as educate the public about the signs and symptoms of different medical conditions and the medications that treat these conditions surround patients today. This phenomenon, called direct to consumer advertisement (DTCA), has grown rapidly in the last two decades. DTCA is currently the most noticeable type of health communication that the public encounters (Donohue, Cevasco, \& Rosenthal, 2007; Rosenthal, Berndt, Donohue, Frank, \& Epstein, 2002).

However, the public is split on DTCA between opponents who claim that it does nothing but harm, and proponents who believe that DTCA has many advantages that should not be overlooked. According to the proponents, DTCA informs as well as educates the public of certain medical conditions that they might have without them knowing about it. This eventually will encourage people to seek help and talk to their physicians if they think they have one of the symptoms listed in a medication's advertisement, which will in turn strengthen the patient-physician relationship by empowering patients to open up constructive dialogs with physicians. This would reduce the healthcare costs by people seeking help earlier before it is too late for medications to work. On the other hand, opponents of DTCA say that it misinforms patients. Opponents claim that most pharmaceutical companies advocate for the use of their medications by 
devoting most of their commercial advertisement time to the benefits of taking their medications and spend far less time on the possible adverse effects. By doing so, pharmaceutical companies overemphasize the benefits of their medications and underestimate the potential risks associated with their use. Another issue that critics have is the hastiness of the pharmaceutical companies to release their commercial advertisements of their new medications in the media without giving the post-marketing surveillance an adequate amount of time to check the safety of the medication on a larger scale, such as with (Vioxx ${ }^{\circledR}$, Merck) incident. Opponents also believe that DTCA poses a real threat to (a) public health through inappropriate prescribing by some physicians who feel pushed sometimes by patients to prescribe a certain medication for them although they do not need it, and (b) the economy by exacerbating the rate of rising healthcare costs (Ventola, 2011).

Minorities and Internet savvy people are more likely to be in favor of DTCA, while people with higher level of education are more likely to oppose DTCA. Overall, DTCA is more appealing to many individuals with less power and control given the fact that it directly reaches the public without being channeled through the healthcare system (Ceccoli \& Klotz, 2013).

\subsubsection{Online Search for Health Information}

When it comes to the information sought by patients online and not directly presented to them through DTCA, fewer studies have investigated the impact on patient health behavior. The development of online health education websites is rapid with the potential to influence the way patients interact with their physicians (Sciamanna, Clark, Diaz, \& Newton, 2003). It has been claimed that $80 \%$ of the U.S. adults and $60 \%$ of their European counterparts use the Internet to seek medical advice (Sillence, Briggs, Harris, \& Fishwick, 2007). Internet use for health-related activities assessed by the 2002 Pew Internet and American Life Project found that 6 out of 10 Americans have access to the Internet (Sciamanna et al., 2003).

Unlike the DTCAs that are usually presented to the public in a simple language format (i.e., story structure), several issues face consumers and patients alike when they search online for information about a medication or a medical device. Patient health literacy, the complexity of information or medical jargon, the variability of the content quality, and the potential for commercial interests to influence the content of the online information are some examples of issues that face patients when they use the Internet to look for information about a medical condition or a medication (Winker et al., 2000). In a systematic meta-analysis of health-related websites evaluations, $70 \%$ of studies reported that the quality of websites was an issue (Sillence et al., 2007). Despite these issues, many patients turn to the Internet to seek information about health and treatment as well as support. According to the National Cancer Institute's Health Information National Trends Survey, $56.5 \%$ of the breast cancer patients visited an online website to learn more about their clinical condition. They also have reported that the Internet represents their second source of information after their physicians. Online information was also 
found to have a positive effect on the physician-patient relationship (Shaw et al., 2007). In another cross-sectional study, patients who do not have Internet access and felt that their physicians engaged them in the decision making process were more interested in using the Internet for health-related activities compared to those who felt that their physicians engaged them less in the decision making process. On the other hand, no association was found between having interest to use the Internet for health-related activities and physician-patient relationship among those who have access to the Internet. This suggests that once people have access to the Internet they no longer view it as filling in gaps in their communication with physicians, but as a secondary source of information after their physicians' advice (Sciamanna et al., 2003). In another national survey, the access to reliable online health-related websites has been linked to reduced anxiety, a feeling of self-efficacy, and reduced utilization of ambulatory healthcare services (Ybarra $\&$ Suman, 2006). Evidence also suggests that online health information may in fact encourage individuals to seek healthcare (Ybarra \& Suman, 2006).

Research has shown that most online health information seekers use a general search

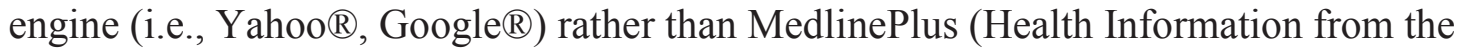
National Library of Medicine). They typically spend about half an hour browsing two to five websites and afterwards do not remember the website's name from which they obtained the information. They usually seek information online to enhance their knowledge of their medical conditions, help them diagnose a medical condition, and sometimes verify their physician's diagnosis and medical advice (Ybarra \& Suman, 2006). Minorities have greater interest in using the Internet to seek health information as well as to check the appropriateness of their medical treatment because they feel the Internet is relatively race neutral (Sciamanna et al., 2003). Adults who are $\geq 65$ years of age have been found to be the least users of the Internet (Jenkins \& Dunn, 2004). Whereas middle-aged adults were more likely to use the Internet for health-related information, and $41 \%$ of the adolescents have reported changing their health behavior as result of visiting health educating websites (Ybarra \& Suman, 2006).

In a qualitative study that aimed to test how patients trust online health-related information, 15 white postmenopausal women with at least high school degree were enrolled in a longitudinal study that was conducted between August 2003 and April 2004 in the United Kingdom. All were keen to learn more about this critical period of their life, and have reported visiting women's health websites at least once a week. The theoretical staged model of trust that was proposed for the study was divided into three phases (Figure 2-4). In the first phase, each participant attended a two-hour session in an Internet café for four weeks. During each session, the participants were given an hour to search the Internet for information related to women's health, followed by a 50 -minute discussion with a facilitator. In the discussion session, participants were asked about their current online information sources, their search strategies, trusted and mistrusted websites, their first impressions, and the revisited websites. In the next phase, the participants were asked to log their online health search behavior in diaries over the 


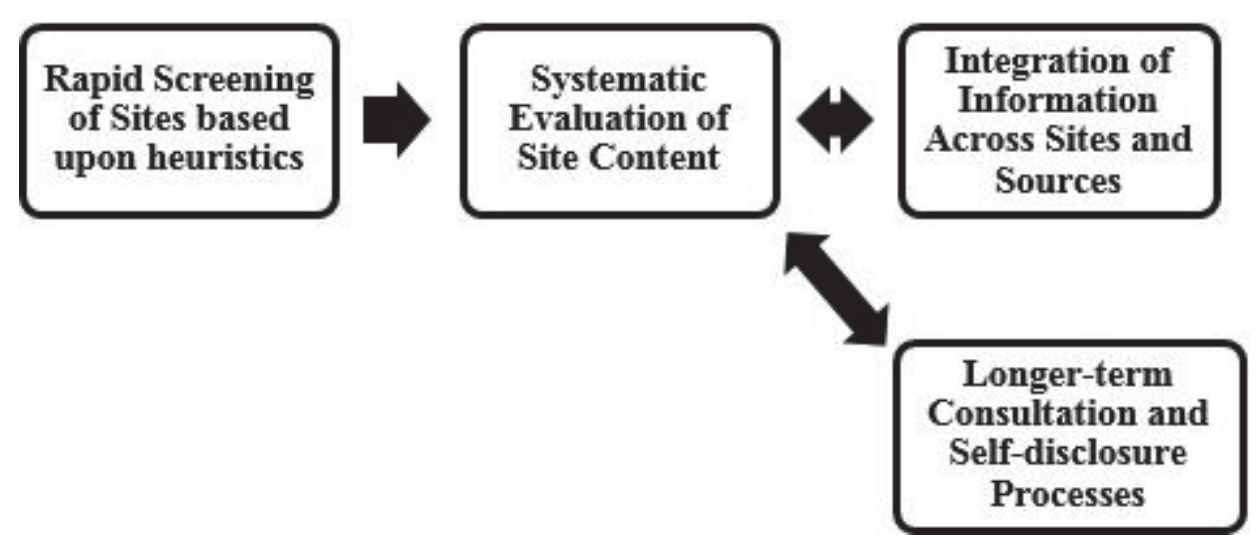

Figure 2-4. Staged model of trust.

Source: Reprinted from Social Science and Medicine, 64(9), Sillence, Briggs, Harris \& Fishwick, How do Patients Evaluate and Make Use of Online Health Information?/Figure 1, 1853-1862, $2007 \mathrm{Feb}$, with permission from Elsevier. 
following 6 months. In the final phase, that followed the second phase by one month, the participants underwent a structured telephone interview to assess the influence of the online sources on participants' relationships with their physicians as well as their level of involvement in the decision-making process. All discussions were recorded and transcribed, and then extracts of trust and mistrust were coded. Diaries were analyzed based on the thematic analysis, and the interviews according to the emergent themes. The participants reported that the design and feel of the website was one of the deciding factors on whether they accept or reject a website (i.e., websites with pop-up advertisements were more likely to be rejected). Furthermore, websites that belong to credible organizations (i.e., reputable healthcare institutions), and reviewed by experts were more likely be accepted. The participants also reported that websites that address most of their questions, have relevant answers, and have information written by laypeople were likely to be revisited. The online search for health-related information increased the participants' feelings of social support, and provided them with an opportunity to explore alternative treatment options. In addition, the online information was found to influence the patients' preference for health decision-making without having any negative effect on their relationship with their physicians (Sillence et al., 2007). In another study, factors such as convenience and anonymity of getting information through online health websites were found to be crucial for consumers who browse such websites. In addition, the readability of the information presented on the health websites is highly important given the fact that the average American reads at $8^{\text {th }}$ grade level and $20 \%$ of the Americans read at $5^{\text {th }}$ grade level (Jenkins \& Dunn, 2004).

Visiting online health-related websites had a positive impact on the patient adherence to treatment (Kuppersmith, 2002). It also had several potential benefits with regard to the physician-patient relationship by helping patients to make informed healthcare decisions, empowering them to collaborate with their physicians, getting them involved in the decision-making process, using the time with physicians more efficiently, helping them find online support groups, and hearing about other patient experiences with the same medical condition or on similar treatment (Wald, Dube, \& Anthony, 2007). However, patient access to online health-related websites can also have potential disadvantages. In a study that investigated the role of the Internet on the physician-patient relationship, $90 \%$ of the people who visit health-related websites frequently felt that they could manage their own health issues by themselves, and $82 \%$ of them stated that the websites provided more useful information on new medications and alternative treatment options than their physicians or pharmacists. The lack of attention to details, the personal touch that once existed in the physician-patient relationship, and the limited period of time patients see physicians were cited as the main reasons behind the findings (Erdem \& Harrison-Walker, 2006). Access to the websites by patients may also diminish their trust in their physicians as well as in the healthcare system creating a real challenge to physicians to regain their patients' trust back again (Wald et al., 2007). Also, patients trust in the websites may lead to self-diagnosis, treatment using over-the-counter medications, result in misdiagnosis, and inappropriate treatment if incorrect information was relied on (Erdem \& Harrison-Walker, 2006). Furthermore, health-educating websites may exacerbate socioeconomic health disparities due to the fact that some patients do not have access to the Internet (Wald et al., 2007). 
The rapid expansion of online medical information, easier access to online health information by patients, and heightened consumer expectations has changed the role of the physician drastically. Physicians today must help patients interpret information they have gathered, guide them to reliable sources of information, and develop a strategy for finding and integrating new information. (Kuppersmith, 2002). Today, patients can go online and search for good physicians (i.e., reading people's reviews and stars ratings) by browsing multiple physicians' rating websites. However, the Internet does not only have physician evaluation websites, it also has several medication and medical device rating websites. These websites reflect other patient experiences with medications, treatment approaches, and medical conditions in general. Assessing and understanding the value of these websites to patients is important. 


\section{CHAPTER 3. METHODOLOGY}

\subsection{Study Design}

The primary purpose of the research study was to explore the value of online ratings of medications to the elderly population and evaluate if older adults' views regarding such online websites providing patient feed-backs of their medications varies with their sociodemographics, quality of life, beliefs about medication, health literacy, preferences for involvement in decision making, and medication adherence. The study main goal was to explore the relevance of such online websites to older adults' care (i.e., facilitating physician-patient communication, and encouraging patients to take part in the decisionmaking). Further, participants' views of such online websites (i.e., do they trust the online ratings of medications) were also considered. Relevant information thought to impact older adults' opinions of such websites including their sociodemographics, health literacy, medication adherence, preference for involvement in health decision-making, beliefs about medications, and quality of life were collected using validated questionnaires. Seven senior centers in the State of Tennessee were visited and older adults ( $\geq 60$ years of age) were asked to complete Patient Reviews of Medication Experiences questionnaire that examines the value of online ratings of medication websites. Alongside PROMEX, participants were also asked to complete other validated questionnaires that collected information about factors that may affect the elderly participants' opinions of such online websites. Permissions to use these questionnaires were received prior to the beginning of the study (Appendix A).

\subsection{Settings and Subjects}

Data were collected in Tennessee at senior centers in Memphis and the surrounding areas of Arlington, Bartlett, Cordova, and Somerville. Older adults visit these senior centers to socialize with their peers and spend fun time together. Seniors who met the following criteria (1) being 60 years of age and older and (2) taking prescription medications were asked to participate in the study. Further, those who reported having HTN were asked to complete a second part of the PROMEX questionnaire that assessed the level of adherence to their antihypertensive medications.

\subsection{Sampling Plan}

A convenience sample of 300 elderly subjects from the senior centers were recruited. Both the principal and co-investigator chose this method due to time and resource limitations. However, we tried to make our sample as representative as possible by recruiting participants from different locations. 


\subsection{Data Collection}

The Senior Centers' coordinators were contacted at least a week prior to the planned visit and a date and time was set up. Two research assistants visited the following senior centers:, the Orange Mound Senior Center, McWherter Senior Center in Memphis, Frayser-Raleigh Senior Center and Bert Ferguson Community Center in Cordova located in Memphis; the Bartlett Senior Center in Bartlett, the Somerville Senior Center in Somerville, and the Senior Citizens Center in Arlington. In reserved private rooms in these Senior Centers, the survey administrators explained to the seniors that their participation was voluntary and they could withdraw from the study at any time without penalty. Further, the first page of the survey explained the purpose of the study, the rights of the participants and asked participants to sign a consent form before starting the survey.

The survey consists of two parts: all older adults on prescription medications regardless of their medical conditions should complete the first part; however, the second part was completed only participants with HTN should since it includes a medication adherence questionnaire that measures adherence among those participants. Those who completed the survey received a \$20 Kroger gift card as an appreciation for their participation. Data collection was started in August 2013 and was completed in December 2013.

\subsection{Participant-Reported Outcome Measures}

\subsubsection{Older Adults' Opinions of the Online Medication Rating Websites}

A validated measure that surveys individuals about the usefulness of online reviews of medications by patients did not exist. Therefore, a questionnaire was created to address important aspects of the online medications rating websites that are important to the older adults. The Patient Reviews of Medication Experience (PROMEX) questionnaire has two domains:

I. The value of such websites in general as well as in facilitating patientphysician communication.

II. The trustworthiness and the influence of online patients reviews of medications on the participant's medication preference.

The first proposed domain consists of four questions with a five-point Likert scale, in which the first question inquires about the usefulness of such websites in general from the perspective of older adults. Further, to explore the usefulness of the online patients' medications reviews, the participants were asked about the likelihood they would mention it to their physicians/prescribers. The third question inquired about the likelihood such online reviews would facilitate communication with their physicians. The final question inquired about the probability that physicians would be upset if the participants brought up the online reviews. 
The second proposed domain contains three questions with a Likert scale of five points. The first question in this domain inquired about the trustworthiness of such websites to participants. To examine how much older adults trust such websites that show them medications reviews, we asked them about the likelihood they would provide their own comments and ratings of their prescribed medications. The final question inquired about the influence of the online patient reviews of medications on the participants' medication preference. The total number of questions in both domains is seven with proposed maximum points of 35 and a minimum of seven. The higher the score, the more likely older adults believe that these online websites are useful in general as well as in facilitating their communication with physicians.

Since the PROMEX questionnaire was newly created and recently used, it was validated using Principal Component Analysis and Varimax Rotation methods to test for its construct validity. To test for reliability, the internal consistency (Cronbach's Alpha) method was used.

\subsubsection{Patient-Centered Practice Attributes}

The Primary Care Assessment Survey (PCAS) is a validated 51-item, self-report questionnaire which is designed to operationalize the formal definitions of primary care. The PCAS measures seven domains of primary care through 11 validated summary Likert-scaled measures which perform consistently well across population subgroups defined based on age, sex, education, race, household income, and health status. Each scale ranges from 0 to 100 with higher scores indicating more of the underlying attribute (Safran et al., 1998).

The Communication and the Interpersonal Treatment are two validated scales within the Primary Care Assessment Survey (PCAS) (Safran et al., 1998). Both the Communication and the Interpersonal Treatment summary scales have excellent reliability with high Cronbach's Alpha (0.95) (Nunnally, 2010; Safran et al., 1998). In the communication scale of the PCAS, participants were asked to rate their physicians on six important aspects of primary care that are aligned with the Institute of Medicine (IOM) definition of primary care. These aspects are: the thoroughness of the questions being asked about their symptoms, attention to what they have to say, explanations provided about their medical conditions and treatment, instructions about symptoms to report and when to seek help, advice and help in making decisions about their own care, and finally whether they leave their Physicians' offices with unanswered questions (Care, Donaldson, Yordy, \& Vanselow, 1994; Safran et al., 1998). The interpersonal treatment scale addresses another five aspects of primary care that are also aligned with the IOM definition of primary care; participants were asked to rate their physicians on the amount of time spent with them, patience with their questions, friendliness and warmth received, care and concern, and finally the level of showed respect to them (Safran et al., 1998).

Each of the covered items in both the communication and the interpersonal treatment scales have six possible answers based on the Likert scale. Each one of them is assigned a 
value (i.e., Very poor $=1$, Poor $=2$, Fair $=3$, Good=4, Very good=5, Excellent $=6$; or Always $=1$, Almost always $=2$, A lot of the time $=3$, Some of the time $=4$, Almost never $=5$, Never=6). The Communication scale has six questions with six possible answers for each question. The highest possible score of 36 , the lowest possible score is six, and the possible raw score range is 30 . The interpersonal treatment scale has five questions with six possible answers. The highest possible score is 30 , the lowest possible score is 5 , and the possible raw score range is 25 . The higher the scores of both the PCASCommunication and PCAS-interpersonal treatment scales, the higher the satisfaction of the respondents of both their physicians' communication and interpersonal treatment.

\subsubsection{Health-Related Quality of Life}

Participants' Health-Related Quality of Life (HRQoL) was measured using the Short Form Health Survey (SF-12v2). The SF-12v2 is a validated generic questionnaire (Cronbach's Alpha $>0.7$ ), which assesses the general self-reported health as well as limitations in everyday activity owing to physical and mental health in the past four weeks(Ware Jr et al., 1996). It has two component summary scales, the Physical Component Summary (PCS-12) and the Mental Component Summary (MCS-12) with higher scores (ranges between 0 to 100) indicating better quality of life (Ware Jr et al., 1996).

\subsubsection{Patients' Beliefs about Medications}

The patients' beliefs about medications were assessed using the Beliefs about Medicine Questionnaire (BMQ). The BMQ was developed by Horne in the United Kingdom and has been validated across multiple health conditions (Horne et al., 1999). It consists of two sections, one general and one specific. The general section contains eight statements that can be broken down into two themes. The first theme is the "GeneralHarm", which comprised beliefs about the intrinsic nature of medications and the extent to which they are perceived as harmful. The second theme is the "General-Overuse", which is comprised of beliefs about the way medications are used and in particular, whether physicians overprescribe them. The second section consists of ten statements that can be broken down into two themes. The first theme is the "necessity", which focuses on the perceived necessity of the medication to maintain and improve the health. The second theme is the "concerns", which focuses on the perceived concerns of the potential adverse effects of the medications. Respondents can indicate their level of agreement with each statement on a five-point Likert scale (Horne et al., 1999). Since seniors who were taking prescribed medications were surveyed about their opinions of the online reviews of medications, and were not focusing on a certain disease, the general BMQ was used. 


\subsubsection{Medication Adherence}

Medication adherence was measured using Morisky Medication Adherence Scale (MMAS-8) among those who reported having hypertension. The MMAS-8 is a validated self-report questionnaire that consists of eight questions. An alpha reliability of 0.83 was computed among 1367 patients who were diagnosed with essential HTN by primary care providers in an outpatient clinic of a large teaching hospital and was significantly associated with blood pressure control $(\mathrm{p}<0.05)$. The underpinning theory of this questionnaire was that failure to adhere to treatment regimen could stem from several factors such as forgetfulness and complexity of the treatment regimen. The MMAS- 8 questions were phrased in a way to avoid the "yes-saying" bias, which is usually the patients' tendency to give positive answers to healthcare providers. The questions address patient medication taking behavior but not medication adherence determinants; with a dichotomous response (yes/no) to 7 out of 8 questions and 5-point Likert response for the last question. The total scale has a range between zero and eight with higher scores indicating better adherence. A cutpoint of $<6$ is used to identify patients with poor adherence to an antihypertensive treatment regimen with $93 \%$ sensitivity and $53 \%$ specificity. Each question was given a score of either zero or one. If the participant answered questions 1, 2, 3, 4, 6, and 7 with "Yes", a score of zero was assigned to each response; and if their answers was "No" a score of one will be assigned to their responses. However, in question five, if participants answered the question with "Yes", a score of one was assigned to their response, and zero if their answer was "No". In question eight which has 5-point Likert response scale, a score of one was assigned to participants' response if they chose "Never", 0.75 if "Once in a while", 0.5 if "Sometimes", 0.25 if "Usually", and 0 if "All the time" was selected. The predictive validity of this scale has been assessed through association with blood pressure readings, attitude, social support, coping techniques with stress, knowledge about their medical condition and treatment, and patients' satisfaction with the provided care (Krousel-Wood et al., 2009; Morisky, Ang, Krousel-Wood, \& Ward, 2008; Morisky \& DiMatteo, 2011).

\subsubsection{Older Adults' Evaluation of Their Antihypertensive Medication Regimens}

To further understand the value of PROMEX and examine the association between participants' evaluations of their own medications and medication adherence as well as other participant-reported outcomes (PROs) such as the quality of life, a simulation of PROMEX was created at the end of survey. We asked the participants who reported taking medications for HTN to rate their medications on a scale from 1 to 5 on five different medication use aspects (i.e., effectiveness, side effects, ease of use, cost, and food interactions) and give an overall rating for each medication. Four medication-rating tables were provided in case the participant was taking more than one medication for HTN. A specific score was created for each participant by taking the average of each participant's antihypertensive medication regimen ratings for every single medication use aspect as well as the overall rating. Both the overall rating score of the participants' antihypertensive medication regimens as well as the specific medication use aspects rating scores were reported. 


\subsection{Participants' Characteristics}

\subsubsection{Sociodemographics}

Participants were asked to report their age, gender, race, and years of education, marital status, and the household member(s) they live with via either filling in the blanks or checking off the answer that best describes their situation. The participants' age was categorized into four groups (i.e., 50-60, 61-70, 71-80, and $>80$ years of age). Further, the participants' mean age \pm standard deviation was compared across senior centers. Race was categorized into four groups (i.e., African Americans, Caucasians, Hispanics, and Others). Marital status was dichotomized into two groups (i.e., married vs. unmarried) ${ }^{1}$. Education was categorized into three groups based on the number of years spent in school or higher education (i.e., high school or less, college degree, post-graduate degree). Living status was dichotomized into two groups (i.e., alone vs. not alone) ${ }^{2}$.

\subsubsection{Health Decision Sharing Preference}

Patients' engagement in their own health care has been associated with both lower health costs and hospital admissions (Hibbard \& Greene, 2013). Research shows patients in general want to be involved in their health care (Bernabeo \& Holmboe, 2013). However, understanding the factors that influence patients' decision sharing preference is still elusive (Légaré \& Witteman, 2013). Therefore, many like to describe the patients' preference for involvement in the health care decision making as patient-specific (Bernabeo \& Holmboe, 2013). Thus, a validated question was included that assessed the participant's preference for engagement in their health care (Lawler, 1998). Participants were asked the following question (Lawler, 1998, p.1549; Ray, 1997):

"What do you prefer for involvement in decisions about your health care? Would you prefer to:

- Keep control in your own hands?

- Have an equal partnership with the doctor?

- Leave it in the doctor's hands?"

The health care decision sharing preferences across the different senior centers were compared. However, to know whether the health decision sharing preference had any impact on participants' views of PROMEX, they were categorized into two groups. Even though response options I and III were distinctly different, they share one thing, a health decision non-sharing preference. Therefore, they were labeled as a healthcare decision

\footnotetext{
${ }^{1}$ Unmarried includes all those who reported being widowed, divorced, separated, and single.

${ }^{2}$ Not alone includes all participants who reported living with a spouse, friend, community center, family members...etc.
} 
non-sharing group. The second group includes those who preferred to have an equal partnership with their physicians.

\subsubsection{Health Literacy}

Health literacy is variable among different patient populations and has a significant impact on several health outcomes such as medication adherence (Kripalani, Gatti, \& Jacobson, 2010; Kutner, Greenberg, \& Baer, 2005). Therefore, controlling for this important variable is crucial in understanding the relationship between any two participant-reported outcome measures. There are several validated questionnaires that have been widely used to assess patients' health literacy level such as the Test of Functional Health Literacy in Adults (TOFHLA) (Parker, Baker, \& Williams, 1995). However, due to the length of the questionnaires, new and shorter versions of the same health literacy assessment tools have been developed (Baker, Williams, Parker, Gazmararian, \& Nurss, 1999). Further, health literacy screening questions with high Area under the Receiver Operating Characteristic (AUROC) have been created and validated to assess patients' health literacy with only one question (Wallace, Rogers, Roskos, Holiday, \& Weiss, 2006). Thus, the following question was used "How confident are you filling out medical forms by yourself?" (Extremely, quite a bit, somewhat, a little bit, or not at all) with an AUROC of $0.79(95 \% \mathrm{CI}=0.74$ to 0.83$)$ when plotted against the Rapid Estimate of Adult Literacy in Medicine (REALM). The "somewhat" response was recommended as the optimal cutoff point to identify participants with limited or marginal health literacy skills (Chew, Bradley, \& Boyko, 2004; Wallace et al., 2006, p.874). Thus, the respondents were dichotomized into two groups: marginal/limited and good health literacy.

\subsubsection{Medical Conditions}

Senior participants were asked to identify diseases they had from a list of more than 14 medical conditions prevalent among the U.S. population in general and among the U.S. elderly population in particular (Ward, 2013). The list included the following:

1. Hypertension.

2. Angina pectoris or coronary artery disease (CAD).

3. Congestive Heart Failure (CHF).

4. Myocardial infarction or heart attack.

5. Stroke.

6. Asthma, emphysema or COPD (Chronic Obstructive Pulmonary Disease).

7. Diabetes.

8. Arthritis or any kind of rheumatism.

9. Chronic back pain or sciatica.

10. Depression.

11. Gastroesophageal Reflux Disease (i.e. chronic heartburn "GERD) or ulcers. 
12. Cancer (other than skin cancer).

13. Sexual dysfunction.

14. Irritable bowel syndrome or indigestion.

Further, the participants were asked to write down the number of prescription medications that they were currently taking. In addition, those who had HTN were asked to write down the number of years since they were diagnosed with HTN as well as the number of medications they were taking.

\subsection{Statistical Analysis}

\subsubsection{Sample Size Estimation}

The estimated minimum sample size for a medium effect size at a power $=0.80$ and $\alpha=0.05$ for multiple regression analysis and for eight independent variables based on the Cohen statistical power analysis method is 107 participants (Cohen, 1992). In addition to the Cohen statistical power analysis method, the GPOWER software was also used to estimate the minimum sample size using the same criteria and determined 127 participants were needed for twelve explanatory (i.e., independent) variables (Erdfelder, Faul, \& Buchner, 1996). In this research project, 300 seniors have participated and completed the survey.

\subsubsection{Descriptive Statistics}

Frequencies and means were reported for sociodemographic and medical history variables. Means and standard deviations were reported for continuous variables. For ordinal and nominal variables, percentages were reported. The comparisons between the groups were made with the use of a two-sided student's t-test for continuous data and chisquare test for categorical data. Further, one-way analysis of variance (ANOVA) was used to test the difference in the means between the different categorical variables (Tabachnick \& Fidell, 2001).

\subsubsection{Assessing PROMEX Reliability}

The reliability of PROMEX was computed using the Cronbach's alpha (Seibert et al., 1999). Cronbach's alpha is a measure of internal consistency that is commonly used in questionnaires' reliability validation (Thorndike \& Hagen, 1961). A questionnaire with Cronbach's alpha of $\geq 0.7$ is considered to be internally consistent (Cronbach, 1951). 


\subsubsection{Principal Component Analysis}

Principal Component Analysis was used to identify the underlying factor structure of the Patient Reviews of Medication Experiences (PROMEX) questionnaire. Although two factors or domains have been hypothesized to be the underlying construct of PROMEX, the Principal Component Analysis was conducted to verify the hypothesis (Suhr, 2005). An eigenvalue greater than or equal to one along with the results of the scree plot were used to determine the number of possible factors or domains that can be extracted from PROMEX. Further, varimax rotation was also used to determine the loading of each variable on each potential factor (Jolliffe, 2005).

\subsubsection{Path Analysis}

Wanting to examine the association between different participant-reported outcomes such as quality of life and medication adherence with the participants' views of PROMEX, the running of simple linear regression models where potentially more than one dependent variable can exist was not possible. Therefore, using path analyses in which multiple dependent variables can coexist is more plausible. As an extension of multiple regression (Streiner, 2005). Path models have several advantages over multiple regression. Firstly, it is a powerful technique in which complex models with multiple dependent variables as well as chains of influence can coexist may be more plausible in certain research settings like ours (Streiner, 2005). Secondly, the path analysis approach is more flexible than the ordinary least square method as the structure of the path models can be modified to increase the model's fitness (Nazim \& Ahmad, 2014). Thirdly, it enables one to disentangle complex interrelationships among variables and eventually identify the most significant pathway in predicting the outcome (i.e., dependent) variable (Lleras, 2005).

\subsubsection{The Association between the Older Adults' Views of the Online Reviews of Medications and Their Satisfaction with Physician Communication}

In order to determine whether the association between participant satisfactions with their physicians' communication and their views of the online rating of medications, a path model based on the evidence based predictors of patients' satisfaction with physicians' quality of care was created. The model created represented the evidence based sociodemographic and health status predictors of the satisfaction with physicians' communication. Age, education, marital status, health literacy, comorbidities, race, and gender are significant predictors of patients satisfactions with physicians (Hall \& Dornan, 1990; LaVeist \& Nuru-Jeter, 2002; Moy \& Bartman, 1995; Tucker \& Kelley, 2000). Then, the association of the Primary Care Assessment Survey (PCAS) the Communication scale and the participant's views of the online rating of medications (PROMEX) was looked at. 


\subsubsection{The Association between the Older Adults' Views of the Online Reviews of Medications and Their Quality of Life}

Any path model that tests the Health related Quality of Life (HRQoL) effect on any outcome variable, should take into consideration the significant predictors of HRQoL. Therefore, a path model was tested taking into account the sociodemographic factors, health status, and interpersonal treatment as well as effective healthcare communication with participants that were significant predictors of HRQoL (Felce, 1997; Low \& Molzahn, 2007; Odigie \& Marshall, 2008; Xavier et al., 2003).

\subsubsection{The Association between the Older Adults' Views of the Online Reviews of Medications and Their Beliefs about Medications}

In order to examine the influence of participants' beliefs about medications on their views of the online reviews of medications, the evidence-based predictors of participants' beliefs about medications must be accounted for in a path model. Then, the effect of beliefs about medications on participants' views of online rating of medications can be examined in the same model. Physicians' communication style, participants' age, culture or ethnicity, education, gender, and the number of prescription medications the participants take on a daily basis are considered significant predictors of participants' beliefs of medications (Bultman \& Svarstad, 2000; Horne et al., 2004; Iihara et al., 2004; Isacson \& Bingefors, 2002; Mårdby et al., 2007).

\subsubsection{The Association between the Older Adults' Views of the Online Reviews of Medications and Their Adherence to Antihypertensive Medications}

In order to examine the effect of medication adherence on the participants' views of online medication reviews (PROMEX), a path model was constructed based on evidencebased predictors of medication adherence. Age, gender, race, beliefs about medications, health literacy, satisfaction with physicians' communication, education, the number of prescription medications, comorbidities, and overall rating of antihypertensive treatment regimen were included in the model (Gellad et al., 2011; Krousel-Wood et al., 2009; Morisky et al., 2008; Sa'ed et al., 2013).

\subsubsection{The Association between the Older Adults' Views of the Online Reviews of Medications and Their Satisfaction with Physicians' Communication, Beliefs about medications, and Health-Related Quality of Life}

The association between participants' views of online medication rating websites (PROMEX) and their satisfaction with physicians' communication, beliefs about medications, and health-related quality of life was examined in one model in which most of the evidence-based predictors for each of the included participant-reported outcomes were controlled for in this overarching model. 
In this model, race, gender, marital status, and health literacy were specified as direct predictors of the participants' satisfaction with their physicians' communication, which was measured by the PCAS-Communication scale (Hall \& Dornan, 1990; LaVeist \& Nuru-Jeter, 2002; Moy \& Bartman, 1995; Tucker \& Kelley, 2000). With regard to participants' beliefs about medications, which was measured by the BMQ-general, the number of prescription medications participants reported taking, participants' satisfaction with their physicians' communication, gender, and race were specified as direct predictors participants' beliefs about prescription medications (Horne et al., 2004). Further, the participants' health-related quality of life scores measured by the PCS-12 and MCS-12 of the SF-12v2 were included in the model with the number of chronic health conditions, age, number of prescription medications, health literacy, marital status, and education specified as direct predictors of these two health-related quality of life scales (Felce, 1997; Low \& Molzahn, 2007; Odigie \& Marshall, 2008; Xavier et al., 2003). Moreover, even though some variables, which were collected in the study, and may predict certain participant-reported outcomes, such as health literacy and BMQ-general, were not specified as direct predictors of these outcomes, these variables were controlled for indirectly since all of the sociodemographic and medical factors that were collected from the participants in this study were included in this model.

Finally, the PCS-12, MCS-12, and the health decision sharing preference were specified as direct predictors of the participants' views of online medication rating websites, which was measured by PROMEX. These three variables were specified as direct predictors of PROMEX for several reasons. The health-related quality of life is a multidimensional concept that is influenced by an array of factors. Therefore, the specified predictors of both the PCS-12 and MCS-12 in the model captured most of the variables, and hence the impact of other variables on PROMEX can be indirectly examined. In addition, the health decision sharing preference was specified as a direct predictor of PROMEX since it is participant-specific (Bernabeo \& Holmboe, 2013).

\subsubsection{Regression Analysis}

In addition to the path analysis, multiple linear regression analysis was conducted to assess the relationship between the perceived value of the online patients' reviews of medications by older adults and each of the aforementioned participant-reported outcomes. The dependent variable of interest was the total score of PROMEX. The independent variables of interest were the scores of the communication domain of the PCAS, Mental and Physical Component Summaries (MCS \& PCS) of the SF-12v2, Beliefs about Medicines Questionnaire (BMQ) General Overuse and Harm domains, and Morisky Medication Adherence Scale (MMAS-8). Other independent variables were age, gender, race (i.e. African Americans, Caucasians, Hispanic, and others), years of education, number of chronic medical conditions, number of prescription medications, and health literacy. The model adequacy was checked through diagnostic tools such as the normality of the residuals. 
I. The Regression Model for the Association between the Older Adults' Views of the Online Reviews of Medications and Their Satisfaction with Physician Communication:

PROMEX $=\beta^{\circ}+\beta_{1}$ (PCAS-Communication) $+\beta_{2}$ (Age) $+\beta_{3}$ (Comorbidities) $+\beta_{4}($ Education $)+\beta_{5}($ Race $)+\beta_{6}$ (Health Literacy $)+\beta_{7}($ Gender $)+\beta_{8}$ $($ Gender $)+\beta_{9}$ (Marital Status) $+\varepsilon$.

II. The Regression Model for the Association between the Older Adults' Views of the Online Reviews of Medications and Their Quality of Life:

PROMEX $=\beta^{\circ}+\beta_{1}(\mathrm{PCS}-12)+\beta_{2}(\mathrm{MCS}-12)+\beta_{3}(\mathrm{PCAS}-\mathrm{Communication})+$ $\beta_{4}($ Age $)+\beta_{5}$ (Comorbidities) $+\beta_{6}$ (Education) $+\beta_{7}$ (Race) $+\beta_{8}$ (Health Literacy) $+\beta_{9}$ (Gender) $+\beta_{10}$ (Marital Status) $+\varepsilon$.

III. The Regression Model for the Association between the Older Adults' Views of the Online Reviews of Medications and Their Beliefs about Medications:

PROMEX $=\beta^{\circ}+\beta_{1}($ BMQ-Overuse $)+\beta_{2}($ BMQ-Harm $)+\beta_{3}$ (PCASCommunication $)+\beta_{4}$ (Age) $+\beta_{5}$ (Number of Prescription Medications) + $\beta_{6}($ Education $)+\beta_{7}($ Race $)+\beta_{8}($ Gender $)+\varepsilon$.

IV. The Regression Model for the Association between the Older Adults' Views of the Online Reviews of Medications and Their Adherence to Antihypertensive Medications:

PROMEX $=\beta^{\circ}+\beta_{1}($ MMAS- $)+\beta_{2}($ PCAS-Communication $)+\beta_{3}($ BMQOveruse $)+\beta_{4}$ (BMQ-Harm) $+\beta_{5}$ (Overall Rating of HTN Medications $)+$ $\beta_{6}($ Age $)+\beta_{7}$ (Comorbidities) $+\beta_{8}$ (Race) $+\beta_{9}$ (Health Literacy) $+\beta_{10}$ (Gender) $+\beta_{11}$ (Number of Prescription Medications) $+\beta_{12}$ (Marital Status) $+\varepsilon$.

\subsubsection{The Association between Participants' Rating of Their Antihypertensive Medication Regimens and Participant-Reported Outcomes (PROs)}

Since online rating of medications is an evaluation of patients' medications experiences, participants who reported having HTN were asked to complete the Morisky Medication Adherence Scale (MMAS-8) and rate their antihypertensive medications that reported taking. Multiple linear regression analyses were done to examine the association between each participant-reported outcome and participants' evaluation of their antihypertensive medications. The dependent variables were the scores of the communication domain of the PCAS, Mental and Physical Component Summaries (MCS \& PCS) of the SF-12v2, Beliefs about Medicines Questionnaire (BMQ) General Overuse and Harm domains, and Morisky Medication Adherence Scale (MMAS-8). The main independent variable of interest was the participant-specific overall rating score of the 
antihypertensive medication regimen. The other independent variables were age, gender, race (i.e. African Americans, Caucasians, Hispanic, and others), years of education, number of chronic medical conditions, number of prescription medications, and health literacy. All statistical analyses were conducted using SAS ${ }^{\circledR} 9.4$ (SAS Institute, Inc., Cary, NC, USA).

I. The Regression Model for the Association between the Overall Rating of Antihypertensive Medication Regimen and Satisfaction with Physician Communication:

PCAS-Communication $=\beta^{o}+\beta_{1}$ (Overall Rating of HTN Medications $)+\beta_{2}$ $($ Age $)+\beta_{3}$ (Comorbidities) $+\beta_{4}$ (Education) $+\beta_{5}$ (Race) $+\beta_{6}$ (Health Literacy) $+\beta_{7}$ (Gender) $+\beta_{8}$ (Number of Prescription Medications) $+\beta_{9}$ (Marital Status) $+\varepsilon$.

II. The Regression Model for the Association between the Overall Rating of Antihypertensive Medication Regimen and the Quality of Life:

i. Regression Model for the Association between the Overall Rating of Antihypertensive Medication Regimen and the PCS-12:

PCS-12 $=\beta^{\circ}+\beta_{1}$ (Overall Rating of HTN Medications $)+\beta_{2}($ Age $)+\beta_{3}$ $($ Comorbidities $)+\beta_{4}($ Education $)+\beta_{5}($ Race $)+\beta_{6}$ (Health Literacy) $+\beta_{7}$ (Gender) $+\beta_{8}$ (Number of Prescription Medications) $+\beta_{9}$ (Marital Status) $+\varepsilon$.

ii. Regression Model for the Association between the Overall Rating of Antihypertensive Medication Regimen and the MCS-12:

MCS-12 $=\beta_{\circ}+\beta_{1}$ (Overall Rating of HTN Medications $)+\beta_{2}($ Age $)+\beta_{3}$ $($ Comorbidities $)+\beta_{4}$ (Education) $+\beta_{5}$ (Race) $+\beta_{6}$ (Health Literacy) $+\beta_{7}$ (Gender) $+\beta_{8}$ (Number of Prescription Medications) $+\beta_{9}$ (Marital Status) $+\varepsilon$.

III. The Regression Model for the Association between the Overall Rating of Antihypertensive Medication Regimen and the Beliefs About Medication:

i. Regression Model for the Association between the Overall Rating of Antihypertensive Medication Regimen and the BMQ-Overuse:

BMQ-overuse $=\beta^{\circ}+\beta_{1}$ (Overall Rating of HTN Medications $)+\beta_{2}($ Age $)+$ $\beta_{3}$ (Comorbidities) $+\beta_{4}$ (Education) $+\beta_{5}$ (Race) $+\beta_{6}$ (Health Literacy) + $\beta_{7}$ (Gender) $+\beta_{8}$ (Number of Prescription Medications) $+\beta_{9}$ (Marital Status) $+\varepsilon$. 


\title{
ii. Regression Model for the Association between the Overall Rating of Antihypertensive Medication Regimen and the BMQ-Harm:
}

BMQ-Harm $=\beta^{\circ}+\beta_{1}$ (Overall Rating of HTN Medications $)+\beta_{2}($ Age $)+\beta_{3}$ (Comorbidities) $+\beta_{4}$ (Education) $+\beta_{5}$ (Race) $+\beta_{6}$ (Health Literacy) $+\beta_{7}$ (Gender) $+\beta_{8}$ (Number of Prescription Medications) $+\beta_{9}$ (Marital Status) $+\varepsilon$.

\section{The Regression Model for the Association between the Overall Rating of Antihypertensive Medication Regimen and Medication Adherence:}

\author{
MMAS- $8=\beta^{\circ}+\beta_{1}$ (Overall Rating of HTN Medications $)+\beta_{2}($ Age $)+\beta_{3}$ \\ $($ Comorbidities $)+\beta_{4}($ Education $)+\beta_{5}$ (Race) $+\beta_{6}$ (Health Literacy) $+\beta_{7}$ \\ (Gender) $+\beta_{8}$ (Number of Prescription Medications) $+\beta_{9}$ (Marital Status) \\ $+\varepsilon$.
}

\subsection{Consideration of Human Subjects}

The study was granted an expedited status by the institutional review board (IRB) at the University of Tennessee Health Science Center (Appendix B). Although, it was not necessary for the participants to sign the consent form since no personal identifiers or access to medical records was asked for, a cover letter was included that served as consent form as well as an explanation of the research project. All completed surveys were securely maintained. 


\section{CHAPTER 4. RESULTS}

\subsection{Study Sample Characteristics}

Three hundred participants were recruited for the study from seven senior centers in and around Memphis, Tennessee. Out of those, 298 participants completed the PROMEX questionnaire. The number of eligible participants who were aged 60 years and over as well as reported taking one or more prescription medications was 286 participants. The participant-reported characteristics are listed in Table 4-1. The mean age of the participants was 72 years. Seventy-seven percent of the participants were female. Sixtythree percent of the participants were married ${ }^{3}$. Forty-four percent of the participants were living alone. Forty-five percent of the participants had a high school degree or less, about $41 \%$ had some college degree, and $13 \%$ had a post-graduate degree (i.e., master or $\mathrm{PhD})$. Seventy-two percent of the participants had good health literacy level based on their response to the question, "How confident are you filling out medical forms by yourself?" The majority of the participants (i.e., $>80 \%$ ) reported taking at least two prescription medications daily. The mean number of diseases that each participant had from the listed 14 comorbidities common among the elderly was three. Almost $76 \%$ of the study participants reported having hypertension. The self-reported race was 55\% Caucasians/white, 40\% African Americans/black, 2\% Hispanics, and 3\% others ${ }^{4}$. With regard to the participants' preference to share the healthcare decision with their physicians', 79.1\% preferred to share their decision. The participants' Short Form Health Questionnaire (SF-12v2) mental and physical component summaries (MCS-12 \& PCS12) scores, Primary Care Assessment Survey (PCAS) communication and interpersonal treatment scales scores, and Beliefs about Medicine Questionnaire general overuse and harm domains scores are listed in Table 4-2. The mean scores of the PCS-12 and MCS12 of the SF-12v2 were 45.8 and 52.3, respectively. Further, the mean scores for the PCAS communication and interpersonal treatment scales were 72.8 and 72.6 , respectively. Finally, the mean scores for both the BMQ-overuse and BMQ-Harm for the study sample were 12.6 and 9.03 , respectively.

\subsection{Item Analysis and Reliability of Patient Reviews of Medication Experiences (PROMEX)}

An item analysis was performed on the seven questions of Patient Reviews of Medication Experiences (PROMEX) questionnaire. The initial Cronbach's alpha was 0.76. Table 4-2 lists item means, standard deviations, and the minimum and maximum possible score for each item. Further, the inter-item correlation was examined to determine items that did not correlate well with one another. Table 4-3 shows that item-7 had a poor inter-item correlation ( $\mathrm{p} \geq 0.05$ ) with items-1, 4, and 5. In addition, item-7 had a negative inter-item correlation with the other items on the questionnaire. Thus, item-7

\footnotetext{
${ }^{3}$ The unmarried comprised of the single, divorced, widowed, separated ...etc.

${ }^{4}$ Others were comprised of Asians and Alaska Natives.
} 
Table 4-1. Baseline characteristics of the participants across the senior centers.

\begin{tabular}{|c|c|c|c|c|c|c|c|c|c|}
\hline \multirow[b]{2}{*}{ Characteristics } & \multicolumn{8}{|c|}{ Senior centers } & \multirow[b]{2}{*}{ p-Value } \\
\hline & $\begin{array}{c}\text { Frayser- } \\
\text { Raleigh } \\
(n=50)\end{array}$ & $\begin{array}{l}\text { Orange- } \\
\text { Mound } \\
(n=94)\end{array}$ & $\begin{array}{c}\text { Arlington } \\
(n=24)\end{array}$ & $\begin{array}{l}\text { Bartlett } \\
(n=48)\end{array}$ & $\begin{array}{c}\text { Bert } \\
\text { Ferguson } \\
(n=21)\end{array}$ & $\begin{array}{c}\text { McWherter } \\
(n=41)\end{array}$ & $\begin{array}{c}\text { Somerville } \\
(n=22)\end{array}$ & $\begin{array}{c}\text { Total } \\
(n=300)\end{array}$ & \\
\hline $\begin{array}{l}\text { Age-yrs. } \\
(\text { Mean } \pm \text { SD) } \\
\text { Sex }\end{array}$ & $74.98 \pm 8.32$ & $68.25 \pm 25$ & $73.13 \pm 7.76$ & $72.81 \pm 7.71$ & $74.21 \pm 6.96$ & $73.63 \pm 9.71$ & $72.3 \pm 8.58$ & $71.95 \pm 8.65$ & $0.001 *$ \\
\hline $\begin{array}{l}\text { Female } \\
\text { Male }\end{array}$ & $\begin{array}{l}37(74 \%) \\
13(26 \%)\end{array}$ & $\begin{array}{l}75(80.7 \%) \\
18(19.4 \%)\end{array}$ & $\begin{array}{c}15(62.5 \%) \\
9(37.5 \%)\end{array}$ & $\begin{array}{c}42(87.5 \%) \\
6(12.5 \%)\end{array}$ & $\begin{array}{c}18(85.7 \%) \\
3(14.3 \%)\end{array}$ & $\begin{array}{l}27(65.9 \%) \\
14(34.2 \%)\end{array}$ & $\begin{array}{c}17(77.3 \%) \\
5(22.7 \%)\end{array}$ & $\begin{array}{c}231(77.3 \%) \\
68(22.7 \%)\end{array}$ & 0.100 \\
\hline Marital status & & & & & & & & & \\
\hline $\begin{array}{l}\text { Married } \\
\text { Unmarried }\end{array}$ & $\begin{array}{l}20(40 \%) \\
30(60 \%)\end{array}$ & $\begin{array}{l}24(25.8 \%) \\
69(74.2 \%)\end{array}$ & $\begin{array}{l}16(66.7 \%) \\
8(33.3 \%)\end{array}$ & $\begin{array}{l}17(35.4 \%) \\
31(64.5 \%)\end{array}$ & $\begin{array}{l}10(47.6 \%) \\
11(52.4 \%)\end{array}$ & $\begin{array}{l}15(36.6 \%) \\
26(63.4 \%)\end{array}$ & $\begin{array}{c}8(36.4 \%) \\
14(63.6 \%)\end{array}$ & $\begin{array}{l}189(63.2 \%) \\
110(36.8 \%)\end{array}$ & $0.017 *$ \\
\hline Education & & & & & & & & & \\
\hline $\begin{array}{l}\leq \text { High school } \\
(1-12 \text { yrs. })\end{array}$ & $23(46 \%)$ & $42(44.7 \%)$ & $13(54.2 \%)$ & $21(43.8 \%)$ & $4(19.1 \%)$ & $15(36.6 \%)$ & $18(81.8 \%)$ & $136(45.3 \%)$ & $0.014 *$ \\
\hline $\begin{array}{l}\text { Some college } \\
\text { degree (13-16 yrs.) }\end{array}$ & $19(38 \%)$ & $43(45.7 \%)$ & $9(37.5 \%)$ & $18(37.5 \%)$ & $11(52.4 \%)$ & $20(48.8 \%)$ & $4(18.2 \%)$ & $124(41.3 \%)$ & \\
\hline $\begin{array}{l}\text { Post-graduate } \\
\text { degree ( } \geq 17 \text { yrs.) } \\
\text { Race }\end{array}$ & $8(16 \%)$ & $9(9.6 \%)$ & $2(8.3 \%)$ & $9(18.8 \%)$ & $6(28.6 \%)$ & $6(14.6 \%)$ & $0(0 \%)$ & $40(13.3 \%)$ & \\
\hline Caucasians & $40(80 \%)$ & $0(0 \%)$ & $24(100 \%)$ & $43(91.5 \%)$ & $21(100 \%)$ & $32(78.1 \%)$ & $4(18.2 \%)$ & $164(54.9 \%)$ & $<0.001 *$ \\
\hline African Americans & $8(16 \%)$ & $88(93.6 \%)$ & $0(0 \%)$ & $0(0 \%)$ & $0(0 \%)$ & $6(14.6 \%)$ & $18(81.8 \%)$ & $120(40.1 \%)$ & \\
\hline Hispanics & $1(2 \%)$ & $2(2.1 \%)$ & $0(0 \%)$ & $1(2.13 \%)$ & $0(0 \%)$ & $2(4.9 \%)$ & $0(0 \%)$ & $6(2.01)$ & \\
\hline Others & $1(2 \%)$ & $4(4.3 \%)$ & $0(0 \%)$ & $3(6.4 \%)$ & $0(0 \%)$ & $1(2.4 \%)$ & $0(0 \%)$ & $9(3.01 \%)$ & \\
\hline Health literacy & & & & & & & & & \\
\hline Good & $42(84 \%)$ & $62(66 \%)$ & $0(0 \%)$ & $41(85.5 \%)$ & $14(66.7 \%)$ & $33(80.5 \%)$ & $8(36.4 \%)$ & $200(72.5 \%)$ & $0.001 *$ \\
\hline $\begin{array}{l}\text { Marginal/limited } \\
\text { Healthcare } \\
\text { decision sharing }\end{array}$ & $8(16 \%)$ & $32(34 \%)$ & $0(0 \%)$ & $7(14.6 \%)$ & $7(33.3 \%)$ & $8(19.5 \%)$ & $14(63.6 \%)$ & $76(27.5)$ & \\
\hline Yes & $43(87.8 \%)$ & $74(78.7 \%)$ & $18(75 \%)$ & $38(80.8 \%)$ & $18(85.7 \%)$ & $29(72.5 \%)$ & $15(68.2 \%)$ & $235(79.1 \%)$ & 0.450 \\
\hline No & $6(12.2 \%)$ & $20(21.3 \%)$ & $6(25 \%)$ & $9(19.2 \%)$ & $3(14.3 \%)$ & $11(27.5 \%)$ & $7(31.8 \%)$ & $62(20.9 \%)$ & \\
\hline
\end{tabular}


Table 4-1. Continued.

\begin{tabular}{|c|c|c|c|c|c|c|c|c|c|}
\hline \multirow[b]{2}{*}{ Characteristics } & \multicolumn{7}{|c|}{ Senior centers } & \multirow[b]{2}{*}{$\begin{array}{c}\text { Total } \\
(\mathbf{n}=\mathbf{3 0 0})\end{array}$} & \multirow[b]{2}{*}{ p-Value } \\
\hline & $\begin{array}{c}\text { Frayser- } \\
\text { Raleigh } \\
(\mathrm{n}=\mathbf{5 0})\end{array}$ & $\begin{array}{l}\text { Orange- } \\
\text { Mound } \\
(n=94)\end{array}$ & $\begin{array}{c}\text { Arlington } \\
(n=24)\end{array}$ & $\begin{array}{c}\text { Bartlett } \\
(n=48)\end{array}$ & $\begin{array}{c}\text { Bert } \\
\text { Ferguson } \\
(\mathrm{n}=21)\end{array}$ & $\begin{array}{c}\text { McWherter } \\
(n=41)\end{array}$ & $\begin{array}{c}\text { Somerville } \\
(\mathrm{n}=\mathbf{2 2})\end{array}$ & & \\
\hline Stroke & $5(10 \%)$ & $5(5.4 \%)$ & $1(4.2 \%)$ & $6(12.5 \%)$ & $1(4.8 \%)$ & $3(7.3 \%)$ & $5(22.7 \%)$ & $26(8.7 \%)$ & 0.181 \\
\hline HTN & $38(76 \%)$ & $75(80.7 \%)$ & $24(100 \%)$ & $34(70.8 \%)$ & $34(70.8 \%)$ & $28(68.3 \%)$ & $13(59.1 \%)$ & $226(75.6 \%)$ & $0.020 *$ \\
\hline $\begin{array}{l}\text { Angina Pectoris } \\
\text { or CAD }\end{array}$ & $10(20 \%)$ & $10(10.8 \%)$ & $4(16.7 \%)$ & $2(4.2 \%)$ & $1(4.8 \%)$ & $4(9.8 \%)$ & $3(13.6 \%)$ & $34(11.4 \%)$ & 0.238 \\
\hline CHF & $6(12 \%)$ & $5(5.4 \%)$ & $0(0 \%)$ & $3(6.3 \%)$ & $1(4.8 \%)$ & $2(4.9 \%)$ & $2(9.1 \%)$ & $19(6.35 \%)$ & 0.547 \\
\hline $\begin{array}{l}\text { Myocardial } \\
\text { Infarction (MI) }\end{array}$ & $7(14 \%)$ & $5(5.4 \%)$ & $1(4.2 \%)$ & $2(4.2 \%)$ & $0(0 \%)$ & $3(7.3 \%)$ & $2(9.1 \%)$ & $20(6.7 \%)$ & 0.320 \\
\hline $\begin{array}{l}\text { Asthma, } \\
\text { emphysema or } \\
\text { COPD }\end{array}$ & $5(10 \%)$ & $13(13.9 \%)$ & $4(16.7 \%)$ & $6(12.5 \%)$ & $2(9.5 \%)$ & $4(10 \%)$ & $3(13.6 \%)$ & $37(12.4 \%)$ & 0.972 \\
\hline Diabetes & $16(32 \%)$ & $40(43.01 \%)$ & $2(8.3 \%)$ & $13(27.1 \%)$ & $1(4.8 \%)$ & $11(26.8 \%)$ & $11(50 \%)$ & $94(31.4 \%)$ & $0.001 *$ \\
\hline $\begin{array}{l}\text { Arthritis or any } \\
\text { kind of } \\
\text { rheumatism }\end{array}$ & $32(64 \%)$ & $48(51.6 \%)$ & $13(54.2 \%)$ & $25(52.1 \%)$ & $13(61.9 \%)$ & $22(53.7 \%)$ & $13(59.1 \%)$ & $166(55.5 \%)$ & 0.834 \\
\hline $\begin{array}{l}\text { Chronic back } \\
\text { pain or sciatica }\end{array}$ & $12(24 \%)$ & $18(19.4 \%)$ & $7(29.2 \%)$ & $17(35.4 \%)$ & $3(14.3 \%)$ & $4(9.8 \%)$ & $7(31.8 \%)$ & $68(22.7 \%)$ & 0.076 \\
\hline Depression & $7(14 \%)$ & $15(16.1 \%)$ & $2(8.3 \%)$ & $12(25 \%)$ & $2(9.5 \%)$ & $6(14.6 \%)$ & $3(13.6 \%)$ & $47(15.7 \%)$ & 0.550 \\
\hline $\begin{array}{l}\text { Chronic heart } \\
\text { burn }\end{array}$ & $4(8 \%)$ & $12(12.9 \%)$ & $4(16.7 \%)$ & $7(14.6 \%)$ & $0(0 \%)$ & $5(12.2 \%)$ & $7(31.8 \%)$ & $39(13.04 \%)$ & 0.073 \\
\hline $\begin{array}{l}\text { Any cancer } \\
\text { (other than skin } \\
\text { cancer) }\end{array}$ & $9(18 \%)$ & $8(8.6 \%)$ & $8(33.3 \%)$ & $12(25 \%)$ & $2(9.5 \%)$ & $4(9.8 \%)$ & $3(13.6 \%)$ & $46(15.4 \%)$ & $0.024 *$ \\
\hline $\begin{array}{l}\text { Sexual } \\
\text { dysfunction }\end{array}$ & $3(6 \%)$ & $7(7.5 \%)$ & $2(8.3 \%)$ & $1(2.1 \%)$ & $2(9.5 \%)$ & $1(2.4 \%)$ & $2(9.1 \%)$ & $18(6.02 \%)$ & 0.721 \\
\hline $\begin{array}{l}\text { IBS or stomach } \\
\text { ulcer or } \\
\text { indigestion }\end{array}$ & $10(20 \%)$ & $12(12.9 \%)$ & $5(20.8 \%)$ & $10(20.8 \%)$ & $2(9.5 \%)$ & $5(12.2 \%)$ & $3(13.6 \%)$ & $47(15.7 \%)$ & 0.712 \\
\hline
\end{tabular}


Table 4-1. Continued.

\begin{tabular}{|c|c|c|c|c|c|c|c|c|c|}
\hline \multirow[b]{2}{*}{ Characteristics } & \multicolumn{7}{|c|}{ Senior centers } & \multirow[b]{2}{*}{$\begin{array}{c}\text { Total } \\
(n=300)\end{array}$} & \multirow[b]{2}{*}{ p-Value } \\
\hline & $\begin{array}{c}\text { Frayser- } \\
\text { Raleigh } \\
(\mathrm{n}=50)\end{array}$ & $\begin{array}{l}\text { Orange- } \\
\text { Mound } \\
(\mathrm{n}=94)\end{array}$ & $\begin{array}{c}\text { Arlington } \\
(\mathrm{n}=\mathbf{2 4})\end{array}$ & $\begin{array}{c}\text { Bartlett } \\
(n=48)\end{array}$ & $\begin{array}{c}\text { Bert } \\
\text { Ferguson } \\
(\mathrm{n}=21)\end{array}$ & $\begin{array}{c}\text { McWherter } \\
(n=41)\end{array}$ & $\begin{array}{c}\text { Somerville } \\
(\mathrm{n}=\mathbf{2 2})\end{array}$ & & \\
\hline $\begin{array}{l}\text { Comorbidity } \\
\text { score } \\
\text { Living status }\end{array}$ & $3.3 \pm 2.30$ & $2.94 \pm 1.98$ & $3.21 \pm 1.56$ & $3.13 \pm 2.03$ & $2.09 \pm 1.51$ & $2.47 \pm 1.96$ & $3.50 \pm 2.87$ & $2.97 \pm 2.07$ & 0.162 \\
\hline Alone & $25(50 \%)$ & $39(42.9 \%)$ & $4(16.7 \%)$ & $26(54.2 \%)$ & $9(42.9)$ & $20(50 \%)$ & $9(40.9 \%)$ & $132(44.6 \%)$ & 0.098 \\
\hline $\begin{array}{l}\text { Not alone } \\
\text { Number of } \\
\text { prescription } \\
\text { medications }\end{array}$ & $25(50 \%)$ & $52(57.1 \%)$ & $20(83.3 \%)$ & $22(45.8 \%)$ & $12(57.1 \%)$ & $20(50 \%)$ & $13(59.1 \%)$ & $164(55.4 \%)$ & \\
\hline $0-1$ & $12(24 \%)$ & $23(24.5 \%)$ & $0(0 \%)$ & $5(10.4 \%)$ & $3(14.3 \%)$ & $8(19.5 \%)$ & $4(18.2 \%)$ & $55(18.3 \%)$ & $0.047 *$ \\
\hline $2-4$ & $16(32 \%)$ & $43(45.7 \%)$ & $14(58.3 \%)$ & $19(39.6 \%)$ & $15(71.4 \%)$ & $20(48.8 \%)$ & $9(40.9 \%)$ & $136(45.3 \%)$ & \\
\hline $5-7$ & $16(32 \%)$ & $22(23.4 \%)$ & $7(29.2 \%)$ & $21(43.8 \%)$ & $3(14.3 \%)$ & $10(24.39 \%)$ & $5(22.7 \%)$ & $84(28 \%)$ & \\
\hline$\geq 8$ & $6(12 \%)$ & $6(6.4 \%)$ & $3(12.5 \%)$ & $3(6.3 \%)$ & $3(6.3 \%)$ & $3(7.3 \%)$ & $4(18.2 \%)$ & $25(8.3 \%)$ & \\
\hline
\end{tabular}

Notes: Unmarried $=$ single, divorced, widowed, and separated. Others $=$ Asians and Alaska Natives. $(*)=$-value below 0.05. Not alone includes all participants who reported living with a spouse, friend, community center, family members...etc. 
Table 4-2. Item means, standard deviations, and minimum and maximum scores for each PROMEX item.

\begin{tabular}{lcccc}
\hline Item & Mean & SD & Min & Max \\
\hline $\begin{array}{l}\text { How trustworthy do you find PROMEX? } \\
\text { (Item-1) }\end{array}$ & 3.315 & 0.932 & 1.00 & 5.00 \\
$\begin{array}{l}\text { How likely is it for you to provide your ratings } \\
\text { and reviews for PROMEX? (Item-2) }\end{array}$ & 3.161 & 1.107 & 1.00 & 5.00 \\
$\begin{array}{l}\text { Would you ask your doctor to prescribe the } \\
\text { most highly recommended medication from }\end{array}$ & 3.053 & 1.084 & 1.00 & 5.00 \\
$\begin{array}{l}\text { PROMEX? (Item-3) } \\
\text { How useful do you find PROMEX? (Item-4) }\end{array}$ & 3.600 & 1.325 & 1.00 & 5.00 \\
$\begin{array}{l}\text { If you came across PROMEX like the example } \\
\text { above how likely, is it for you to mention it to }\end{array}$ & 3.553 & 1.121 & 1.00 & 5.00 \\
$\begin{array}{l}\text { your doctor? (Item-5) } \\
\text { Do you believe that PROMEX will facilitate } \\
\text { communication with your doctor? (Item-6) } \\
\text { How likely is it for your doctor to get upset if } \\
\text { you mention PROMEX? (Item-7) }\end{array}$ & 3.456 & 1.180 & 1.00 & 5.00 \\
\hline
\end{tabular}


Table 4-3. Pearson correlation coefficients between PROMEX items and p-values.

\begin{tabular}{lccrrrrr}
\hline Item & \multicolumn{1}{c}{$\mathbf{1}$} & $\mathbf{2}$ & $\mathbf{3}$ & $\mathbf{4}$ & $\mathbf{5}$ & \multicolumn{1}{c}{$\mathbf{6}$} & \multicolumn{1}{c}{$\mathbf{7}$} \\
\hline $\mathbf{1}$ & 1.00 & 0.462 & 0.409 & 0.508 & 0.508 & 0.627 & -0.089 \\
& & $<0.001$ & $<0.001$ & $<0.001$ & $<0.001$ & $<0.001$ & 0.124 \\
$\mathbf{2}$ & 0.462 & 1.00 & 0.477 & 0.420 & 0.377 & 0.471 & -0.138 \\
& $<0.001$ & & $<0.001$ & $<0.001$ & $<0.001$ & $<0.001$ & 0.016 \\
$\mathbf{3}$ & 0.409 & 0.477 & 1.00 & 0.371 & 0.509 & 0.525 & -0.126 \\
& $<0.001$ & $<0.001$ & & $<0.001$ & $<0.001$ & $<0.001$ & 0.028 \\
$\mathbf{4}$ & 0.554 & 0.420 & 0.371 & 1.00 & 0.371 & 0.508 & -0.113 \\
& $<0.001$ & $<0.001$ & $<0.001$ & & $<0.001$ & $<0.001$ & 0.050 \\
$\mathbf{5}$ & 0.508 & 0.377 & 0.509 & 0.625 & 1.00 & 0.627 & -0.093 \\
& $<0.001$ & $<0.001$ & $<0.001$ & $<0.001$ & & $<0.001$ & 0.106 \\
$\mathbf{6}$ & 0.627 & 0.471 & 0.525 & 0.508 & 0.627 & 1.00 & -0.128 \\
& $<0.001$ & $<0.001$ & $<0.001$ & $<0.001$ & $<0.001$ & & 0.026 \\
$\mathbf{7}$ & -0.089 & -0.138 & -0.126 & -0.113 & -0.093 & -0.128 & 1.00 \\
& 0.124 & 0.016 & 0.028 & 0.050 & 0.106 & 0.026 & \\
\hline
\end{tabular}


was considered for removal. Moreover, the item-total statistics were examined to determine whether removing item-7 would result in an improvement in the Cronbach's alpha of the instrument. Table 4-4 shows that item-7 has a low and negative item-total correlation (i.e., -0.15). Further, the Cronbach's alpha of the instrument improved from 0.77 to 0.85 when item- 7 was deleted. Therefore, item- 7 was deleted.

Principal Component Analysis was also performed to determine the number of constructs or factors that can be extracted from the questionnaire. The Kaiser's MeyerOkin Measure of Sampling Adequacy (KMO) was 0.83, which indicates that the sample size was large enough to extract a factor or factors from this questionnaire (Cortina, 1993). According to Kaiser-Guttman rule, the number of factors to be extracted should be equal to the number of factors having an eigenvalue (i.e., variance) greater than one (Kaiser, 1960). Table 4-5 shows that only one factor has an eigenvalue greater than one. In addition, the scree plot in Figure 4-1 helps illustrates the rate of change in the magnitude of the eigenvalues. As can be shown in Figure 4-1, only one factor has an eigenvalue greater than one, and there was a significant drop in the second factor eigenvalue to less than one. Therefore, only one factor was extracted. The loading of each item on the extracted factor is shown in Table 4-6.

The final PROMEX instrument consists of six items after deleting item-7 due to its lack of inter-item correlation with some of the instrument items, negative and low totalitem correlation. Further, the questionnaire's Cronbach's alpha was significantly improved after deleting item-7 (i.e.,0.85) (Field, 2009). Varimax rotation was not performed because only one factor was extracted (Hatcher, 2005). This factor was named the "value of online medication rating websites to older adults". The minimum possible score of PROMEX is six and the maximum possible score is 30 after excluding item-7. The higher the score of PROMEX, the more useful participants believe online medication rating websites are.

\subsection{Patient Reviews of Medication Experiences (PROMEX)}

The mean scores of PROMEX for the different sociodemographic groups are listed in Table 4-7. The overall mean and standard deviation scores of PROMEX for study participants was $20.14 \pm 5.16$ and participants from the different age groups did not have significantly different PROMEX mean scores $(p=0.921)$. Therefore, participants from the different age groups viewed the online medication rating websites similarly. Likewise, male and female participants did not have significantly different PROMEX mean scores $(p=0.511)$. Thus, male and female participants viewed the online medication rating websites in a similar way. Further, the number of prescription medications that participants take daily did not influence their views of online medication rating websites. The study participants with one or no medical condition (i.e., comorbidity score $\leq 1$ ) did not have a significantly different PROMEX mean score than those with more than one medical condition (i.e., comorbidity score $>1)(p=0.270)$. Hence, the number of medical conditions or the comorbidity score for each participant did not influence their views of 
Table 4-4. Cronbach coefficient alpha with deleted PROMEX item.

\begin{tabular}{|c|c|c|c|c|}
\hline \multirow[b]{2}{*}{ Deleted item } & \multicolumn{2}{|c|}{ Raw item } & \multicolumn{2}{|c|}{ Standardized item } \\
\hline & $\begin{array}{c}\text { Correlation } \\
\text { with total }\end{array}$ & Alpha & $\begin{array}{c}\text { Correlation } \\
\text { with total }\end{array}$ & Alpha \\
\hline How trustworthy do you find PROMEX? (Item-1) & 0.655 & 0.725 & 0.646 & 0.707 \\
\hline $\begin{array}{l}\text { How likely is it for you to provide your ratings and reviews } \\
\text { for PROMEX? (Item-2) }\end{array}$ & 0.530 & 0.744 & 0.527 & 0.733 \\
\hline $\begin{array}{l}\text { Would you ask your doctor to prescribe the most highly } \\
\text { recommended medication from PROMEX? (Item-3) }\end{array}$ & 0.559 & 0.739 & 0.555 & 0.727 \\
\hline How useful do you find PROMEX? (Item-4) & 0.616 & 0.724 & 0.614 & 0.714 \\
\hline $\begin{array}{l}\text { If you came across PROMEX like the example above how } \\
\text { likely, is it for you to mention it to your doctor? (Item-5) }\end{array}$ & 0.684 & 0.712 & 0.671 & 0.702 \\
\hline $\begin{array}{l}\text { Do you believe that PROMEX will facilitate communication } \\
\text { with your doctor? (Item-6) }\end{array}$ & 0.695 & 0.707 & 0.695 & 0.696 \\
\hline $\begin{array}{l}\text { How likely is it for your doctor to get upset if you mention } \\
\text { PROMEX? (Item-7) }\end{array}$ & -0.151 & 0.853 & -0.150 & 0.856 \\
\hline
\end{tabular}


Table 4-5. Eigenvalues of the correlation matrix.

\begin{tabular}{lcccc}
\hline Factor & Eigenvalue & Difference & Proportion & Cumulative \\
\hline $\mathbf{1}$ & 3.505 & 2.779 & 0.584 & 0.584 \\
$\mathbf{2}$ & 0.725 & 0.122 & 0.121 & 0.705 \\
$\mathbf{3}$ & 0.602 & 0.093 & 0.101 & 0.805 \\
$\mathbf{4}$ & 0.509 & 0.132 & 0.084 & 0.890 \\
$\mathbf{5}$ & 0.376 & 0.095 & 0.062 & 0.953 \\
$\mathbf{6}$ & 0.280 & & 0.046 & 1.000 \\
\hline
\end{tabular}




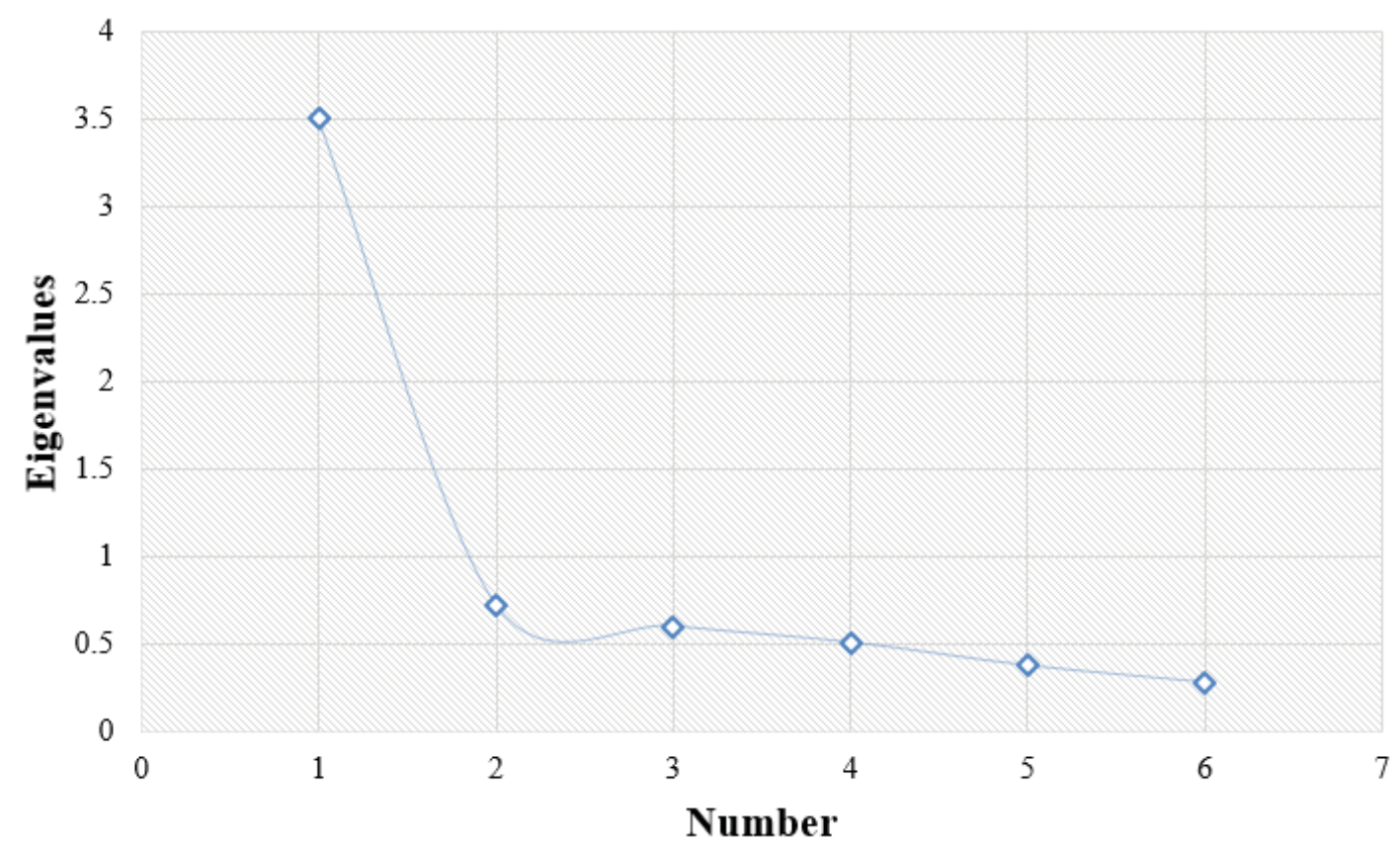

Figure 4-1. Scree plot of the possible number of factors that can be extracted from the 6-items PROMEX questionnaire. 
Table 4-6. Loading of each item of PROMEX on the extracted factor.

\begin{tabular}{lc}
\hline Items & Factor-1 \\
\hline Item 6: Do you believe that PROMEX will facilitate communication & 0.830 \\
with your doctor? & \\
Item 5: If you came across PROMEX like the example above how & 0.804 \\
likely, is it for you to mention it to your doctor? & \\
Item 1: How trustworthy do you find PROMEX? & 0.783 \\
Item 4: How useful do you find PROMEX? & 0.762 \\
Item 3: Would you ask your doctor to prescribe the most highly & 0.709 \\
recommended medication from PROMEX? & \\
Item 2: How likely is it for you to provide your ratings and reviews for & 0.685 \\
PROMEX? & \\
\hline
\end{tabular}


Table 4-7. Patient Reviews of Medication Experiences (PROMEX) scores of different sociodemographic subgroups $(\mathrm{n}=\mathbf{2 9 8})$.

\begin{tabular}{|c|c|c|c|c|c|c|}
\hline \multirow[b]{2}{*}{ Characteristics } & \multicolumn{5}{|c|}{ PROMEX score } & \multirow[b]{2}{*}{ p-Value } \\
\hline & $\mathbf{n}$ & Min & Median & Mean \pm SD & Max & \\
\hline \multicolumn{7}{|l|}{ Age } \\
\hline $50-60$ yrs. & 25 & 6 & 21.0 & $20.80 \pm 5.85$ & 30 & 0.921 \\
\hline $61-70$ yrs. & 117 & 7 & 21.0 & $20.12 \pm 5.12$ & 30 & \\
\hline $71-80$ yrs. & 97 & 7 & 21.0 & $20.07 \pm 5.03$ & 30 & \\
\hline$>80$ yrs. & 54 & 7 & 20.5 & $19.96 \pm 5.15$ & 28 & \\
\hline \multirow{2}{*}{\multicolumn{7}{|c|}{$\begin{array}{l}\text { Number of prescription } \\
\text { medications }\end{array}$}} \\
\hline & & & & & & \\
\hline $0-1$ & 55 & 7 & 21.0 & $19.98 \pm 5.73$ & 29 & 0.744 \\
\hline $2-4$ & 136 & 6 & 21.0 & $19.89 \pm 5.11$ & 30 & \\
\hline $5-7$ & 82 & 7 & 20.0 & $20.39 \pm 4.73$ & 30 & \\
\hline$\geq 8$ & 25 & 9 & 21.0 & $21.00 \pm 5.61$ & 30 & \\
\hline \multicolumn{7}{|l|}{$\overline{\text { Sex }}$} \\
\hline Male & 68 & 7 & 21.0 & $20.50 \pm 5.46$ & 30 & 0.511 \\
\hline Female & 229 & 6 & 21.0 & $20.03 \pm 5.08$ & 30 & \\
\hline \multicolumn{7}{|l|}{ Living status } \\
\hline Alone & 131 & 6 & 21.0 & $20.09 \pm 5.45$ & 30 & 0.879 \\
\hline Not alone & 163 & 7 & 21.0 & $20.18 \pm 4.97$ & 29 & \\
\hline \multicolumn{7}{|l|}{ Marital status } \\
\hline Unmarried & 187 & 6 & 21.0 & $20.21 \pm 5.41$ & 30 & 0.759 \\
\hline Married & 110 & 7 & 20.0 & $20.02 \pm 4.75$ & 29 & \\
\hline \multicolumn{7}{|l|}{ Comorbidity score } \\
\hline$\leq 1$ & 74 & 7 & 21.0 & $19.57 \pm 5.72$ & 29 & 0.270 \\
\hline$>1$ & 224 & 6 & 21.0 & $20.33 \pm 4.95$ & 30 & \\
\hline \multicolumn{7}{|l|}{ Race } \\
\hline Caucasians & 163 & 6 & 20.0 & $19.57 \pm 4.91$ & 30 & 0.205 \\
\hline African Americans & 119 & 7 & 21.0 & $20.87 \pm 5.32$ & 30 & \\
\hline Hispanics & 6 & 9 & 22.0 & $19.67 \pm 6.00$ & 27 & \\
\hline Others & 9 & 8 & 21.0 & $21.00 \pm 6.66$ & 29 & \\
\hline \multicolumn{7}{|l|}{ Education } \\
\hline $\begin{array}{l}\leq \text { High school } \\
(1-12 \text { yrs. })\end{array}$ & 135 & 7 & 21.0 & $20.45 \pm 4.66$ & 30 & 0.617 \\
\hline $\begin{array}{l}\text { Some college degree } \\
(13-16 \text { yrs.) }\end{array}$ & 124 & 6 & 20.0 & $19.82 \pm 5.49$ & 30 & \\
\hline $\begin{array}{l}\text { Post-graduate degree } \\
\text { ( } \geq 17 \text { yrs.) }\end{array}$ & 39 & 8 & 21.0 & $20.08 \pm 5.73$ & 29 & \\
\hline \multicolumn{7}{|l|}{ Health literacy } \\
\hline Marginal/limited & 76 & 9 & 21.0 & $20.30 \pm 5.18$ & 29 & 0.813 \\
\hline Good & 199 & 6 & 21.0 & $20.14 \pm 5.24$ & 30 & \\
\hline
\end{tabular}


Table 4-7. Continued.

\begin{tabular}{|c|c|c|c|c|c|c|}
\hline \multirow[b]{2}{*}{ Characteristics } & \multicolumn{5}{|c|}{ PROMEX score } & \multirow[b]{2}{*}{ p-Value } \\
\hline & $\mathbf{n}$ & Min & Median & Mean \pm SD & Max & \\
\hline \multicolumn{7}{|l|}{$\begin{array}{l}\text { Healthcare decision } \\
\text { sharing }\end{array}$} \\
\hline No & 61 & 6 & 20.0 & $19.07 \pm 5.18$ & 30 & 0.080 \\
\hline Yes & 234 & 7 & 21.0 & $20.36 \pm 5.13$ & 30 & \\
\hline \multicolumn{7}{|l|}{$\begin{array}{l}\text { Healthcare decision } \\
\text { sharing preference }\end{array}$} \\
\hline $\begin{array}{l}\text { Keep control in my } \\
\text { own hand }\end{array}$ & 34 & 6 & 20.0 & $19.38 \pm 5.38$ & 30 & 0.187 \\
\hline $\begin{array}{l}\text { Have an equal } \\
\text { partnership }\end{array}$ & 234 & 7 & 21.0 & $20.36 \pm 5.13$ & 30 & \\
\hline $\begin{array}{l}\text { Leave it in the doctor's } \\
\text { hands }\end{array}$ & 27 & 9 & 19.5 & $18.67 \pm 4.99$ & 30 & \\
\hline
\end{tabular}

Note: $(*)=p<0.05$. 
online rating of medication websites. In addition, the PROMEX mean scores were not significantly different across the different marital and living status groups $(p=0.879)$. Moreover, PROMEX mean scores were not significantly different between the different education, health literacy and racial subgroups $(p \geq 0.05)$. Finally, the PROMEX mean scores were not significantly different between the different health decision sharing and preference groups $(\mathrm{p}=0.08)$.

\subsection{The Health-Related Quality of Life (HRQoL)}

\subsubsection{The SF-12v2 Physical Component Summary (PCS-12)}

The number of the participants who completed the Physical Component Summary (PCS-12) section of the SF-12v2 survey was 298 participants. The mean scores of the PCS-12 for the different sociodemographic subgroups are listed in Table 4-8. As the number of prescription medications a participant took daily increased, the PCS-12 mean score decreased. Participants who were taking one or more prescription medications had significantly lower PCS-12 mean scores than participants on one prescription medication or not on any prescription medications $(\mathrm{p}<0.001)$. Therefore, participants who were taking multiple prescription medications report lower physical health or physical HRQoL than participants taking only one medication or not taking any prescription medications. Similarly, participants with more than one medical condition had a significantly lower PCS-12 mean score than participants with no medical conditions or with only one medical condition $(\mathrm{p}<0.001)$. Hence, participants with multiple comorbidities had lower physical health or physical HRQoL than those with one or no comorbidities. Participants with some college or post-graduate degrees had significantly higher PCS-12 mean scores than those with high school diploma or lower $(p=0.011)$. Thus, participants with higher educations (i.e., some college or post-graduate degrees) reported better physical health or physical HRQoL than participants with lower educations (i.e., high school diploma or lower). The mean scores of the PCS-12 were not significantly different across age, sex, marital status, living status, racial, health literacy, and health decision sharing preference subgroups $(\mathrm{p} \geq 0.05)$.

\subsubsection{The SF-12v2 Mental Component Summary (MCS-12)}

The number of participants who completed the Mental Component Summary (MCS12) section of the SF-12v2 survey was 298 participants. The mean scores of the SF-12v2 Mental Component Summary (MCS-12) for the different sociodemographic subgroups are listed in Table 4-9. The mean scores of the MCS-12 for the study participants aged 61 years and above were significantly higher than those aged 60 or less years $(p=0.001)$. Participants whose age was between 71 and 80 years had the highest mental health or mental HRQoL compared to the other age subgroups. Further, married participants had a significantly higher MCS-12 mean score compared to the unmarried participants $(p=0.039)$. In addition, the mean score of the MCS-12 for participants with good health 
Table 4-8. SF-12v2 Physical Component Summary (PCS-12) scores of different sociodemographic subgroups $(n=298)$.

\begin{tabular}{|c|c|c|c|c|c|c|}
\hline \multirow[b]{2}{*}{ Characteristics } & \multicolumn{5}{|c|}{ PCS-12 score } & \multirow[b]{2}{*}{ p-Value } \\
\hline & $\mathbf{n}$ & Min & Median & Mean \pm SD & Max & \\
\hline \multicolumn{7}{|l|}{ Age } \\
\hline 50-60 yrs. & 25 & 26 & 46.3 & $47.16 \pm 9.62$ & 60 & 0.285 \\
\hline 61-70 yrs. & 117 & 24 & 48.9 & $46.84 \pm 10.3$ & 67 & \\
\hline $71-80$ yrs. & 97 & 22 & 45.0 & $45.12 \pm 9.47$ & 63 & \\
\hline$>80$ yrs & 54 & 13 & 44.3 & $43.99 \pm 11.3$ & 61 & \\
\hline \multicolumn{7}{|c|}{$\begin{array}{l}\text { Number of prescription } \\
\text { medications }\end{array}$} \\
\hline $0-1$ & 55 & 28 & 55.9 & $52.04 \pm 8.54$ & 63 & $<0.001 *$ \\
\hline $2-4$ & 136 & 13 & 46.5 & $45.70 \pm 9.44$ & 61 & \\
\hline $5-7$ & 82 & 22 & 44.3 & $44.11 \pm 10.4$ & 67 & \\
\hline$\geq 8$ & 25 & 26 & 38.8 & $38.47 \pm 9.51$ & 53 & \\
\hline \multicolumn{7}{|l|}{ Sex } \\
\hline Male & 68 & 24 & 44.8 & $44.73 \pm 9.45$ & 63 & 0.298 \\
\hline Female & 229 & 13 & 47.2 & $46.19 \pm 10.4$ & 67 & \\
\hline \multicolumn{7}{|l|}{ Living status } \\
\hline Alone & 131 & 21 & 48.9 & $46.89 \pm 9.82$ & 63 & 0.095 \\
\hline Not alone & 163 & 13 & 44.9 & $44.9 \pm 10.37$ & 67 & \\
\hline \multicolumn{7}{|l|}{ Marital status } \\
\hline Unmarried & 187 & 13 & 47.1 & $46.24 \pm 10.3$ & 67 & 0.396 \\
\hline Married & 110 & 24 & 46.2 & $45.20 \pm 9.91$ & 61 & \\
\hline \multicolumn{7}{|l|}{ Comorbidity score } \\
\hline$\leq 1$ & 74 & 30 & 53.8 & $51.56 \pm 7.49$ & 63 & $<0.001 *$ \\
\hline$>1$ & 224 & 13 & 43.8 & $43.94 \pm 10.2$ & 67 & \\
\hline \multicolumn{7}{|l|}{ Race } \\
\hline Caucasians & 163 & 21 & 48.0 & $46.15 \pm 10.2$ & 30 & 0.781 \\
\hline African Americans & 119 & 13 & 45.1 & $45.40 \pm 9.92$ & 30 & \\
\hline Hispanics & 6 & 33 & 46.0 & $47.14 \pm 11.5$ & 27 & \\
\hline Others & 9 & 22 & 44.7 & $43.17 \pm 12.8$ & 29 & \\
\hline
\end{tabular}


Table 4-8. Continued.

\begin{tabular}{|c|c|c|c|c|c|c|}
\hline \multirow[b]{2}{*}{ Characteristics } & \multicolumn{5}{|c|}{ PCS-12 score } & \multirow[b]{2}{*}{ p-Value } \\
\hline & $\mathbf{n}$ & Min & Median & Mean \pm SD & $\operatorname{Max}$ & \\
\hline \multicolumn{7}{|l|}{ Education } \\
\hline $\begin{array}{l}\leq \text { High school } \\
(1-12 \text { yrs. })\end{array}$ & 135 & 13 & 43.5 & $44.18 \pm 9.65$ & 61 & $0.011 *$ \\
\hline $\begin{array}{l}\text { Some college degree } \\
\text { (13-16 yrs.) }\end{array}$ & 124 & 21 & 51.1 & $47.88 \pm 10.2$ & 67 & \\
\hline $\begin{array}{l}\text { Post-graduate degree } \\
\text { ( } \geq 17 \text { yrs.) }\end{array}$ & 39 & 24 & 47.8 & $45.03 \pm 10.7$ & 61 & \\
\hline \multicolumn{7}{|l|}{ Health literacy } \\
\hline Marginal/limited & 76 & 21 & 44.2 & $44.68 \pm 9.18$ & 67 & 0.121 \\
\hline Good & 199 & 13 & 48.9 & $46.78 \pm 10.4$ & 63 & \\
\hline \multicolumn{7}{|l|}{$\begin{array}{l}\text { Healthcare decision } \\
\text { sharing }\end{array}$} \\
\hline No & 61 & 26 & 45.7 & $45.46 \pm 9.21$ & 61 & 0.668 \\
\hline Yes & 234 & 13 & 47.2 & $46.08 \pm 10.3$ & 67 & \\
\hline \multicolumn{7}{|l|}{$\begin{array}{l}\text { Healthcare decision } \\
\text { sharing preference }\end{array}$} \\
\hline $\begin{array}{l}\text { Keep control in my own } \\
\text { hand }\end{array}$ & 34 & 28 & 49.6 & $47.25 \pm 9.27$ & 59 & 0.273 \\
\hline Have an equal partnership & 234 & 13 & 47.2 & $46.08 \pm 10.3$ & 67 & \\
\hline $\begin{array}{l}\text { Leave it in the doctor's } \\
\text { hands }\end{array}$ & 27 & 26 & 43.0 & $43.21 \pm 8.80$ & 61 & \\
\hline
\end{tabular}

Note: $(*)=p<0.05$. 
Table 4-9. SF-12v2 Mental Component Summary (MCS-12) scores of different sociodemographic subgroups $(n=298)$.

\begin{tabular}{|c|c|c|c|c|c|c|}
\hline \multirow[b]{2}{*}{ Characteristics } & \multicolumn{5}{|c|}{ MCS-12 score } & \multirow[b]{2}{*}{ p-Value } \\
\hline & $\mathbf{n}$ & Min & Median & Mean \pm SD & Max & \\
\hline \multicolumn{7}{|l|}{ Age } \\
\hline $50-60$ yrs. & 25 & 26 & 47.5 & $45.63 \pm 9.80$ & 58 & $0.001 *$ \\
\hline $61-70$ yrs. & 117 & 30 & 55.5 & $52.05 \pm 9.88$ & 68 & \\
\hline $71-80$ yrs. & 97 & 29 & 58.5 & $54.99 \pm 9.13$ & 72 & \\
\hline$>80$ yrs. & 54 & 33 & 53.4 & $52.49 \pm 8.46$ & 73 & \\
\hline \multicolumn{7}{|c|}{$\begin{array}{l}\text { Number of prescription } \\
\text { medications }\end{array}$} \\
\hline $0-1$ & 55 & 30 & 54.8 & $52.78 \pm 8.87$ & 72 & 0.763 \\
\hline $2-4$ & 136 & 29 & 54.4 & $51.69 \pm 9.61$ & 73 & \\
\hline $5-7$ & 82 & 26 & 55.2 & $53.07 \pm 9.72$ & 69 & \\
\hline$\geq 8$ & 25 & 25 & 56.7 & $52.35 \pm 12.9$ & 67 & \\
\hline \multicolumn{7}{|l|}{ Sex } \\
\hline Male & 68 & 25 & 53.0 & $50.11 \pm 11.3$ & 72 & 0.053 \\
\hline Female & 229 & 26 & 55.8 & $53.04 \pm 9.21$ & 73 & \\
\hline \multicolumn{7}{|l|}{ Living status } \\
\hline Alone & 131 & 25 & 53.1 & $51.68 \pm 9.64$ & 69 & 0.235 \\
\hline Not alone & 163 & 26 & 55.8 & $53.04 \pm 9.87$ & 73 & \\
\hline \multicolumn{7}{|l|}{ Marital status } \\
\hline Unmarried & 187 & 25 & 53.0 & $51.47 \pm 9.91$ & 73 & $0.039 *$ \\
\hline Married & 110 & 29 & 56.8 & $53.90 \pm 9.41$ & 72 & \\
\hline \multicolumn{7}{|l|}{ Comorbidity score } \\
\hline$\leq 1$ & 74 & 30 & 56.6 & $52.95 \pm 8.98$ & 67 & 0.530 \\
\hline$>1$ & 224 & 25 & 54.3 & $52.12 \pm 10.1$ & 73 & \\
\hline \multicolumn{7}{|l|}{ Race } \\
\hline Caucasians & 163 & 25 & 56.9 & $53.53 \pm 9.13$ & 72 & 0.067 \\
\hline African Americans & 119 & 26 & 52.4 & $51.02 \pm 10.4$ & 73 & \\
\hline Hispanics & 6 & 34 & 46.5 & $46.02 \pm 9.82$ & 58 & \\
\hline Others & 9 & 36 & 51.7 & $51.50 \pm 11.9$ & 69 & \\
\hline
\end{tabular}


Table 4-9. Continued.

\begin{tabular}{|c|c|c|c|c|c|c|}
\hline \multirow[b]{2}{*}{ Characteristics } & \multicolumn{5}{|c|}{ MCS-12 score } & \multirow[b]{2}{*}{ p-Value } \\
\hline & $\mathbf{n}$ & Min & Median & Mean \pm SD & $\operatorname{Max}$ & \\
\hline \multicolumn{7}{|l|}{ Education } \\
\hline $\begin{array}{l}\leq \text { High school } \\
(1-12 \text { yrs. })\end{array}$ & 135 & 26 & 52.7 & $51.04 \pm 10.5$ & 73 & 0.077 \\
\hline $\begin{array}{l}\text { Some college degree } \\
(13-16 \text { yrs.) }\end{array}$ & 124 & 25 & 56.2 & $53.0 \pm 9.24$ & 72 & \\
\hline $\begin{array}{l}\text { Post-graduate degree } \\
\text { ( } \geq 17 \text { yrs.) }\end{array}$ & 39 & 31 & 55.3 & $54.64 \pm 8.42$ & 68 & \\
\hline \multicolumn{7}{|l|}{ Health literacy } \\
\hline Marginal/limited & 76 & 26 & 48.1 & $48.02 \pm 10.5$ & 69 & $<0.001$ \\
\hline Good & 199 & 25 & 55.6 & $53.23 \pm 9.13$ & 73 & \\
\hline \multicolumn{7}{|l|}{$\begin{array}{l}\text { Healthcare decision } \\
\text { sharing }\end{array}$} \\
\hline No & 61 & 25 & 51.8 & $50.29 \pm 11.3$ & 72 & 0.060 \\
\hline Yes & 234 & 29 & 55.8 & $52.93 \pm 9.28$ & 73 & \\
\hline \multicolumn{7}{|l|}{$\begin{array}{l}\text { Healthcare decision } \\
\text { sharing preference }\end{array}$} \\
\hline $\begin{array}{l}\text { Keep control in my own } \\
\text { hand }\end{array}$ & 34 & 25 & 53.9 & $50.91 \pm 11.7$ & 72 & 0.147 \\
\hline Have an equal partnership & 234 & 29 & 55.8 & $52.93 \pm 9.28$ & 73 & \\
\hline $\begin{array}{l}\text { Leave it in the doctor's } \\
\text { hands }\end{array}$ & 27 & 26 & 48.1 & $49.51 \pm 11.0$ & 65 & \\
\hline
\end{tabular}

Note: $(*)=p<0.05$. 
literacy was significantly higher than the one for participants with limited health literacy $(p<0.001)$. Finally, the mean scores of the MCS- 12 were not significantly different across the different sex, comorbidities, number of prescription medications, living status, educations, racial, and health decision sharing preference subgroups $(\mathrm{p} \geq 0.05)$.

\subsection{Satisfaction with Physician Communication and Interpersonal Treatment}

\subsubsection{The Primary Care Assessment Survey-Communication Scale (PCAS- Communication)}

The number of the study participants who completed the Primary Care Assessment Survey Communication domain (PCAS-Communication) was 300. The PCASCommunication scale mean scores for the different sociodemographic groups are listed in Table 4-10. The mean score of the PCAS-Communication for female participants was significantly higher than the score for male participants $(\mathrm{p}=0.048)$. Female participants were more satisfied with the physician communication than their male counterparts were. Married participants also had a significantly higher PCAS-Communication mean score than the unmarried participants $(\mathrm{p}=0.013)$. Married participants were more satisfied with the physician communication compared to the unmarried participants. Further, the mean score of the PCAS-Communication for Caucasians was significantly higher than the scores for African Americans, Hispanics, and other racial subgroups $(p=0.041)$. The Caucasian participants had the highest satisfaction level with the physician communication among the other racial subgroups. Hispanics had the lowest satisfaction level with the physician communication among the other racial subgroups. In addition, participants with good health literacy level had a significantly higher PCASCommunication mean score than participants with limited health literacy $(\mathrm{p}=0.001)$. Finally, the mean scores of PCAS-Communication scores across the different age, number of prescription medications, living status, comorbidity score, education, healthcare decision sharing, and healthcare decision sharing preference subgroups were not significantly different $(\mathrm{p} \geq 0.05)$.

\subsubsection{The PCAS-Interpersonal Treatment Scale}

The number of the study participants who completed the Primary Care Assessment Survey Interpersonal Treatment domain (PCAS-Interpersonal Treatment) was 300. The PCAS-interpersonal treatment scale mean scores for the different sociodemographic subgroups are listed in Table 4-11. Married participants had a significantly higher PCASinterpersonal treatment mean score than the unmarried participants did $(p=0.029)$. Therefore, the married participants' level of satisfaction with the physician interpersonal treatment was significantly higher than the level of satisfaction for the unmarried. However, the mean scores of the PCAS-interpersonal treatment did not significantly differ across the age, education, living status, number of prescription medications, sex, comorbidities, race, health literacy, healthcare decision sharing, and healthcare decision 
Table 4-10. Primary Care Assessment Survey (PCAS-Communication) scale $(n=300)$.

\begin{tabular}{|c|c|c|c|c|c|c|}
\hline \multirow[b]{2}{*}{ Characteristics } & \multicolumn{5}{|c|}{ PCAS-Communication scale score } & \multirow[b]{2}{*}{ p-Value } \\
\hline & $\mathbf{n}$ & Min & Median & Mean \pm SD & $\operatorname{Max}$ & \\
\hline \multicolumn{7}{|l|}{ Age } \\
\hline $50-60$ yrs. & 25 & 10 & 68.0 & $68.53 \pm 21.4$ & 100 & 0.133 \\
\hline $61-70$ yrs. & 117 & 28 & 76.7 & $73.85 \pm 16.9$ & 100 & \\
\hline $71-80$ yrs. & 98 & 20 & 75.0 & $74.95 \pm 16.8$ & 100 & \\
\hline$>80$ yrs. & 55 & 30 & 66.7 & $69.33 \pm 17.1$ & 100 & \\
\hline \multicolumn{7}{|c|}{$\begin{array}{l}\text { Number of prescription } \\
\text { medications }\end{array}$} \\
\hline $0-1$ & 55 & 10 & 76.7 & $73.78 \pm 17.7$ & 100 & 0.295 \\
\hline $2-4$ & 136 & 30 & 73.3 & $71.55 \pm 16.9$ & 100 & \\
\hline $5-7$ & 84 & 20 & 76.7 & $75.27 \pm 17.8$ & 100 & \\
\hline$\geq 8$ & 25 & 40 & 70.0 & $69.07 \pm 17.6$ & 100 & \\
\hline \multicolumn{7}{|l|}{ Sex } \\
\hline Male & 68 & 30 & 66.7 & $69.11 \pm 16.5$ & 100 & $0.048^{*}$ \\
\hline Female & 231 & 10 & 73.3 & $73.85 \pm 17.6$ & 100 & \\
\hline \multicolumn{7}{|l|}{ Living status } \\
\hline Alone & 132 & 10 & 70.0 & $70.93 \pm 18.4$ & 100 & 0.092 \\
\hline Not alone & 164 & 28 & 76.7 & $74.37 \pm 16.5$ & 100 & \\
\hline \multicolumn{7}{|l|}{ Marital status } \\
\hline Unmarried & 189 & 10 & 70.0 & $70.87 \pm 18.2$ & 100 & $0.013^{*}$ \\
\hline Married & 110 & 30 & 80.0 & $76.04 \pm 15.6$ & 100 & \\
\hline \multicolumn{7}{|l|}{ Comorbidity score } \\
\hline$\leq 1$ & 74 & 20 & 75.0 & $73.53 \pm 17.9$ & 100 & 0.676 \\
\hline$>1$ & 226 & 10 & 73.3 & $72.55 \pm 17.3$ & 100 & \\
\hline \multicolumn{7}{|l|}{ Race } \\
\hline Caucasians & 164 & 30 & 76.7 & $74.59 \pm 17.5$ & 100 & $0.041^{*}$ \\
\hline African Americans & 120 & 10 & 73.3 & $71.77 \pm 17.3$ & 100 & \\
\hline Hispanics & 6 & 43 & 60.0 & $60.56 \pm 14.9$ & 87 & \\
\hline Others & 9 & 37 & 60.0 & $62.59 \pm 12.3$ & 80 & \\
\hline
\end{tabular}


Table 4-10. Continued.

\begin{tabular}{|c|c|c|c|c|c|c|}
\hline \multirow[b]{2}{*}{ Characteristics } & \multicolumn{5}{|c|}{ PCAS-Communication scale score } & \multirow[b]{2}{*}{ p-Value } \\
\hline & $\mathbf{n}$ & Min & Median & Mean \pm SD & Max & \\
\hline \multicolumn{7}{|l|}{ Education } \\
\hline $\begin{array}{l}\leq \text { High school } \\
(1-12 \text { yrs. })\end{array}$ & 136 & 28 & 70.0 & $71.66 \pm 16.2$ & 100 & 0.346 \\
\hline $\begin{array}{l}\text { Some college degree } \\
(13-16 \text { yrs.) }\end{array}$ & 124 & 20 & 73.3 & $72.94 \pm 17.9$ & 100 & \\
\hline $\begin{array}{l}\text { Post-graduate degree } \\
\text { ( } \geq 17 \text { yrs.) }\end{array}$ & 40 & 10 & 80.0 & $76.22 \pm 19.5$ & 100 & \\
\hline \multicolumn{7}{|l|}{ Health literacy } \\
\hline Marginal/limited & 76 & 30 & 66.7 & $66.77 \pm 15.8$ & 97 & $0.001 *$ \\
\hline Good & 200 & 10 & 76.7 & $74.97 \pm 17.5$ & 100 & \\
\hline \multicolumn{7}{|l|}{$\begin{array}{l}\text { Healthcare decision } \\
\text { sharing }\end{array}$} \\
\hline No & 62 & 36 & 67.3 & $70.61 \pm 18.4$ & 100 & 0.263 \\
\hline Yes & 235 & 10 & 73.3 & $73.41 \pm 17.2$ & 100 & \\
\hline \multicolumn{7}{|l|}{$\begin{array}{l}\text { Healthcare decision } \\
\text { sharing preference }\end{array}$} \\
\hline $\begin{array}{l}\text { Keep control in my own } \\
\text { hand }\end{array}$ & 34 & 36 & 67.3 & $67.88 \pm 16.9$ & 100 & 0.213 \\
\hline Have an equal partnership & 235 & 10 & 73.3 & $73.41 \pm 17.2$ & 100 & \\
\hline $\begin{array}{l}\text { Leave it in the doctor's } \\
\text { hands }\end{array}$ & 28 & 40 & 70.0 & $73.93 \pm 19.8$ & 100 & \\
\hline
\end{tabular}

Note: $\left(^{*}\right)=p<0.05$. 
Table 4-11. Primary Care Assessment Survey (PCAS-Interpersonal Treatment) scale $(n=300)$.

\begin{tabular}{|c|c|c|c|c|c|c|}
\hline \multirow[b]{2}{*}{ Characteristics } & \multicolumn{5}{|c|}{ PCAS-Interpersonal Treatment scale score } & \multirow[b]{2}{*}{ p-Value } \\
\hline & $\mathbf{n}$ & Min & Median & Mean \pm SD & Max & \\
\hline \multicolumn{7}{|l|}{ Age } \\
\hline $50-60$ yrs. & 25 & 40 & 68.0 & $71.96 \pm 20.3$ & 100 & \multirow[t]{4}{*}{0.618} \\
\hline $61-70$ yrs. & 117 & 27 & 76.0 & $72.84 \pm 18.9$ & 100 & \\
\hline $71-80$ yrs. & 98 & 27 & 76.0 & $74.31 \pm 17.8$ & 100 & \\
\hline$>80$ yrs & 55 & 35 & 72.0 & $70.27 \pm 16.3$ & 100 & \\
\hline \multicolumn{7}{|c|}{$\begin{array}{l}\text { Number of prescription } \\
\text { medications }\end{array}$} \\
\hline $0-1$ & 55 & 40 & 76.0 & $73.36 \pm 21.1$ & 100 & \multirow[t]{4}{*}{0.605} \\
\hline $2-4$ & 136 & 27 & 72.0 & $71.75 \pm 17.3$ & 100 & \\
\hline $5-7$ & 84 & 27 & 76.0 & $74.37 \pm 17.7$ & 100 & \\
\hline$\geq 8$ & 25 & 28 & 68.0 & $69.60 \pm 18.4$ & 100 & \\
\hline \multicolumn{7}{|l|}{ Sex } \\
\hline Male & 68 & 27 & 74.0 & $69.35 \pm 17.6$ & 100 & \multirow[t]{2}{*}{0.084} \\
\hline Female & 231 & 27 & 76.0 & $73.68 \pm 18.3$ & 100 & \\
\hline \multicolumn{7}{|l|}{ Living status } \\
\hline Alone & 132 & 27 & 72.0 & $70.87 \pm 18.8$ & 100 & \multirow[t]{2}{*}{0.099} \\
\hline Not alone & 164 & 27 & 76.0 & $74.37 \pm 17.6$ & 100 & \\
\hline \multicolumn{7}{|l|}{ Marital status } \\
\hline Unmarried & 189 & 27 & 72.0 & $70.95 \pm 18.6$ & 100 & \multirow[t]{2}{*}{$0.029 *$} \\
\hline Married & 110 & 28 & 80.0 & $75.69 \pm 17.2$ & 100 & \\
\hline \multicolumn{7}{|c|}{ Comorbidity score } \\
\hline$\leq 1$ & 74 & 27 & 72.0 & $72.00 \pm 19.8$ & 100 & \multirow[t]{2}{*}{0.742} \\
\hline$>1$ & 226 & 27 & 76.0 & $72.80 \pm 17.7$ & 100 & \\
\hline \multicolumn{7}{|c|}{$\begin{array}{l}\text { Healthcare decision } \\
\text { sharing }\end{array}$} \\
\hline No & 62 & 28 & 72.0 & $71.77 \pm 18.9$ & 100 & \multirow[t]{2}{*}{0.668} \\
\hline Yes & 235 & 27 & 76.0 & $72.90 \pm 18.1$ & 100 & \\
\hline
\end{tabular}


Table 4-11. Continued.

\begin{tabular}{|c|c|c|c|c|c|c|}
\hline \multirow[b]{2}{*}{ Characteristics } & \multicolumn{5}{|c|}{ PCAS-Interpersonal Treatment scale score } & \multirow[b]{2}{*}{ p-Value } \\
\hline & $\mathbf{n}$ & Min & Median & Mean \pm SD & Max & \\
\hline \multicolumn{7}{|l|}{ Education } \\
\hline $\begin{array}{l}\leq \text { High school } \\
(1-12 \text { yrs. })\end{array}$ & 136 & 28 & 72.0 & $71.53 \pm 17.2$ & 100 & \multirow[t]{3}{*}{0.205} \\
\hline $\begin{array}{l}\text { College degree } \\
(13-16 \text { yrs.) }\end{array}$ & 124 & 27 & 76.0 & $72.26 \pm 19.6$ & 100 & \\
\hline $\begin{array}{l}\text { Post-graduate degree } \\
\text { ( } \geq 17 \text { yrs.) }\end{array}$ & 40 & 40 & 80.0 & $77.30 \pm 16.9$ & 100 & \\
\hline \multicolumn{7}{|l|}{ Race } \\
\hline Caucasians & 164 & 35 & 76.0 & $73.85 \pm 18.3$ & 100 & \multirow[t]{4}{*}{0.059} \\
\hline African Americans & 120 & 27 & 75.5 & $72.57 \pm 18.1$ & 100 & \\
\hline Hispanics & 6 & 44 & 60.0 & $62.67 \pm 18.4$ & 88 & \\
\hline Others & 9 & 40 & 60.0 & $59.22 \pm 12.9$ & 76 & \\
\hline \multicolumn{7}{|l|}{ Health literacy } \\
\hline Marginal/limited & 76 & 28 & 72.0 & $69.37 \pm 17.4$ & 100 & \multirow[t]{2}{*}{0.056} \\
\hline Good & 200 & 27 & 76.0 & $74.04 \pm 18.4$ & 100 & \\
\hline \multicolumn{7}{|l|}{$\begin{array}{l}\text { Healthcare decision } \\
\text { sharing preference }\end{array}$} \\
\hline $\begin{array}{l}\text { Keep control in my own } \\
\text { hand }\end{array}$ & 34 & 40 & 66.0 & $68.53 \pm 19.3$ & 100 & \multirow[t]{3}{*}{0.278} \\
\hline Have an equal partnership & 235 & 27 & 76.0 & $72.90 \pm 18.1$ & 100 & \\
\hline $\begin{array}{l}\text { Leave it in the doctor's } \\
\text { hands }\end{array}$ & 28 & 28 & 74.0 & $75.71 \pm 18.2$ & 100 & \\
\hline
\end{tabular}

Note: $(*)=p<0.05$. 
sharing preference subgroups ( $\mathrm{p} \geq 0.05)$.

\subsection{The General Domains of Beliefs about Medicines Questionnaire (BMQ)}

\subsubsection{BMQ-Overuse Scale}

The number of the participants who completed the Beliefs about Medicine Questionnaire-Overuse scale was 297. The BMQ-Overuse scale mean scores across the different sociodemographic subgroups are listed in Table 4-12. Participants who reported taking zero or only one prescription medication had significantly higher BMQ GeneralOveruse mean scores than other participants who reported taking multiple prescription medications $(\mathrm{p}=0.016)$. As the number of prescription medications participants were taking increased, their belief that medications are overprescribed or overused decreased. Female participants had a significantly higher BMQ General-Overuse mean score than their male counterparts $(\mathrm{p}=0.009)$. Hence, female participants' beliefs about medications being overused or overprescribed were stronger than their male counterparts. Further, the mean scores of the BMQ General-Overuse for participants who liked to be involved in the health decision along with the physicians or have an equal partnership, and those who liked to keep the health decision in their own hands were significantly higher than the participants who liked to keep the health decision in the physicians' hands ( $\mathrm{p}=0.017$ ). Participants who liked to be involved with physicians' in the health decision or have an equal partnership held the strongest beliefs that medications are overprescribed or overused; however, participants who liked to leave the health decision in the physicians' hands had the weakest beliefs than medications are overprescribed or overused. Finally, the mean scores of the BMQ General-Overuse for the different age, education, marital and living status, comorbidities, race, and health literacy groups were not significantly different $(\mathrm{p} \geq 0.05)$.

\subsubsection{BMQ-Harm Scale}

The number of the participants who completed the Beliefs about Medicine Questionnaire-Harm scale was 298. The BMQ-Harm scale mean scores across the different sociodemographic subgroups are listed in Table 4-13. The participants who reported taking zero or one prescription medication had the highest BMQ-Harm mean score compared to the mean scores of those taking multiple medications $(\mathrm{p}=0.038)$. As the number of prescription medications taken by the participants increased, their belief that prescription medications are inherently harmful decreased. The Caucasian/white participants had the lowest BMQ-Harm mean score in comparison to the other racial groups $(\mathrm{p}=0.014)$. Hence, the Caucasian participants' beliefs that prescription medications are generally harmful were not as strong as the beliefs of other racial groups. On the other hand, Asians and Alaska Natives (i.e., Others) held the strongest beliefs that medications are generally harmful in comparison to other racial groups $(\mathrm{p}=0.014)$. The mean scores of BMQ-Harm across other sociodemographic, comorbidities, health 
Table 4-12. Beliefs about Medicines Questionnaire-Overuse (BMQ-Overuse) scale scores of different sociodemographic subgroups $(n=297)$.

\begin{tabular}{|c|c|c|c|c|c|c|}
\hline \multirow[b]{2}{*}{ Characteristics } & \multicolumn{5}{|c|}{ BMQ-Overuse score } & \multirow[b]{2}{*}{ p-Value } \\
\hline & $\mathbf{n}$ & Min & Median & Mean \pm SD & Max & \\
\hline \multicolumn{7}{|l|}{ Age } \\
\hline $50-60$ yrs. & 25 & 4 & 13.0 & $12.48 \pm 3.74$ & 19 & \multirow[t]{4}{*}{0.592} \\
\hline $61-70$ yrs. & 116 & 4 & 13.0 & $12.62 \pm 2.77$ & 18 & \\
\hline $71-80$ yrs. & 98 & 5 & 13.0 & $12.91 \pm 3.20$ & 20 & \\
\hline$>80$ yrs. & 53 & 6 & 12.0 & $12.23 \pm 2.46$ & 18 & \\
\hline \multicolumn{7}{|c|}{$\begin{array}{l}\text { Number of prescription } \\
\text { medications }\end{array}$} \\
\hline $0-1$ & 55 & 4 & 14.0 & $13.49 \pm 3.65$ & 20 & \multirow[t]{4}{*}{$0.016^{*}$} \\
\hline $2-4$ & 134 & 4 & 13.0 & $12.66 \pm 2.80$ & 20 & \\
\hline $5-7$ & 83 & 6 & 13.0 & $12.23 \pm 2.63$ & 17 & \\
\hline$\geq 8$ & 25 & 4 & 12.0 & $11.40 \pm 3.21$ & 16 & \\
\hline \multicolumn{7}{|l|}{ Sex } \\
\hline Male & 68 & 4 & 12.0 & $11.78 \pm 2.96$ & 16 & \multirow[t]{2}{*}{$0.009 *$} \\
\hline Female & 228 & 4 & 13.0 & $12.86 \pm 2.96$ & 20 & \\
\hline \multicolumn{7}{|l|}{ Living status } \\
\hline Alone & 131 & 4 & 13.0 & $12.81 \pm 3.12$ & 20 & \multirow[t]{2}{*}{0.277} \\
\hline Not Alone & 162 & 4 & 13.0 & $12.43 \pm 2.90$ & 20 & \\
\hline \multicolumn{7}{|l|}{ Marital status } \\
\hline Unmarried & 86 & 4 & 13.0 & $12.80 \pm 2.98$ & 20 & \multirow[t]{2}{*}{0.149} \\
\hline Married & 110 & 4 & 12.0 & $12.28 \pm 2.99$ & 20 & \\
\hline \multicolumn{7}{|l|}{ Comorbidity score } \\
\hline$\leq 1$ & 74 & 4 & 13.0 & $12.93 \pm 3.13$ & 19 & \multirow[t]{2}{*}{0.257} \\
\hline$>1$ & 223 & 4 & 13.0 & $12.48 \pm 2.96$ & 20 & \\
\hline \multicolumn{7}{|l|}{ Race } \\
\hline Caucasians & 162 & 5 & 12.5 & $12.56 \pm 2.84$ & 20 & \multirow[t]{4}{*}{0.895} \\
\hline African Americans & 120 & 4 & 13.0 & $12.65 \pm 3.21$ & 19 & \\
\hline Hispanics & 5 & 7 & 12.0 & $11.60 \pm 4.16$ & 16 & \\
\hline Others & 9 & 7 & 13.0 & $12.56 \pm 2.60$ & 18 & \\
\hline
\end{tabular}


Table 4-12. Continued.

\begin{tabular}{|c|c|c|c|c|c|c|}
\hline \multirow[b]{2}{*}{ Characteristics } & \multicolumn{5}{|c|}{ BMQ-Overuse score } & \multirow[b]{2}{*}{ p-Value } \\
\hline & $\mathbf{n}$ & Min & Median & Mean \pm SD & Max & \\
\hline \multicolumn{7}{|l|}{ Education } \\
\hline $\begin{array}{l}\leq \text { High school } \\
(1-12 \text { yrs. })\end{array}$ & 133 & 4 & 12.0 & $12.32 \pm 3.19$ & 20 & 0.313 \\
\hline $\begin{array}{l}\text { College degree } \\
(13-16 \text { yrs.) }\end{array}$ & 124 & 4 & 13.0 & $12.89 \pm 2.95$ & 19 & \\
\hline $\begin{array}{l}\text { Post-graduate degree } \\
\text { ( } \geq 17 \text { yrs.) }\end{array}$ & 40 & 7 & 12.5 & $12.58 \pm 2.45$ & 17 & \\
\hline \multicolumn{7}{|l|}{ Health literacy } \\
\hline Marginal/limited & 76 & 4 & 13.0 & $12.79 \pm 3.40$ & 20 & 0.480 \\
\hline Good & 198 & 4 & 13.0 & $12.48 \pm 2.78$ & 18 & \\
\hline \multicolumn{7}{|l|}{$\begin{array}{l}\text { Healthcare decision } \\
\text { sharing }\end{array}$} \\
\hline No & 60 & 4 & 12.5 & $11.93 \pm 3.80$ & 20 & 0.118 \\
\hline Yes & 235 & 5 & 13.0 & $12.76 \pm 2.76$ & 20 & \\
\hline \multicolumn{7}{|l|}{$\begin{array}{l}\text { Healthcare decision } \\
\text { sharing preference }\end{array}$} \\
\hline $\begin{array}{l}\text { Keep control in my } \\
\text { own Hand }\end{array}$ & 34 & 4 & 13.5 & $12.65 \pm 3.76$ & 20 & $0.017^{*}$ \\
\hline Have an equal partnership & 235 & 5 & 13.0 & $12.76 \pm 2.76$ & 20 & \\
\hline $\begin{array}{l}\text { Leave it in the doctor's } \\
\text { hands }\end{array}$ & 26 & 4 & 10.5 & $11.0 \pm 3.71$ & 17 & \\
\hline
\end{tabular}

Note: $(*)=p<0.05$. 
Table 4-13. Beliefs about Medicines Questionnaire-Harm (BMQ-Harm) scale scores of different sociodemographic subgroups $(n=298)$.

\begin{tabular}{|c|c|c|c|c|c|c|}
\hline \multirow[b]{2}{*}{ Characteristics } & \multicolumn{5}{|c|}{ BMQ-Harm score } & \multirow[b]{2}{*}{ p-Value } \\
\hline & $\mathbf{n}$ & Min & Median & Mean \pm SD & Max & \\
\hline \multicolumn{7}{|l|}{ Age } \\
\hline $50-60$ yrs. & 25 & 4 & 10.0 & $9.92 \pm 3.38$ & 17 & 0.062 \\
\hline $61-70$ yrs. & 115 & 4 & 9.0 & $9.35 \pm 2.91$ & 18 & \\
\hline $71-80$ yrs. & 98 & 4 & 8.0 & $8.71 \pm 2.62$ & 14 & \\
\hline$>80$ yrs & 55 & 4 & 8.0 & $8.45 \pm 2.79$ & 18 & \\
\hline \multicolumn{7}{|c|}{$\begin{array}{l}\text { Number of prescription } \\
\text { medications }\end{array}$} \\
\hline $0-1$ & 55 & 4 & 9.0 & $9.80 \pm 3.00$ & 18 & $0.038^{*}$ \\
\hline $2-4$ & 135 & 4 & 9.0 & $8.99 \pm 2.79$ & 17 & \\
\hline $5-7$ & 84 & 4 & 8.5 & $8.92 \pm 2.72$ & 17 & \\
\hline$\geq 8$ & 24 & 4 & 7.5 & $7.83 \pm 3.06$ & 16 & \\
\hline \multicolumn{7}{|l|}{ Sex } \\
\hline Male & 67 & 4 & 9.0 & $8.66 \pm 2.36$ & 13 & 0.177 \\
\hline Female & 230 & 4 & 9.0 & $9.13 \pm 2.99$ & 18 & \\
\hline \multicolumn{7}{|l|}{ Living Status } \\
\hline Alone & 131 & 4 & 9.0 & $9.02 \pm 2.94$ & 17 & 0.963 \\
\hline Not Alone & 163 & 4 & 9.0 & $9.03 \pm 2.84$ & 18 & \\
\hline \multicolumn{7}{|l|}{ Marital Status } \\
\hline Unmarried & 187 & 4 & 9.0 & $8.98 \pm 2.79$ & 17 & 0.756 \\
\hline Married & 110 & 4 & 9.0 & $9.09 \pm 3.00$ & 18 & \\
\hline \multicolumn{7}{|l|}{ Comorbidity Score } \\
\hline$\leq 1$ & 74 & 4 & 9.0 & $9.15 \pm 2.77$ & 18 & 0.673 \\
\hline$>1$ & 224 & 4 & 9.0 & $8.99 \pm 2.89$ & 18 & \\
\hline \multicolumn{7}{|l|}{ Race } \\
\hline Caucasians & 164 & 4 & 8.0 & $8.55 \pm 2.60$ & 16 & $0.014^{*}$ \\
\hline African Americans & 118 & 4 & 9.0 & $9.53 \pm 3.01$ & 18 & \\
\hline Hispanics & 6 & 4 & 9.0 & $9.17 \pm 4.96$ & 13 & \\
\hline Others & 9 & 5 & 11.0 & $10.44 \pm 2.46$ & 18 & \\
\hline
\end{tabular}


Table 4-13. Continued.

\begin{tabular}{|c|c|c|c|c|c|c|}
\hline \multirow[b]{2}{*}{ Characteristics } & \multicolumn{5}{|c|}{ BMQ-Harm score } & \multirow[b]{2}{*}{ p-Value } \\
\hline & $\mathbf{n}$ & Min & Median & Mean \pm SD & Max & \\
\hline \multicolumn{7}{|l|}{ Education } \\
\hline $\begin{array}{l}\leq \text { High school } \\
(1-12 \text { yrs. })\end{array}$ & 134 & 4 & 9.0 & $9.37 \pm 2.74$ & 18 & \multirow[t]{2}{*}{0.148} \\
\hline $\begin{array}{l}\text { College degree } \\
(13-16 \text { yrs.) }\end{array}$ & 124 & 4 & 9.0 & $8.81 \pm 2.93$ & 18 & \\
\hline $\begin{array}{l}\text { Post-graduate degree } \\
\text { ( } \geq 17 \text { yrs.) }\end{array}$ & 40 & 4 & 8.0 & $8.55 \pm 2.95$ & 16 & \\
\hline \multicolumn{7}{|l|}{ Health literacy } \\
\hline Marginal/limited & 76 & 4 & 9.5 & $9.51 \pm 3.00$ & 17 & \multirow[t]{2}{*}{0.115} \\
\hline Good & 198 & 4 & 8.5 & $8.90 \pm 2.83$ & 18 & \\
\hline \multicolumn{7}{|l|}{$\begin{array}{l}\text { Healthcare decision } \\
\text { sharing }\end{array}$} \\
\hline No & 62 & 4 & 9.0 & $9.52 \pm 3.43$ & 18 & \multirow[t]{2}{*}{0.185} \\
\hline Yes & 233 & 4 & 9.0 & $8.89 \pm 2.69$ & 18 & \\
\hline \multicolumn{7}{|l|}{$\begin{array}{l}\text { Healthcare decision } \\
\text { sharing preference }\end{array}$} \\
\hline $\begin{array}{l}\text { Keep control in my } \\
\text { own hand }\end{array}$ & 34 & 4 & 9.5 & $9.74 \pm 3.49$ & 18 & \multirow[t]{3}{*}{0.248} \\
\hline Have an equal partnership & 233 & 4 & 9.0 & $8.89 \pm 2.69$ & 18 & \\
\hline $\begin{array}{l}\text { Leave it in the doctor's } \\
\text { hands }\end{array}$ & 28 & 4 & 9.0 & $9.25 \pm 3.40$ & 16 & \\
\hline
\end{tabular}

Note: $(*)=p<0.05$. 
literacy, and health decision sharing preference groups were not significantly different $(\mathrm{p} \geq 0.05)$.

\subsection{The Hypertensive Study Sample Characteristics}

The number of participants who reported having hypertension was 226 (75.3\%). Out of this sample, 218 reported taking prescription medications for hypertension. The sociodemographic characteristics of the hypertensive study sample who reported taking antihypertensive medications are listed in Table 4-14. The mean age of this sample was 72 years, $76.6 \%$ of the study sample were female; $63.8 \%$ were unmarried; $54 \%$ had either some college or postgraduate degrees. The self-reported race of the sample was $55 \%$ Caucasians/white, $40 \%$ African Americans/black, 2\% Hispanics, and 3\% Others (i.e., Asians and Alaska Natives). Forty-four percent were living alone, while $56 \%$ were not. Finally, more than $90 \%$ of the participants were taking more than two prescription medications.

\subsection{Medication Adherence Levels among the Hypertensive Sample}

Adherence to antihypertensive medication regimens were categorized into three distinct categories based on Morisky Medication Adherence Scale (MMAS-8) scores. High medication adherence level is achieved when the MMAS-8 score is eight. However, medium and low adherence levels are achieved when the MMAS- 8 scores are between six and less than eight, and less than six, respectively (Krousel-Wood et al., 2009; Morisky et al., 2008; Morisky \& DiMatteo, 2011). The adherence levels to antihypertensive medication regimens among the hypertensive sample across the seven senior centers are listed in Table 4-15. The proportion of the sample with high, medium, and low adherence levels to their antihypertensive medication regime was $49 \%, 30 \%$, and $21 \%$, respectively. Further, the hypertensive participants were categorized into adherent and non-adherent based on their MMAS-8 scores. If the MMAS-8 score is eight, then participant was considered adherent to his/her antihypertensive medication regimen, however, if the MMAS- 8 score is less than eight, then the participant was considered non-adherent to his/her antihypertensive medication regimen (Wong et al., 2014). The adherence levels across the different sociodemographic and medical groups are listed in Table 4-16. The proportion of adherent participants among the hypertensive sample significantly increased as their age increased $(p<0.001)$. The majority of the participants aged 71 years and above were adherent to their antihypertensive medication regimens (i.e., $>60 \%$ ); however, less than $33 \%$ of the participants aged 70 years and less were adherent. In addition, the proportion of adherent participants among the Caucasians was significantly higher than the non-adherent participants $(\mathrm{p}=0.021)$. Further, most of the Caucasians/white participants were adherent to their antihypertensive medication regimens (i.e., 58\%) in comparison to $40 \%$ of the African Americans, $20 \%$ of Hispanics, and $29 \%$ of other racial subgroups (i.e., Asians and Alaska Natives). Finally, the proportions of adherent participants were not significantly different across the remaining sociodemographic and medical subgroups $(\mathrm{p} \geq 0.05)$. 
Table 4-14. Baseline characteristics of the hypertensive participants $(n=218)$.

\begin{tabular}{|c|c|c|c|c|c|c|c|c|c|}
\hline \multirow[b]{2}{*}{ Characteristics } & \multicolumn{7}{|c|}{ Senior centers } & \multirow[b]{2}{*}{$\begin{array}{c}\text { Total } \\
(n=218)\end{array}$} & \multirow[b]{2}{*}{ p-Value } \\
\hline & $\begin{array}{c}\text { Frayser- } \\
\text { Raleigh } \\
(\mathrm{n}=\mathbf{3 6})\end{array}$ & $\begin{array}{c}\text { Orange- } \\
\text { Mound } \\
(n=71)\end{array}$ & $\begin{array}{c}\text { Arlington } \\
(n=24)\end{array}$ & $\begin{array}{c}\text { Bartlett } \\
(n=33)\end{array}$ & $\begin{array}{c}\text { Bert } \\
\text { Ferguson } \\
(n=14)\end{array}$ & $\begin{array}{c}\text { McWherter } \\
(n=28)\end{array}$ & $\begin{array}{l}\text { Somerville } \\
(n=12)\end{array}$ & & \\
\hline $\begin{array}{l}\text { Age-yrs. } \\
\text { (Mean } \pm \text { SD) } \\
\text { Sex }\end{array}$ & $76.25 \pm 8.35$ & $69.43 \pm 8.51$ & $73.13 \pm 7.76$ & $72.13 \pm 7.32$ & $75.38 \pm 7.25$ & $72.96 \pm 10.68$ & $70.17 \pm 6.59$ & $72.25 \pm 8.65$ & $0.005^{*}$ \\
\hline Female & $25(69.4 \%)$ & $56(78.9 \%)$ & $15(62.5 \%)$ & $29(87.9 \%)$ & $13(92.9 \%)$ & $20(71.4 \%)$ & $9(75 \%)$ & $167(76.6 \%)$ & 0.188 \\
\hline Male & $11(30.6 \%)$ & $15(21.1 \%)$ & $9(37.5 \%)$ & $4(12.1 \%)$ & $1(7.1 \%)$ & $8(28.6 \%)$ & $3(25 \%)$ & $51(23.4 \%)$ & \\
\hline Marital status & & & & & & & & & \\
\hline Married & $13(36.1 \%)$ & $16(22.5 \%)$ & $16(66.7 \%)$ & $12(36.4 \%)$ & $7(50 \%)$ & $10(35.7 \%)$ & $5(41.7 \%)$ & $79(36.2 \%)$ & $0.010^{*}$ \\
\hline $\begin{array}{l}\text { Unmarried } \\
\text { Education }\end{array}$ & $23(63.9 \%)$ & $55(77.5 \%)$ & $8(33.3 \%)$ & $21(63.6 \%)$ & $7(50 \%)$ & $18(64.3 \%)$ & $7(58.3 \%)$ & $139(63.8 \%)$ & \\
\hline $\begin{array}{l}\leq \text { High school } \\
\text { (1-12 yrs.) }\end{array}$ & $17(47.2 \%)$ & $35(49.3 \%)$ & $13(54.2 \%)$ & $16(48.5 \%)$ & $2(14.3 \%)$ & $9(32.1 \%)$ & $9(75 \%)$ & $101(46.3 \%)$ & 0.075 \\
\hline $\begin{array}{l}\text { Some college } \\
\text { degree } \\
(13-16 \text { yrs.) }\end{array}$ & $15(41.7 \%)$ & $30(42.3 \%)$ & $9(37.5 \%)$ & $12(36.4 \%)$ & $7(50 \%)$ & $16(57.1 \%)$ & $3(25 \%)$ & $92(42.2 \%)$ & \\
\hline $\begin{array}{l}\text { Post-graduate } \\
\text { degree } \\
(\geq 17 \text { yrs.) }\end{array}$ & $4(11.1 \%)$ & $6(8.5 \%)$ & $2(8.3 \%)$ & $5(15.2 \%)$ & $5(35.7 \%)$ & $3(10.7 \%)$ & $0(0 \%)$ & $25(11.5 \%)$ & \\
\hline Race & & & & & & & & & \\
\hline Caucasians & $29(80.6 \%)$ & $0(0 \%)$ & $24(100 \%)$ & $29(87.9 \%)$ & $14(100 \%)$ & $21(75 \%)$ & $2(16.7 \%)$ & $119(54.6 \%)$ & $<0.001 *$ \\
\hline $\begin{array}{l}\text { African } \\
\text { Americans }\end{array}$ & $5(13.9 \%)$ & $66(92.9 \%)$ & $0(0 \%)$ & $0(0 \%)$ & $0(0 \%)$ & $6(21.4 \%)$ & $10(83.3 \%)$ & $87(39.9 \%)$ & \\
\hline Hispanics & $1(2.8 \%)$ & $2(2.8 \%)$ & $0(0 \%)$ & $1(3 \%)$ & $0(0 \%)$ & $1(3.6 \%)$ & $0(0 \%)$ & $5(2.3 \%)$ & \\
\hline Others & $1(2.8 \%)$ & $3(4.2 \%)$ & $0(0 \%)$ & $3(9.1 \%)$ & $0(0 \%)$ & $0(0 \%)$ & $0(0 \%)$ & $7(3.2 \%)$ & \\
\hline Living status & & & & & & & & & \\
\hline Alone & $20(55.6 \%)$ & $31(44.3 \%)$ & $4(16.7 \%)$ & $16(48.5 \%)$ & $6(42.9 \%)$ & $13(48.1 \%)$ & $5(41.7 \%)$ & $95(43.98 \%)$ & 0.136 \\
\hline Not alone & $16(44.4 \%)$ & $39(55.7 \%)$ & $20(83.3 \%)$ & $17(51.5 \%)$ & $8(57.1 \%)$ & $14(51.9 \%)$ & $7(58.3 \%)$ & $121(56.02 \%)$ & \\
\hline
\end{tabular}


Table 4-14. Continued.

\begin{tabular}{|c|c|c|c|c|c|c|c|c|c|}
\hline \multirow[b]{2}{*}{ Characteristics } & \multicolumn{7}{|c|}{ Senior centers } & \multirow[b]{2}{*}{$\begin{array}{c}\text { Total } \\
(n=218)\end{array}$} & \multirow[b]{2}{*}{ p-Value } \\
\hline & $\begin{array}{c}\text { Frayser- } \\
\text { Raleigh } \\
(\mathrm{n}=\mathbf{3 6})\end{array}$ & $\begin{array}{l}\text { Orange- } \\
\text { Mound } \\
(\mathrm{n}=71)\end{array}$ & $\begin{array}{c}\text { Arlington } \\
(\mathrm{n}=24)\end{array}$ & $\begin{array}{c}\text { Bartlett } \\
(\mathrm{n}=\mathbf{3 3})\end{array}$ & $\begin{array}{c}\text { Bert } \\
\text { Ferguson } \\
(n=14)\end{array}$ & $\begin{array}{c}\text { McWherter } \\
(\mathrm{n}=\mathbf{2 8})\end{array}$ & $\begin{array}{c}\text { Somerville } \\
(\mathrm{n}=12)\end{array}$ & & \\
\hline \multicolumn{10}{|l|}{$\begin{array}{l}\text { Number of } \\
\text { prescription } \\
\text { medications }\end{array}$} \\
\hline $0-1$ & $4(11.1 \%)$ & $8(11.3 \%)$ & $0(0 \%)$ & $0(0 \%)$ & $1(7.1 \%)$ & $3(10.7 \%)$ & $1(8.3 \%)$ & $17(7.8 \%)$ & 0.116 \\
\hline $2-4$ & $13(36.1 \%)$ & $38(53.5 \%)$ & $14(58.3 \%)$ & $13(39.4 \%)$ & $10(71.4 \%)$ & $12(42.9 \%)$ & $4(33.3 \%)$ & $104(47.7 \%)$ & \\
\hline $5-7$ & $15(41.7 \%)$ & $20(28.2 \%)$ & $7(29.2 \%)$ & $17(51.5 \%)$ & $3(21.4 \%)$ & $10(35.7 \%)$ & $3(25 \%)$ & $75(34.4 \%)$ & \\
\hline$\geq 8$ & $4(11.1 \%)$ & $5(7.0 \%)$ & $3(12.5 \%)$ & $3(9.1 \%)$ & $0(0 \%)$ & $3(10.7 \%)$ & $4(33.3 \%)$ & $22(10.1 \%)$ & \\
\hline
\end{tabular}

Note: $(*)=p<0.05$. 
Table 4-15. Morisky Medication Adherence Scale (MMAS-8) levels among the hypertensive sample (n=218).

\begin{tabular}{|c|c|c|c|c|c|c|c|c|c|}
\hline \multirow[b]{2}{*}{$\begin{array}{l}\text { Adherence } \\
\text { level }\end{array}$} & \multicolumn{7}{|c|}{ Senior centers } & \multirow[b]{2}{*}{$\begin{array}{c}\text { Total } \\
(n=218)\end{array}$} & \multirow[b]{2}{*}{ p-Value } \\
\hline & $\begin{array}{c}\text { Frayser- } \\
\text { Raleigh } \\
(\mathbf{n}=\mathbf{3 6})\end{array}$ & $\begin{array}{l}\text { Orange- } \\
\text { Mound } \\
(n=71)\end{array}$ & $\begin{array}{c}\text { Arlington } \\
(n=24)\end{array}$ & $\begin{array}{c}\text { Bartlett } \\
(n=33)\end{array}$ & $\begin{array}{c}\text { Bert } \\
\text { Ferguson } \\
(n=14)\end{array}$ & $\begin{array}{c}\text { McWherter } \\
(n=28)\end{array}$ & $\begin{array}{c}\text { Somerville } \\
(n=12)\end{array}$ & & \\
\hline $\begin{array}{l}\text { High } \\
(\text { MMAS-8 } \\
\text { score }=8)\end{array}$ & $21(58.3 \%)$ & $28(39.4 \%)$ & $10(41.7 \%)$ & $20(60.6 \%)$ & $9(64.3 \%)$ & $12(42.9 \%)$ & $7(58.3 \%)$ & $107(49.1 \%)$ & $0.005^{*}$ \\
\hline $\begin{array}{l}\text { Medium } \\
(\text { MMAS-8 } \\
\text { score }=6-<8)\end{array}$ & $10(27.8 \%)$ & $21(29.6 \%)$ & $9(37.5 \%)$ & $10(30.3 \%)$ & $5(35.7 \%)$ & $7(25 \%)$ & $4(33.3 \%)$ & $66(30.3 \%)$ & \\
\hline $\begin{array}{l}\text { Low } \\
(\text { MMAS-8 } \\
\text { score }<6)\end{array}$ & $5(13.9 \%)$ & $22(31.0 \%)$ & $5(20.8 \%)$ & $3(9.1 \%)$ & $0(0 \%)$ & $9(32.14 \%)$ & $1(8.3 \%)$ & $45(20.6 \%)$ & \\
\hline
\end{tabular}

Note: $(*)=\mathrm{p}<0.05$. 
Table 4-16. Morisky Medication Adherence Scale (MMAS-8) levels across the hypertensive subgroups.

\begin{tabular}{|c|c|c|c|}
\hline Characteristics & $\begin{array}{c}\text { Non-adherent } \\
\text { (MMAS-8<8) } \\
\text { (n) }\end{array}$ & $\begin{array}{c}\text { Adherent } \\
\text { (MMAS-8 =8) } \\
\text { (n) }\end{array}$ & p-Value \\
\hline \multicolumn{4}{|l|}{ Age } \\
\hline $50-60$ yrs. & $13(72.2 \%)$ & $5(27.8 \%)$ & \multirow[t]{4}{*}{$<0.001^{*}$} \\
\hline $61-70$ yrs. & $55(66.3 \%)$ & $28(33.7 \%)$ & \\
\hline 71-80 yrs. & $28(38.4 \%)$ & $45(61.6 \%)$ & \\
\hline$>80$ yrs. & $12(29.3 \%)$ & $29(70.7 \%)$ & \\
\hline \multicolumn{4}{|c|}{$\begin{array}{l}\text { Number of prescription } \\
\text { medications }\end{array}$} \\
\hline $0-1$ & $8(47.1 \%)$ & $9(52.9 \%)$ & \multirow[t]{4}{*}{0.951} \\
\hline $2-4$ & $55(52.9 \%)$ & $49(47.1 \%)$ & \\
\hline $5-7$ & $37(49.3 \%)$ & $38(50.7 \%)$ & \\
\hline$\geq 8$ & $11(50 \%)$ & $11(50 \%)$ & \\
\hline \multicolumn{4}{|l|}{ Sex } \\
\hline Male & $29(56.9 \%)$ & $22(43.1 \%)$ & \multirow[t]{2}{*}{0.331} \\
\hline Female & $82(49.1 \%)$ & $85(50.9 \%)$ & \\
\hline \multicolumn{4}{|l|}{ Living status } \\
\hline Alone & $51(53.7 \%)$ & $44(46.3 \%)$ & \multirow[t]{2}{*}{0.401} \\
\hline Not alone & $58(47.9 \%)$ & $63(52.1 \%)$ & \\
\hline \multicolumn{4}{|l|}{ Marital status } \\
\hline Unmarried & $72(51.8 \%)$ & $67(48.2 \%)$ & \multirow[t]{2}{*}{0.729} \\
\hline Married & $39(49.4 \%)$ & $40(50.6 \%)$ & \\
\hline \multicolumn{4}{|c|}{ Comorbidity score } \\
\hline$\leq 1$ & $11(39.3 \%)$ & $17(60.7 \%)$ & \multirow[t]{2}{*}{0.187} \\
\hline$>1$ & $100(52.6 \%)$ & $90(47.4 \%)$ & \\
\hline \multicolumn{4}{|l|}{ Health literacy } \\
\hline Marginal/limited & $29(61.7 \%)$ & $18(38.3 \%)$ & \multirow[t]{2}{*}{0.065} \\
\hline Good & $68(46.3 \%)$ & $79(53.7 \%)$ & \\
\hline
\end{tabular}


Table 4-16. Continued.

\begin{tabular}{|c|c|c|c|}
\hline Characteristics & $\begin{array}{c}\text { Non-adherent } \\
\text { (MMAS-8<8) } \\
\text { (n) }\end{array}$ & $\begin{array}{c}\text { Adherent } \\
\text { (MMAS-8 =8) } \\
\text { (n) }\end{array}$ & p-Value \\
\hline \multicolumn{4}{|l|}{$\begin{array}{l}\text { Healthcare decision } \\
\text { sharing }\end{array}$} \\
\hline $\begin{array}{l}\text { No } \\
\text { Yes }\end{array}$ & $\begin{array}{c}22(50 \%) \\
89(51.45 \%)\end{array}$ & $\begin{array}{c}22(50 \%) \\
84(48.55 \%)\end{array}$ & 0.864 \\
\hline $\begin{array}{l}\text { Education } \\
\leq \text { High school (1-12 yrs.) }\end{array}$ & $53(52.5 \%)$ & $48(47.5 \%)$ & 0.509 \\
\hline College degree (13-16 yrs.) & $48(52.2 \%)$ & $44(47.8 \%)$ & \\
\hline Post-graduate degree ( $\geq 17$ yrs.) & $10(40 \%)$ & $15(60 \%)$ & \\
\hline \multicolumn{4}{|l|}{ Race } \\
\hline Caucasians & $50(42.02 \%)$ & $69(57.9 \%)$ & $0.021 *$ \\
\hline African Americans & $52(59.8 \%)$ & $35(40.2 \%)$ & \\
\hline Hispanics & $4(80 \%)$ & $1(20 \%)$ & \\
\hline Others & $5(71.4 \%)$ & $2(28.6 \%)$ & \\
\hline \multicolumn{4}{|l|}{$\begin{array}{l}\text { Healthcare decision sharing } \\
\text { preference }\end{array}$} \\
\hline Keep control in my own hand & $12(52.2 \%)$ & $11(47.8 \%)$ & 0.941 \\
\hline Have an equal partnership & $89(51.45 \%)$ & $84(48.55 \%)$ & \\
\hline Leave it in the doctor's hands & $10(47.6 \%)$ & $11(52.4 \%)$ & \\
\hline \multicolumn{4}{|l|}{$\begin{array}{l}\text { Satisfaction with the } \\
\text { antihypertensive regimen }\end{array}$} \\
\hline Dissatisfied & $1(100 \%)$ & $0(0 \%)$ & 0.100 \\
\hline Not satisfied & $2(100 \%)$ & $0(0 \%)$ & \\
\hline Somewhat satisfied & $9(75 \%)$ & $3(25 \%)$ & \\
\hline Satisfied & $35(54.7 \%)$ & $29(45.3 \%)$ & \\
\hline Very satisfied & $62(45.3 \%)$ & $75(54.7 \%)$ & \\
\hline
\end{tabular}

Note: $\left.{ }^{*}\right)=p<0.05$. 


\subsection{Participant Rating of Antihypertensive Medication Regimens}

The hypertensive participants were asked to rate their satisfaction with each antihypertensive medication they reported taking on a 5-point Likert scale (i.e., 1-low to 5-high) in terms of their side effects, effectiveness, ease of use, cost of medication, and food interactions. Further, participants were asked to provide an overall rating of each antihypertensive medication. Then, participant-specific satisfaction with the overall antihypertensive medication regimen was calculated by taking the mean score of each rated aspect of medication use (i.e., side effects, effectiveness, etc...) for every hypertensive participant. The number of study participants who rated their antihypertensive medications was 193 participants. The participant-specific mean scores of each rated medication use aspect for the antihypertensive medication regimen across the seven senior centers are listed in Table 4-17.

Table 4-18 presents the correlation matrix of the rated aspects of medication use. All of the rated medication use aspects for the antihypertensive medication regimens were positively and significantly correlated with each other $(\mathrm{p}<0.05)$. Further, the instrument's internal consistency (i.e., Cronbach's alpha) was measured and found to be adequate (i.e., $\alpha=0.82$ ). In addition, the medication-specific average rating of the antihypertensive medications that were rated by ten or more hypertensive participants are listed in Table 4.19. Ten or more participants rated the following antihypertensive medications: Atenolol, Amlodipine, Hydrochlorothiazide (HCTZ), Lisinopril, Losartan, Metoprolol, and Valsartan. All of the rated antihypertensive medications had high rating scores; however, they slightly differ (Figure 4-2). For example, Losartan had the highest effectiveness rating among the other rated antihypertensive medications, and Valsartan had the lowest rating (Figure 4-3). Likewise, Losartan had the highest rating in terms of medication ease of use, and amlodipine had the lowest rating (Figure 4-4). With regard to medication cost, Hydrochlorothiazide (HCTZ) had the highest rating, whereas, Amlodipine had the lowest rating (Figure 4-5). Similarly, HCTZ had the highest rating in terms of medication food interactions, and Atenolol had the lowest rating (Figure 4-6); while HCTZ had the highest rating in terms of medication side effects, and Lisinopril had the lowest rating (Figure 4-7). Finally, Lisinopril had the highest overall rating, whereas, Valsartan had the lowest rating (Figure 4-8).

\subsection{Pearson Correlation Coefficients between Participant-Reported Outcomes} (PROs)

The Pearson correlation coefficients between the Patient Reviews of Medication Experiences (PROMEX) and the Primacy Care Assessment Survey (PCAS) communication and interpersonal treatment scales, Beliefs about Medicines Questionnaire (BMQ) general harm and overuse scales, the Mental and Physical Component Summaries (MCS-12 and PCS-12) of the Short Form Health Questionnaire (SF-12v2), and the Morisky Medication Adherence Scale (MMAS-8) for hypertensive participants are listed in Table 4-20. PROMEX was not associated with any of the participant-reported outcomes ( $\mathrm{p} \geq 0.05$ ). The PCAS-Communication and 
Table 4-17. Participants' evaluations of their antihypertensive medications ( $n=193)$.

\begin{tabular}{|c|c|c|c|c|c|c|c|c|c|}
\hline \multirow[b]{2}{*}{$\begin{array}{l}\text { Medication } \\
\text { use aspect }\end{array}$} & \multicolumn{7}{|c|}{ Senior centers } & \multirow[b]{2}{*}{$\begin{array}{c}\text { Total } \\
(n=193)\end{array}$} & \multirow[b]{2}{*}{ p-Value } \\
\hline & $\begin{array}{c}\text { Frayser- } \\
\text { Raleigh } \\
(\mathrm{n}=\mathbf{3 3})\end{array}$ & $\begin{array}{l}\text { Orange- } \\
\text { Mound } \\
(\mathrm{n}=59)\end{array}$ & $\begin{array}{c}\text { Arlington } \\
(n=21)\end{array}$ & $\begin{array}{c}\text { Bartlett } \\
(n=34)\end{array}$ & $\begin{array}{c}\text { Bert } \\
\text { Ferguson } \\
(n=13)\end{array}$ & $\begin{array}{c}\text { McWherter } \\
(n=26)\end{array}$ & $\begin{array}{c}\text { Somerville } \\
(n=7)\end{array}$ & & \\
\hline Effectiveness & $4.43 \pm 0.82$ & $4.15 \pm 1.18$ & $4.78 \pm 0.41$ & $4.57 \pm 0.70$ & $4.38 \pm 0.87$ & $4.32 \pm 0.81$ & $4.70 \pm 0.67$ & $4.40 \pm 0.91$ & 0.073 \\
\hline Side effects & $3.43 \pm 1.54$ & $2.98 \pm 1.65$ & $2.95 \pm 1.88$ & $4.15 \pm 1.42$ & $3.86 \pm 1.61$ & $3.01 \pm 1.73$ & $3.63 \pm 1.77$ & $3.33 \pm 1.67$ & $0.025 *$ \\
\hline Ease of use & $4.44 \pm 1.06$ & $4.27 \pm 1.13$ & $4.84 \pm 0.47$ & $4.57 \pm 0.85$ & $4.69 \pm 0.63$ & $4.62 \pm 0.92$ & $4.75 \pm 0.46$ & $4.51 \pm 0.95$ & 0.217 \\
\hline Cost & $4.32 \pm 1.07$ & $3.82 \pm 1.34$ & $4.23 \pm 1.20$ & $4.17 \pm 1.16$ & $4.26 \pm 1.04$ & $4.02 \pm 1.47$ & $3.25 \pm 1.98$ & $4.04 \pm 1.29$ & 0.269 \\
\hline $\begin{array}{l}\text { Food } \\
\text { interaction }\end{array}$ & $4.09 \pm 1.39$ & $3.81 \pm 1.48$ & $3.82 \pm 1.56$ & $4.15 \pm 1.39$ & $4.03 \pm 1.32$ & $3.69 \pm 1.74$ & $4.00 \pm 1.41$ & $3.93 \pm 1.47$ & 0.880 \\
\hline Overall & $4.49 \pm 0.83$ & $4.27 \pm 1.01$ & $4.77 \pm 0.40$ & $4.59 \pm 0.88$ & $4.69 \pm 0.63$ & $4.46 \pm 0.86$ & $4.71 \pm 0.49$ & $4.49 \pm 0.86$ & 0.255 \\
\hline
\end{tabular}

Notes: Participants were asked to evaluate each aspect of their antihypertensive medication regimens in a scale from one to five. The higher the score, the more satisfied the participants are with their medications. $\left(^{*}\right)=p<0.05$. 
Table 4-18. Pearson correlation coefficients between the participants' rated antihypertensive medication use aspects and their p-values $(n=193)$.

\begin{tabular}{|c|c|c|c|c|c|c|c|}
\hline $\begin{array}{l}\text { Medication use } \\
\text { aspect }\end{array}$ & Effectiveness & $\begin{array}{c}\text { Side } \\
\text { effects }\end{array}$ & $\begin{array}{c}\text { Ease of } \\
\text { use }\end{array}$ & $\begin{array}{c}\text { Cost of } \\
\text { medication }\end{array}$ & $\begin{array}{c}\text { Food } \\
\text { interactions }\end{array}$ & $\begin{array}{c}\text { Overall } \\
\text { rating }\end{array}$ & $\begin{array}{c}\text { Total } \\
\text { correlation }\end{array}$ \\
\hline \multirow[t]{2}{*}{ Effectiveness } & 1.00 & 0.251 & 0.589 & 0.408 & 0.249 & 0.591 & 0.603 \\
\hline & & $0.001 *$ & $<0.001^{*}$ & $<0.001 *$ & $0.001 *$ & $<0.001 *$ & \\
\hline \multirow[t]{2}{*}{ Side effects } & 0.251 & 1.00 & 0.290 & 0.363 & 0.564 & 0.349 & 0.405 \\
\hline & $0.001 *$ & & $<0.001 *$ & $<0.001 *$ & $<0.001 *$ & $<0.001 *$ & \\
\hline \multirow[t]{2}{*}{ Ease of use } & 0.589 & 0.290 & 1.00 & 0.460 & 0.447 & 0.571 & 0.649 \\
\hline & $<0.001 *$ & $<0.001 *$ & & $<0.001 *$ & $<0.001^{*}$ & $<0.001 *$ & \\
\hline \multirow{2}{*}{$\begin{array}{l}\text { Cost of } \\
\text { medication }\end{array}$} & 0.408 & 0.363 & 0.460 & 1.00 & 0.514 & 0.498 & 0.610 \\
\hline & $<0.001 *$ & $<0.001 *$ & $<0.001^{*}$ & & $<0.001^{*}$ & $<0.001 *$ & \\
\hline \multirow[t]{2}{*}{ Food interactions } & 0.249 & 0.564 & 0.447 & 0.514 & 1.00 & 0.408 & 0.575 \\
\hline & $0.001 *$ & $<0.001 *$ & $<0.001 *$ & $<0.001 *$ & & $<0.001 *$ & \\
\hline \multirow[t]{2}{*}{ Overall rating } & 0.591 & 0.349 & 0.571 & 0.498 & 0.408 & 1.00 & 0.669 \\
\hline & $<0.001 *$ & $<0.001 *$ & $<0.001 *$ & $<0.001^{*}$ & $<0.001 *$ & & \\
\hline
\end{tabular}

Note: $(*)=\mathrm{p}<0.05$. 
Table 4-19. Antihypertensive medication rating (medication-specific) $(n=148)$.

\begin{tabular}{|c|c|c|c|c|c|c|c|c|c|c|c|c|}
\hline \multirow[b]{2}{*}{$\begin{array}{l}\text { Medication } \\
\text { name }\end{array}$} & \multicolumn{2}{|c|}{ Effectiveness } & \multicolumn{2}{|c|}{ Ease of use } & \multicolumn{2}{|c|}{$\begin{array}{c}\text { Cost of } \\
\text { medication }\end{array}$} & \multicolumn{2}{|c|}{$\begin{array}{c}\text { Food } \\
\text { interaction }\end{array}$} & \multicolumn{2}{|c|}{ Side effects } & \multicolumn{2}{|r|}{ Overall } \\
\hline & $\mathbf{n}$ & Mean \pm SD & $\mathbf{n}$ & Mean \pm SD & n & Mean \pm SD & n & Mean \pm SD & $\mathbf{n}$ & Mean \pm SD & n & Mean \pm SD \\
\hline Atenolol & 14 & $4.58 \pm 0.67$ & 10 & $4.55 \pm 0.70$ & 10 & $4.36 \pm 0.84$ & 10 & $3.64 \pm 1.66$ & 9 & $3.40 \pm 1.66$ & 10 & $4.55 \pm 0.70$ \\
\hline Amlodipine & 35 & $4.31 \pm 0.72$ & 34 & $4.41 \pm 1.08$ & 32 & $3.91 \pm 1.30$ & 33 & $3.88 \pm 1.52$ & 34 & $2.94 \pm 1.86$ & 32 & $4.50 \pm 0.76$ \\
\hline $\begin{array}{l}\text { Hydro- } \\
\text { chlorothiazide } \\
\text { (HCTZ) }\end{array}$ & 14 & $4.85 \pm 0.29$ & 12 & $4.92 \pm 0.29$ & 12 & $4.92 \pm 0.29$ & 12 & $4.85 \pm 0.39$ & 12 & $4.08 \pm 1.15$ & 12 & $4.77 \pm 0.39$ \\
\hline Lisinopril & 35 & $4.56 \pm 0.84$ & 28 & $4.77 \pm 0.65$ & 28 & $4.27 \pm 1.12$ & 28 & $3.93 \pm 1.52$ & 29 & $2.81 \pm 1.80$ & 27 & $4.79 \pm 0.40$ \\
\hline Losartan & 14 & $5.00 \pm 0.00$ & 13 & $5.00 \pm 0.00$ & 13 & $4.50 \pm 1.33$ & 12 & $4.15 \pm 1.68$ & 13 & $3.86 \pm 1.79$ & 13 & $4.71 \pm 1.11$ \\
\hline Metoprolol & 26 & $4.76 \pm 0.45$ & 24 & $4.69 \pm 0.87$ & 23 & $4.32 \pm 0.99$ & 22 & $3.83 \pm 1.69$ & 23 & $3.44 \pm 1.78$ & 23 & $4.44 \pm 0.99$ \\
\hline Valsartan & 10 & $4.11 \pm 0.82$ & 10 & $4.88 \pm 0.41$ & 10 & $4.56 \pm 0.76$ & 10 & $4.14 \pm 1.74$ & 10 & $3.14 \pm 1.99$ & 10 & $4.38 \pm 0.82$ \\
\hline
\end{tabular}


Effectiveness $\square$ Ease of Use $\square$ Side Effects $\square$ Cost of Medication $\square$ Food Interaction $\varpi$ Overall

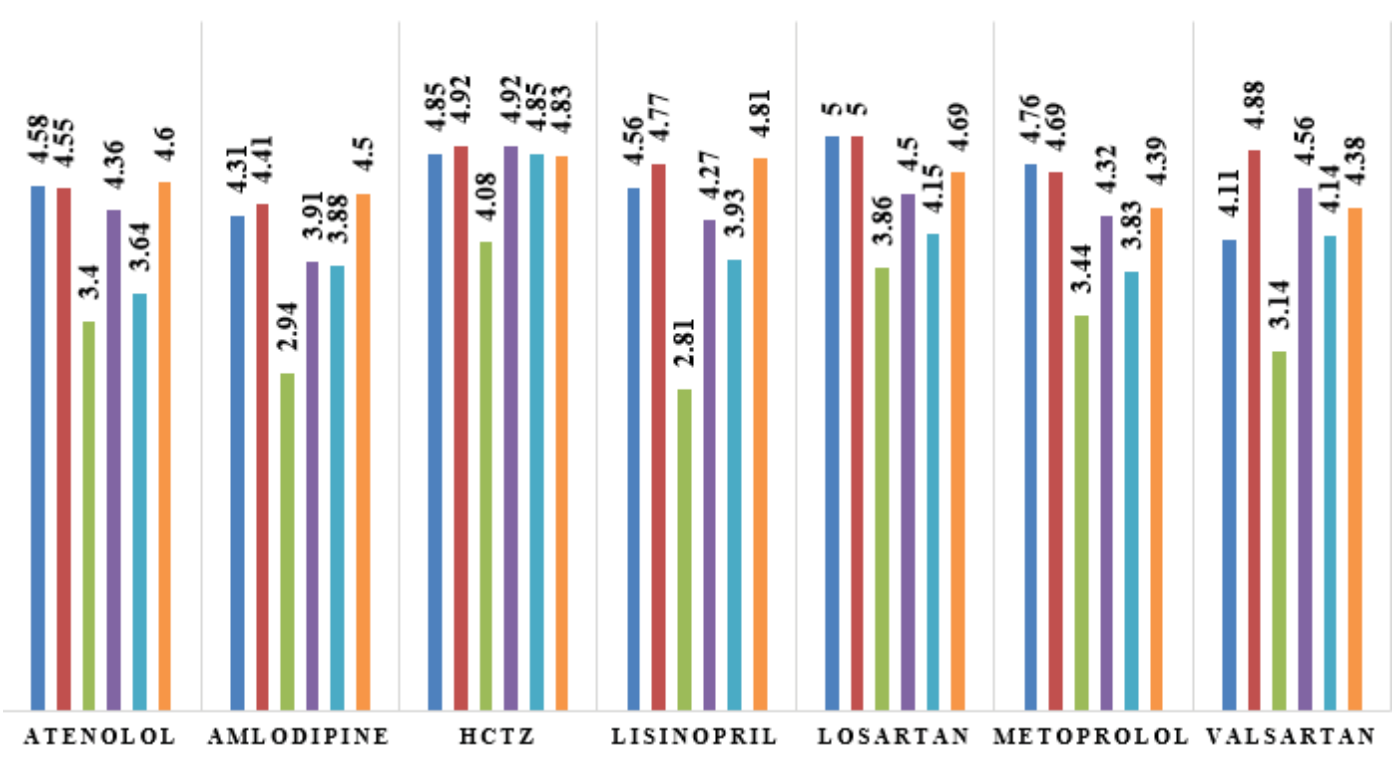

Figure 4-2. Antihypertensive medication ratings. 


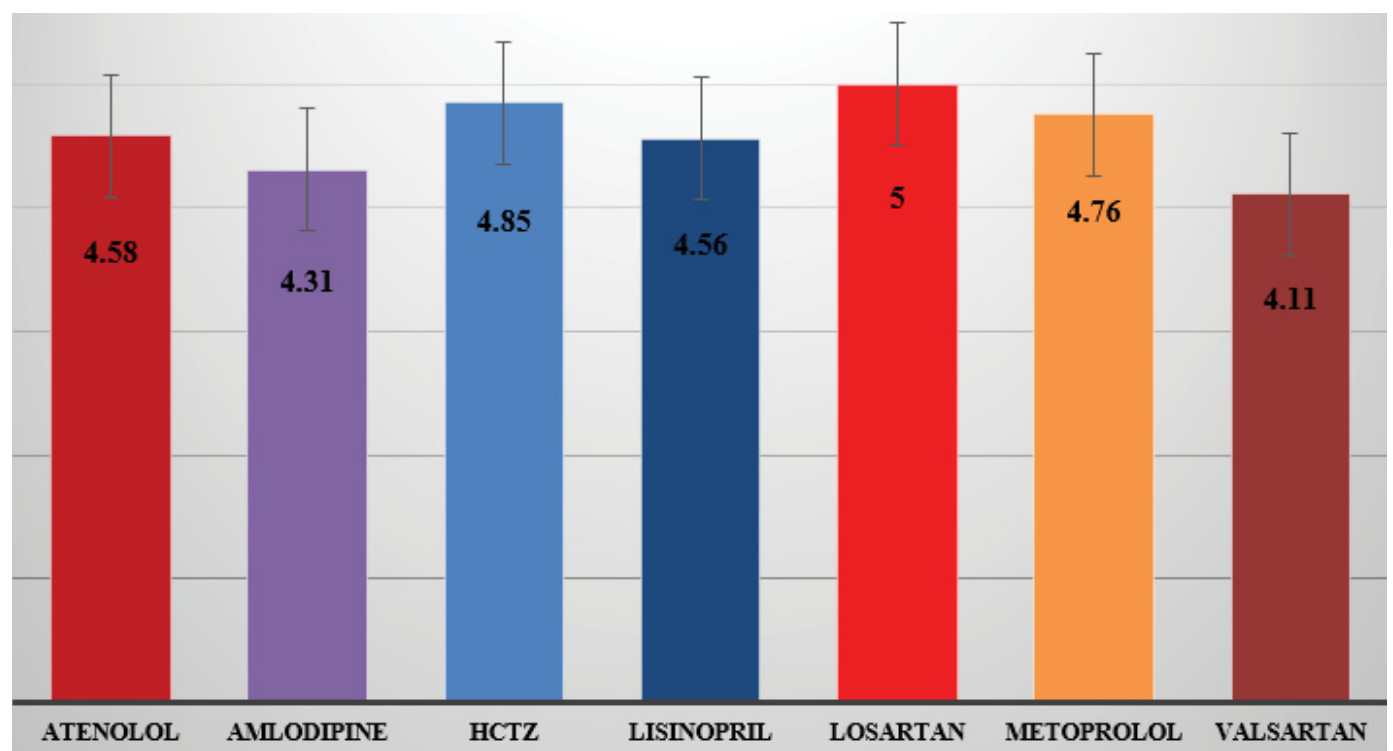

Figure 4-3. Rating of antihypertensive medications' effectiveness. 


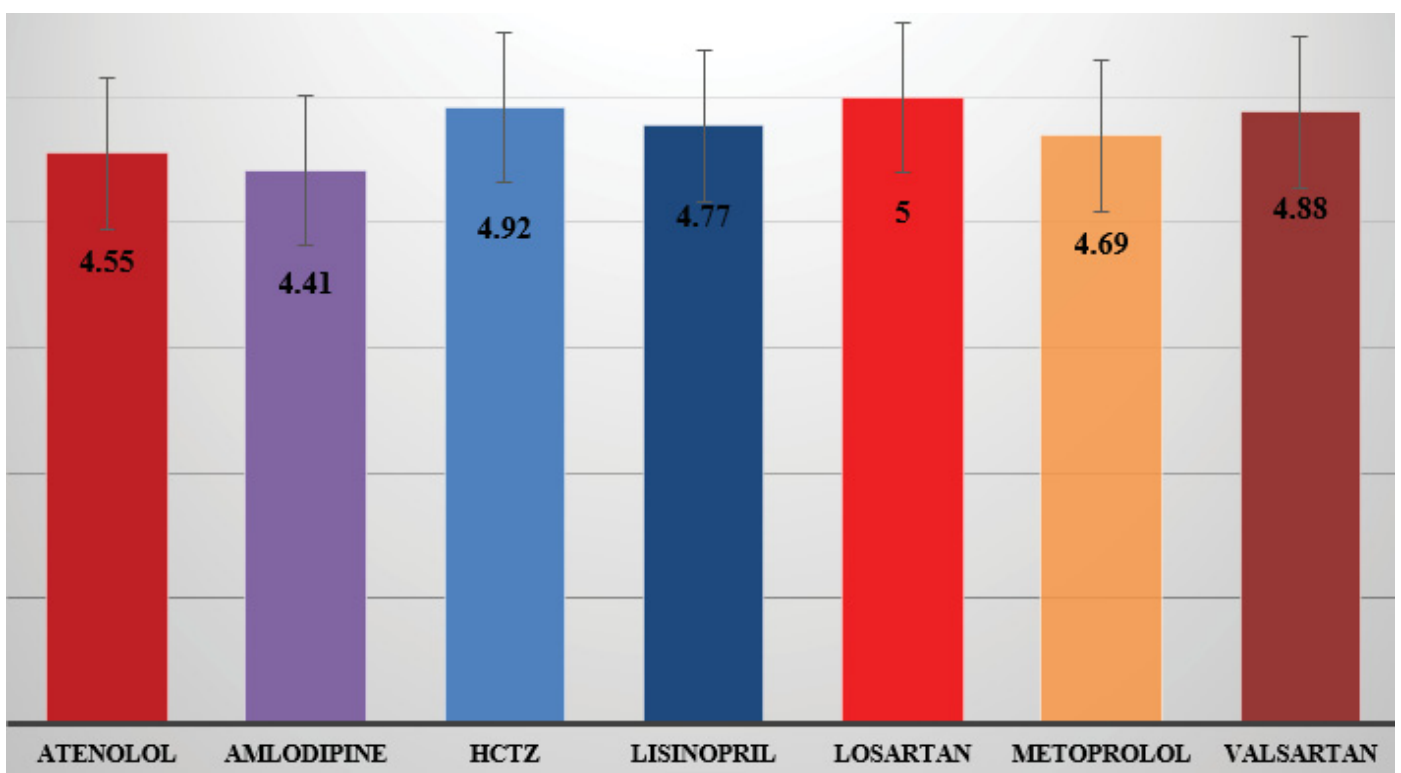

Figure 4-4. Rating of antihypertensive medications' ease of use. 


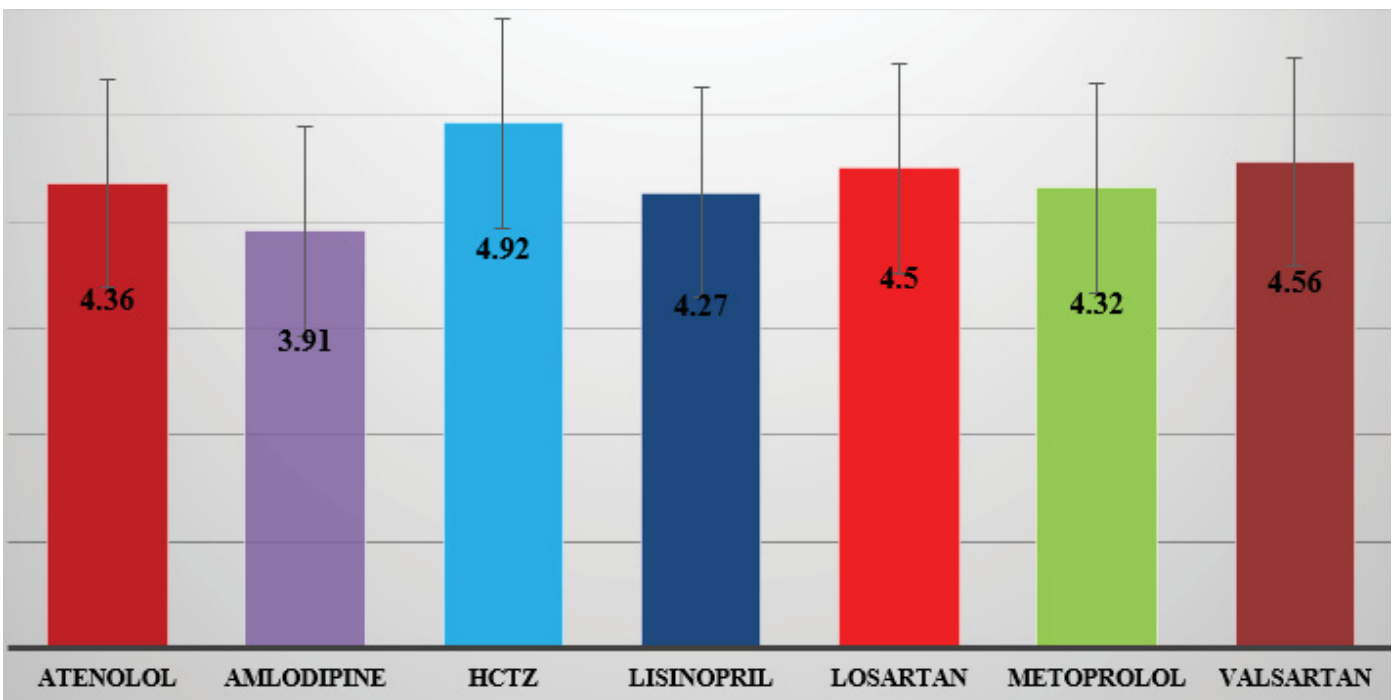

Figure 4-5. Rating of antihypertensive medications' cost. 


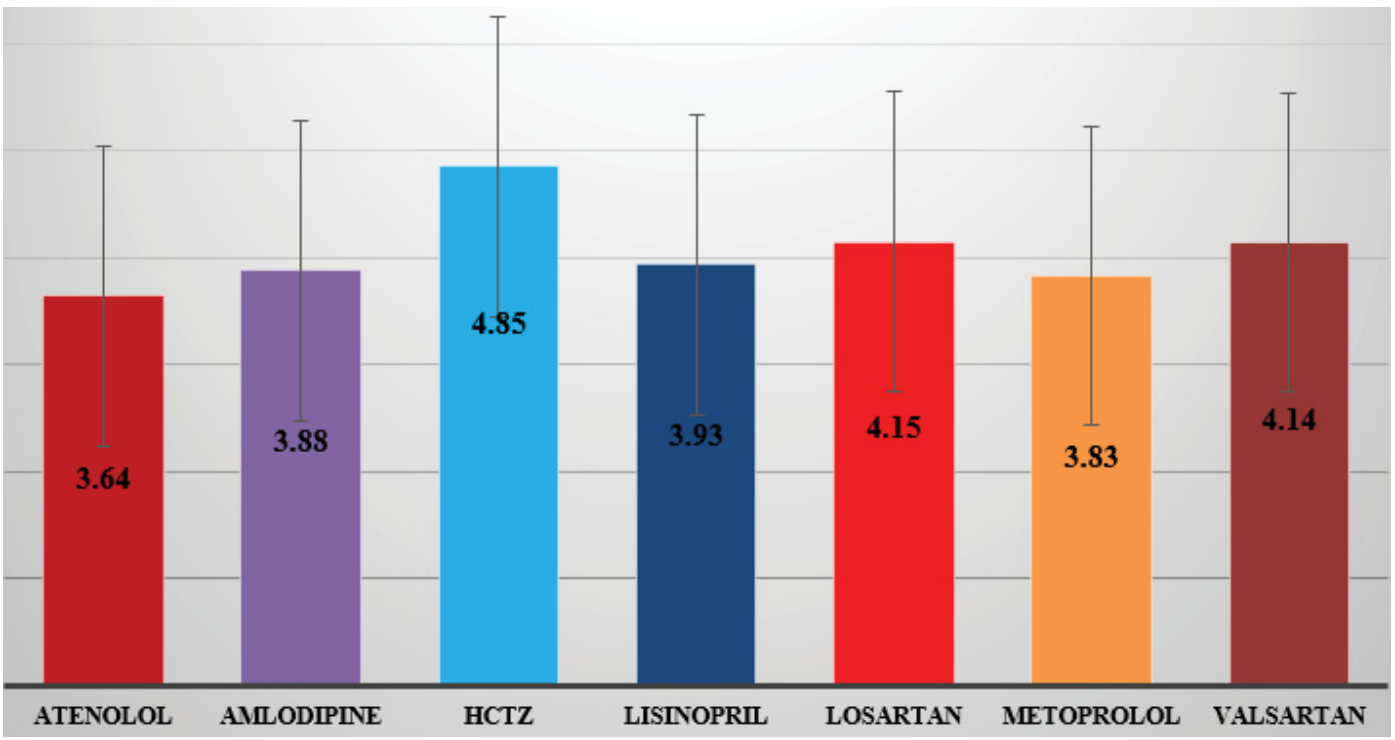

Figure 4-6. Rating of antihypertensive medications' food interactions. 


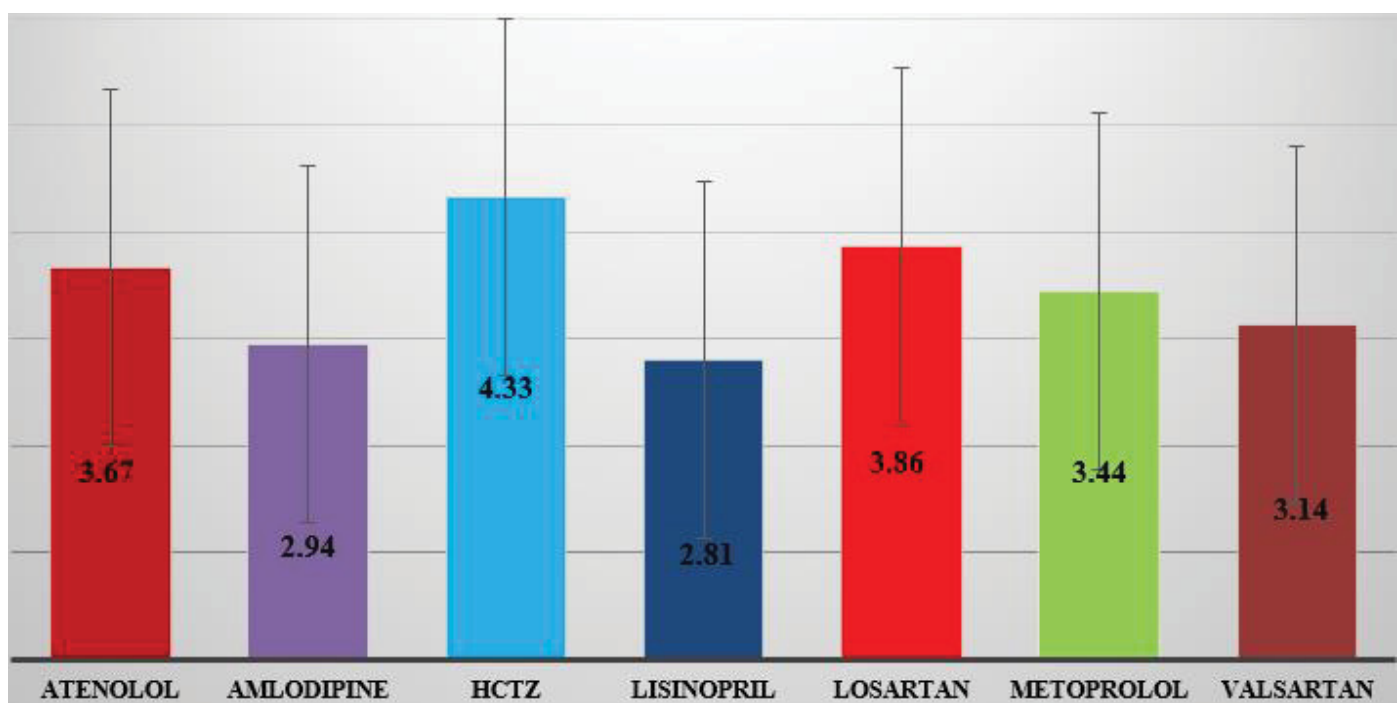

Figure 4-7. Rating of antihypertensive medications' side effects. 


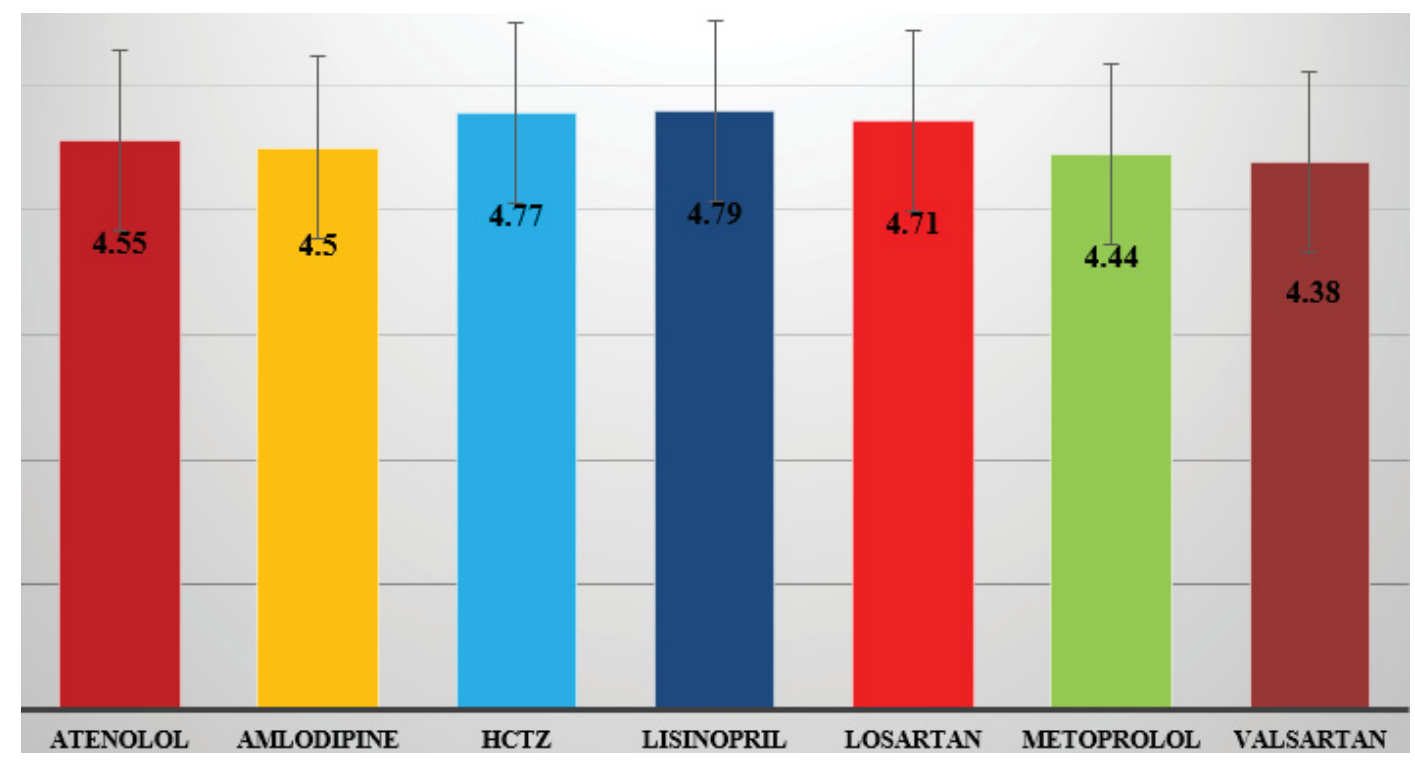

Figure 4-8. Overall rating of antihypertensive medications. 
Table 4-20. Pearson correlation coefficients between the participant-reported outcomes (PROs) and their p-values $(n=298)$.

\begin{tabular}{|c|c|c|c|c|c|c|c|c|}
\hline PRO variable & PROMEX & $\begin{array}{c}\text { PCAS- } \\
\text { Communication }\end{array}$ & $\begin{array}{c}\text { PCAS- } \\
\text { Interpersonal }\end{array}$ & MCS-12 & PCS-12 & $\begin{array}{c}\text { BMQ- } \\
\text { Overuse }\end{array}$ & $\begin{array}{l}\text { BMQ- } \\
\text { Harm }\end{array}$ & MMAS-8 \\
\hline \multirow[t]{2}{*}{ PROMEX } & 1.00 & 0.048 & 0.030 & -0.110 & -0.106 & -0.080 & -0.042 & -0.066 \\
\hline & & 0.407 & 0.604 & 0.055 & 0.066 & 0.168 & 0.470 & 0.327 \\
\hline PCAS- & 0.048 & 1.00 & 0.872 & 0.161 & 0.134 & -0.164 & -0.231 & 0.204 \\
\hline Communication & 0.407 & & $<0.001^{*}$ & $0.005^{*}$ & $0.020^{*}$ & $0.004 *$ & $<0.001 *$ & $0.002 *$ \\
\hline PCAS- & 0.030 & 0.872 & 1.00 & 0.148 & 0.100 & -0.155 & -0.209 & 0.193 \\
\hline Interpersonal & 0.604 & $<0.001 *$ & & $0.010 *$ & 0.082 & $0.007 *$ & $0.001 *$ & $0.004 *$ \\
\hline \multirow[t]{2}{*}{ MCS-12 } & -0.110 & 0.161 & 0.148 & 1.00 & -0.056 & 0.056 & -0.142 & 0.180 \\
\hline & $0.055^{*}$ & $0.005^{*}$ & $0.010 *$ & & 0.328 & 0.335 & $0.014 *$ & $0.007 *$ \\
\hline \multirow[t]{2}{*}{ PCS-12 } & -0.106 & 0.134 & 0.100 & -0.056 & 1.00 & 0.086 & 0.041 & 0.120 \\
\hline & 0.066 & $0.020 *$ & 0.082 & 0.328 & & 0.135 & 0.471 & 0.076 \\
\hline \multirow[t]{2}{*}{ BMQ-Overuse } & -0.080 & -0.164 & -0.155 & 0.056 & 0.086 & 1.00 & 0.460 & -0.108 \\
\hline & 0.168 & $0.004^{*}$ & $0.007^{*}$ & 0.335 & 0.135 & & $<0.001$ & 0.112 \\
\hline \multirow[t]{2}{*}{ BMQ-Harm } & -0.042 & -0.231 & -0.209 & -0.142 & 0.041 & 0.460 & 1.00 & -0.089 \\
\hline & 0.470 & $<0.001 *$ & $0.001 *$ & $0.014^{*}$ & 0.471 & $<0.001 *$ & & 0.190 \\
\hline \multirow[t]{2}{*}{ MMAS-8 } & -0.066 & 0.204 & 0.193 & 0.180 & 0.120 & -0.108 & -0.089 & 1.00 \\
\hline & 0.327 & $0.002 *$ & $0.004 *$ & $0.007 *$ & 0.076 & 0.112 & 0.190 & \\
\hline
\end{tabular}

Note: $(*)=\mathrm{p}<0.05$. 
PCAS-interpersonal treatment were associated with each other $(\mathrm{r}=0.872 ; \mathrm{p}<0.001)$. Further, the PCAS-Communication was associated with both the MCS-12 ( $\mathrm{r}=0.162$; $\mathrm{p}=0.005)$ and PCS-12 $(\mathrm{r}=0.134 ; \mathrm{p}=0.020)$ of the SF-12v2. In addition, the PCASCommunication was associated with both the BMQ-overuse $(r=-0.164 ; \mathrm{p}=0.004)$ and BMQ-Harm $(\mathrm{r}=-0.231 ; \mathrm{p}<0.001)$. Moreover, the PCAS-Communication was associated with MMAS-8 $(\mathrm{r}=0.204 ; \mathrm{p}=0.002)$. Likewise, the PCAS-Interpersonal treatment was associated the MCS-12 $(r=0.148 ; p=0.010)$ but not with the PCS-12 $(p \geq 0.05)$. Further, the PCAS-interpersonal treatment was associated with both the BMQ-overuse ( $\mathrm{r}=-0.155$; $\mathrm{p}=0.007)$ and BMQ-Harm $(\mathrm{r}=-0.209 ; \mathrm{p}=0.001)$. In addition, the PCAS-interpersonal treatment was associated with the MMAS-8 $(\mathrm{r}=0.193 ; \mathrm{p}=0.004)$. The MCS-12 was associated with BMQ-Harm ( $r=-0.142 ; \mathrm{p}=0.014)$ and with the MMAS-8 $(\mathrm{r}=0.180$; $\mathrm{p}=0.007)$. Finally, the BMQ-overuse and BMQ-Harm were associated with each other $(\mathrm{r}=0.460 ; \mathrm{p}<0.001)$.

\subsection{Pearson Correlation Coefficients between the Participant-Specific Ratings of Antihypertensive Medication Regimens and PROs}

The correlation coefficients between participant-specific ratings of antihypertensive medication regimens and participant-reported outcomes are listed in Table 4-21. The participant-specific rating of antihypertensive medication regimen effectiveness was associated with both the PCAS-Communication $(\mathrm{r}=0.192 ; \mathrm{p}=0.006)$ and interpersonal treatment $(\mathrm{r}=0.189 ; \mathrm{p}=0.007)$ scales. Further, the participant-specific rating of antihypertensive medication regimen effectiveness was associated with the PCS-12 $(\mathrm{r}=0.178 ; \mathrm{p}=0.012)$. Likewise, the participant-specific antihypertensive medication regimen ease of use rating was associated with the PCAS-Communication ( $\mathrm{r}=0.157$; $\mathrm{p}=0.030$ ). The participant-specific antihypertensive medication regimen cost, side effects, and food interactions ratings were not associated with any of the measured participantreported outcomes $(\mathrm{p} \geq 0.05)$. Finally, the participant-specific overall antihypertensive medication regimen rating was associated with PCAS-Communication $(\mathrm{r}=0.280$; $\mathrm{p}=0.001)$, PCAS-interpersonal treatment $(\mathrm{r}=0.223 ; \mathrm{p}=0.002)$, and the BMQ-Harm $(\mathrm{r}=-0.184 ; \mathrm{p}=0.012)$ scales.

\subsection{Older Adult Participants' Views of Online Medication Rating Websites and Their Satisfaction with Physician Communication}

\subsubsection{Path Model for the Association between PROMEX and PCAS- Communication}

A path model was built to examine the association between participants' satisfaction with physician communication and their views of online medication rating websites. The PCAS-Communication scale was used to assess participant satisfaction with physician communication, whereas, PROMEX was used to assess participant views of online medication rating websites. Education, gender, age, health literacy, race, marital status, and comorbidities were treated as exogenous variables that influence the 
Table 4-21. Pearson correlation coefficients between the participant-specific rating of antihypertensive medication regimens and participant-reported outcomes (PROs) variables.

\begin{tabular}{|c|c|c|c|c|c|c|c|c|}
\hline $\begin{array}{l}\text { Medication } \\
\text { use aspect }\end{array}$ & PROMEX & $\begin{array}{c}\text { PCAS- } \\
\text { Communication }\end{array}$ & $\begin{array}{c}\text { PCAS- } \\
\text { Interpersonal }\end{array}$ & MCS-12 & PCS-12 & $\begin{array}{c}\text { BMQ- } \\
\text { Overuse }\end{array}$ & $\begin{array}{l}\text { BMQ- } \\
\text { Harm }\end{array}$ & MMAS-8 \\
\hline \multirow[t]{2}{*}{ Effectiveness } & -0.010 & 0.192 & 0.189 & 0.096 & 0.178 & -0.082 & -0.133 & 0.131 \\
\hline & 0.887 & $0.006^{*}$ & $0.007 *$ & 0.180 & $0.012 *$ & 0.250 & 0.062 & 0.066 \\
\hline \multirow[t]{2}{*}{ Side effects } & -0.070 & -0.073 & -0.052 & -0.021 & 0.085 & 0.036 & -0.052 & 0.024 \\
\hline & 0.337 & 0.315 & 0.475 & 0.771 & 0.245 & 0.622 & 0.475 & 0.742 \\
\hline \multirow[t]{2}{*}{ Ease of use } & 0.005 & 0.157 & 0.138 & 0.044 & 0.094 & -0.073 & -0.122 & 0.115 \\
\hline & 0.944 & $0.030^{*}$ & 0.055 & 0.545 & 0.195 & 0.314 & 0.093 & 0.111 \\
\hline \multirow[t]{2}{*}{ Cost } & 0.036 & 0.108 & 0.116 & -0.059 & 0.106 & -0.075 & -0.129 & 0.094 \\
\hline & 0.617 & 0.139 & 0.112 & 0.421 & 0.146 & 0.308 & 0.078 & 0.198 \\
\hline Food & -0.002 & 0.071 & 0.096 & -0.062 & 0.074 & 0.005 & -0.092 & -0.045 \\
\hline interaction & 0.975 & 0.339 & 0.197 & 0.408 & 0.324 & 0.946 & 0.217 & 0.544 \\
\hline \multirow[t]{2}{*}{ Overall } & -0.089 & 0.280 & 0.223 & 0.134 & 0.124 & -0.128 & -0.184 & 0.107 \\
\hline & 0.229 & $0.001 *$ & $0.002 *$ & 0.069 & 0.095 & 0.082 & $0.012 *$ & 0.148 \\
\hline
\end{tabular}

Note: $(*)=\mathrm{p}<0.05$. 
participant satisfaction with physician communication (i.e., PCAS-Communication). The PCAS-Communication was treated as both an endogenous variable in which it is influenced by the exogenous variables, as well as an exogenous variable in which it influences participant views of online medication rating websites (i.e., PROMEX). The results of the path analysis are presented in Figure 4-9 and Table 4-22. Participant views of online medication rating websites (i.e., PROMEX) were not influenced by participant satisfaction with physician communication (i.e., PCAS-Communication) ( $p \geq 0.05$ ). Further, their views were not influenced by other exogenous variables (i.e., age, race, education, etc.) ( $\mathrm{p} \geq 0.05)$. However, participant satisfaction with physician communication (i.e., PCAS-Communication) was positively influenced by marital status $(\beta=0.119 ; p=0.049)$, health literacy $(\beta=0.18 ; p=0.002)$, and gender $(\beta=0.123 ; p=0.038)$, and negatively influenced by race $(\beta=-0.14 ; p=0.019)$. An analysis of the fit indices indicated adequate model fit (comparative fit index $=1.00$, adjusted goodness of fit index $=0.99$, root mean square error of approximation $=0.00$, and standardized root mean square residual $=0.020$ ).

\subsubsection{Multiple Linear Regression for the Association between PROMEX and PCAS-Communication}

In addition to the path analysis, a multiple linear regression analysis was completed to examine the association between PROMEX and the PCAS-Communication controlling for the same sociodemographic factors in the path model as well as comorbidities. As with the path analysis, no significant association was found between PROMEX and PCAS-Communication ( $\mathrm{p} \geq 0.05)$ (Table 4-23).

\subsection{Older Adult Participants' Satisfaction with Physician Communication and Overall Rating of Their Antihypertensive Medication Regimens}

The results of the multiple linear regression analysis that examined the association between the Primary Care Assessment Survey communication scale (PCASCommunication) and participants' overall rating of their antihypertensive medication regimens are listed in Table 4-24. The higher the overall rating of antihypertensive medication regimen score, the higher the score of the PCAS-Communication $(\beta=5.031$; $\mathrm{p}=0.005)$. Hypertensive participants with high overall rating of their antihypertensive medication regimens were more likely to have high PCAS-Communication score compared to participants with low overall rating of their antihypertensive medication regimens controlling for their age, comorbidities, race, education, and gender, marital status, number of prescription medications, and health literacy level. Health literacy also influenced the satisfaction with physician communication; participants with good health literacy level were more likely to have higher PCAS-Communication scores $(\beta=9.965$; $\mathrm{p}=0.007$ ). Age, comorbidities, race, education, gender, number of prescription medications, and marital status were not associated with the PCAS-Communication $(\mathrm{p} \geq 0.05)$. 


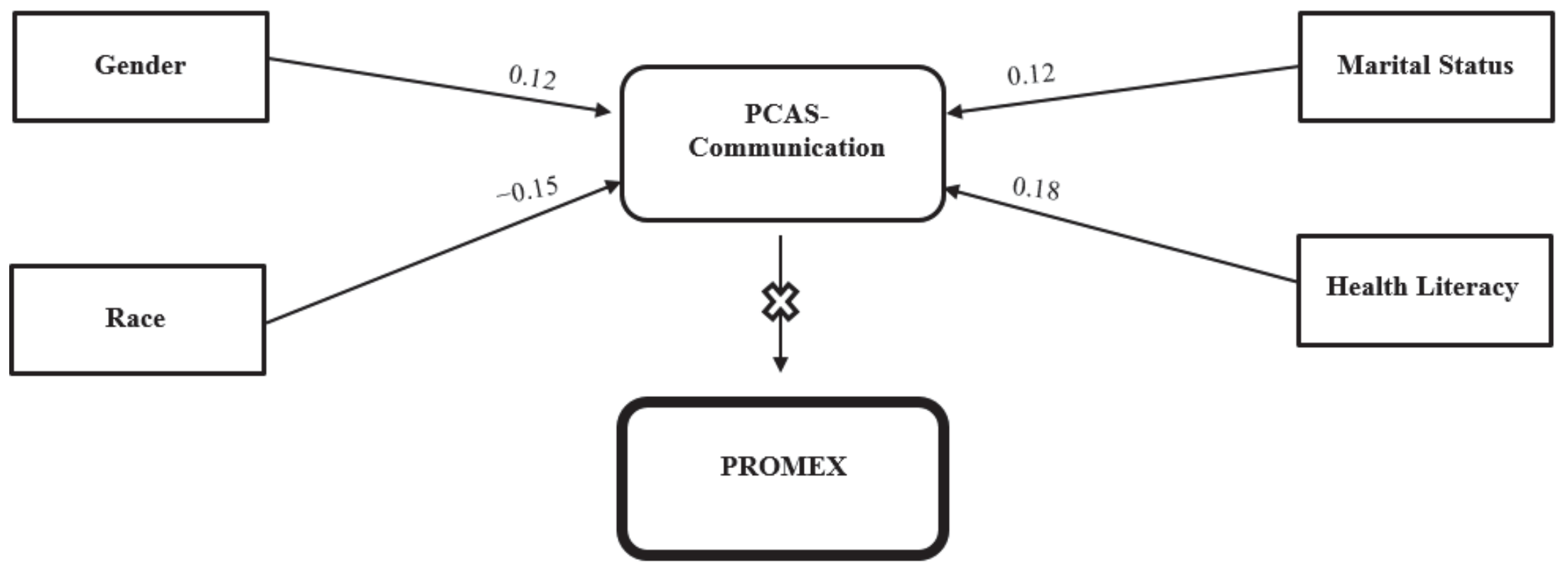

Figure 4-9. Path analysis: Association between PROMEX and PCAS-Communication. 
Table 4-22. Path analysis: Standardized direct, indirect, and total effects of the variables evaluated on PROMEX and PCAS-Communication $(\mathrm{n}=\mathbf{2 8 6})$.

\begin{tabular}{|c|c|c|c|c|c|c|}
\hline Outcome variables & $\mathbf{R}^{2}$ & $\begin{array}{l}\text { Predictor } \\
\text { variables }\end{array}$ & $\begin{array}{c}\text { Standardized } \\
\text { direct effect }(\beta)\end{array}$ & $\begin{array}{c}\text { Standardized } \\
\text { indirect effect }(\beta)\end{array}$ & $\begin{array}{l}\text { Standardized } \\
\text { total effect }(\beta)\end{array}$ & p-Value \\
\hline $\begin{array}{l}\text { Patient Reviews of } \\
\text { Medication Experiences }\end{array}$ & 0.002 & $\begin{array}{c}\text { PCAS- } \\
\text { Communication }\end{array}$ & 0.045 & 0.00 & 0.045 & 0.465 \\
\hline \multirow[t]{7}{*}{ (PROMEX) } & & Age & 0.00 & -0.002 & -0.002 & 0.606 \\
\hline & & Education & 0.00 & 0.001 & 0.001 & 0.727 \\
\hline & & Marital status & 0.00 & 0.005 & 0.005 & 0.494 \\
\hline & & Health literacy & 0.00 & 0.008 & 0.008 & 0.478 \\
\hline & & Comorbidities & 0.00 & -0.002 & -0.002 & 0.546 \\
\hline & & Race & 0.00 & -0.006 & -0.006 & 0.486 \\
\hline & & Gender & 0.00 & 0.005 & 0.005 & 0.491 \\
\hline \multirow[t]{7}{*}{ PCAS-Communication } & 0.11 & Age & -0.04 & 0.00 & -0.04 & 0.466 \\
\hline & & Education & 0.024 & 0.00 & 0.024 & 0.692 \\
\hline & & Marital status & 0.119 & 0.00 & 0.119 & $0.049 *$ \\
\hline & & Health literacy & 0.181 & 0.00 & 0.181 & $0.002 *$ \\
\hline & & Comorbidities & -0.06 & 0.00 & -0.06 & 0.283 \\
\hline & & Race & -0.14 & 0.00 & -0.14 & $0.019^{*}$ \\
\hline & & Gender & 0.123 & 0.00 & 0.123 & $0.038^{*}$ \\
\hline
\end{tabular}

Notes: R-Square $=0.01 .\left({ }^{*}\right)=\mathrm{p}<0.05$. 
Table 4-23. Multiple linear regression: The association between PROMEX and PCAS-Communication $(n=286)$.

\begin{tabular}{lcccc}
\hline & & & \multicolumn{2}{c}{$\mathbf{9 5 \%}$ Confidence limits } \\
\cline { 4 - 5 } Variable & Beta $(\boldsymbol{\beta})$ estimate & p-Value & Lower & Upper \\
\hline PCAS- & 0.023 & 0.230 & -0.01 & 0.062 \\
Communication & & & & \\
Age & 0.001 & 0.973 & -0.08 & 0.084 \\
Comorbidity & 0.215 & 0.164 & -0.08 & 0.520 \\
score & & & & \\
Education & -0.02 & 0.831 & -0.29 & 0.235 \\
Race & 0.747 & 0.167 & -0.31 & 1.810 \\
Health literacy & -0.06 & 0.937 & -1.57 & 1.458 \\
Gender & -0.89 & 0.276 & -2.49 & 0.718 \\
Marital status & 0.083 & 0.906 & -1.31 & 1.486 \\
\hline
\end{tabular}

Notes: R-Square $=0.02 .(*)=\mathrm{p}<0.05$. 
Table 4-24. Multiple linear regression: The association between hypertensive participants' PCAS-Communication scale scores and overall ratings of their antihypertensive medication regimens $(n=193)$.

\begin{tabular}{lcccr}
\hline & & & \multicolumn{2}{c}{$\mathbf{9 5 \%}$ Confidence limits } \\
\cline { 4 - 5 } Variable & Beta $(\boldsymbol{\beta})$ estimate & p-Value & Lower & Upper \\
\hline Overall rating & 5.031 & $0.005^{*}$ & 1.513 & 8.550 \\
of HTN & & & & \\
medications & & & & \\
Age & -0.026 & 0.884 & -0.391 & 0.337 \\
Comorbidity & 0.318 & 0.695 & -1.290 & 1.928 \\
score & & & & \\
Education & 0.582 & 0.340 & -0.621 & 1.787 \\
Race & -1.490 & 0.523 & -6.094 & 3.113 \\
Health literacy & 9.965 & $0.007 *$ & 2.648 & 17.282 \\
Gender & 3.285 & 0.358 & -3.755 & 10.325 \\
Number of & -0.662 & 0.343 & -2.039 & 0.714 \\
prescription & & & & \\
medications & & & -3.263 & 9.287 \\
Marital status & 3.012 & 0.344 & & \\
\hline
\end{tabular}

Notes: R-Square $=0.17 .(*)=\mathrm{p}<0.05$. 


\subsection{Older Adults' Views of Online Medication Rating Websites and Their Quality of Life}

\subsubsection{Path Model for the Association between PROMEX and MCS-12}

The results of the path model that tested the association between participants' views of online medication rating websites (i.e., PROMEX) and their mental health quality of life (MCS-12) are presented in Figure 4-10 and Table 4-25. The participants' views of online medication rating websites (i.e., PROMEX) were not influenced by their mental health quality of life (i.e., MCS-12) ( $\mathrm{p} \geq 0.05)$. Further, their views were not influenced by other exogenous variables (i.e., age, race, education...etc.) ( $\mathrm{p} \geq 0.05)$. However, the older adults' mental health quality of life (MCS-12) was positively influenced by their age $(\beta=0.219 ; p=0.001)$, education $(\beta=0.144 ; p=0.014)$, and health literacy $(\beta=0.243$; $\mathrm{p}=<0.001)$, and negatively influenced by their comorbidities $(\beta=-0.178 ; \mathrm{p}=0.001)$. An analysis of the fit indices indicated adequate model fit (comparative fit index $=1.00$, adjusted goodness of fit index $=0.99$, root mean square error of approximation $=0.00$, and standardized root mean square residual $=0.015$ ).

\subsubsection{Path Model for the Association between PROMEX and PCS-12}

The results of the path model that tested the association between participants' views of online medication rating websites (i.e., PROMEX) and their physical health quality of life (PCS-12) are presented in Figure 4-11 and Table 4-26. The participants' views of online medication rating websites (i.e., PROMEX) were significantly influenced by their physical health quality of life (i.e., PCS-12) $(\beta=-0.126 ; p=0.040)$. Participants with low PCS-12 scores were more likely to have favorable views of online medication rating websites. However, their views were not influenced by other exogenous variables (i.e., age, race, education...etc.) ( $\mathrm{p} \geq 0.05)$. The participants' physical health quality of life (PCS-12) was positively influenced by their satisfaction with physician communication (i.e., PCAS-Communication) $(\beta=0.125 ; p=0.035)$. However, it was negatively influenced by their age $(\beta=-0.120 ; p=0.048)$ and comorbidities $(\beta=-0.360 ; p<0.001)$. An analysis of the fit indices indicated adequate model fit (comparative fit index $=1.00$, adjusted goodness of fit index $=0.99$, root mean square error of approximation $=0.00$, and standardized root mean square residual $=0.015$ ).

\subsubsection{Multiple Linear Regression for the Association between PROMEX and Both PCS-12 and MCS-12}

In addition to the path analyses, we did multiple linear regression analyses to examine the association between PROMEX and the quality of life scales (i.e., PCS-12 and MCS12) controlling for the same variables in the path analyses. In the first regression model, we examined the association between the mental quality of life (i.e., MCS-12) and participants' views of online medication rating websites (i.e., PROMEX). As with the 


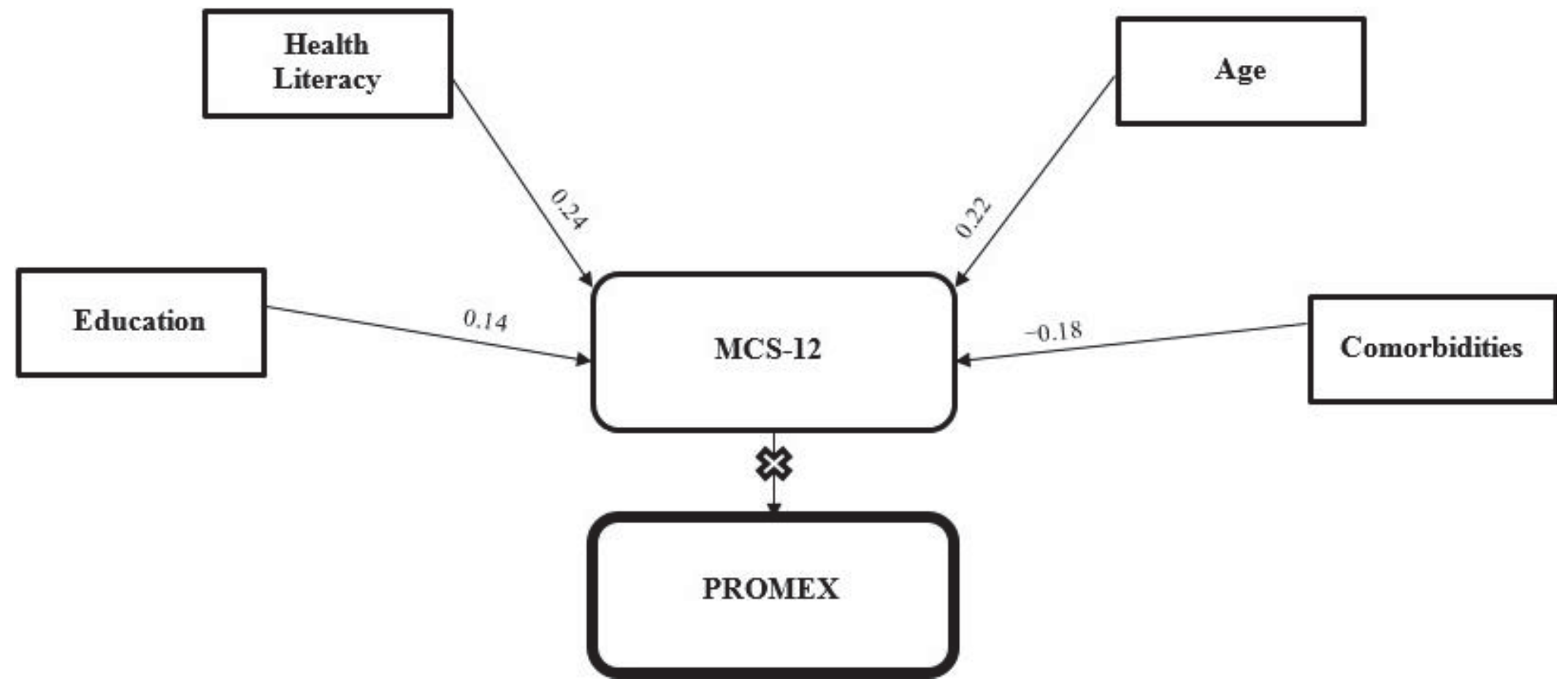

Figure 4-10. Path analysis: The association between PROMEX and MCS-12. 
Table 4-25. Path analysis: Standardized direct, indirect, and total effects of the variables evaluated on PROMEX and MCS-12 (n=286).

\begin{tabular}{|c|c|c|c|c|c|c|}
\hline Outcome variables & $\mathbf{R}^{2}$ & $\begin{array}{l}\text { Predictor } \\
\text { variables }\end{array}$ & $\begin{array}{c}\text { Standardized } \\
\text { direct effect }(\beta)\end{array}$ & $\begin{array}{c}\text { Standardized } \\
\text { indirect effect }(\beta)\end{array}$ & $\begin{array}{l}\text { Standardized } \\
\text { total effect }(\beta)\end{array}$ & p-Value \\
\hline \multirow{10}{*}{$\begin{array}{l}\text { Patient Reviews of } \\
\text { Medication Experiences } \\
\text { (PROMEX) }\end{array}$} & 0.012 & MCS-12 & -0.111 & 0.00 & -0.111 & 0.071 \\
\hline & & PCAS- & 0.00 & -0.01 & -0.01 & 0.188 \\
\hline & & $\begin{array}{l}\text { Interpersonal } \\
\text { Treatment }\end{array}$ & & & & \\
\hline & & Age & 0.00 & -0.024 & -0.024 & 0.107 \\
\hline & & Education & 0.00 & -0.016 & -0.016 & 0.147 \\
\hline & & Marital status & 0.00 & -0.011 & -0.011 & 0.209 \\
\hline & & Health literacy & 0.00 & -0.027 & 0.099 & 0.099 \\
\hline & & Comorbidities & 0.00 & 0.019 & 0.019 & 0.118 \\
\hline & & Race & 0.00 & -0.004 & -0.004 & 0.561 \\
\hline & & Gender & 0.00 & -0.012 & -0.012 & 0.194 \\
\hline \multirow[t]{9}{*}{ MCS-12 } & 0.189 & PCAS- & 0.11 & 0.00 & 0.111 & 0.052 \\
\hline & & $\begin{array}{c}\text { Interpersonal } \\
\text { Treatment }\end{array}$ & & & & \\
\hline & & Age & 0.219 & 0.00 & 0.219 & $0.001 *$ \\
\hline & & Education & 0.144 & 0.00 & 0.144 & $0.014^{*}$ \\
\hline & & Marital status & 0.103 & 0.00 & 0.103 & 0.078 \\
\hline & & Health literacy & 0.243 & 0.00 & 0.243 & $<0.001 *$ \\
\hline & & Comorbidities & -0.178 & 0.00 & -0.178 & $0.001 *$ \\
\hline & & Race & 0.037 & 0.00 & 0.037 & 0.539 \\
\hline & & Gender & 0.108 & 0.00 & 0.108 & 0.060 \\
\hline
\end{tabular}

Notes: R-Square $=0.01 .\left({ }^{*}\right)=\mathrm{p}<0.05$. 


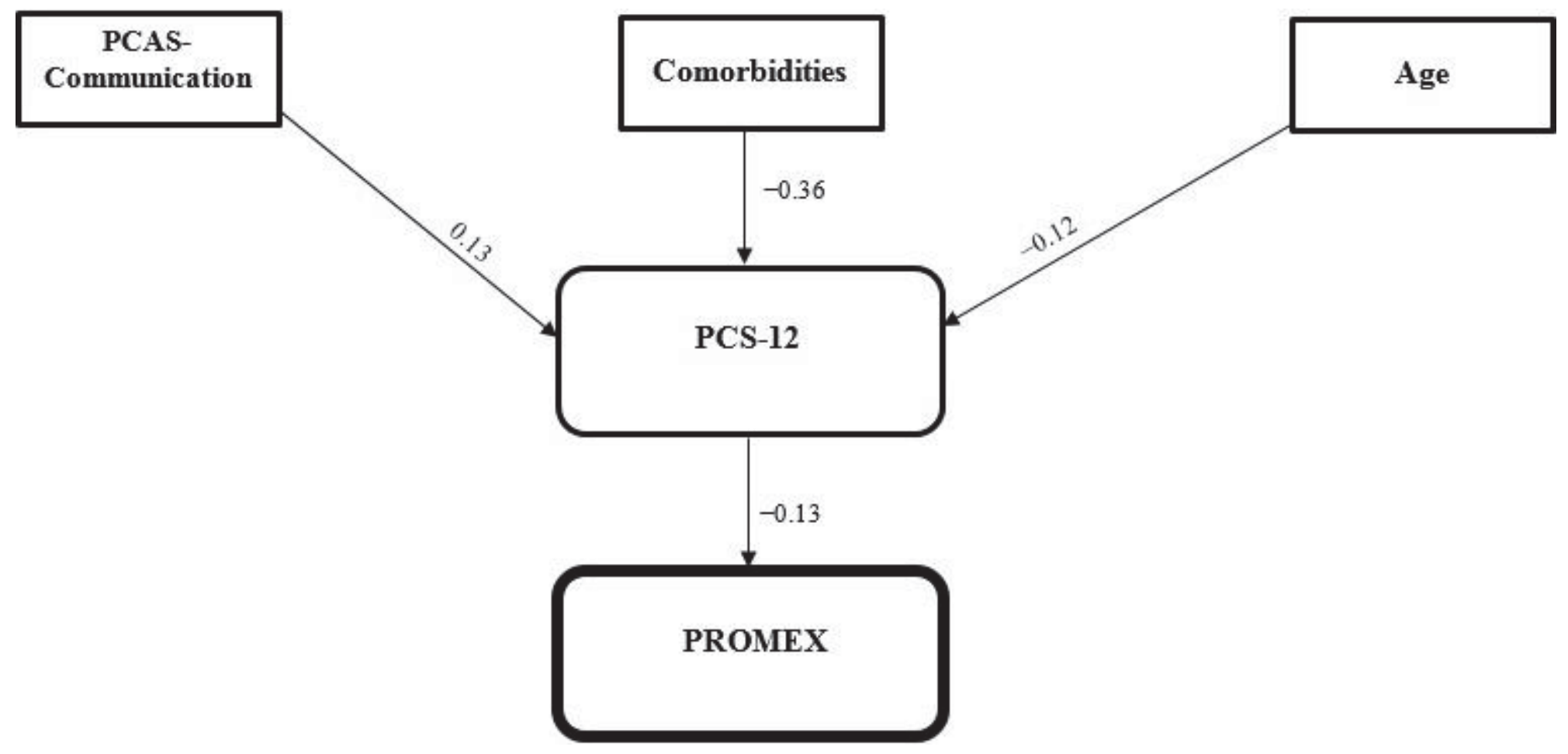

Figure 4-11. Path analysis: The association between PROMEX and PCS-12. 
Table 4-26. Path analysis: Standardized direct, indirect, and total effects of the variables evaluated on PROMEX and PCS-12 (n=286).

\begin{tabular}{|c|c|c|c|c|c|c|}
\hline Outcome variables & $\mathbf{R}^{2}$ & $\begin{array}{l}\text { Predictor } \\
\text { variables }\end{array}$ & $\begin{array}{c}\text { Standardized } \\
\text { direct effect }(\beta)\end{array}$ & $\begin{array}{c}\text { Standardized } \\
\text { indirect effect }(\beta)\end{array}$ & $\begin{array}{l}\text { Standardized } \\
\text { total effect }(\beta)\end{array}$ & p-Value \\
\hline Patient Reviews of & 0.016 & PCS-12 & -0.126 & 0.00 & -0.126 & $0.040 *$ \\
\hline \multirow[t]{8}{*}{$\begin{array}{l}\text { Medication Experiences } \\
\text { (PROMEX) }\end{array}$} & & $\begin{array}{c}\text { PCAS- } \\
\text { Communication }\end{array}$ & 0.00 & -0.015 & -0.015 & 0.142 \\
\hline & & Age & 0.00 & 0.015 & 0.015 & 0.156 \\
\hline & & Education & 0.00 & -0.001 & -0.001 & 0.939 \\
\hline & & Marital Status & 0.00 & 0.013 & 0.013 & 0.167 \\
\hline & & Health Literacy & 0.00 & -0.001 & -0.001 & 0.977 \\
\hline & & Comorbidities & 0.00 & 0.045 & 0.045 & 0.051 \\
\hline & & Race & 0.00 & 0.007 & 0.007 & 0.369 \\
\hline & & Gender & 0.00 & 0.002 & 0.002 & 0.786 \\
\hline \multirow[t]{8}{*}{ PCS-12 } & 0.174 & $\begin{array}{c}\text { PCAS- } \\
\text { Communication }\end{array}$ & 0.125 & 0.00 & 0.125 & $0.035^{*}$ \\
\hline & & Age & -0.120 & 0.00 & -0.120 & $0.048 *$ \\
\hline & & Education & 0.004 & 0.00 & 0.004 & 0.939 \\
\hline & & Marital Status & -0.110 & 0.00 & -0.110 & 0.061 \\
\hline & & Health Literacy & 0.001 & 0.00 & 0.001 & 0.977 \\
\hline & & Comorbidities & -0.360 & 0.00 & -0.360 & $<0.001 *$ \\
\hline & & Race & -0.061 & 0.00 & -0.061 & 0.317 \\
\hline & & Gender & -0.015 & 0.00 & -0.015 & 0.784 \\
\hline
\end{tabular}

Notes: R-Square $=0.01 .(*)=\mathrm{p}<0.05$. 
path analysis, the MCS-12 did not influence PROMEX ( $\mathrm{p} \geq 0.05)$ (Table 4-27). In the second regression model, we examined the association between the physical quality of life (i.e., PCS-12) and participants' views of online medication rating websites (i.e., PROMEX). Contrary to the path analysis, the PCS-12 did not influence PROMEX $(\mathrm{p} \geq 0.05)$ (Table 4-28). In the third regression model, we included both the PCS-12 and the MCS-12 to examine the effects of both HRQoL measures on participants' views of online medication rating websites; however, no significant association was found between either PCS-12 or MCS-12 and PROMEX ( $\mathrm{p} \geq 0.05)$ (Table 4-29).

\subsection{The Health-Related Quality of Life and the Overall Rating of Antihypertensive Regimens}

\subsubsection{The Association between the MCS-12 and the Overall Rating of Antihypertensive Regimens}

The results of the multiple regression analysis that examined the association between the MCS-12 and the overall rating of antihypertensive medication regimens are presented in Table 4-30. The participants' overall rating of antihypertensive medication regimens did not influence their mental health quality of life (i.e. MCS-12) $(\mathrm{p} \geq 0.05)$. However, age and health literacy were positively associated the MCS-12, and participants' comorbidities was negatively associated with MCS-12 $(\mathrm{p}<0.05)$.

\subsubsection{The Association between the PCS-12 and the Overall Rating of Antihypertensive Regimens}

The results of the multiple regression analysis that examined the association between the PCS-12 and the overall rating of antihypertensive medication regimens are presented in Table 4-31. The participants' overall rating of antihypertensive medication regimens significantly influenced their physical health quality of life (i.e., PCS-12) $(\beta=2.740$; $\mathrm{p}=0.005)$. The higher the overall rating of antihypertensive medication regimens, the more likely participants will have high PCS-12 scores controlling for their age, comorbidities, race, education, and gender, marital status, number of prescription medications, and health literacy level. Further, comorbidities also influenced participants' physical health quality of life (i.e., PCS-12) $(\beta=-1.202 ; p=0.008)$. The more diseases participants have, the more likely they will have lower PCS-12 scores. 
Table 4-27. Multiple linear regression: The association between PROMEX and HRQoL (MCS-12) $(n=286)$.

\begin{tabular}{lcccc}
\hline & & & \multicolumn{2}{c}{$\mathbf{9 5 \%}$ Confidence limits } \\
\cline { 4 - 5 } Variable & Beta $(\boldsymbol{\beta})$ estimate & p-Value & Lower & Upper \\
\hline MCS-12 & -0.057 & 0.127 & -0.130 & 0.016 \\
PCAS- & 0.025 & 0.189 & -0.012 & 0.064 \\
Communication & & & & \\
Age & 0.015 & 0.714 & -0.069 & 0.100 \\
Comorbidity & 0.170 & 0.277 & -0.138 & 0.480 \\
score & & & & \\
Education & 0.003 & 0.980 & -0.262 & 0.269 \\
Race & 0.776 & 0.150 & -0.284 & 1.837 \\
Health literacy & 0.229 & 0.772 & -1.330 & 1.790 \\
Gender & -0.741 & 0.366 & -2.358 & 0.874 \\
Marital status & 0.206 & 0.773 & -1.201 & 1.614 \\
\hline
\end{tabular}

Note: R-Square $=0.03$. 
Table 4-28. Multiple linear regression: The association between PROMEX and HRQoL (PCS-12) $(n=286)$.

\begin{tabular}{lcccc}
\hline & & & \multicolumn{2}{c}{$\mathbf{9 5 \%}$ Confidence limits } \\
\cline { 4 - 5 } Variable & Beta $(\boldsymbol{\beta})$ estimate & p-Value & Lower & Upper \\
\hline PCS-12 & -0.059 & 0.089 & -0.129 & 0.009 \\
PCAS- & 0.028 & 0.157 & -0.010 & 0.067 \\
Communication & & & & \\
Age & -0.007 & 0.861 & -0.090 & 0.076 \\
Comorbidity & 0.112 & 0.497 & -0.213 & 0.438 \\
score & & & & \\
Education & -0.027 & 0.837 & -0.289 & 0.235 \\
Race & 0.690 & 0.200 & -0.370 & 1.751 \\
Health literacy & -0.058 & 0.939 & -1.571 & 1.455 \\
Gender & -0.914 & 0.262 & -2.517 & 0.689 \\
Marital status & -0.057 & 0.935 & -1.464 & 1.349 \\
\hline
\end{tabular}

Note: R-Square $=0.03$. 
Table 4-29. Multiple linear regression: The association between PROMEX and HRQoL (PCS-12 and MCS-12) (n=286).

\begin{tabular}{lcccc}
\hline & & & \multicolumn{2}{c}{$\mathbf{9 5 \%}$ Confidence limits } \\
\cline { 4 - 5 } Variable & Beta $(\boldsymbol{\beta})$ estimate & p-Value & Lower & Upper \\
\hline PCS-12 & -0.067 & 0.056 & -0.137 & 0.001 \\
MCS-12 & -0.065 & 0.079 & -0.139 & 0.007 \\
PCAS- & 0.031 & 0.115 & -0.007 & 0.070 \\
Communication & & & & \\
Age & 0.008 & 0.850 & -0.076 & 0.092 \\
Comorbidity & 0.047 & 0.777 & -0.284 & 0.380 \\
score & & & & \\
Education & 0.009 & 0.944 & -0.255 & 0.274 \\
Race & 0.716 & 0.183 & -0.340 & 1.773 \\
Health literacy & 0.277 & 0.725 & -1.275 & 1.830 \\
Gender & -0.745 & 0.361 & -2.353 & 0.862 \\
Marital status & 0.066 & 0.926 & -1.341 & 1.473 \\
\hline
\end{tabular}

Note: R-Square $=0.04$. 
Table 4-30. Multiple linear regression: The association between hypertensive participants' MCS-12 scores and overall ratings of their antihypertensive medication regimens $(n=193)$.

\begin{tabular}{lcccc}
\hline & & & \multicolumn{2}{c}{$\mathbf{9 5 \%}$ Confidence limits } \\
\cline { 4 - 5 } Variable & Beta $(\boldsymbol{\beta})$ estimate & p-Value & Lower & Upper \\
\hline $\begin{array}{l}\text { Overall rating } \\
\text { of HTN }\end{array}$ & 0.410 & 0.636 & -1.300 & 2.120 \\
medications & & & & \\
$\begin{array}{l}\text { Age } \\
\text { Comorbidity }\end{array}$ & 0.329 & $0.001^{*}$ & 0.152 & 0.507 \\
Score & -1.299 & $0.001^{*}$ & -2.082 & -0.515 \\
$\begin{array}{l}\text { Education } \\
\text { Race }\end{array}$ & 0.375 & & & \\
Health literacy & 1.191 & 0.210 & -0.213 & 0.965 \\
$\begin{array}{l}\text { Gender } \\
\text { Number of }\end{array}$ & 5.230 & 0.295 & -1.051 & 3.434 \\
prescription & 2.193 & $0.004^{*}$ & 1.672 & 8.788 \\
medications & 0.591 & 0.207 & -1.228 & 5.616 \\
Marital status & & 0.082 & -0.077 & 1.260 \\
\hline
\end{tabular}

Notes: R-Square: 0.20. $(*)=p<0.05$. 
Table 4-31. Multiple linear regression: The association between hypertensive participants' PCS-12 scores and overall ratings of their antihypertensive medication regimens $(n=193)$.

\begin{tabular}{lcccr}
\hline & & & \multicolumn{2}{c}{$\mathbf{9 5 \%}$ Confidence limits } \\
\cline { 4 - 5 } Variable & Beta $(\boldsymbol{\beta})$ estimate & p-Value & Lower & Upper \\
\hline $\begin{array}{l}\text { Overall rating } \\
\text { of HTN }\end{array}$ & 2.740 & $0.005^{*}$ & 0.809 & 4.672 \\
medications & & & & \\
Age & & & & \\
Comorbidity & -0.071 & 0.481 & -0.271 & 0.128 \\
score & -1.202 & $0.008^{*}$ & -2.087 & -0.318 \\
Education & & & & \\
Race & 0.064 & 0.848 & -0.600 & 0.730 \\
Health & -2.123 & 0.099 & -4.655 & 0.409 \\
literacy & -3.972 & 0.052 & -7.989 & 0.044 \\
$\begin{array}{l}\text { Gender } \\
\text { Number of } \\
\text { prescription } \\
\text { medications }\end{array}$ & -0.558 & & & \\
Marital status & -0.540 & 0.775 & -4.422 & 3.305 \\
\hline & & 0.159 & -1.296 & 0.214 \\
& -0.598 & & & \\
& & 0.731 & -4.044 & 2.846 \\
\hline
\end{tabular}

Notes: R-Square $=0.15 .(*)=p<0.05$. 


\subsection{Older Adult Participants' Views of Online Medication Rating Websites and Their Beliefs about Medications}

\subsubsection{Path Model for the Association between PROMEX and BMQ-Overuse Scale}

The results of the path analysis that examined the association between participants' views of online medication rating websites and BMQ-overuse are presented in Figure 4-12 and Table 4-32. The participants' views of online medication rating websites (i.e., PROMEX), were not influenced by the beliefs that medications are generally overused or overprescribed (i.e., BMQ-overuse) ( $\mathrm{p} \geq 0.05$ ). Further, PROMEX was not influenced by the other exogenous variables (i.e., age, gender, education, etc.). However, BMQ-overuse was negatively influenced by PCAS-Communication $(\beta=-0.194 ; p=0.001)$, and the number of prescription medications taken $(\beta=-0.202$; $\mathrm{p}=0.001)$, and positively influenced by gender $(\beta=0.175, \mathrm{p}=0.001)$. Participants who were satisfied with their physician communication were less likely to believe that medications are overused or overprescribed. Further, the higher the number of prescription medications taken by participants, the less likely they believe medications are overprescribed or overused. On the other hand, women were more likely than men to believe that medications are overprescribed or overused. An analysis of the fit indices indicated adequate model fit (comparative fit index $=1.00$, adjusted goodness of fit index $=0.999$, root mean square error of approximation $=0.00$, and standardized root mean square residual $=0.017$ ).

\subsubsection{Path Model for the Association between PROMEX and BMQ-Harm Scale}

The results of the path analysis that examined the association between participants' views of online medication rating websites and BMQ-Harm are presented in Figure 4-13 and Table 4-33. The participants' views of online medication rating websites (i.e., PROMEX), were not influenced by the beliefs that medications are inherently harmful (i.e., BMQ-overuse) ( $\mathrm{p} \geq 0.05)$. Further, PROMEX was not influenced by the other exogenous variables (i.e., age, gender, education, etc.). However, the BMQ-Harm was negatively influenced by the PCAS-Communication $(\beta=-0.221 ; p<0.001)$, age $(\beta=-0.177 ; p=0.002)$, education $(\beta=-0.124 ; p=0.030)$, and number of prescription medications taken $(\beta=-0.185 ; p=0.001)$. Participants who were satisfied with their physician communication were less likely to believe that medications are harmful. Further, the older the participants, the less likely they believe that medications are harmful. In addition, participants with higher levels of education were less likely to believe medications are harmful. Moreover, the higher the number of prescription medications taken by participants, the less likely they believe medications are harmful. An analysis of the fit indices indicated adequate model fit (comparative fit index $=0.993$, adjusted goodness of fit index $=0.999$, root mean square error of approximation $=0.01$, and standardized root mean square residual $=0.021$ ). 


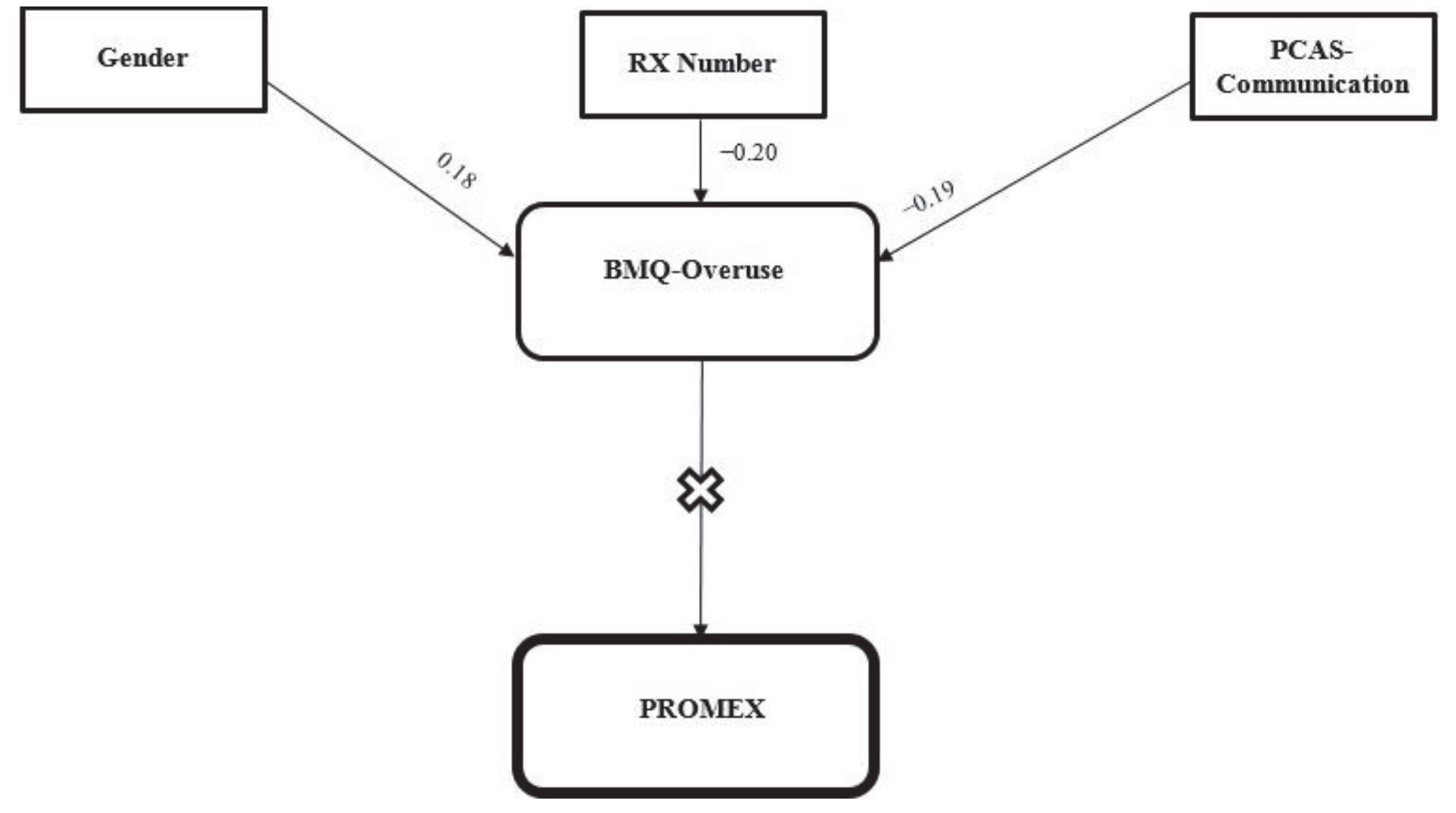

Figure 4-12. Path analysis: The association between PROMEX and BMQ-Overuse. 
Table 4-32. Path analysis: Standardized direct, indirect, and total effects of the variables evaluated on PROMEX and BMQ-Overuse $(n=286)$.

\begin{tabular}{|c|c|c|c|c|c|c|}
\hline Outcome variables & $\mathbf{R}^{2}$ & Predictor variables & $\begin{array}{c}\text { Standardized } \\
\text { direct effect }(\beta)\end{array}$ & $\begin{array}{c}\text { Standardized } \\
\text { indirect effect }(\beta)\end{array}$ & $\begin{array}{l}\text { Standardized } \\
\text { total effect }(\beta)\end{array}$ & p-Value \\
\hline \multirow{8}{*}{$\begin{array}{l}\text { Patient Reviews of } \\
\text { Medication Experiences } \\
\text { (PROMEX) }\end{array}$} & 0.005 & BMQ-Overuse & -0.070 & 0.00 & -0.070 & 0.236 \\
\hline & & PCAS- & 0.00 & 0.013 & 0.013 & 0.264 \\
\hline & & Communication & & & & \\
\hline & & Age & 0.00 & 0.002 & 0.002 & 0.606 \\
\hline & & Education & 0.00 & -0.00 & -0.00 & 0.426 \\
\hline & & $\begin{array}{l}\text { Number of } \\
\text { prescription } \\
\text { medications }\end{array}$ & 0.00 & 0.014 & 0.014 & 0.261 \\
\hline & & Race & 0.00 & 0.004 & 0.004 & 0.447 \\
\hline & & Gender & 0.00 & -0.01 & -0.01 & 0.269 \\
\hline \multirow[t]{7}{*}{ BMQ-Overuse } & 0.111 & PCAS- & -0.194 & 0.00 & -0.194 & $0.001 *$ \\
\hline & & Communication & & & & \\
\hline & & Age & -0.034 & 0.00 & -0.034 & 0.567 \\
\hline & & Education & 0.063 & 0.00 & 0.063 & 0.282 \\
\hline & & $\begin{array}{l}\text { Number of } \\
\text { prescription } \\
\text { medications }\end{array}$ & -0.202 & 0.00 & -0.202 & $0.001 *$ \\
\hline & & Race & -0.059 & 0.00 & -0.059 & 0.321 \\
\hline & & Gender & 0.175 & 0.00 & 0.175 & $0.001 *$ \\
\hline
\end{tabular}

Notes: R-Square $=0.01 .(*)=\mathrm{p}<0.05$. 


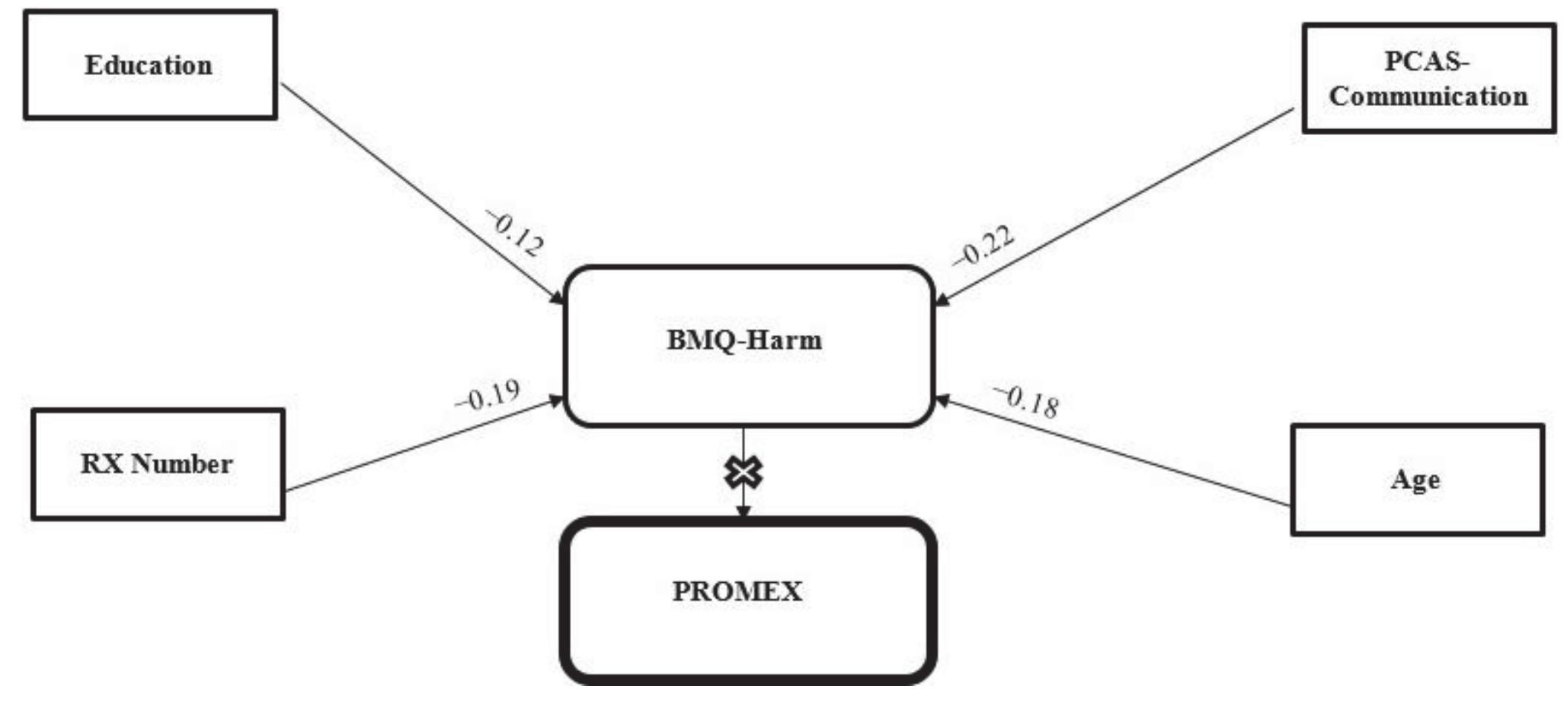

Figure 4-13. Path analysis: The association between PROMEX and BMQ-Harm. 
Table 4-33. Path analysis: Standardized direct, indirect, and total effects of the variables evaluated on PROMEX and BMQ-Harm ( $=286)$.

\begin{tabular}{|c|c|c|c|c|c|c|}
\hline Outcome variables & $\mathbf{R}^{2}$ & Predictor variables & $\begin{array}{c}\text { Standardized } \\
\text { direct effect }(\beta)\end{array}$ & $\begin{array}{c}\text { Standardized } \\
\text { indirect effect }(\beta)\end{array}$ & $\begin{array}{l}\text { Standardized } \\
\text { total effect }(\beta)\end{array}$ & p-Value \\
\hline Patient Reviews of & 0.003 & BMQ-Harm & -0.052 & 0.00 & -0.052 & 0.379 \\
\hline \multirow{7}{*}{$\begin{array}{l}\text { Medication Experiences } \\
\text { (PROMEX) }\end{array}$} & & PCAS- & 0.00 & 0.011 & 0.011 & 0.391 \\
\hline & & Communication & & & & \\
\hline & & Age & 0.00 & 0.009 & 0.009 & 0.398 \\
\hline & & Education & 0.00 & 0.006 & 0.006 & 0.415 \\
\hline & & $\begin{array}{l}\text { Number of } \\
\text { prescription } \\
\text { medications }\end{array}$ & 0.00 & 0.009 & 0.009 & 0.395 \\
\hline & & Race & 0.00 & -0.001 & -0.001 & 0.667 \\
\hline & & Gender & 0.00 & -0.003 & -0.003 & 0.471 \\
\hline \multirow[t]{7}{*}{ BMQ-Harm } & 0.140 & PCAS- & -0.221 & 0.00 & -0.221 & $<0.001^{*}$ \\
\hline & & Communication & & & & \\
\hline & & Age & -0.177 & 0.00 & -0.177 & $0.002 *$ \\
\hline & & Education level & -0.124 & 0.00 & -0.124 & $0.030 *$ \\
\hline & & $\begin{array}{l}\text { Number of } \\
\text { prescription } \\
\text { medications }\end{array}$ & -0.185 & 0.00 & -0.185 & $0.001^{*}$ \\
\hline & & Race & 0.028 & 0.00 & 0.028 & 0.623 \\
\hline & & Gender & 0.070 & 0.00 & 0.070 & 0.208 \\
\hline
\end{tabular}

Notes: R-Square $=0.01 .(*)=\mathrm{p}<0.05$. 


\subsubsection{Multiple Linear Regression for the Association between PROMEX and Both BMQ-Overuse and BMQ-Harm}

In addition to the path analyses, a multiple linear regression analysis was performed to examine the association between PROMEX and beliefs about medications (i.e., BMQoveruse \& BMQ-Harm) controlling for the same variables as in the path analyses. The results of this multiple linear regression in which both BMQ-overuse and BMQ-Harm were included are presented in Table 4-34. Neither BMQ-overuse nor BMQ-Harm influenced PROMEX (i.e., participants' views of online medication rating websites) $(\mathrm{p} \geq 0.05)$.

\subsection{Beliefs about Medications and the Overall Rating of Antihypertensive Regimens}

\subsubsection{The Association between BMQ-Overuse and the Overall Rating of Antihypertensive Regimens}

The results of the regression analysis that examined the association between BMQOveruse and the overall rating of antihypertensive medication are presented in Table 4-35. The overall rating of antihypertensive medication regimens did not significantly influence the BMQ-Overuse controlling for age, race, education, and health literacy, number of prescription medications, comorbidities, gender, and marital status $(\mathrm{p} \geq 0.05)$. Female participants were more likely to have high BMQ-Overuse score compared to male participants $(\beta=1.204, p=0.024)$, controlling for their age, race, education, and health literacy, number of prescription medications, comorbidities, and marital status. On the other hand, the number of prescription medication negatively influenced the BMQ-Overuse score $(\beta=-0.256, p=0.014)$, controlling for their age, race, education, and health literacy, comorbidities, overall rating of antihypertensive medication regimens, gender, and marital status.

\subsubsection{The Association between BMQ-Harm and the Overall Rating of Antihypertensive Regimens}

The results of the regression analysis that examined the association between BMQHarm and the overall rating of antihypertensive medication are presented in Table 4-36. The overall rating of antihypertensive medication regimens significantly influenced the BMQ-Harm ( $\beta=-0.601 ; p=0.035)$. The higher overall rating of antihypertensive medication regimens, the less likely participants believe medications are harmful controlling for age, race, education, health literacy, number of prescription medications, comorbidities, gender, and marital status. Further, age ( $\beta=-0.077 ; \mathrm{p}=0.009)$, and education ( $\beta=-0.219 ; \mathrm{p}=0.024)$, significantly influenced the BMQ-Harm score. The older the participants, and the lower their level of education the less likely they believe that medications are harmful controlling for race, health literacy, number of prescription 
Table 4-34. Multiple linear regression: The association between PROMEX and BMQ-Overuse and BMQ-Harm ( $\mathrm{n}=\mathbf{2 8 6})$.

\begin{tabular}{lcccc}
\hline & & & \multicolumn{2}{c}{$\mathbf{9 5 \%}$ Confidence Limits } \\
\cline { 4 - 5 } Variable & Beta $(\boldsymbol{\beta})$ estimate & p-Value & Lower & Upper \\
\hline BMQ-Overuse & -0.02 & 0.855 & -0.26 & 0.221 \\
BMQ-Harm & -0.04 & 0.707 & -0.30 & 0.209 \\
PCAS- & 0.023 & 0.208 & -0.01 & 0.060 \\
Communication & & & & \\
Age & -0.01 & 0.756 & -0.09 & 0.067 \\
$\begin{array}{l}\text { Number of } \\
\text { prescription }\end{array}$ & 0.146 & 0.227 & -0.09 & 0.385 \\
medications & & & & \\
Education & -0.02 & 0.834 & -0.28 & 0.230 \\
$\begin{array}{l}\text { Race } \\
\text { Gender }\end{array}$ & 0.856 & 0.100 & -0.16 & 1.879 \\
\hline & -0.60 & 0.427 & -2.09 & 0.891 \\
\hline
\end{tabular}

Notes: R-Square $=0.02 .\left({ }^{*}\right)=\mathrm{p}<0.05$. 
Table 4-35. Multiple linear regression: The association between hypertensive participants' overall ratings of their antihypertensive medication regimens and BMQ-Overuse $(n=193)$.

\begin{tabular}{lcccc}
\hline & & & \multicolumn{2}{c}{$\mathbf{9 5 \%}$ Confidence limits } \\
\cline { 4 - 5 } Variable & Beta $(\boldsymbol{\beta})$ estimate & p-Value & Lower & Upper \\
\hline Overall rating & -0.514 & 0.053 & -1.036 & 0.007 \\
of HTN & & & & \\
medications & & & & \\
Age & -0.005 & 0.849 & -0.059 & 0.048 \\
Comorbidity & 0.048 & 0.688 & -0.190 & 0.287 \\
score & & & & \\
Education & 0.070 & 0.434 & -0.107 & 0.249 \\
Race & -0.050 & 0.883 & -0.733 & 0.632 \\
Health literacy & -0.036 & 0.946 & -1.121 & 1.048 \\
Gender & 1.204 & $0.024 *$ & 0.160 & 2.248 \\
Number of & -0.256 & $0.014 *$ & -0.461 & -0.052 \\
prescription & & & & \\
medications & & & & \\
Marital status & -0.208 & 0.659 & -1.138 & 0.722 \\
\hline
\end{tabular}

Notes: R-Square $=0.12 .(*)=\mathrm{p}<0.05$. 
Table 4-36. Multiple linear regression: The association between hypertensive participants' overall ratings of their antihypertensive medication regimens and BMQ-Harm (n=193).

\begin{tabular}{lcccc}
\hline & & & \multicolumn{2}{c}{$\mathbf{9 5 \%}$ Confidence limits } \\
\cline { 4 - 5 } Variable & Beta $(\boldsymbol{\beta})$ estimate & p-Value & Lower & Upper \\
\hline Overall rating & -0.601 & $0.035^{*}$ & -1.161 & -0.042 \\
of HTN & & & & \\
medications & & & & \\
Age & -0.077 & $0.009^{*}$ & -0.135 & -0.019 \\
Comorbidity & -0.041 & 0.747 & -0.298 & 0.214 \\
score & & & & \\
Education & -0.219 & $0.024^{*}$ & -0.411 & -0.028 \\
Race & -0.041 & 0.909 & -0.767 & 0.683 \\
Health literacy & -0.002 & 0.997 & -1.163 & 1.158 \\
Gender & 0.529 & 0.354 & -0.598 & 1.657 \\
Number of & -0.143 & 0.207 & -0.366 & 0.080 \\
prescription & & & & \\
medications & & & & \\
Marital status & 0.246 & 0.626 & -0.752 & 1.244 \\
\hline
\end{tabular}

Notes: R-Square $=0.13 .\left({ }^{*}\right)=\mathrm{p}<0.05$. 
medications, comorbidities, gender, and marital status. Further, age $(\beta=-0.077 ; p=0.009)$, and education $(\beta=-0.219 ; p=0.024)$, significantly influenced the BMQ-Harm score. The older the participants, and the lower their level of education the less likely they believe that medications are harmful controlling for race, health literacy, number of prescription medications, comorbidities, overall rating of antihypertensive medication regimens, gender, and marital status.

\subsection{Older Adult Participants' Views of Online Medication Rating Websites and Adherence to Antihypertensive Medication Regimens}

\subsubsection{Path Model for the Association between PROMEX and Morisky Medication Adherence Scale (MMAS-8)}

The results of the path analysis that examined the association between participants' views of online medication rating websites (i.e., PROMEX) and adherence to antihypertensive medication regimens are presented in Figure 4-14 and Table 4-37. The Morisky Medication Adherence scale (MMAS-8) (i.e., medication adherence) was not associated with participants' views of the online medications rating websites (i.e., PROMEX) ( $\mathrm{p} \geq 0.05)$. Moreover, none of the other exogenous variables (i.e., age, education, gender, etc.) were associated with PROMEX $(\mathrm{p} \geq 0.05)$. However, participants' satisfaction with physician communication (i.e., PCAS-Communication) was positively associated with medication adherence $(\beta=0.22 ; p=0.003)$. Participants with high levels of satisfaction with physician communication (i.e., high PCAS-Communication score) were more likely to have high adherence levels to their antihypertensive medication regimens. Further, age was also positively associated with medication adherence $(\beta=0.26 ; p=0.001)$. Adherence to antihypertensive medication regimens increased as the age of the participants increased. In addition, the overall rating of regimens were positively associated with medication adherence $(\beta=0.21 ; p=0.003)$. The higher the overall rating of regimens, the more likely participants will be adherent to the regimens. Education, gender, age, comorbidities, the number of prescription medications, Beliefs about Medicine (BMQ) General-Overuse domain, and race were not associated with medication adherence ( $\mathrm{p} \geq 0.05)$. Further, BMQ-Harm was negatively associated with participants' overall rating of their regimens $(\beta=-0.18 ; p=0.018)$. Older adults who did not believe medications are generally harmful were more likely to give a high overall rating to their regimens. Health literacy was also positively associated with the overall rating of regimens $(\beta=0.24 ; p=0.001)$. Participants with good health literacy level were more likely to give high overall rating to their regimens. On the other hand, the number of

prescription medications taken was not associated with the overall rating of antihypertensive medications $(\mathrm{p} \geq 0.05)$. An analysis of the fit indices indicated adequate model fit (comparative fit index $=0.985$, adjusted goodness of fit index $=0.995$, root mean square error of approximation $=0.02$, and standardized root mean square residual $=0.035$ ). 


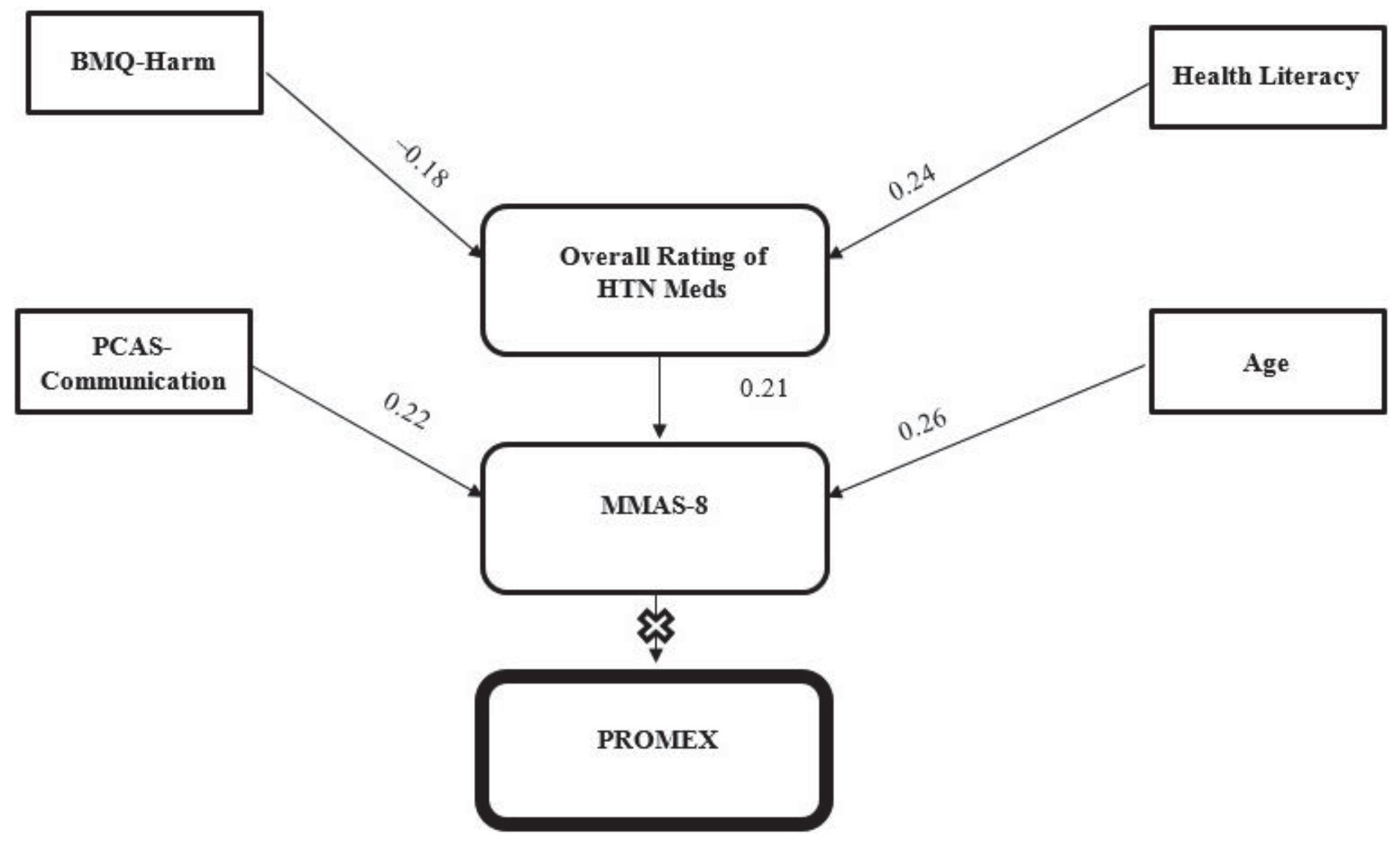

Figure 4-14. Path analysis: The association between PROMEX and MMAS-8 (adherence). 
Table 4-37. Path analysis: Standardized direct, indirect, and total effects of the variables evaluated on PROMEX and MMAS-8 (n=286).

\begin{tabular}{|c|c|c|c|c|c|c|}
\hline Outcome variables & $\mathbf{R}^{2}$ & Predictor variables & $\begin{array}{c}\text { Standardized } \\
\text { direct effect }(\beta)\end{array}$ & $\begin{array}{c}\text { Standardized } \\
\text { indirect effect }(\beta)\end{array}$ & $\begin{array}{l}\text { Standardized } \\
\text { total effect }(\beta)\end{array}$ & p-Value \\
\hline \multirow{12}{*}{$\begin{array}{l}\text { Patient Reviews of } \\
\text { Medication Experiences } \\
\text { (PROMEX) }\end{array}$} & 0.018 & Medication Adherence & -0.13 & 0.00 & -0.13 & 0.079 \\
\hline & & Age & 0.00 & -0.03 & -0.03 & 0.118 \\
\hline & & BMQ-Overuse & 0.00 & 0.002 & 0.002 & 0.836 \\
\hline & & BMQ-Harm & 0.00 & 0.005 & 0.005 & 0.208 \\
\hline & & Race & 0.00 & 0.011 & 0.011 & 0.355 \\
\hline & & Overall Rating HTN Meds & 0.00 & -0.02 & -0.02 & 0.134 \\
\hline & & Communication & 0.00 & -0.03 & -0.03 & 0.136 \\
\hline & & Comorbidities & 0.00 & -0.00 & -0.00 & 0.933 \\
\hline & & Gender & 0.00 & -0.01 & -0.01 & 0.280 \\
\hline & & Health Literacy & 0.00 & -0.006 & -0.006 & 0.176 \\
\hline & & $\begin{array}{c}\text { Number of Prescription } \\
\text { Medications }\end{array}$ & 0.00 & -0.00 & -0.00 & 0.241 \\
\hline & & Education & 0.00 & 0.011 & 0.011 & 0.353 \\
\hline \multirow{8}{*}{$\begin{array}{l}\text { Medication adherence } \\
\text { (MMAS-8) }\end{array}$} & 0.211 & BMQ-Overuse & -0.01 & 0.00 & -0.01 & 0.835 \\
\hline & & Gender & 0.100 & 0.00 & 0.100 & 0.168 \\
\hline & & $\begin{array}{c}\text { Overall Rating of HTN } \\
\text { Meds }\end{array}$ & 0.207 & 0.00 & 0.207 & $0.003 *$ \\
\hline & & Communication & 0.218 & 0.00 & 0.218 & $0.003 *$ \\
\hline & & Age & 0.260 & 0.00 & 0.260 & $0.001 *$ \\
\hline & & Education & -0.08 & 0.00 & -0.08 & 0.272 \\
\hline & & Comorbidities & -0.006 & 0.00 & -0.006 & 0.933 \\
\hline & & Race & -0.08 & 0.00 & -0.08 & 0.275 \\
\hline \multirow{3}{*}{$\begin{array}{l}\text { Overall rating of } \\
\text { hypertension (HTN) } \\
\text { medication regimen }\end{array}$} & 0.123 & BMQ-Harm & -0.17 & 0.00 & -0.17 & $0.018 *$ \\
\hline & & Health Literacy & 0.237 & 0.00 & 0.237 & $0.001 *$ \\
\hline & & $\begin{array}{l}\text { Number of Prescription } \\
\text { Medications (RX number) }\end{array}$ & 0.142 & 0.00 & 0.142 & 0.056 \\
\hline
\end{tabular}

Notes: R-Square $=0.01 .\left({ }^{*}\right)=\mathrm{p}<0.05$. 


\subsubsection{Regression Model for the Association between PROMEX and Morisky Medication Adherence Scale ( MMAS-8)}

The results of the regression model that examined the association between PROMEX and MMAS-8 are presented in Table 4-38. Medication adherence to antihypertensive medication regimens did not influence participants' views of online medication rating websites (i.e., PROMEX) ( $\mathrm{p} \geq 0.05)$, however, comorbidity score did influence PROMEX $(\beta=0.492 ; p=0.045)$. Hypertensive participants with multiple comorbidities or diseases were more likely to have favorable views of online medication rating websites controlling for their medication adherence, satisfaction with physician communication, beliefs about medications, overall rating of antihypertensive medication regimens, age, education, race, health literacy, gender, the number of prescription medications, and marital status.

\subsection{Medication Adherence and the Overall Rating of Antihypertensive Regimens}

The results of the regression model that examined the association between medication adherence and the overall rating of antihypertensive medication regimens are presented in Table 4-39. As with path analysis, the overall rating of antihypertensive medication regimens was positively associated with Morisky Medication Adherence Scale Score $(\mathrm{MMAS}-8)(\beta=0.408 ; p=0.004)$. The higher the overall rating of antihypertensive medication regimens, the higher the adherence level to these medication regimens controlling for age, comorbidities, education, race, health literacy, gender, number of prescription medications, and marital status. Further, age was positively associated with medication adherence to the regimens controlling for the overall rating of these medication regimens, comorbidities, education, race, health literacy, gender, the number of prescription medications, and marital status $(\beta=0.049 ; \mathrm{p}=0.001)$.

\subsection{An Overarching Path Model of the Association between Older Adults' Views of Online Medication Rating Websites and Participant-Reported Outcomes}

The results of the path model that examined the association of participants' online medication rating websites (i.e., PROMEX), health-related quality of life (i.e., PCS-12 and MCS-12), and beliefs about medications (i.e., BMQ-Harm and BMQ-Overuse) are presented in Figure 4-15 and Table 4-40. The healthcare decision sharing preference was positively associated with $\operatorname{PROMEX}(\beta=0.179 ; p=0.003)$. Participants who like to have an equal partnership with their physicians concerning their healthcare were likely to have favorable views of the online medication rating websites compared to those who like to either keep their healthcare decision in their own hands or leave it in the doctors' hands. Further, both PCS-12 $(\beta=-0.129 ; p=0.033)$ and MCS $-12(\beta=-0.130 ; p=0.032)$ of the SF12 v2 were negatively associated with PROMEX. Participants with poor physical and mental HRQoL were more likely to have favorable views of the online medication rating websites compared to those with good quality of life. In addition, comorbidity score was positively associated with PROMEX $(\beta=0.059 ; p=0.007)$. Participants with multiple diseases or comorbidities were more likely to view the online medication rating websites 
Table 4-38. Multiple linear regression: The association between participants' medication adherence (MMAS-8 Score) and PROMEX $(n=286)$.

\begin{tabular}{lcccr}
\hline & & & \multicolumn{2}{c}{$\mathbf{9 5 \%}$ Confidence limits } \\
\cline { 4 - 5 } Variable & Beta $(\boldsymbol{\beta})$ estimate & p-Value & Lower & Upper \\
\hline MMAS-8 & -0.460 & 0.146 & -1.084 & 0.163 \\
(adherence) & & & & \\
PCAS- & 0.040 & 0.125 & -0.011 & 0.092 \\
Communication & & & & \\
BMQ-Overuse & 0.078 & 0.670 & -0.284 & 0.441 \\
BMQ-Harm & 0.082 & 0.633 & -0.257 & 0.422 \\
Overall rating & -0.425 & 0.446 & -1.529 & 0.677 \\
of HTN & & & & \\
medications & & & & \\
Age & 0.030 & 0.608 & -0.085 & 0.146 \\
Comorbidity & 0.492 & $0.045 *$ & 0.009 & 0.975 \\
score & & & & \\
Education & -0.069 & 0.715 & -0.445 & 0.306 \\
Race & 0.953 & 0.171 & -0.416 & 2.322 \\
Health literacy & 0.406 & 0.720 & -1.831 & 2.644 \\
$\begin{array}{l}\text { Gender } \\
\text { Number of }\end{array}$ & -1.321 & 0.235 & -3.513 & 0.869 \\
prescription & -0.020 & 0.927 & -0.454 & 0.414 \\
medications & & & & \\
Marital status & -0.073 & 0.939 & -1.963 & 1.817 \\
\hline
\end{tabular}

Notes: R-Square $=0.09 .(*)=\mathrm{p}<0.05$. 
Table 4-39. Multiple linear regression: The association between overall ratings of antihypertensive medication regimens and MMAS-8 score $(n=193)$.

\begin{tabular}{lcccc}
\hline & & & \multicolumn{2}{c}{$\mathbf{9 5 \%}$ Confidence limits } \\
\cline { 4 - 5 } Variable & Beta $(\boldsymbol{\beta})$ estimate & p-Value & Lower & Upper \\
\hline $\begin{array}{l}\text { Overall rating } \\
\text { of HTN }\end{array}$ & 0.408 & $0.004^{*}$ & 0.131 & 0.684 \\
medications & & & & \\
$\begin{array}{l}\text { Age } \\
\text { Comorbidity }\end{array}$ & 0.049 & $0.001^{*}$ & 0.020 & 0.078 \\
score & 0.020 & 0.749 & -0.119 & 0.133 \\
Education & & & & \\
Race & -0.053 & 0.268 & -0.143 & 0.046 \\
Health literacy & -0.124 & 0.502 & -0.503 & 0.220 \\
$\begin{array}{l}\text { Gender } \\
\text { Number of }\end{array}$ & 0.478 & 0.102 & -0.103 & 1.047 \\
prescription & 0.403 & 0.153 & -0.107 & 0.999 \\
medications & -0.010 & 0.851 & -0.113 & 0.103 \\
Marital status & & & & \\
\hline
\end{tabular}

Notes: R-Square $=0.19 .(*)=\mathrm{p}<0.05$. 
Figure 4-15. Path analysis: The association between PROMEX and PROs.

Notes: Dashed lines represent the indirect relationships. Continuous lines represent direct relationships. 


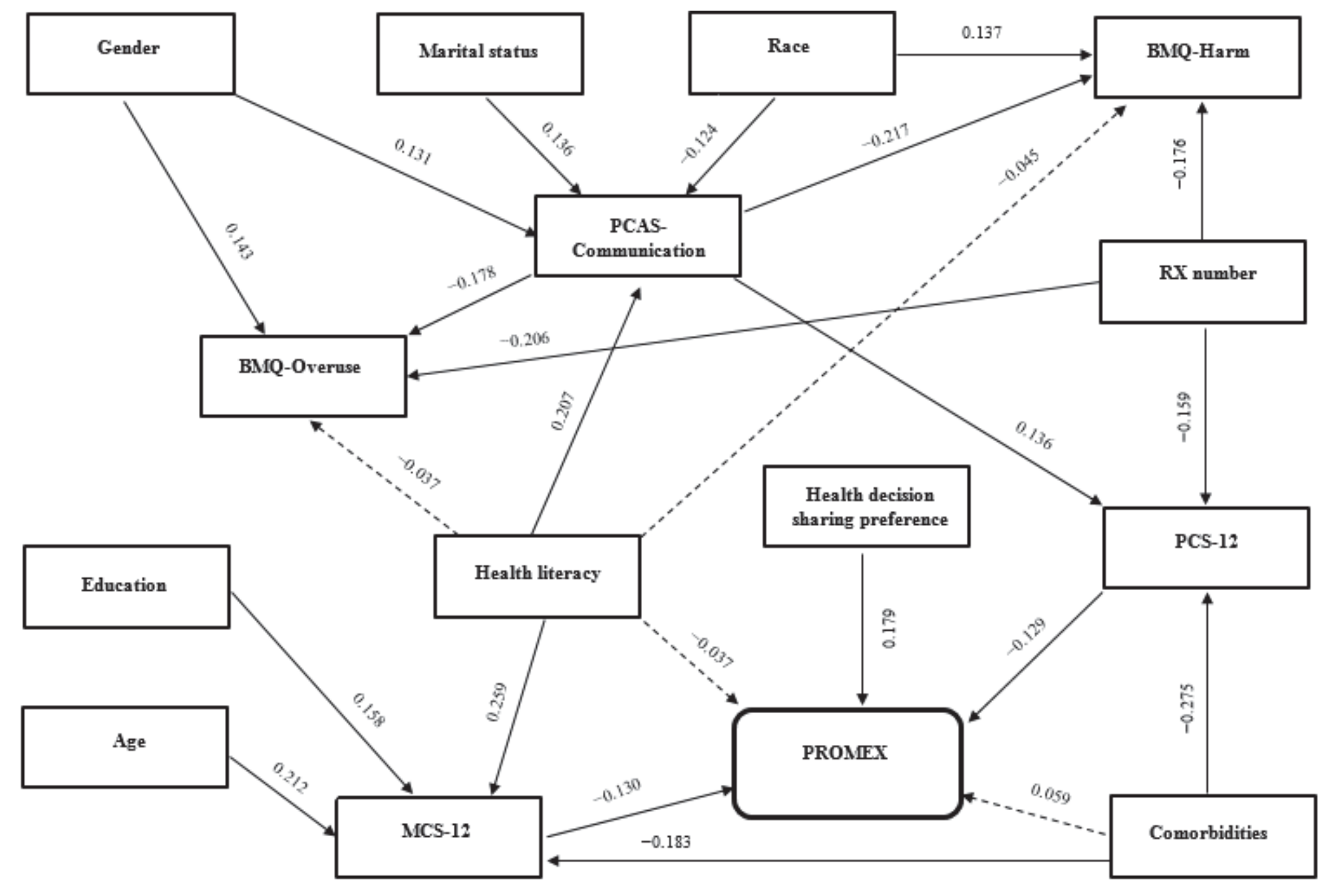


Table 4-40. Standardized direct, indirect, and total effects of the variables evaluated on PROMEX, PCS-12, MCS-12, BMQ-Harm and BMQ-Overuse, and PCAS-Communication scales $(\mathrm{n}=\mathbf{2 8 6})$.

\begin{tabular}{|c|c|c|c|c|c|c|}
\hline Outcome variables & $\mathbf{R}^{2}$ & Predictor variables & $\begin{array}{c}\text { Standardized } \\
\text { direct effect }(\beta)\end{array}$ & $\begin{array}{c}\text { Standardized } \\
\text { indirect effect }(\beta)\end{array}$ & $\begin{array}{l}\text { Standardized } \\
\text { total effect }(\beta)\end{array}$ & p-Value \\
\hline \multirow{12}{*}{$\begin{array}{l}\text { Patient Reviews of } \\
\text { Medication Experiences } \\
\text { (PROMEX) }\end{array}$} & 0.063 & $\begin{array}{c}\text { Healthcare decision } \\
\text { sharing }\end{array}$ & 0.179 & 0.00 & 0.179 & $0.003 *$ \\
\hline & & $\begin{array}{c}\text { SF-12v2 Physical } \\
\text { Component Summary } \\
\text { (PCS-12) }\end{array}$ & -0.129 & 0.00 & -0.129 & $0.033^{*}$ \\
\hline & & $\begin{array}{c}\text { SF-12v2 Mental } \\
\text { Component Summary } \\
\text { (MCS-12) }\end{array}$ & -0.130 & 0.00 & -0.130 & $0.032 *$ \\
\hline & & PCAS-Communication & 0.00 & -0.02 & -0.02 & 0.057 \\
\hline & & Age & 0.00 & -0.01 & -0.01 & 0.319 \\
\hline & & Comorbidities & 0.00 & 0.059 & 0.059 & $0.007 *$ \\
\hline & & Education & 0.00 & -0.01 & -0.01 & 0.177 \\
\hline & & Race & 0.00 & 0.003 & 0.003 & 0.168 \\
\hline & & Gender & 0.00 & -0.00 & -0.00 & 0.155 \\
\hline & & Health literacy & 0.00 & -0.037 & -0.037 & $0.034 *$ \\
\hline & & Marital status & 0.00 & -0.01 & -0.01 & 0.141 \\
\hline & & $\begin{array}{c}\text { Number of prescription } \\
\text { medications }\end{array}$ & 0.00 & -0.02 & -0.02 & 0.113 \\
\hline
\end{tabular}


Table 4-40. Continued.

\begin{tabular}{|c|c|c|c|c|c|c|}
\hline Outcome variables & $\mathbf{R}^{2}$ & Predictor variables & $\begin{array}{c}\text { Standardized } \\
\text { direct effect }(\beta)\end{array}$ & $\begin{array}{c}\text { Standardized } \\
\text { indirect effect }(\beta)\end{array}$ & $\begin{array}{l}\text { Standardized } \\
\text { total effect }(\beta)\end{array}$ & p-Value \\
\hline SF-12v2 Mental & 0.179 & Marital status & 0.089 & 0.00 & 0.089 & 0.124 \\
\hline Component Summary & & PCAS-Communication & 0.068 & 0.00 & 0.068 & 0.251 \\
\hline \multirow[t]{6}{*}{$(\mathrm{MCS}-12)$} & & Age & 0.212 & 0.00 & 0.212 & $0.001 *$ \\
\hline & & Education & 0.158 & 0.00 & 0.158 & $0.007^{*}$ \\
\hline & & Health literacy & 0.259 & 0.00 & 0.259 & $<0.001^{*}$ \\
\hline & & Comorbidities & -0.183 & 0.00 & -0.183 & $0.001 *$ \\
\hline & & Gender & 0.00 & 0.008 & 0.008 & 0.312 \\
\hline & & Race & 0.00 & -0.00 & -0.00 & 0.319 \\
\hline SF-12v2 Physical & 0.176 & Age & -0.076 & 0.00 & -0.076 & 0.193 \\
\hline Component Summary & & PCAS-Communication & 0.136 & 0.00 & 0.136 & $0.017^{*}$ \\
\hline \multirow[t]{7}{*}{$(\mathrm{PCS}-12)$} & & $\begin{array}{c}\text { Number of prescription } \\
\text { Medications }\end{array}$ & -0.159 & 0.00 & -0.159 & $0.017^{*}$ \\
\hline & & Comorbidities & -0.275 & 0.00 & -0.275 & $<0.001 *$ \\
\hline & & Education & -0.007 & 0.00 & -0.007 & 0.904 \\
\hline & & Race & 0.00 & -0.01 & -0.01 & 0.125 \\
\hline & & Gender & 0.00 & 0.017 & 0.017 & 0.110 \\
\hline & & Health literacy & 0.00 & 0.028 & 0.028 & 0.052 \\
\hline & & Marital status & 0.00 & 0.018 & 0.018 & 0.104 \\
\hline \multirow[t]{4}{*}{ PCAS-Communication } & 0.1 & Race & -0.123 & 0.00 & -0.123 & $0.043^{*}$ \\
\hline & & Gender & 0.131 & 0.00 & 0.131 & $0.030^{*}$ \\
\hline & & Health literacy & 0.206 & 0.00 & 0.206 & $0.001 *$ \\
\hline & & Marital status & 0.135 & 0.00 & 0.135 & $0.025^{*}$ \\
\hline
\end{tabular}


Table 4-40. Continued.

\begin{tabular}{|c|c|c|c|c|c|c|}
\hline Outcome variables & $\mathbf{R}^{2}$ & Predictor variables & $\begin{array}{c}\text { Standardized } \\
\text { direct effect }(\beta)\end{array}$ & $\begin{array}{c}\text { Standardized } \\
\text { indirect effect }(\beta)\end{array}$ & $\begin{array}{l}\text { Standardized } \\
\text { total effect }(\beta)\end{array}$ & p-Value \\
\hline \multirow[t]{6}{*}{ BMQ-Harm } & 0.1 & PCAS-Communication & -0.21 & 0.00 & -0.21 & $0.001 *$ \\
\hline & & Race & 0.136 & 0.00 & 0.136 & $0.014^{*}$ \\
\hline & & $\begin{array}{c}\text { Number of prescription } \\
\text { medications }\end{array}$ & -0.17 & 0.00 & -0.17 & $0.003^{*}$ \\
\hline & & Gender & 0.00 & -0.02 & -0.02 & 0.064 \\
\hline & & Health literacy & 0.00 & -0.044 & -0.044 & $0.013^{*}$ \\
\hline & & Marital status & 0.00 & -0.02 & -0.02 & 0.058 \\
\hline \multirow[t]{6}{*}{ BMQ-Overuse } & 0.1 & PCAS-Communication & -0.178 & 0.00 & -0.178 & $0.002 *$ \\
\hline & & Gender & 0.143 & 0.00 & 0.143 & $0.009 *$ \\
\hline & & $\begin{array}{c}\text { Number of prescription } \\
\text { medications }\end{array}$ & -0.206 & 0.00 & -0.206 & $0.001^{*}$ \\
\hline & & Race & 0.00 & 0.022 & 0.022 & 0.095 \\
\hline & & Health literacy & 0.00 & -0.03 & -0.03 & $0.025^{*}$ \\
\hline & & Marital status & 0.00 & -0.02 & -0.02 & 0.074 \\
\hline
\end{tabular}

Notes: $(*)=p<0.05$ 
favorably compared to the healthy participants. Further, health literacy was negatively associated with PROMEX $(\beta=-0.037 ; \mathrm{p}=0.034)$. Participants with good health literacy were less likely to view the online medication rating websites favorably than those with limited health literacy. Age, education, and health literacy were positively associated with the MCS-12, whereas, the comorbidity score was negatively associated with it $(\mathrm{p}<0.05)$. The PCAS-Communication was positively associated with the PCS-12, however, the number of prescription medication and the comorbidity score were negatively associated with it $(p<0.05)$. Gender, health literacy, and marital status were positively associated the PCAS-Communication, whereas, race was negatively associated with it $(\mathrm{p}<0.05)$. Race was positively associated with BMQ-Harm; however, the PCAS-Communication, health literacy, and the number of prescription medications were negatively associated with it $(\mathrm{p}<0.05)$. Finally, health literacy, number of prescription medications, and the PCASCommunication were negatively associated with BMQ-Overuse; however, gender was positively associated with it. An analysis of the fit indices indicated adequate model fit (comparative fit index $=0.977$, adjusted goodness of fit index $=0.994$, root mean square error of approximation $=0.03$, standardized root mean square residual $=0.03$ ). 


\section{CHAPTER 5. DISCUSSION}

\section{$5.1 \quad$ Overview}

The advent of the Internet has revolutionized health care delivery (Campbell \& Nolfi, 2005). Today, patients can go online to browse an immense amount of educational information about a variety of health conditions and treatment options. Further, patients can go online and read other patients' feedback about different physicians and health products to make informed decisions before choosing a certain physician or over-thecounter (OTC) medication (Emmert, Meier, et al., 2013; Faber et al., 2009). Medication rating websites are a new frontier in the online health-related websites market. Currently, patients can go online and post their feedback about the medications they are taking for others to read. These websites ask patients who want to share their medication experiences with others to rate these medications in terms of their effectiveness, side effects, cost, etc... The online medication rating websites have the potential as other online health-related information websites, to empower patients to ask more questions during their physician office visits, adopt healthy lifestyle habits, follow their physicians' advice more closely, and improve their health outcomes (Iverson, Howard, \& Penney, 2008; Lau, Campbell, Tang, Thompson, \& Elliott, 2014). These potential benefits of the online medication rating websites are needed especially among the U.S. elderly ( $\geq 65$ years).

According to Pew Internet and American Life Project, six in ten or 59\% of U.S. seniors reported using the Internet in 2013 (i.e. 59\%) (Duggan \& Smith, 2013). Older adults are more likely to have chronic diseases (i.e., diabetes and hypertension) than their younger counterparts (N. C. o. Aging, 2014). Additionally, more than $80 \%$ of U.S. older adults take at least one prescription medication, and about one third take five or more prescription medications daily (Qato et al., 2008). Further, infirm patients such as elderly are prone to medication side effects due to their diminished physiological reserve (Wasson, 2008). Moreover, several studies that examined the appropriateness of physician prescribing patterns among elderly have found multiple prescribing patterns that were inconsistent with evidence-based practice (Goulding, 2004; Spinewine et al., 2007). Therefore, older adults are well poised to evaluate the usefulness of the online medication rating websites.

The aim of this study was to examine the association between older adults' views of the online medication rating websites in terms of facilitating patient-physician communication and participant-reported outcomes, i.e., and their satisfaction with physician communication, health-related quality of life, beliefs about medications, and medication adherence. Further, the association between older adults' actual overall rating/evaluation of their antihypertensive medications and each of the aforementioned participant-reported outcomes was examined. The final sample of this study was 286 participants that examined the association between the value of online medication rating websites to older adults (i.e., PROMEX) and each of the participant-reported outcomes with the exception of medication adherence. The sample size for both path and regression 
analyses that examined the association between PROMEX and medication adherence among hypertensive participants was 193. Finally, the sample size for the regression analyses that examined the association between each of the participant-reported outcomes and the overall rating of antihypertensive medications among the hypertensive participants was 193 .

\subsection{Patient Reviews of Medication Experiences (PROMEX)}

In order to assess older adults' views of online medication rating websites, we developed a self-report questionnaire, Patient Reviews of Medication Experiences (PROMEX). First, participants were presented with a table that included five commonly prescribed antihypertensive medications that were rated online by anonymous users. Then, participants were asked to answer seven questions that explored their views of online medication rating websites like the example in table. After refining this instrument, the final questionnaire includes six questions with a Cronbach's alpha of 0.85. Although we proposed two domains or constructs within this questionnaire, only one construct was extracted from it. We named this construct the "value of online medication rating websites to older adults". Therefore, PROMEX is sufficiently reliable to measure the value of online medication rating websites in terms of facilitating physician-patient communication among this surveyed sample of older adults (Field, 2009).

\subsection{PROMEX and Participant-Reported Outcomes (PROs)}

Participants' views of online medication rating websites (i.e., PROMEX) were not influenced by the sociodemographic factors (Table 4-7). Further, PROMEX was not associated with participants' health-related quality of life or HRQoL, satisfaction with physician communication, beliefs about medications, and medication adherence

(Table 4-21). However, in the path analyses that we conducted to determine the causal effects among the variables of participants' views of online medication rating websites (PROMEX), HRQoL (PCS-12 and MCS-12), satisfaction with physician communication (PCAS-Communication), and beliefs about medications (BMQ-Overuse and BMQHarm) several variables directly or indirectly influenced PROMEX.

The Physical Component Summary (PCS-12) of the SF-12v2 that measured the physical quality of life of the older adult participants in the past four weeks was significantly associated with their views of online medication rating websites (PROMEX) $(\mathrm{p}<0.05)$ (Figure 4-11 and Table 4-27). Participants with poor physical HRQoL were more likely to have favorable views of online medication rating websites than those with good physical HRQoL $(\beta=-0.13, \mathrm{p}=0.040)$. Further, older adults with poor physical HRQoL were more likely to be unsatisfied with their physician communication than those with good physical HRQoL $(\beta=0.13, p=0.035)$. Additionally, participants with poor physical HRQoL were more likely to have multiple comorbidities (i.e., chronic diseases) than those with good physical HRQoL $(\beta=-0.36, p<0.001)$. Moreover, older 
participants were more likely to have poor physical HRQoL $(\beta=-0.12, p=0.048)$. Further, participants with poor physical HRQoL were more likely to be on multiple prescription medications than those with good physical HRQoL $(\beta=-0.16, p=0.017)$ (Table 4-40).

Similarly, the Mental Component Summary (MCS-12) of the SF-12v2 that measured the mental HRQoL of the participants in the past four weeks was significantly associated with participants' views of online medication rating websites (PROMEX) $(p<0.05)$

(Figure 4-15 and Table 4-40). Contrary to the PCS-12, the significant association between MCS-12 and PROMEX was not detected in the path model the investigated the association between only MCS-12 and PROMEX, but rather in the overarching path model that included the entire participant-reported outcome variables. Participants with poor mental HRQoL were more likely to have favorable views of online medication rating websites compared to participants with good HRQoL $(\beta=-0.13, p=0.032)$. Further, participants with poor mental HRQoL were more likely to have multiple comorbidities than those with good mental HRQoL $(\beta=-0.18, p=0.001)$. In addition, participants with poor mental HRQoL were more likely to have limited health literacy $(\beta=0.26, p<0.001)$. Interestingly, participants who were younger $(\beta=0.21, p=0.001)$ and participant who had less education $(\beta=0.16, p=0.007)$ were more likely to have poor mental HRQoL.

Therefore, the older adults in this study who had poor physical and mental HRQoL believed that the online medication rating websites are useful and helpful in facilitating the communication with their physicians. Further, the fact that the older adults with poor HRQoL were more likely to have multiple comorbidities, take multiple prescription medications, have limited health literacy, and lower education is consistent with the literature (Low \& Molzahn, 2007). What is more interesting is that these very factors not only influenced the participants' HRQoL they also influenced participants' views of online medication rating websites. Elderly participants with multiple comorbidities (i.e., chronic diseases) were more likely to view the online medication rating websites more favorably than their healthier counterparts were. The hypertensive participants' views of online medication rating websites were directly influenced by their comorbidity score as shown in Table 4-39 controlling for sociodemographics, medication adherence, number of prescription medications, overall rating of antihypertensive medications, satisfaction with physician communication, and beliefs about medications $(\beta=0.492, p=0.045)$. Further, the comorbidity score indirectly influenced the participants' views of online medication rating websites (i.e., hypertensive and non-hypertensive) $(\beta=0.059, p=0.007)$ (Table 4-40). In addition, participants with limited health literacy were more likely to have positive views of online medication rating websites than those with good health literacy $(\beta=-0.037, p=0.034)$ (Table 4-40). Moreover, participants who liked to share the health decision with physicians were more likely to view the online medication rating websites more favorably than those who liked to keep the health decision to themselves or leave it to their physicians $(\beta=0.179, \mathrm{p}=0.003)$ (Table 4-40).

These findings suggest that older adults with multiple chronic health conditions and limited health literacy perceive the online medication rating websites more useful in terms of facilitating the communication with their physicians than their healthier and 
more educated counterparts. This partly may be explained by the fact that the online patients' reviews of medications were written in nonprofessional terms and show the rating of medications in a simple way (i.e., star ratings) for an average person to understand. However, well-educated older adults with good health literacy level may prefer to refer to other traditional sources of information (i.e., books, medical articles, magazines) should they need to know about a certain medication (Campbell \& Nolfi, 2005). Further, older adults with poor physical HRQoL were more likely to be on multiple medications. Therefore, they are more likely to experience medication side effects (Borchelt, 1994). This is consistent with the medical literature, in which medication side effects had negative impact on both the physical and mental aspects of patients' quality of life (Bebbington et al., 2009). Hence, the favorable opinion of online patients' reviews of medications among older adults with poor physical HRQoL may stem from the fact that they want to know about other treatment options that have better safety and efficacy profiles than their current medications. In addition, participants with poor physical HRQoL were more likely to be unsatisfied with physician communication.

Effective physician-patient communication, in which physicians recognize patients' needs and concerns, listen attentively, and explain thoroughly in a simplified way the treatment plan to their patient, is quintessential in any patient-centered care model (Berwick, 2009). Research has shown that the quality of physician-patient communication can indirectly predict multiple health outcomes such as medication adherence and quality of life (Stewart, 1995; Street Jr et al., 2009). Therefore, the older adult participants in this study with poor physical HRQoL, who were more likely to be unsatisfied with their physicians' communication, may have felt that the online patients' reviews of medication could facilitate their communication with physicians. This is further substantiated when we know that the average amount of time that physicians spend with their patients is fifteen minutes ((Belzer, 1999; Morgan, 2003). Further, research has shown that older adults receive less information from physicians than their younger counterparts receive during their clinic visits (Beisecker, 1988). Thus, older adults may want to use the little time they have with their physicians more efficiently, and the online patients' reviews of medications may help them achieve this goal. Further, older adults with multiple comorbidities, who were more likely to have poor quality of life (i.e., both physical and mental health), were more likely as well to have favorable views of the online patients' reviews of medications. This is consistent with the literature in which the presence of multiple health issues among older adults motivated them to seek health-related information online (Meloche, 2013).

Most patients like to have a partnership or a therapeutic alliance with physicians to manage their health conditions (Bernabeo \& Holmboe, 2013; Mazur, Hickam, Mazur, \& Mazur, 2005). However, many older adults complain about being marginalized in their health decision-making process (Gladden, 2000). The majority of participants in this study expressed their desire to have an equal partnership with their physicians (Table 4-1). Further, older adults in this study who liked to have an equal partnership with their physicians were more likely to have favorable views of online patients' reviews of medications. Therefore, these older adults were more likely to believe that the online patient reviews of medications will facilitate the communication with their 
physicians. Hence, the online patients' reviews of medications could play a patientempowering role like other online health-related information (Meloche, 2013; Suter, Suter, \& Johnston, 2011).

The participants' satisfaction with physician communication (PCAS-Communication) was not associated with their views of the online medication rating websites (PROMEX) (Figure 4-9 and Table 4-23). However, multiple sociodemographic factors influenced the participants' satisfaction with their physicians' communication. Female, married, and Caucasian non-Hispanic participants with good health literacy were likely to have higher PCAS-Communication scores $(p<0.05)$ (Table 4-23 and Table 4-40). Therefore, these participants were more likely to be satisfied with their physician communication. Our findings are consistent with the literature. Female patients are usually more satisfied with the provided health care than their male counterparts (Arora \& McHorney, 2000; Carlin et al., 2012). Further, married patients are more likely to be satisfied with medical care that the unmarried patients (Hall \& Dornan, 1990; Xiao \& Barber, 2008). In addition, patients with better education and health literacy are more likely to be satisfied with the received health care than the patients with less education and limited health literacy (Xiao \& Barber, 2008). Moreover, whites are more likely than minorities (i.e., blacks, Hispanics, and Asians) to be satisfied with the provided health care (Haviland, Morales, Reise, \& Hays, 2003). Finally, the PCAS-Communication and PCAS-interpersonal treatment were highly correlated. The participants in this study, who were satisfied with their physician communication, were also likely to be satisfied with their physician interpersonal treatment (i.e., amount of time spent, friendliness and warmth received, patience, care and concern, and respect).

Participants' general beliefs about medications (BMQ-Overuse and BMQ-Harm) were not associated with their views of the online medication rating websites (PROMEX) (Figures 4-12, 4-13 and Tables 4-33, 4-34). However, the BMQ-Overuse and BMQHarm were influenced by several factors. The BMQ-Overuse and BMQ-Harm scores were significantly lower among participants who take multiple prescription medications $(\mathrm{p}<0.05)$ (Tables 4-13 and 4-14). As the number of prescription medications taken by the participants increased, their BMQ-Overuse and BMQ-Harm scores decreased. Further, participants taking multiple prescription medications were less likely to believe that prescription medications are inherently harmful and overprescribed by physicians $(\mathrm{p}<0.05)$ (Table 4-40). This is consistent with the literature, which shows that patients who take multiple prescription medications are more likely to have positive beliefs about medications than patients who do not take any prescription medications (Ramstrom, 2006). Further, participants with good health literacy level were more likely to have a lower BMQ-Overuse and BMQ-Harm scores than their counterparts with limited health literacy $(\mathrm{p}<0.05)$ (Table 4-40). This is also consistent with the literature; patients with high literacy level are more likely to have positive beliefs about medications in comparison to the ones with limited health literacy level (Horne et al., 2004; Isacson \& Bingefors, 2002). Additionally, research has shown that effective physician-patient communication had a positive impact on patients' beliefs about medication (Bultman \& Svarstad, 2000). In our study we have found that the higher the satisfaction with physician communication (i.e., high PCAS-Communication score), the more likely the 
participants will have positive beliefs about medications (low BMQ-Overuse and BMQHarm scores) $(p<0.05)$ (Table 4-40). The impact of participants' gender on their beliefs about medications is controversial. Some studies have indicated that men are more likely to have negative views about prescription medications in comparison to women (Horne et al., 2004). However, other studies have shown the opposite (Isacson \& Bingefors, 2002). In this study, we have found that women are more likely to believe that prescription medications are being overused and overprescribed (i.e., high BMQ-Overuse scores) $(\mathrm{p}<0.05)$ (Tables 4-33 and 4-41). Race is another interesting factor. Research has shown that Caucasians are more likely to have positive views of prescription medications than minorities (i.e., blacks, Hispanics, and Asians), who tend to have negative views of medications (Horne et al., 2004; Iihara et al., 2004). Similarly, Caucasians participants in this study were less likely to believe that prescription medications are inherently harmful or poisonous (i.e., high BMQ-Harm score) in comparison to minority participants (i.e., African Americans, Hispanics, and Asians) $(\mathrm{p}<0.05)$ (Tables 4-34 and 4-41).

Adherence to antihypertensive medication regimens among the study participants who reported having hypertension was measured using Morisky Medication Adherence scale (MMAS-8). The number of participants with hypertension who reported low or medium adherence levels (i.e., MMAS-8 score $\leq 6$ ) was 111 participants, which represented $50.9 \%$ of the hypertensive subsample (Table 4-16). We examined the association between the hypertensive participants' views of online medication rating websites (i.e., PROMEX) and their adherence to their antihypertensive medications; however, no significant association was found $(\mathrm{p} \geq 0.05)$ (Figure 4-14 and Table 4-38). Nonetheless, adherence to antihypertensive medication regimens was associated with several variables. Participants who were satisfied with their physicians' communication (i.e., high PCAS-Communication scores) were more likely to achieve high adherence levels to their antihypertensive medication regimens (i.e., high MMAS-8 scores) than their unsatisfied counterparts (i.e., low PCAS-Communication scores). This is consistent with the findings in the literature that effective physician-patient communication is highly correlated with better patient adherence (Zolnierek \& DiMatteo, 2009). Further, participant adherence to antihypertensive medication regimens improved with increasing age (Table 4-17). Older participants were more likely to be adherent to their prescribed antihypertensive medication regimens (Table 4-38). The role of age as a determinant of medication adherence is controversial. Some studies have found that medication nonadherence is common among the older adults due to their tendency to forget (KrouselWood et al., 2009). However, our results seem to support the findings of other studies, which suggest that older adults are more likely to be adherent to their prescribed medication regimens than their younger counterparts (Billups et al., 2000; Cohen et al., 2012).

Race is another sociodemographic factor that has shown to affect patient adherence to prescription medications (Rolnick, Pawloski, Hedblom, Asche, \& Bruzek, 2013). Research has shown that racial differences in medication adherence remains an issue even after controlling for insurance status (Zhang \& Baik, 2014). In our study, race was not associated with adherence to antihypertensive medications in both the path and regression analyses; however, the proportion of participants with high level of adherence 
to antihypertensive medications (i.e., MMAS-8 score=8) was significantly higher among Caucasians compared to African Americans, Hispanics, and the other racial groups (Table 4-17). Additionally, participants with good health literacy level and positive views of medications (i.e., low BMQ-Harm scores) were more likely to have a high overall rating of their antihypertensive medication regimens. This, in turn was positively associated with medication adherence (Figure 4-14). Participants with high overall rating of their antihypertensive medication regimens were more likely to be adherent to these medication regimens. This supports the findings of other published studies, which found a positive association between hypertensive patients' overall satisfaction with their antihypertensive medications and their medication adherence levels (Bharmal et al., 2009; Sa'ed et al., 2013). Finally, although researchers have shown significant association between patient beliefs about medications and medication adherence, this association was not significant among our participants in our study (Horne \& Weinman, 1999).

\subsection{Participants' Rating of Their Antihypertensive Medications and Participant- Reported Outcomes (PROs)}

We asked the hypertensive participants to write down the names of their antihypertensive medications and rate each one of them on a five-point Likert scale (i.e., 1-low to 5-high) based on their effectiveness, side effects, cost of medication, ease of use, food interactions, and then provide an overall rating to that medication. Since older adults with hypertension may take multiple medications to control their hypertension, we provided space for four different antihypertensive medications. The higher the rating of the medication, the more likely the participants are satisfied with their antihypertensive medications. Ten or more hypertensive participants rated the following antihypertensive medications: Atenolol, Amlodipine, Hydrochlorothiazide (HCTZ), Lisinopril, Losartan, Valsartan, and Metoprolol. Then, we compared the participants' ratings of these medications in terms of their effectiveness, side effects, cost of medication, and ease of use, food interactions, and overall ratings (Figure 4-2 and Table 4-20). Although there was not a significant difference in the ratings of these medications given the small sample size, participants rated them differently. For example, the overall ratings of Amlodipine and lisinopril were high and comparable to the other antihypertensive medications; however, their side effect ratings were the lowest compared to the other antihypertensive medications (Figure 4-7). This could be attributable to the higher likelihood of druginduced throat irritation and cough as well as angioedema particularly among the African Americans in the case of Lisinopril (Gibbs, Lip, \& Beevers, 1999; Naidu, Usha, Rao, \& Shobha, 2000). Further, the incidence of dizziness and ankle edema with Amlodipine is higher among the elderly hypertensive patients compared to their younger counterparts (Kloner, Sowers, DiBona, Gaffney, \& Marilee, 1996; Naidu et al., 2000). Another example is with Hydrochlorothiazide (HTCZ), which had the highest cost of medication rating compared to the other antihypertensive medications that were rated by ten or more

participants (Figure 4-5). This could be explained by the fact that Hydrochlorothiazide as well as other diuretics had the lowest out-of-pocket expense per Medicare beneficiary 
with hypertension per year, according to the U.S. Agency for Healthcare Research and Quality (Townsend et al., 2011).

However, since we are interested in the participant-specific ratings of antihypertensive medication regimens and not the medication-specific ratings, we have taken the average rating of each aspect of medication use (i.e., effectiveness, side effects, cost of medication, ease of use, food interaction, and the overall ratings) for every participant who reported taking medications for hypertension. The average participantspecific ratings of the antihypertensive medication regimens across the visited senior centers are listed in Table 4-18. All of the participant-specific aspects of medication use were positively correlated with each other $(p<0.05)$ (Table 4-19). However, the correlations between the rated aspect of medication use and the participant-reported outcomes were not all significant (Table 4-22). The participant-specific effectiveness rating of the antihypertensive medication regimens was positively correlated with the PCAS-Communication, PCAS-interpersonal treatment, and with the PCS-12 of the SF$12 \mathrm{v} 2(\mathrm{p}<0.05)$. Further, participant-specific ease of use rating of the antihypertensive medication regimens was positively correlated with the PCAS-Communication $(p<0.05)$. Moreover, participant-specific overall rating of the antihypertensive medication regimens was positively correlated with the PCAS-Communication and PCAS-interpersonal treatment and was negatively correlated with the BMQ-Harm. The participant-specific overall rating of the antihypertensive medication regimens total correlation with the other rated medication use aspects (i.e., effectiveness, side effects, cost of medication, ease of use, and food interactions) was the highest among them (i.e., $r=0.66$ ) (Table 4-19). Further, since the independent variables in the multivariate regression models should be strongly related to the dependent variable, and not to each other; we have used the participant-specific overall rating of the antihypertensive medication regimens to examine the association between the participant-reported outcomes and the participant' rating of their antihypertensive medication regimens (Tabachnick \& Fidell, 2001).

The relationship between treatment satisfaction and medication adherence among hypertensive participants has been examined before, and was found to be positive and significant (Bharmal et al., 2009; Sa'ed et al., 2013). Similarly, the participants' overall rating of their antihypertensive medication regimens, which is a proxy of patient satisfaction with their hypertension treatment, was positively associated with their medication adherence $(\mathrm{p}<0.05)$ (Sa'ed et al., 2013). The higher the overall rating of the antihypertensive medication regimens, the more likely the participants with hypertension will be adherent to these medication regimens controlling for their age, gender, education, race, health literacy, marital status, comorbidities, and number of prescription medications (Table 4-40). Although the relationship between patient satisfaction with antihypertensive medication regimens and medication adherence has been studied before (Bharmal et al., 2009; Sa'ed et al., 2013), our study findings are unique because we have examined this relationship among older adults. Medication adherence is a complex psycho-behavioral issue that is influenced by a multitude of factors including age (Gellad et al., 2011). Further, medication non-adherence among patients with chronic diseases such as hypertension has been linked to serious consequences (Osterberg \& Blaschke, 2005). Therefore, understanding the relationship between treatment satisfaction and 
medication adherence among older adults could help physicians in identifying strategies to address this potential barrier to medication adherence.

Patient satisfaction with physician communication had a positive impact on multiple health outcomes including medication adherence (R. Epstein \& Street, 2007; Zolnierek \& DiMatteo, 2009). However, few studies have examined the relationship between treatment satisfaction and patient satisfaction with physician communication (Beinart et al., 2003; Bultman \& Svarstad, 2000). Therefore, we have examined the relationship between participant-specific overall ratings of antihypertensive medication regimens and the participants' satisfaction with their physicians' communication. Participants with hypertension, who highly rated their antihypertensive medication regimens, were more likely to be satisfied with their physicians' communication (i.e., high PCASCommunication scores) than participants with low overall rating of their antihypertensive medication regimens controlling for their age, gender, education, race, health literacy, marital status, comorbidities, and number of prescription medications $(p<0.05)$

(Table 4-25). This indicates that physicians who effectively communicate with their patients (i.e., attentively listen, explain thoroughly, provide help and support) are more likely to prescribe medications that work for their patients from the patient perspective, and this eventually affects patients' satisfaction with their physicians' communication. Further, both the participant satisfaction with physician communication (i.e., PCASCommunication) and the participant-specific overall rating of the antihypertensive medication regimens have significantly affected medication adherence among the older adults with hypertension in our study (Figure 4-14). Hence, effective physician-patient communication is a crucial element in any successful treatment plan.

The relationship between treatment satisfaction and quality of life has been examined in multiple studies. Patient satisfaction with treatment has been linked to quality of life improvement (H. Chen et al., 2013; Porter et al., 2012; Stull et al., 2014). However, the relationship between patient satisfaction with antihypertensive medications and the quality of life among elderly patients has not been examined before. The relationship between the two component summaries of the SF-12v2 and the participant-specific overall rating of antihypertensive medication regimens was examined in multiple regression analyses controlling for age, gender, education, race, health literacy, marital status, comorbidities, and number of prescription medications. The Mental Component Summary (MCS-12) of the SF-12v2 was not associated with the participant-specific overall rating of antihypertensive medication regimens (Table 4-31). However, the Physical Component Summary (PCS-12) of the SF-12v2 was positively associated with the participant-specific overall rating of antihypertensive medication regimens $(p<0.05)$. The higher the participant-specific overall rating of antihypertensive medication regimens, the more likely participants will have higher PCS-12 scores (Table 4-32). Thus, participants who provided a high overall rating of their antihypertensive medication regimens were more likely to have higher physical HRQoL. This indicates that participants' satisfaction with their antihypertensive medication regimens does influence their physical HRQoL. Our results are consistent with the findings in the literature, the Physical Component Summary (PCS) of the SF-36 was positively correlated with the Medication Satisfaction Questionnaire (MSQ) that is used to assess patient satisfaction 
with their medications (Vernon et al., 2010). Participant satisfaction with physician communication was positively correlated with both the physical HRQoL and the overall rating of antihypertensive medications (Tables 4-21 and 4-22). Therefore, understanding the relationship between patients' satisfaction with their prescription medications and their quality of life may encourage physicians to engage in patient-centered communication.

Patient beliefs about medications as well as satisfaction with prescription medications have been shown to significantly affect medication adherence (Bharmal et al., 2009; Hugon et al., 2014; Sa'ed et al., 2013). However, the relationship between the patients' beliefs about medication and the satisfaction with their prescribed medications has not been examined yet. Therefore, we have examined the association between the general domain of the Beliefs about Medicines Questionnaire (BMQ) and the participant-specific overall rating of antihypertensive medication regimens. The general domain of the BMQ consists of two scales: the BMQ-Overuse and the BMQ-Harm. The BMQ-Overuse assesses whether the patient believes that prescription medications are overprescribed by physicians and overused by patients. The higher the score of the BMQ-Overuse, the more likely patients believe that medications are overprescribed and overused, and vice versa. On the other hand, the BMQ-Harm assesses whether the patients believe that prescription medications are inherently harmful. The higher the BMQ-Harm score, the more likely patients believe that prescription medications are harmful, and vice versa (Horne et al., 1999).

The BMQ-Overuse was not associated with the participants' overall rating of their antihypertensive medication regimens; however, the BMQ-Harm was negatively associated with the overall rating of antihypertensive medication regimens (Table 4-22). Further, the BMQ-Harm has negatively influenced the overall rating of antihypertensive medications, which then positively influenced medication adherence (Figure 4-14). Hence, older adults who believe that medications are inherently harmful (i.e., high BMQHarm scores) are less likely to be satisfied with their antihypertensive medication regimens (i.e., low overall rating of their antihypertensive medication regimens). Moreover, the association between the participants' overall rating of antihypertensive medication regimens and their beliefs about medications was examined in multiple regression analyses controlling for the participants' age, gender, education, race, health literacy, marital status, comorbidities, and number of prescription medications. However, since we wanted to see whether the participants' beliefs about medication were affected by their satisfaction with the antihypertensive medications; the beliefs about medication variables (i.e., BMQ-Harm and BMQ-Overuse) were treated here as dependent variables. The participant-specific overall rating of the antihypertensive medication regimen did not significantly influence the BMQ-Overuse $(\mathrm{p} \geq 0.05)$ (Table 4-36). However, the participant-specific overall rating of the antihypertensive medication regimens did negatively influence the BMQ-Harm $(\mathrm{p}<0.05)$ (Table 4-37). Thus, the participants' satisfaction with their antihypertensive medication regimens had a positive impact on their beliefs about medications. Our results should highlight the importance of choosing the right prescription medication for the elderly patients since their medication satisfaction influenced both their beliefs about medications as well as their medication 
adherence. Therefore, effective physician-patient communication should yield positive beliefs about medications, better medication satisfaction, and ultimately higher medication adherence.

\subsection{Limitations}

We have assessed participants views of online medication rating websites using a new developed instrument (i.e., PROMEX). Although, this instrument had an adequate internal consistency and high loadings on the construct this tool is intended to assess (i.e., value of online medication rating websites to older adults), it has not been validated across different patient populations. Furthermore, the participants' satisfaction with antihypertensive medications was assessed using a newly developed tool that has not been validated, yet it achieved a high internal consistency reliability $(\alpha=0.82)$. Therefore, our findings cannot be generalized to other patient populations due to the aforementioned reasons as well as convenience sampling that were used in this study. Further, the likelihood of recall bias with respect to the number of prescription medications, name of antihypertensive medications, and past medical history is high. Additionally, the administered survey consists of a battery of validated questionnaires that requires a completion time of at least twenty-five minutes. Hence, it places a significant cognitive burden on the respondents particularly with this mode of administration in which the respondents has to read, comprehend, recall, and then answer the requested information (Bowling, 2005). Further, the willingness of the respondents to disclose some information, which is believed to be sensitive from their own perspective is a common limitation in survey research (Bowling, 2005). For instance, many of the respondents refused to answer the question about their estimated annual income even after explaining the purpose of this research as well as the anonymity and confidentiality of their responses. Thus, we have not controlled for older adults' annual income in our analyses.

The general domain of the Beliefs about Medicines Questionnaire (BMQ) was used to assess participants' beliefs about medications. Although, research has confirmed a significant association between the general domain of the BMQ and medication adherence in general, the specific domain of the BMQ was not included (Horne \& Weinman, 1999; Sjölander, Eriksson, \& Glader, 2013). Among hypertensive participants in this study, the general domain of the BMQ has failed to show a consistent association with the medication adherence contrary to the specific domain of the BMQ, which consistently showed a significant association with medication adherence among this patient population (Gatti et al., 2009; Rajpura \& Nayak, 2014). In addition, health literacy was assessed using a single screening question (Chew et al., 2004). Although, this single health literacy-screening question has been validated using both the Test of Functional Health Literacy in Adults (TOFHLA) and the Rapid Estimate of Adult Literacy in Medicine (REALM) as reference standards, it is not as accurate as these two standard tests of health literacy (Wallace et al., 2006).

The utilization of path analyses to examine the relationship between the participants' views of online medication rating websites (i.e., PROMEX) and the participant-reported 
outcomes (i.e., participant satisfaction with communication, quality of life, beliefs about medications, and medication adherence) has several advantages over multiple regressions analyses. First, path analysis involves a series of multiple regressions rather than one regression. Second, in multiple regression analysis, the relationship between only one dependent variable and several independent variables is analyzed; however, no relations between the independent variables are analyzed. Nevertheless, in path analysis the relationships between the independent variables are analyzed. Therefore, the path analysis enables researchers to disentangle complex relationships between multiple variables (Streiner, 2005). Further, several hypotheses can be tested by examining both the causal (i.e., direct and indirect effects) on as well as the non-causal effects on the dependent variables (Lleras, 2005; Nazim \& Ahmad). However, the path analysis is not limitation-free. The path analysis follows the same theoretical assumptions of the multiple regression analyses. Further, the causality in the hypothesized path model is recursive (i.e., flows in one direction). Additionally, the path model has to assume that each measured variable is free of measurement errors. These assumptions are difficult to meet in social research (Lleras, 2005). Moreover, the path model in this study could not explain more than $6 \%$ at best of the variance in participants' views of online medication rating websites (i.e., PROMEX). Furthermore, the sample size was another limitation of this study. Although, the minimum sample size required for a medium effect size at a power $=0.80$ and $\alpha=0.05$ was satisfied, the sample size was not large enough to detect small sized effects. The sample size of our study is 286 , however, the sample size required for a power of 0.8 and a small effect size is 757 (J. Cohen, 1992). Finally, this is a cross-sectional study where causality cannot be ascertained between HRQoL and participants' views of online medication rating websites as an example; however, we clearly can say that there is a significant association between the two that needs to be further investigated in better-designed studies such as cohort studies.

\subsection{Conclusions}

In summary, older adults from seven senior centers were surveyed about the usefulness of the online medication rating websites in facilitating the communication with their physicians using a newly developed questionnaire. Participants with poor HRQoL viewed the online medication rating websites more favorably compared to their counterparts with good HRQoL. Further, participants with multiple chronic conditions had favorable views of the online medication rating websites. Therefore, participants who are more likely to take prescription medications favorably viewed the online medication rating websites. Moreover, older adults with limited health literacy were more likely to view the online medication rating websites more favorably than older adults with good health literacy level. Moreover, we have found that participants' satisfaction with their antihypertensive medication regimens was associated with positive participant-reported outcomes (i.e., higher physical HRQoL scores, positive beliefs about medications, higher satisfaction with physician communication, and better medication adherence).

Older adults' satisfaction with physician communication was associated with higher HRQoL, better medication adherence, positive beliefs about medications, and higher 
overall rating of antihypertensive medication regimens. Thus, participants with poor HRQoL, who were more likely to view the online medication rating websites more favorably compared to their counterparts with good of quality of life, were more likely as well to have a low level of satisfaction with their physicians' communication. Further, since older adults with poor HRQoL were more likely to have both lower education and health literacy, the availability of accessible online health information portrayed in a visual and easy to understand language such as the online patient reviews of medications may enhance the physician-patient communication, and result in favorable outcomes.

In addition, many older adults feel that their role is marginal in the decision-making process. Therefore, many of them expressed their desire to become active partners in the health decision-making process together with their physicians (Gladden, 2000). In this study, participants who liked to share their health decision with their physicians, were more likely to view the online medication rating websites more favorably than their counterparts, who liked to either keep their health decision in their own hands or leave it to their physicians. Thus, online patient reviews of medications could play a beneficial role by empowering older adults to participate actively in decisions related to their health care.

Nonetheless, some studies have questioned the integrity of the online health information as they frequently contain inaccurate and sometimes misleading information (Erdem \& Harrison-Walker, 2006). Furthermore, the online health information may strain the physician-patient relationship especially when patients think that they know more than their physicians or when they ask for a prescription medication and their physicians refuse to prescribe it due to valid and clinically sound reasons. Physicians' concerns about the harmful effects of the online health information on the relationship with their patients, stems from the fact that they need to spend more time answering and addressing patients' questions and requests especially if the information that the patients encountered online was incorrect or inaccurate (Anderson, Rainey, \& Eysenbach, 2003; Erdem \& Harrison-Walker, 2006). However, most elderly patients like to receive more information from their physicians. In addition, elderly patients tend to turn to their physicians as the primary source of health information (Campbell \& Nolfi, 2005). Further, research has shown that each additional minute spent by physicians with their patients during their visits is associated with an improvement in patient trust (Fiscella et al., 2004). Therefore, physicians' concern over the possibility of the online health information to have a negative impact on the relationship with their patients might be overstated.

Elderly patients are more likely to experience adverse drug events due to their diminished physiological reserve (Wasson, 2008). Further, elderly patients are underrepresented in most clinical trials that were conducted for the approvals of many currently available and widely used drugs (Konrat et al., 2012). Therefore, the creation of secure online patient portals by well-known health organizations (i.e., Centers for Medicare and Medicaid Services, academic health institutions, Food and Drug Administration), where actual patients can share their prescription medication experiences with others anonymously, may help in monitoring adverse drug reactions among patients in general and the elderly ones in particular. Moreover, the clinical 
guidelines that are used in the treatment of elderly patients with multiple comorbidities have proven ineffective in managing the health conditions of this important segment of the patient population (Boyd et al., 2005). Besides the potential role of the online patient reviews of medications in the adverse events reporting and post-marketing surveillance, they may also help physicians and researchers alike in reviewing the current treatment guidelines for elderly patients. Therefore, the roles that online medication-rating websites may play in the future might not be limited to enhancing the physician-patient communication.

Finally, although the findings of this study suggest that online patient reviews of medications may positively influence the patient-physician communication particularly among older adults with poor HRQoL, multiple health conditions, lower educations, and limited health literacy, the results of this study should be interpreted cautiously due to the aforementioned limitations. Future research should examine the impact of the online patient reviews of medications as an intervention on physician-patient communication, and consequently on other participant-reported outcomes. 


\section{LIST OF REFERENCES}

Abrass, I. B. (1990). The biology and physiology of aging. Western Journal of Medicine, $153(6), 641$.

Administration on Aging (AOA), (12/31/2013). Aging Statistics. Retrieved 01/07, 2014, from

http://www.aoa.gov/AoARoot/\%28S\%282ch3qw55k1qylo45dbihar2u\%29\%29/Aging St atistics/index.aspx.

Administration on Aging (AOA), (12/31/2013). Diversity. Retrieved 01/08, 2014, from http://www.aoa.gov/AoA_programs/Tools_Resources/diversity.aspx.

Schwartz, K. (2011). Chronic Disease Self-Management Fact Sheet. from http://www.ncoa.org/improve-health/center-for-healthy-aging/content-library/CDSMPFact-Sheet.pdf.

Aikens, J. E., Nease, D. E., \& Klinkman, M. S. (2008). Explaining patients' beliefs about the necessity and harmfulness of antidepressants. The Annals of Family Medicine, 6(1), 23-29.

Aikens, J. E., Nease, D. E., Nau, D. P., Klinkman, M. S., \& Schwenk, T. L. (2005). Adherence to maintenance-phase antidepressant medication as a function of patient beliefs about medication. The Annals of Family Medicine, 3(1), 23-30.

Albarran, A. B., \& Goff, D. H. (2000). Understanding the web: social, political, and economic dimensions of the Internet: Iowa State University Press.

Annandale, E. (1998). The sociology of health and medicine: a critical introduction: Polity Press Cambridge.

Arora, N. K., \& McHorney, C. A. (2000). Patient preferences for medical decision making: who really wants to participate? Medical care, 38(3), 335-341.

Baker, D. W., Williams, M. V., Parker, R. M., Gazmararian, J. A., \& Nurss, J. (1999). Development of a brief test to measure functional health literacy. Patient education and counseling, 38(1), 33-42.

Baker, R. (1999). The American medical ethics revolution: how the AMA's code of ethics has transformed physicians' relationships to patients, professionals, and society: JHU Press.

Banning, M. (2009). A review of interventions used to improve adherence to medication in older people. International Journal of Nursing Studies, 46(11), 1505-1515. 
Bastiaens, H., Van Royen, P., Pavlic, D. R., Raposo, V., \& Baker, R. (2007). Older people's preferences for involvement in their own care: a qualitative study in primary health care in 11 European countries. Patient education and counseling, 68(1), 33-42.

Beck, R. S., Daughtridge, R., \& Sloane, P. D. (2002). Physician-patient communication in the primary care office: a systematic review. The Journal of the American Board of Family Practice, 15(1), 25-38.

Beisecker, A. E. (1988). Aging and the desire for information and input in medical decisions: Patient consumerism in medical encounters. The Gerontologist, 28(3), 330335.

Belzer, E. J. (1999). Improving patient communication in no time. Fam Pract Manag, $6(5), 23-28$.

Bensing, J. (2000). Bridging the gap.: The separate worlds of evidence-based medicine and patient-centered medicine. Patient education and counseling, 39(1), 17-25.

Bernabeo, E., \& Holmboe, E. S. (2013). Patients, providers, and systems need to acquire a specific set of competencies to achieve truly patient-centered care. Health Affairs, $32(2), 250-258$.

Berwick, D. M. (2009). What 'patient-centered'should mean: confessions of an extremist. Health Affairs, 28(4), w555-w565.

Bharmal, M., \& Thomas III, J. (2006). Comparing the EQ-5D and the SF-6D descriptive systems to assess their ceiling effects in the US general population. Value in Health, 9(4), 262-271.

Billups, S. J., Malone, D. C., \& Carter, B. L. (2000). The Relationship between Drug Therapy Noncompliance and Patient Characteristics, Health-Related Quality of Life, and Health Care Costs. Pharmacotherapy: The Journal of Human Pharmacology and Drug Therapy, 20(8), 941-949.

Black, E. W., Thompson, L. A., Saliba, H., Dawson, K., \& Paradise Black, N. M. (2009). An analysis of healthcare providers' online ratings. Informatics in primary care, 17(4), 249-253.

Bond, C., Blenkinsopp, A., \& Raynor, D. K. (2012). Prescribing and partnership with patients. British journal of clinical pharmacology, 74(4), 581-588.

Bordin, E. S. (1979). The generalizability of the psychoanalytic concept of the working alliance. Psychotherapy: Theory, Research \& Practice, 16(3), 252.

Boult C, W. G. (2010). Comprehensive Primary Care for Older Patients With Multiple Chronic Conditions. Jama, 304(17), 1936-1943. 
Bowling, A. (1991). Measuring health: a review of quality of life measurement scales: Open University Press BuckinghamPhiladelphia.

Boyd, C. M., Darer, J., Boult, C., Fried, L. P., Boult, L., \& Wu, A. W. (2005). Clinical practice guidelines and quality of care for older patients with multiple comorbid diseases. JAMA: the journal of the American Medical Association, 294(6), 716-724.

Boylan, L. S., \& Fontanella, J. A. (2009). Behavioral indices in medical care outcome: the working alliance, adherence, and related factors. Journal of general internal medicine, 24(1), 80-85.

Brennan, J., Rivera-Tovar, A., Martin, P., Hepworth, J., \& Makoul, G. (2010). Using the communication assessment tool in family medicine residency programs. Fam Med, 42(8), 567-573.

Britten, N. (1994). Patients' ideas about medicines: a qualitative study in a general practice population. The British Journal of General Practice, 44(387), 465.

Bruera, E., Sweeney, C., Calder, K., Palmer, L., \& Benisch-Tolley, S. (2001). Patient preferences versus physician perceptions of treatment decisions in cancer care. Journal of Clinical Oncology, 19(11), 2883-2885.

Bultman, D. C., \& Svarstad, B. L. (2000). Effects of physician communication style on client medication beliefs and adherence with antidepressant treatment. Patient education and counseling, 40(2), 173-185.

Bylund, C. L., Gueguen, J. A., Sabee, C. M., Imes, R. S., Li, Y., \& Sanford, A. A. (2007). Provider-patient dialogue about Internet health information: an exploration of strategies to improve the provider-patient relationship. Patient education and counseling, 66(3), 346-352.

Cairncross, F. (2001). The death of distance: How the communications revolution will change our lives: Harvard Business Press.

Calman, K. (1984). Quality of life in cancer patients--an hypothesis. Journal of medical ethics, 10(3), 124-127.

Cameron, L., \& Leventhal, H. (2003). The self-regulation of health and illness behaviour: Psychology Press.

Campbell, R. J., \& Nolfi, D. A. (2005). Teaching elderly adults to use the Internet to access health care information: before-after study. Journal of medical Internet research, $7(2)$.

Donaldson, M. S., Yordy, K. D., \& Vanselow, N. A. (1994). Defining primary care: an interim report: National Academy Press. 
Carlin, C. S., Christianson, J. B., Keenan, P., \& Finch, M. (2012). Chronic illness and patient satisfaction. Health Serv Res, 47(6), 2250-2272.

Carr, A. J., \& Higginson, I. J. (2001). Measuring quality of life: Are quality of life measures patient centred? BMJ: British Medical Journal, 322(7298), 1357.

Ceccoli, S. J., \& Klotz, R. J. (2013). Taking your medicine? Attitudes toward direct-toconsumer advertising (DTCA). The Social Science Journal.

Cella, D. F., \& Tulsky, D. (1990). Measuring quality of life today: methodological aspects. Oncology (Williston Park, NY), 4(5), 29-38; discussion 69.

Charles, C., Gafni, A., \& Whelan, T. (1997). Shared decision-making in the medical encounter: what does it mean?(or it takes at least two to tango). Social science \& medicine, 44(5), 681-692.

Chen, Y., \& Xie, J. (2008). Online consumer review: Word-of-mouth as a new element of marketing communication mix. Management Science, 54(3), 477-491.

Chew, L. D., Bradley, K. A., \& Boyko, E. J. (2004). Brief questions to identify patients with inadequate health literacy. health, 11, 12.

Chin, J. J. (2002). Doctor-patient relationship: from medical paternalism to enhanced autonomy. Singapore medical journal, 43(3), 152-155.

Clarke, G., Hall, R. T., \& Rosencrance, G. (2004). Physician-patient relations: no more models. American Journal of Bioethics, 4(2), 16-19.

Cobb, C. W. (2000). Measurement tools and the quality of life. Redefining Progress.

Cohen, J. (1992). A power primer. Psychological bulletin, 112(1), 155.

Conn, K. M., Halterman, J. S., Lynch, K., \& Cabana, M. D. (2007). The impact of parents' medication beliefs on asthma management. Pediatrics, 120(3), e521-e526.

Conrad, P. (1985). The meaning of medications: another look at compliance. Social science \& medicine, 20(1), 29-37.

Control, C. f. D. (2004). The state of aging and health in America. Washington: Merck Institute of Aging and Health.

Coons, S. J., Rao, S., Keininger, D. L., \& Hays, R. D. (2000). A comparative review of generic quality-of-life instruments. Pharmacoeconomics, 17(1), 13-35.

Cortina, J. M. (1993). What is coefficient alpha? An examination of theory and applications. Journal of applied psychology, 78(1), 98. 
Coulter, A., Parsons, S., \& Askham, J. (2008). Where are the patients in decision-making about their own care? : World Health Organization Regional Office for Europe.

Cronbach, L. J. (1951). Coefficient alpha and the internal structure of tests. psychometrika, 16(3), 297-334.

Dang, B. N., Westbrook, R. A., Black, W. C., Rodriguez-Barradas, M. C., \& Giordano, T. P. (2013). Examining the Link between Patient Satisfaction and Adherence to HIV Care: A Structural Equation Model. PloS one, 8(1), e54729.

Daschle, T., Domenici, P., Frist, W., \& Rivlin, A. (2013). Prescription for PatientCentered Care and Cost Containment. New England Journal of Medicine, 369(5), 471474.

Davis, M. H. (1994). Empathy: A social psychological approach: Westview Press.

DiMaggio, P., Hargittai, E., Neuman, W. R., \& Robinson, J. P. (2001). Social implications of the Internet. Annual review of sociology, 307-336.

Dolovich, L., Nair, K., Sellors, C., Lohfeld, L., Lee, A., \& Levine, M. (2008). Do patients' expectations influence their use of medications? Qualitative study. Canadian Family Physician, 54(3), 384-393.

Donabedian, A. (1966). Evaluating the quality of medical care. The Milbank memorial fund quarterly, 166-206.

Donabedian, A. (2005). Evaluating the quality of medical care. Milbank Quarterly, 83(4), 691-729.

Donohue, J. M., Cevasco, M., \& Rosenthal, M. B. (2007). A decade of direct-toconsumer advertising of prescription drugs. New England Journal of Medicine, 357(7), 673-681.

Doyle, C., Lennox, L., \& Bell, D. (2013). A systematic review of evidence on the links between patient experience and clinical safety and effectiveness. BMJ open, 3(1).

Dreher, B. B. (2001). Communication skills for working with elders: Springer Publishing Company.

Duffy, F. D., Gordon, G. H., Whelan, G., Cole-Kelly, K., \& Frankel, R. (2004). Assessing competence in communication and interpersonal skills: the Kalamazoo II report. Academic Medicine, 79(6), 495-507.

Ekdahl, A. W., Hellström, I., Andersson, L., \& Friedrichsen, M. (2012). Too complex and time-consuming to fit in! Physicians' experiences of elderly patients and their participation in medical decision making: a grounded theory study. BMJ open, 2(3). 
Emanuel, E. J., \& Emanuel, L. L. (2000). Four models of the physicianpatient relationship. Readings in health care ethics, 1, 40-49.

Emerson, E. B. (1985). Evaluating the impact of deinstitutionalization on the lives of mentally retarded people. American Journal of Mental Deficiency.

Emilsson, M., Berndtsson, I., Lötvall, J., Millqvist, E., Lundgren, J., Johansson, A., \& Brink, E. (2011). The influence of personality traits and beliefs about medicines on adherence to asthma treatment. Prim Care Respir J, 20(2), 141-147.

Emmert, M., Maryschok, M., Eisenreich, S., \& Schöffski, O. (2009). [Websites to assess quality of care--appropriate to identify good physicians?]. Gesundheitswesen (Bundesverband der Arzte des Offentlichen Gesundheitsdienstes (Germany)), 71(4), e1827.

Emmert, M., Meier, F., Pisch, F., \& Sander, U. (2013). Physician choice making and characteristics associated with using physician-rating websites: cross-sectional study. Journal of medical Internet research, 15(8).

Emmert, M., Sander, U., Esslinger, A., Maryschok, M., \& Schöffski, O. (2012). Public Reporting in Germany: the Content of Physician Rating Websites*. Methods of information in medicine, 51(2), 112.

Emmert, M., Sander, U., \& Pisch, F. (2013). Eight questions about physician-rating websites: A systematic review. Journal of medical Internet research, 15(2).

Epstein, R., \& Street, R. L. (2007). Patient-centered communication in cancer care: promoting healing and reducing suffering: National Cancer Institute, US Department of Health and Human Services, National Institutes of Health.

Epstein, R. M., Fiscella, K., Lesser, C. S., \& Stange, K. C. (2010). Why the nation needs a policy push on patient-centered health care. Health Affairs, 29(8), 1489-1495.

Epstein, R. M., \& Street, R. L. (2011). The values and value of patient-centered care. The Annals of Family Medicine, 9(2), 100-103.

Erdem, S. A., \& Harrison-Walker, L. J. (2006). The role of the Internet in physicianpatient relationships: The issue of trust. Business Horizons, 49(5), 387-393.

Erdfelder, E., Faul, F., \& Buchner, A. (1996). GPOWER: A general power analysis program. Behavior research methods, instruments, \& computers, 28(1), 1-11.

Esposti, L. D., Saragoni, S., Benemei, S., Batacchi, P., Geppetti, P., Di Bari, M., Marchionni, N., Sturani, A., Buda, S., Esposti, E. D. (2011). Adherence to antihypertensive medications and health outcomes among newly treated hypertensive patients. Clinicoecon Outcomes Res, 3, 47-54. doi: 10.2147/CEOR.S15619. 
Eveleigh, R. M., Muskens, E., van Ravesteijn, H., van Dijk, I., van Rijswijk, E., \& Lucassen, P. (2012). An overview of 19 instruments assessing the doctor-patient relationship: different models or concepts are used. J Clin Epidemiol, 65(1), 10-15.

Faber, M., Bosch, M., Wollersheim, H., Leatherman, S., \& Grol, R. (2009). Public Reporting in Health Care: How Do Consumers Use Quality-of-Care Information?: A Systematic Review. Medical care, 47(1), 1-8.

Fairman, K., \& Matheral, B. (2000). Evaluating medication adherence: which measure is right for your program? strategies, 2, 4 .

Falkum, E., \& Førde, R. (2001). Paternalism, patient autonomy, and moral deliberation in the physician-patient relationship: Attitudes among Norwegian physicians. Social science \& medicine, 52(2), 239-248.

Farmer, A., Kinmonth, A. L., \& Sutton, S. (2006). Measuring beliefs about taking hypoglycaemic medication among people with Type 2 diabetes. Diabetic Medicine, 23(3), 265-270.

Farmer, K. C. (1999). Methods for measuring and monitoring medication regimen adherence in clinical trials and clinical practice. Clinical therapeutics, 21(6), 1074-1090.

Felce, D. (1997). Defining and applying the concept of quality of life. Journal of Intellectual Disability Research, 41(2), 126-135.

Felce, D., \& Perry, J. (1995). Quality of life: Its definition and measurement. Research in developmental disabilities, 16(1), 51-74.

Field, A. (2009). Discovering statistics using SPSS: Sage publications.

Florin, J., Ehrenberg, A., \& Ehnfors, M. (2006). Patient participation in clinical decisionmaking in nursing: a comparative study of nurses' and patients' perceptions. Journal of Clinical Nursing, 15(12), 1498-1508.

Friedman, D. S., Hahn, S. R., Gelb, L., Tan, J., Shah, S. N., Kim, E. E., Zimmerman, T. J, Quigley, H. A. (2008). Doctor-patient communication, health-related beliefs, and adherence in glaucoma: results from the glaucoma adherence and persistency study. Ophthalmology, 115(8), 1320-1327. e1323.

Garattini, S., \& Chalmers, I. (2009). Patients and the public deserve big changes in evaluation of drugs. BMJ: British Medical Journal, 338(7698), 804-806.

Garfield, S., Smith, F., Francis, S.-A., \& Chalmers, C. (2007). Can patients' preferences for involvement in decision-making regarding the use of medicines be predicted? Patient education and counseling, 66(3), 361-367. 
Gatti, M. E., Jacobson, K. L., Gazmararian, J. A., Schmotzer, B., \& Kripalani, S. (2009). Relationships between beliefs about medications and adherence. American Journal of Health-System Pharmacy, 66(7), 657-664.

Gellad, W. F., Grenard, J. L., \& Marcum, Z. A. (2011). A systematic review of barriers to medication adherence in the elderly: looking beyond cost and regimen complexity. The American journal of geriatric pharmacotherapy, 9(1), 11-23.

Given, L. M., Ruecker, S., Simpson, H., Sadler, E. B., \& Ruskin, A. (2007). Inclusive interface design for seniors: Image-browsing for a health information context. Journal of the American Society for Information Science and Technology, 58(11), 1610-1617.

Goulding, M. R. (2004). Inappropriate medication prescribing for elderly ambulatory care patients. Arch Intern Med, 164(3), 305.

Greene, M., \& Adelman, R. (2001). Building the physician-older patient relationship. Aging, communication, and health: Linking research and practice for successful aging, 101-120.

Guyatt, G., Montori, V., Devereaux, P., Schünemann, H., \& Bhandari, M. (2004). Patients at the centre: in our practice, and in our use of language. Evidence Based Medicine, 9(1), 6-7.

Ha, J. F., \& Longnecker, N. (2010). Doctor-patient communication: a review. The Ochsner Journal, 10(1), 38-43.

Hall, J. A., \& Dornan, M. C. (1990). Patient sociodemographic characteristics as predictors of satisfaction with medical care: a meta-analysis. Social science \& medicine, 30(7), 811-818.

Hall, J. A., Roter, D. L., \& Katz, N. R. (1988). Meta-analysis of correlates of provider behavior in medical encounters. Medical care, 657-675.

Hamilton, G. A. (2003). Measuring adherence in a hypertension clinical trial. European Journal of Cardiovascular Nursing, 2(3), 219-228.

Harwood, J. (2007). Understanding communication and aging: Developing knowledge and awareness: Sage.

Hatcher, L. (2005). A step-by-step approach to using the SAS system for factor analysis and structural equation modeling: SAS Institute.

Hays, R. D., \& Morales, L. S. (2001). The RAND-36 measure of health-related quality of life. Annals of medicine, 33(5), 350-357. 
Health, United States, 2012: With Special Feature on Emergency Care. Hyattsville, MD. 2013: U.S. Government Printing Office.

Herdman, M., Gudex, C., Lloyd, A., Janssen, M., Kind, P., Parkin, D., Bonsel, G., Badia, X. (2011). Development and preliminary testing of the new five-level version of EQ-5D (EQ-5D-5L). Quality of Life Research, 20(10), 1727-1736.

Hibbard, J. H., \& Greene, J. (2013). What the evidence shows about patient activation: better health outcomes and care experiences; fewer data on costs. Health Affairs, 32(2), 207-214.

Holt, E. W., Muntner, P., Joyce, C. J., Webber, L., \& Krousel-Wood, M. A. (2010). Health-related quality of life and antihypertensive medication adherence among older adults. Age and ageing, 39(4), 481-487.

Horne, R. (2000). Assessing perceptions of medication: psychological perspectives. In: McGavock, H, editor. Handbook of drug research methodology. Newcastle upon Tyne: United Kingdom Drug Utilisation Research Group, 299-319.

Horne, R. (2005). Concordance, adherence and compliance in medicine taking: Report for the National Co-ordinating Centre for NHS Service Delivery and Organisation R \& D (NCCSDO): NCCSDO.

Horne, R., Graupner, L. d., Frost, S., Weinman, J., Wright, S. M., \& Hankins, M. (2004). Medicine in a multi-cultural society: the effect of cultural background on beliefs about medications. Social science \& medicine, 59(6), 1307-1313.

Horne, R., \& Weinman, J. (1999). Patients' beliefs about prescribed medicines and their role in adherence to treatment in chronic physical illness. Journal of psychosomatic research, 47(6), 555-567.

Horne, R., Weinman, J., \& Hankins, M. (1999). The beliefs about medicines questionnaire: the development and evaluation of a new method for assessing the cognitive representation of medication. Psychology and health, 14(1), 1-24.

Howard, T., Jacobson, K. L., \& Kripalani, S. (2013). Doctor Talk: Physicians' Use of Clear Verbal Communication. Journal of health communication(ahead-of-print), 1-11.

Horne, R. (1999). Patients' beliefs about treatment: the hidden determinant of treatment outcome? Journal of psychosomatic research, 47(6), 491-495.

Huang, I., Frangakis, C., Atkinson, M. J., Willke, R. J., Leite, W. L., Vogel, W. B., \& Wu, A. W. (2008). Addressing ceiling effects in health status measures: A comparison of techniques applied to measures for people with HIV disease. Health Serv Res, 43(1p1), 327-339. 
Hunt, S., McEwen, J., \& McKenna, S. (1985). Measuring health status: a new tool for clinicians and epidemiologists. The Journal of the Royal College of General

Practitioners, 35(273), 185.

I Gouni-Berthold MD, F., \& Berthold, H. (2012). Role of physician gender in drug therapy Sex and Gender Differences in Pharmacology (pp. 183-208): Springer.

Iihara, N., Tsukamoto, T., Morita, S., Miyoshi, C., Takabatake, K., \& Kurosaki, Y. (2004). Beliefs of chronically ill Japanese patients that lead to intentional non-adherence to medication. J Clin Pharm Ther, 29(5), 417-424.

Iosifescu, A., Halm, E. A., McGinn, T., Siu, A. L., \& Federman, A. D. (2008). Beliefs about generic drugs among elderly adults in hospital-based primary care practices. Patient education and counseling, 73(2), 377-383.

Isacson, D., \& Bingefors, K. (2002). Attitudes towards drugs - a survey in the general population. Pharmacy World and Science, 24(3), 104-110.

Jacob, J. (2002). Consumer access to health care information: its effect on the physicianpatient relationship. Alaska medicine, 44(4), 75.

Jeffery, R. (1979). Normal rubbish: deviant patients in casualty departments. Sociology of Health \& Illness, 1(1), 90-107.

Jenkins, M. L., \& Dunn, D. (2004). Enhancing web-based health information for consumer education. Applied Nursing Research, 17(1), 68-70.

Johnson, J. A., \& Pickard, A. S. (2000). Comparison of the EQ-5D and SF-12 health surveys in a general population survey in Alberta, Canada. Medical care, 38(1), 115-121.

Jolliffe, I. (2005). Principal component analysis: Wiley Online Library.

Kadry, B., Chu, L. F., Kadry, B., Gammas, D., \& Macario, A. (2011). Analysis of 4999 online physician ratings indicates that most patients give physicians a favorable rating. Journal of medical Internet research, 13(4).

Kaiser, H. F. (1960). The application of electronic computers to factor analysis. Educational and psychological measurement.

Kannel, W. B. (2003). Prevalence and implications of uncontrolled systolic hypertension. Drugs \& aging, 20(4), 277-286.

Kaplan, S. H., Greenfield, S., \& Ware Jr, J. E. (1989). Assessing the effects of physicianpatient interactions on the outcomes of chronic disease. Medical care, 27(3), S1 10. 
Kim, S. S., Kaplowitz, S., \& Johnston, M. V. (2004). The effects of physician empathy on patient satisfaction and compliance. Evaluation \& the Health Professions, 27(3), 237251.

Klemm, P., Bunnell, D., Cullen, M., Soneji, R., Gibbons, P., \& Holecek, A. (2003). Online cancer support groups: a review of the research literature. Computers Informatics Nursing, 21(3), 136-142.

Konrat, C., Boutron, I., Trinquart, L., Auleley, G.-R., Ricordeau, P., \& Ravaud, P. (2012). Underrepresentation of elderly people in randomised controlled trials. The example of trials of 4 widely prescribed drugs. PloS one, 7(3), e33559.

Kripalani, S., Gatti, M. E., \& Jacobson, T. A. (2010). Association of age, health literacy, and medication management strategies with cardiovascular medication adherence. Patient education and counseling, 81(2), 177-181.

Krousel-Wood, M., Islam, T., Webber, L. S., Re, R., Morisky, D. E., \& Muntner, P. (2009). New medication adherence scale versus pharmacy fill rates in hypertensive seniors. Am J Manag Care, 15(1), 59.

Krousel-Wood, M. A., Muntner, P., Islam, T., Morisky, D. E., \& Webber, L. S. (2009). Barriers to and determinants of medication adherence in hypertension management: perspective of the cohort study of medication adherence among older adults. Medical Clinics of North America, 93(3), 753-769.

Kuppersmith, R. B. (2002). The physician-patient relationship and the Internet. Otolaryngologic Clinics of North America, 35(6), 1143-1147.

Kutner, M. A., Greenberg, E., \& Baer, J. (2005). National Assessment of Adult Literacy (NAAL): A first look at the literacy of America's adults in the 21st Century: National Center for Education Statistics, US Department of Education, Institute of Education Sciences.

Larson, E. B., \& Yao, X. (2005). Clinical empathy as emotional labor in the patientphysician relationship. JAMA: the journal of the American Medical Association, 293(9), 1100-1106.

Laugesen, M. J., \& Rice, T. (2003). Is the doctor in? The evolving role of organized medicine in health policy. Journal of Health Politics, Policy and Law, 28(2-3), 289-316.

LaVeist, T. A., \& Nuru-Jeter, A. (2002). Is doctor-patient race concordance associated with greater satisfaction with care? Journal of health and social behavior, 296-306.

Lavsa, S. M., Holzworth, A., \& Ansani, N. T. (2010). Selection of a validated scale for measuring medication adherence. Journal of the American Pharmacists Association: JAPhA, 51(1), 90-94. 
Lawler, M. K. (1998). Why patients use alternative medicine. Jama, 280(19), 1659-1661.

Lee, Y.-Y., \& Lin, J. L. (2010). Do patient autonomy preferences matter? Linking patient-centered care to patient-physician relationships and health outcomes. Social science \& medicine, 71(10), 1811-1818.

Légaré, F., \& Witteman, H. O. (2013). Shared decision making: examining key elements and barriers to adoption into routine clinical practice. Health Affairs, 32(2), 276-284.

Lennerling, A., \& Forsberg, A. (2012). Self-reported non-adherence and beliefs about medication in a Swedish kidney transplant population. The open nursing journal, 6, 41.

Leung, L. (2010). Effects of Internet connectedness and information literacy on quality of life. Social indicators research, 98(2), 273-290.

Lévesque, J.-F., Haggerty, J., Beninguissé, G., Burge, F., Gass, D., Beaulieu, M.D.,Pineault, R., Santor, Beaulieu, C. (2012). Mapping the coverage of attributes in validated instruments that evaluate primary healthcare from the patient perspective. $B M C$ family practice, 13(1), 20.

Levinson, W., Kao, A., Kuby, A., \& Thisted, R. A. (2005). Not all patients want to participate in decision making. Journal of general internal medicine, 20(6), 531-535.

Levinson, W., Roter, D. L., Mullooly, J. P., Dull, V. T., \& Frankel, R. M. (1997). Physician-patient communication. Jama, 277(7), 553-559.

Lewis, E. T., Combs, A., \& Trafton, J. A. (2010). Reasons for under-use of prescribed opioid medications by patients in pain. Pain Medicine, 11(6), 861-871.

Liang, T. (2011). Association between Use of Internet Services and Quality of Life in Taiwan. Journal of Data Science, 9, 83-92.

Linn, A. J., Vervloet, M., van Dijk, L., Smit, E. G., \& Van Weert, J. C. (2011). Effects of eHealth interventions on medication adherence: a systematic review of the literature.

Journal of medical Internet research, 13(4).

Lionakis, N., Mendrinos, D., Sanidas, E., Favatas, G., \& Georgopoulou, M. (2012). WJC. World, 4(5), 1-000.

Lleras, C. (2005). Path analysis. Encyclopedia of social measurement, 3, 25-30.

Lloyd-Jones, D., Adams, R., Carnethon, M., De Simone, G., Ferguson, T. B., Flegal, K., . Greenlund, K. (2009). Heart disease and stroke statistics - 2009 update a report from the American Heart Association Statistics Committee and Stroke Statistics Subcommittee. Circulation, 119(3), 480-486. 
Longo, D. R., Land, G., Schramm, W., Fraas, J., Hoskins, B., \& Howell, V. (1997). Consumer reports in health care. JAMA: the journal of the American Medical Association, 278(19), 1579-1584.

Lorish, C. D., Richards, B., \& Brown, S. (1990). Perspective of the patient with rheumatoid arthritis on issues related to missed medication. Arthritis \& Rheumatism, $3(2), 78-84$.

Low, G., \& Molzahn, A. E. (2007). Predictors of quality of life in old age: A crossvalidation study. Research in Nursing \& Health, 30(2), 141-150.

Lugtenberg, M., Burgers, J. S., Clancy, C., Westert, G. P., \& Schneider, E. C. (2011). Current guidelines have limited applicability to patients with comorbid conditions: a systematic analysis of evidence-based guidelines. PloS one, 6(10), e25987.

Macías-Núñez, J.-F., Casado, J.-M. R., del Rey, M. d. 1. F., Quiroga, G. B., Tresguerres, J. A., Ariznavarreta, C., \& López-Novoa, J. M. (2008). Biology of the Aging Process and Its Clinical Consequences The Aging Kidney in Health and Disease (pp. 5591): Springer.

Macintyre, S. (1994). Understanding the social patterning of health: the role of the social sciences. Journal of Public Health, 16(1), 53-59.

MacLaughlin, E. J., Raehl, C. L., Treadway, A. K., Sterling, T. L., Zoller, D. P., \& Bond, C. A. (2005). Assessing medication adherence in the elderly. Drugs \& aging, 22(3), 231255.

Mårdby, A.-C., Åkerlind, I., \& Jörgensen, T. (2007). Beliefs about medicines and selfreported adherence among pharmacy clients. Patient education and counseling, 69(1), 158-164.

Mazzaglia, G., Ambrosioni, E., Alacqua, M., Filippi, A., Sessa, E., Immordino, V., Cricelli, C. (2009). Adherence to antihypertensive medications and cardiovascular morbidity among newly diagnosed hypertensive patients. Circulation, 120(16), 15981605.

McKinstry, B. (2000). Do patients wish to be involved in decision making in the consultation? A cross sectional survey with video vignettes. BMJ, 321(7265), 867-871.

Mead, N., \& Bower, P. (2000). Patient-centredness: a conceptual framework and review of the empirical literature. Social science \& medicine, 51(7), 1087-1110.

Mead, N., Bower, P., \& Hann, M. (2002). The impact of general practitioners' patientcentredness on patients' post-consultation satisfaction and enablement. Social science \& medicine, 55(2), 283-299. 
Meadows, K. A. (2011). Patient-reported outcome measures: an overview. British journal of community nursing, 16(3), 146-151.

Mensah, G. A., Mendis, S., Greenland, K., \& MacKay, J. (2004). The atlas of heart disease and stroke: World Health Organization.

Meryn, S. (1998). Improving doctor-patient communication: not an option, but a necessity. BMJ: British Medical Journal, 316(7149), 1922.

Mishler, E. G. (1984). The discourse of medicine: Dialectics of medical interviews (Vol. 3): Greenwood Publishing Group.

Morgan, M. (2003). The doctor-patient relationship. Sociology as applied to medicine, 49-65.

Morisky, D. E., Ang, A., Krousel-Wood, M., \& Ward, H. J. (2008). Predictive validity of a medication adherence measure in an outpatient setting. The Journal of Clinical Hypertension, 10(5), 348-354.

Morisky, D. E., \& DiMatteo, M. R. (2011). Improving the measurement of self-reported medication nonadherence: response to authors. J Clin Epidemiol, 64(3), 255.

Mostaghimi, A., Crotty, B. H., \& Landon, B. E. (2010). The availability and nature of physician information on the internet. Journal of general internal medicine, 25(11), 1152-1156.

Moy, E., \& Bartman, B. A. (1995). Physician race and care of minority and medically indigent patients. Jama, 273(19), 1515-1520.

Mukamel, D. B., \& Mushlin, A. I. (1998). Quality of care information makes a difference: an analysis of market share and price changes after publication of the New York State Cardiac Surgery Mortality Reports. Medical care, 36(7), 945-954.

Mukamel, D. B., Weimer, D. L., Zwanziger, J., Gorthy, S.-F. H., \& Mushlin, A. I. (2004). Quality report cards, selection of cardiac surgeons, and racial disparities: a study of the publication of the New York State Cardiac Surgery Reports. Journal Information, 41(4).

Müller-Nordhorn, J., Roll, S., \& Willich, S. (2004). Comparison of the short form (SF)12 health status instrument with the SF-36 in patients with coronary heart disease. Heart, $90(5), 523-527$.

Nair, K., Dolovich, L., Cassels, A., McCormack, J., Levine, M., Gray, J., Mann, K., Burns, S. (2002). What patients want to know about their medications. Focus group study of patient and clinician perspectives. Canadian Family Physician, 48(1), 104-110. 
Nazim, A., \& Ahmad, S.(2014). A Comparison Between Ordinary Least Square (OLS) And Structural Equation Modeling (SEM) Methods In Estimating The Influencial Factors Of 8th Grades Student's Mathematics Achievement In Malaysia.

Nease Jr, R. F. (1995). Patient desire for information and decision making in health care decisions. Journal of general internal medicine, 10(11), 593-600.

Nunnally, J. C. (2010). Psychometric Theory 3E: Tata McGraw-Hill Education.

Nussbaum, J. F., \& Coupland, J. (2004). Handbook of communication and aging research: Routledge.

O'Neal, E. L., Adams, J. R., McHugo, G. J., Van Citters, A. D., Drake, R. E., $\&$ Bartels, S. J. (2008). Preferences of older and younger adults with serious mental illness for involvement in decision-making in medical and psychiatric settings. American Journal of Geriatric Psych, 16(10), 826-833.

Oates, J., Weston, W. W., \& Jordan, J. (2000). The impact of patient-centered care on outcomes. Fam Pract, 49, 796-804.

Odigie, E. G., \& Marshall, R. (2008). Quality monitoring of physicians: linking patients' experiences of care to clinical quality and outcomes. Journal of general internal medicine, 23(11), 1784-1790.

Ogden, J. (2012). Health psychology: McGraw-Hill International.

Orley, J., Kuyken, W., \& de la Santé, O. M. (1994). Quality of life assessment: international perspectives: Springer.

Osterberg, L., \& Blaschke, T. (2005). Adherence to medication. New England Journal of Medicine, 353(5), 487-497.

Paraskevi, T. (2012). The Effect of Sociodemographic Features and Beliefs about Medicines on Adherence to Chronic Kidney Disease Treatment. Journal of Clinical Research \& Bioethics.

Parker, R. M., Baker, D. W., \& Williams, M. V. (1995). The test of functional health literacy in adults. Journal of general internal medicine, 10(10), 537-541.

Parsons, T. (1951). Illness and the role of the physician: A sociological perspective*. American Journal of orthopsychiatry, 21(3), 452-460.

Patient-centered care for older adults with multiple chronic conditions: a stepwise approach from the American Geriatrics Society: American Geriatrics Society Expert Panel on the Care of Older Adults with Multimorbidity. (2012). J Am Geriatr Soc, 60(10), 1957-1968. doi: 10.111/j.1532-5415.201.04187. 
Pearson, B., Skelly, R., Wileman, D., \& Masud, T. (2002). Unplanned readmission to hospital: a comparison of the views of general practitioners and hospital staff. Age and ageing, 31(2), 141-143.

Persaud, R. (2005). How to improve communication with patients. BMJ Career Focus, 330(7494), 136-137.

Phatak, H. M., \& Thomas, J. (2006). Relationships between beliefs about medications and nonadherence to prescribed chronic medications. The Annals of pharmacotherapy, 40(10), 1737-1742.

Pittman, D. G., Tao, Z., Chen, W., \& Stettin, G. D. (2010). Antihypertensive medication adherence and subsequent healthcare utilization and costs. Am J Manag Care, 16(8), 568576.

Poochikian-Sarkissian, S., Sidani, S., Ferguson-Pare, M., \& Doran, D. (2009). Examining the relationship between patient-centred care and outcomes. Canadian journal of neuroscience nursing, 32(4), 14-21.

Pound, P., Britten, N., Morgan, M., Yardley, L., Pope, C., Daker-White, G., \& Campbell, R. (2005). Resisting medicines: a synthesis of qualitative studies of medicine taking. Social science \& medicine, 61(1), 133-155.

Radecki, S. E., Kane, R. L., Solomon, D. H., Mendenhall, R. C., \& Beck, J. C. (1988). Do physicians spend less time with older patients? Journal of the American Geriatrics Society, 36(8), 713-718.

Ramstrom, H., Afandi, S., Elofsson, K., Peterssonn, S. (2006). Differences in beliefs between patients and pharmaceutical specialists regarding medications. Patient Education \& Counseling, 62, 244-249.

Rao, M., Clarke, A., Sanderson, C., \& Hammersley, R. (2006). Patients' own assessments of quality of primary care compared with objective records based measures of technical quality of care: cross sectional study. $B M J, 333(7557), 19$.

Ray, P. (1997). The emerging culture. American Demographics. Retrieved March 10, 2013, from www.demographics.com.

Reimann, S., \& Strech, D. (2010). The representation of patient experience and satisfaction in physician rating sites. A criteria-based analysis of English-and Germanlanguage sites. BMC Health Serv Res, 10(1), 332.

Robins, L. S., \& Wolf, F. M. (1988). Confrontation and politeness strategies in physicianpatient interactions. Social science \& medicine, 27(3), 217-221. 
Robinson, T. E., White, G., \& Houchins, J. C. (2006). Improving communication with older patients: tips from the literature. Family practice management, 13(8), 73.

Rodriguez-Osorio, C. A., \& Dominguez-Cherit, G. (2008). Medical decision making: paternalism versus patient-centered (autonomous) care. Curr Opin Crit Care, 14(6), 708713.

Rodriguez, K. L., Appelt, C. J., Switzer, G. E., Sonel, A. F., \& Arnold, R. M. (2008). Veterans' decision-making preferences and perceived involvement in care for chronic heart failure. Heart \& Lung: The Journal of Acute and Critical Care, 37(6), 440-448.

Rosenthal, M. B., Berndt, E. R., Donohue, J. M., Frank, R. G., \& Epstein, A. M. (2002). Promotion of prescription drugs to consumers. New England Journal of Medicine, 346(7), 498-505.

Roumie, C. L., Greevy, R., Wallston, K. A., Elasy, T. A., Kaltenbach, L., Kotter, K., Dittus, R. S., Speroff, T. (2011). Patient centered primary care is associated with patient hypertension medication adherence. Journal of behavioral medicine, 34(4), 244-253.

Routledge, P., O'Mahony, M., \& Woodhouse, K. (2004). Adverse drug reactions in elderly patients. British journal of clinical pharmacology, 57(2), 121-126.

Sa’ed, H., Al-Jabi, S. W., Sweileh, W. M., \& Morisky, D. E. (2013). Relationship of treatment satisfaction to medication adherence: findings from a cross-sectional survey among hypertensive patients in Palestine. Health and Quality of life Outcomes, 11(1), 191.

Sabaté, E. (2003). Adherence to long-term therapies: evidence for action: World Health Organization.

Sacco, R. L., Benjamin, E. J., Broderick, J. P., Dyken, M., Easton, J. D., Feinberg, W. M., Goldstein, L. B., Gorelick, P. B., Howard, G.,.Kittner, S. J. (1997). Risk factors. Stroke, 28(7), 1507-1517.

Safran, D. G., Kosinski, M., Tarlov, A. R., Rogers, W. H., Taira, D. A., Lieberman, N., \& Ware, J. E. (1998). The Primary Care Assessment Survey: tests of data quality and measurement performance. Medical care, 36(5), 728-739.

Sandra L. McGinnis, J. M. (March 2006). The Impact of the Aging Population on the Health Workforce in the United States: Summary of Key Findings. Rensselaer, NY:

University at Albany.

Schmader, K., Hanlon, J. T., Weinberger, M., \& Landsman, P. B. (1994).

Appropriateness of medication prescribing in ambulatory elderly patients. Journal of the American Geriatrics Society. 
Schneider, A., Körner, T., Mehring, M., Wensing, M., Elwyn, G., \& Szecsenyi, J. (2006). Impact of age, health locus of control and psychological co-morbidity on patients' preferences for shared decision making in general practice. Patient education and counseling, 61(2), 292-298.

Schüz, B., Wurm, S., Ziegelmann, J. P., Warner, L. M., Tesch-Römer, C., \& Schwarzer, R. (2011). Changes in functional health, changes in medication beliefs, and medication adherence. Health Psychology, 30(1), 31 .

Sciamanna, C. N., Clark, M. A., Diaz, J. A., \& Newton, S. (2003). Filling the gaps in physician communication: The role of the Internet among primary care patients.

International journal of medical informatics, 72(1), 1-8.

Segal, J. (2009). The role of the Internet in doctor performance rating. Pain Physician, 12(3), 659-664.

Seibert, J. H., Brien, J. S., Maaske, B. L., Kochurka, K., Feldt, K., Fader, L., \& Race, K. E. (1999). Assessing Patient Satisfaction across the Continuum of Ambulatory Care: A Revalidation and Validation of Care-Specific Surveys. The Journal of ambulatory care management, 22(2), 9-26.

Shaw, B. R., Han, J. Y., Hawkins, R. P., Stewart, J., McTavish, F., \& Gustafson, D. H. (2007). Doctor-patient relationship as motivation and outcome: examining uses of an interactive cancer communication system. International journal of medical informatics, 76(4), 274-282.

Sillence, E., Briggs, P., Harris, P. R., \& Fishwick, L. (2007). How do patients evaluate and make use of online health information? Social science \& medicine, 64(9), 1853-1862.

Sokol, M. C., McGuigan, K. A., Verbrugge, R. R., \& Epstein, R. S. (2005). Impact of medication adherence on hospitalization risk and healthcare cost. Med Care, 43(6), 521530 .

Spinewine, A., Schmader, K. E., Barber, N., Hughes, C., Lapane, K. L., Swine, C., \& Hanlon, J. T. (2007). Appropriate prescribing in elderly people: how well can it be measured and optimised? The Lancet, 370(9582), 173-184.

Stats, I. W. (2012). Internet usage statistics. The Internet big picture: World Internet users and populations stats.

Stein, K. (2006). Communication is the heart of provider-patient relationship. $J$ Am Diet Assoc, 106(4), 508-512.

Stevenson, D. G. (2006). Is a public reporting approach appropriate for nursing home care? Journal of Health Politics, Policy and Law, 31(4), 773-810. 
Stevenson, F. A., Barry, C. A., Britten, N., Barber, N., \& Bradley, C. P. (2000). Doctorpatient communication about drugs: the evidence for shared decision making. Social science \& medicine, 50(6), 829-840.

Stewart, M. A. (1995). Effective physician-patient communication and health outcomes: a review. CMAJ: Canadian Medical Association Journal, 152(9), 1423.

Street Jr, R. L., Gordon, H., \& Haidet, P. (2007). Physicians' communication and perceptions of patients: Is it how they look, how they talk, or is it just the doctor? Social science \& medicine, 65(3), 586-598.

Street Jr, R. L., Makoul, G., Arora, N. K., \& Epstein, R. M. (2009). How does communication heal? Pathways linking clinician-patient communication to health outcomes. Patient education and counseling, 74(3), 295-301.

Streiner, D. L. (2005). Finding our way: an introduction to path analysis. The Canadian Journal of Psychiatry/La Revue canadienne de psychiatrie.

Strull, W. M., Lo, B., \& Charles, G. (1984). Do patients want to participate in medical decision making? JAMA: the journal of the American Medical Association, 252(21), 2990-2994.

Suhr, D. D. (2005). Principal component analysis vs. exploratory factor analysis. SUGI 30 Proceedings, 203-230.

Tabachnick, B. G., \& Fidell, L. S. (2001). Using multivariate statistics.

Tara Lagu MD, M., Hannon, N. S., Rothberg, M. B., \& Lindenauer, P. K. (2010).

Patients' evaluations of health care providers in the era of social networking: an analysis of physician-rating websites. Journal of general internal medicine, 25(9), 942-946.

Tariman, J., Berry, D., Cochrane, B., Doorenbos, A., \& Schepp, K. (2010). Preferred and actual participation roles during health care decision making in persons with cancer: a systematic review. Annals of Oncology, 21(6), 1145-1151.

Thorndike, R. L., \& Hagen, E. (1961). Measurement and evaluation in psychology and education.

Torrance, G. W., \& Drummond, M. (2005). Methods for the economic evaluation of health care programs: Oxford University Press.

Travaline, J. M., Ruchinskas, R., \& D'Alonzo, G. E. (2005). Patient-physician communication: why and how. JAOA: Journal of the American Osteopathic Association, 105(1), 13-18. 
Trigg, L. (2011). Patients' opinions of health care providers for supporting choice and quality improvement. Journal of health services research \& policy, 16(2), 102-107.

Tucker 3rd, J., \& Kelley, V. A. (2000). The influence of patient sociodemographic characteristics on patient satisfaction. Military medicine, 165(1), 72-76.

U.S. Administration on Aging (AOA). (2012). Retrieved Sptember 15, 2013, from http://www.aoa.gov/AoARoot/Aging_Statistics/Profile/2011/2.aspx.

Van Woerkum, C. M. (2003). The Internet and primary care physicians: coping with different expectations. The American journal of clinical nutrition, 77(4), 1016S-1018S.

Ventola, C. L. (2011). Direct-to-consumer pharmaceutical advertising: therapeutic or toxic? Pharmacy and Therapeutics, 36(10), 669.

Wald, H. S., Dube, C. E., \& Anthony, D. C. (2007). Untangling the Web-the impact of Internet use on health care and the physician-patient relationship. Patient education and counseling, 68(3), 218-224.

Wallace, L. S., Rogers, E. S., Roskos, S. E., Holiday, D. B., \& Weiss, B. D. (2006). Brief report: screening items to identify patients with limited health literacy skills. Journal of general internal medicine, 21(8), 874-877.

Ward, B. W. (2013). Prevalence of multiple chronic conditions among US adults: estimates from the National Health Interview Survey, 2010. Preventing chronic disease, 10.

Ware Jr, J. E., Kosinski, M., \& Keller, S. D. (1996). A 12-Item Short-Form Health Survey: construction of scales and preliminary tests of reliability and validity. Medical care, 34(3), 220-233.

Wasson, J. H. (2008). Adapting what is known. BMJ, 336(7650), 950-951.

WHO. Failure to take prescribed medicine for chronic diseases is a massive, world-wide problem. Press Release. Retrieved 27 October, 2013, from

http://www.who.int/mediacentre/news/releases/2003/pr54/en/.

Wilhelmson, K., Andersson, C., Waern, M., \& Allebeck, P. (2005). Elderly people's perspectives on quality of life. Ageing and Society, 25(4), 585-600.

Wilkinson, C., Khanji, M., Cotter, P., Dunne, O., \& O’keeffe, S. (2008). Preferences of acutely ill patients for participation in medical decision-making. Quality and Safety in Health Care, 17(2), 97-100. 
Winker, M. A., Flanagin, A., Chi-Lum, B., White, J., Andrews, K., Kennett, R. L., . . Musacchio, R. A. (2000). Guidelines for medical and health information sites on the Internet. JAMA: the journal of the American Medical Association, 283(12), 1600-1606.

Xavier, F. M., Ferraz, M., Marc, N., Escosteguy, N. U., \& Moriguchi, E. H. (2003). Elderly people s definition of quality of life. Revista Brasileira de Psiquiatria, 25(1), 31 39.

Ybarra, M. L., \& Suman, M. (2006). Help seeking behavior and the Internet: a national survey. International journal of medical informatics, 75(1), 29-41.

Zachariae, R., Pedersen, C. G., Jensen, A. B., Ehrnrooth, E., Rossen, P., \& Von Der Maase, H. (2003). Association of perceived physician communication style with patient satisfaction, distress, cancer-related self-efficacy, and perceived control over the disease. British Journal of Cancer, 88(5), 658-665.

Zandbelt, L. C., Smets, E., Oort, F. J., Godfried, M. H., \& de Haes, H. C. (2006). Determinants of physicians' patient-centred behaviour in the medical specialist encounter. Social science \& medicine, 63(4), 899-910. 
APPENDIX A. QUESTIONNAIRES AND COPYRIGHT PERMISSIONS 


\section{BELIEFS ABOUT MEDICINES QUESTIONNAIRE (BMQ) PERMISSION}

\section{Conditions for Translation and Usage of the Beliefs about Medicines Questionnaire (BMQ)}

1. The copyright of the translated $\mathrm{BMQ}$ and all adaptations remains with the Originator (Professor Rob Horne). (NOTE: subsequent permission to use the translated questionnaire must be agreed by him).

2. The translated $B M Q$ is used ethically

3. The BMQ is translated and used completely intact. Items or phrases may not be removed or used in other contexts.

4. The back-translation of the BMQ is approved by Professor Horne

5. All copies of the BMQ will have the legend: 'C Professor Rob Horne' clearly indicated on them.

6. The $B M Q$ is analysed and reported in accordance with the instructions of the Originator

7. The BMQ may not be used in studies developing other assessment tools without specific permission of the originator

8. A copy of the translated questionnaire is submitted to Prof Horne.

Publication rights of the BMQ

1. The BMQ itself may not be published except by its constructors.

2. Permitted users are free to publish $B M Q$ scale scores without collaborating with the Originator

3. Publications, which include psychometric data of the BMQ, should include Professor Horne as a coauthor.

I agree to the above conditions for translation of the BMQ:

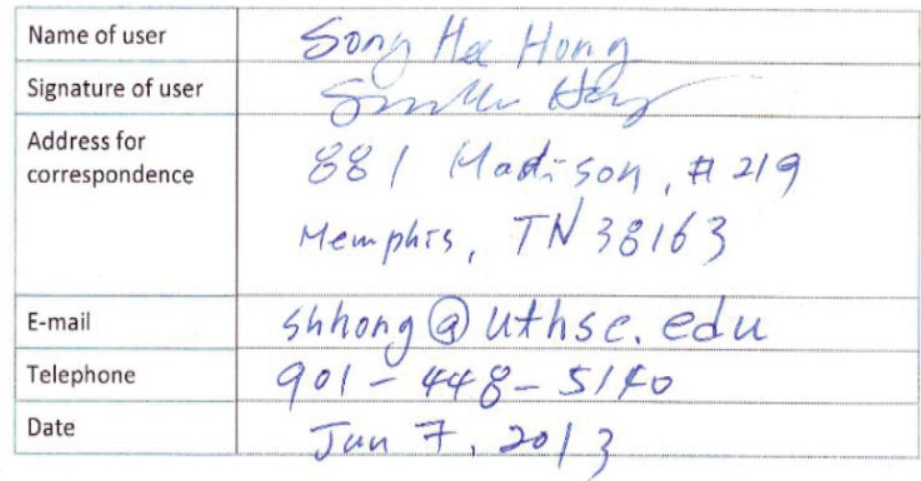

BMQ CONDITIONS for translation and usage form RH 0611. docx 


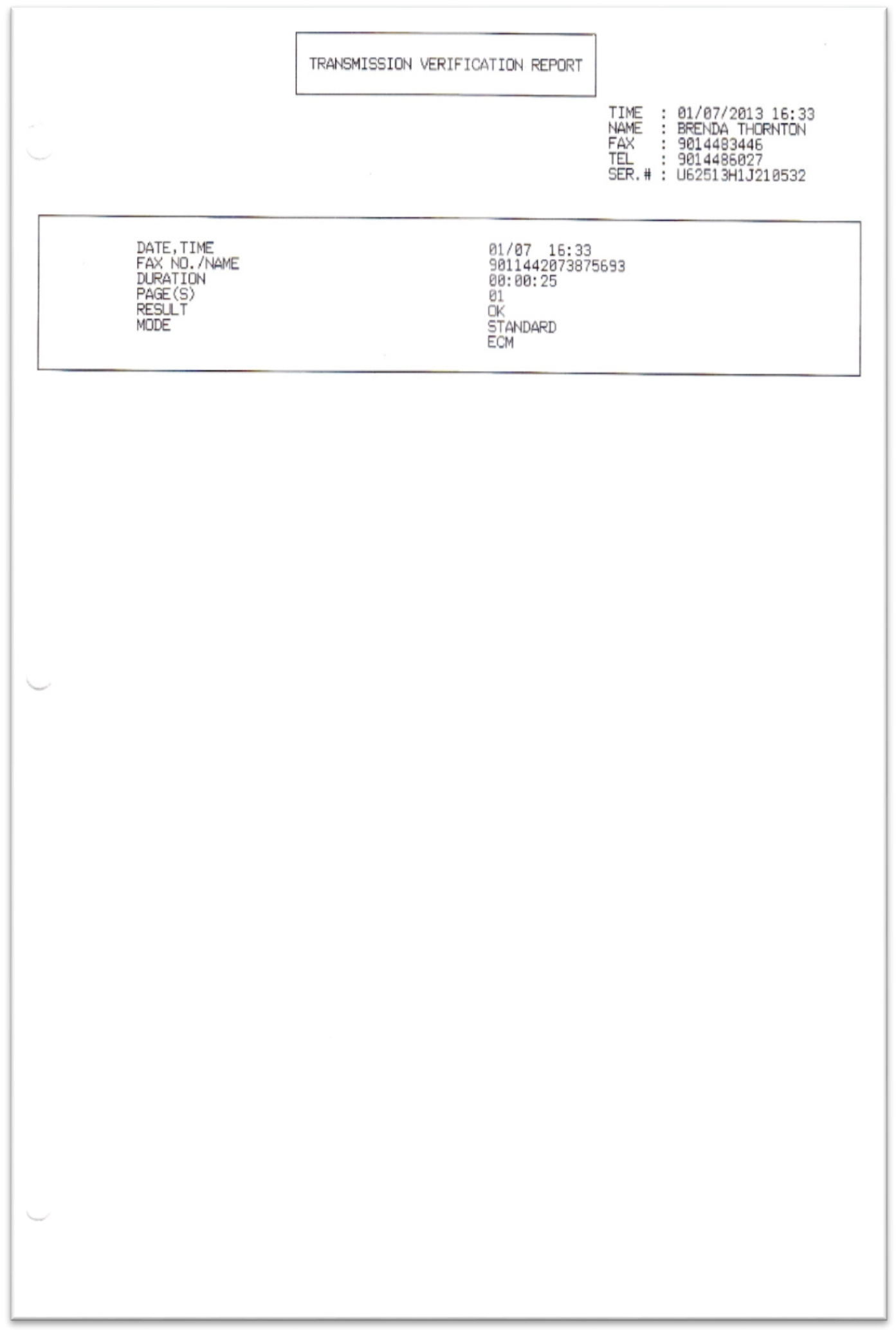




\title{
PRIMARY CARE ASSESSMENT SURVEY (PCAS) PERMISSION
}

\author{
Reply Reply All Forward \\ RE: Primary care assessment survey \\ Li, Angela [Angela.Li@bcbsma.com] \\ To: \\ yalru hi \\ Attachments: \\ (2) Dowrioad all attachments \\ PCAS Surveyzip (110 KB); PCAS Scoringzip (30 KB)
}

Monday, October 01, 20121154 AM

You forwarded this message on 12/8/2012 8:35 PM.

Hello,

My apologies - we have been having problems with the online request form.

Thank you for your interest in the Primary Care Assessment Survey. I have attached two zip files for you to use. The first contains copies of the PCAS (long form and short form), a domains document that indicates which items are used in the various scales, and an up-to-date publication listing that cites work from the PCAS. The second zip file contains scoring information for the PCAS as well as a sample dataset for you to use.

Please let me know if you have any questions or concerns.

Best of luck with your research.

Thanks,

Angela Li

From: yalruthi [mailto:yalruthi@uthsc.edu] Sent: Monday, October 01, 2012 12:48 PM To: Li, Angela

Subject: Primary care assessment survey

Greetings Ms.Angela,

Hope this Email finds you in your best health. Actually, I just need a small favor from you. I have submitted a request through Tuft clinical research and health policy institute a month ago to get a copy of the PRIMARY CARE ASSESSMENT SURVEY (PCAS), but unfortunately I did not receive anything so far. Today, I have made another request and I am hopeful that I will receive a copy. Would you please Email me a copy of the PCAS?

Thank you very much :) attached is copy of the request that I submitted today.

Sincerely,

Yazed Al-Ruthia, B.Sc.Pharm, PharmD

Doctoral Student, Health Outcomes and Policy Research

The University of Tennessee Health Science Center

College of Pharmacy

881, Madison Ave., Suite 212

Memphis, TN 38163

Office: (901)448-3522 


\section{SHORT FORM HEALTH SURVEY (SF-12V2) PERMISSION}

From: Pam Bartley [mailto:pbartley@qualitymetric.com]

Sent: Thursday, May 23, 2013 10:31 AM

To: Hong, Song Hee

Cc: Pam Bartley

Subject: QualityMetric Health Outcomes(tm) Scoring Software 4.5 Activation Key - University of Tennessee Health Science Center - QM017085

Dear Yazed Sulaiman Alruthia,

Thank you for purchasing QualityMetric Health Outcomes $(\mathrm{tm})$ Scoring Software 4.5. Please use the Activation Key provided below to unlock the application for the licensed survey(s) and scoring features. This key will install a pre-determined quantity of scoring credits (as per the license agreement) which will be decremented each time a record is entered/scored. Once the credits are exhausted, you will need to contact OptumInsight Life Sciences to obtain more credits and resume scoring.

ACTIVATION KEY:

1D389-3BD64-F62FF-F332C

LICENSED PRODUCTS AND SCORING FEATURES:

PRODUCT NAME: QualityMetric Health Outcomes $(\mathrm{tm})$ Scoring Software 4.5

PURCHASE DATE: 05/22/13

SF12v2 Credit Count: 400

SF12v2 MDE Enabled: Yes

SF12v2 Utility Index: No

SF12v2 DQE Report: Yes

DOWNLOAD AND INSTALLATION:

You may download QualityMetric Health Outcomes $(\mathrm{tm})$ Scoring Software 4.5 installer from the following location:

http://www.qualitymetric.com/download/SFScoringSoftwareV45Setup.msi

IMPORTANT NOTES - PLEASE READ

Important installation notes are provided below. More detailed instructions are included in the attached. If you are prohibited from installing software or do not feel comfortable doing so, please consult your IT support and bring the items below to their attention: 


\section{MORISKY MEDICATION ADHERENCE SCALE (MMAS-8) PERMISSION}

License Agreement for use of the Morisky Medication Adherence Intellectual Property

In consideration for the right to use certain Morisky proprietary psychometric tools and intellectual property, the undersigned researcher (hereunder "Licensee" or "you") agrees to the following:

A. Ownership and Fees: All psychometric products as well as their translations, adaptations, computer programs, and scoring algorithms, trade secrets, and any other related documents and information (including those in electronic form) which embody or are related to the MMAS tools (including without limitation the Morisky Medication Adherence Scale 4- and 8-item versions, 4-item Morisky Adherence Questionnaire, and any documentation thereof) are intellectual property of Donald E. Morisky, ScD, ScM, MSPH. ("Owner") Professor of Community Health Sciences, UCLA Fielding School of Public Health, Los Angeles, CA 90095-1772 (the add ress for all payments and communications related to this agreement). The license fee is $\mathbf{S 0 . 3 5}$ per administration for each patient, payable in advance (fee waiver available for students and those conducting publicly funded adherence research).

B. Translations: Permission will only be granted to translate the MMAS tools subject to the following requirements: all translations must be made by contracting with the MAPI Institute and final translations must be approved by the Owner. Languages that have already been translated and validated by the MAPI Institute can be requested through the MAPI Trust (notes: the MAPI Institute employs the most rigorous standards in the translation process using two native linguistic experts to independently conduct forward and backwards translation; the Owner is generally involved in validating each item in the scale and grants use of the translated scale through a separate license agreement; those wishing to produce a translation should contact the Owner for further details).

\section{Use: Licensee understands and agrees that}

1) Changes to the wording or phrasing of any Morisky scale, tool or document require written permission. If any changes made to the wording or phrasing of any MMAS item or other Morisky document without permission, the result cannot be considered the MMAS, and subsequent analyses and/or comparisons to other MMAS data may violate Owner's rights.

2) Coding and scoring criteria of the MMAS-8 are trade secrets of the Owner and as such cannot be divulged in any publication or report without the Owner's prior written permission;

3) Permission to use the trademarks "Morisky," "MORISKY SCALE" or "MMAS" is not and will not be granted for any unauthorized use or translations of the MMAS or other MORISKY intellectual property, in whole or in part. No analyses, research results or publications based on unauthorized changes or translated versions, or results thereof, will use MORISKY, MMAS or confusingly similar attributions.

4) The MORISKY SCALE intellectual property legend on the documents provided to you must be included on every page of a MORISKY SCALE questionnaire in study documents, and in any reproductions for manuscript or other publication purposes.

5) In case of scientific, administrative or intellectual property misconduct in using the MORISKY SCALE system of questionnaires or the Morisky name or MMAS names, Owner reserves the right to withdraw permission for use and to pursue all legal remedies. Licensee agrees to the jurisdiction in and venue of the State and Federal Courts in Los Angeles County.

6) Rights granted under this Agreement to use the Morisky scales terminate one-year from the date below or on termination of Licensee's study, whichever is shorter. Licensee acknowledges understanding and agreeing to abide by the above requirements regarding use of any Morisky Medication Adherence Scale or other Morisky intellectual property.

I understand that the licensure fee for use of the copyrighted MMAS-8 will be waived, as I am a doctoral student conducting adherence research with no private funding source. If this situation should change to private sources of funding, then the license is no longer in effect. The license agreement is in effect for a one-year period or the duration of the study, whichever is shorter. If your study is longer than one year, a renewal of license is available based upon a brief status report. I agree with the specification outlined above regarding the use of the Morisky Medication Adherence Scale, 8-Items, MMAS-8 and will abide with its requirements. I agree to provide results of my research to Professor Morisky upon completion of his study. Please fax or scan and email to: Donald E. Morisky, ScD, ScM, MSPH, Professor, Department If Community Health Sciences, UCLA Fielding School of Public Health, 650 Charles E. Young Drive South, Los Angeles, CA 90095-1772. fax 310-794-1805 or email to dmorisky@ucla.edu. 
Name and contact information of Licensee / Researchers:

Yazed Al-Ruthia, B.Sc.Pharm, PharmD

Toctoral Student, Health Outcomes and Policy Research

$\checkmark$ he University of Tennessee Health Science Center

College of Pharmacy

881, Madison Ave., Suite 212

Memphis, TN 38163

Office: (901)448-3522

Cell: (617)755-9170

E-mail: yalruthi@uthsc.edu

Song Hee Hong, Ph.D.

Associate Professor, Pharmaceutical Economics

Dept. of Clinical Pharmacy

University of Tennessee Health Science Center (UTHSC) College of Pharmacy

881 Madison, Room 219

Memphis TN 38163

Phone: $901-448-5140$

email: shhong@uthsc.edu

Title of Research:

The Value of Patients' Ratings \& Reviews of Prescribed Medicines

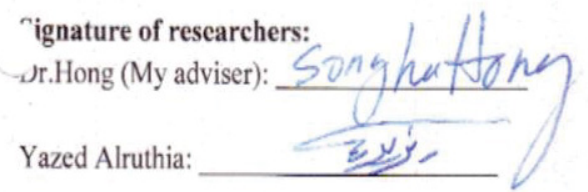

Date: $12 / 12 / 2012$ 
881 Madison Ave., Room 440

vemphis. TN 38163

901) 448-1060 - phone

(901) $443-4731$ - $\operatorname{fax}$

\section{UT Memphis}
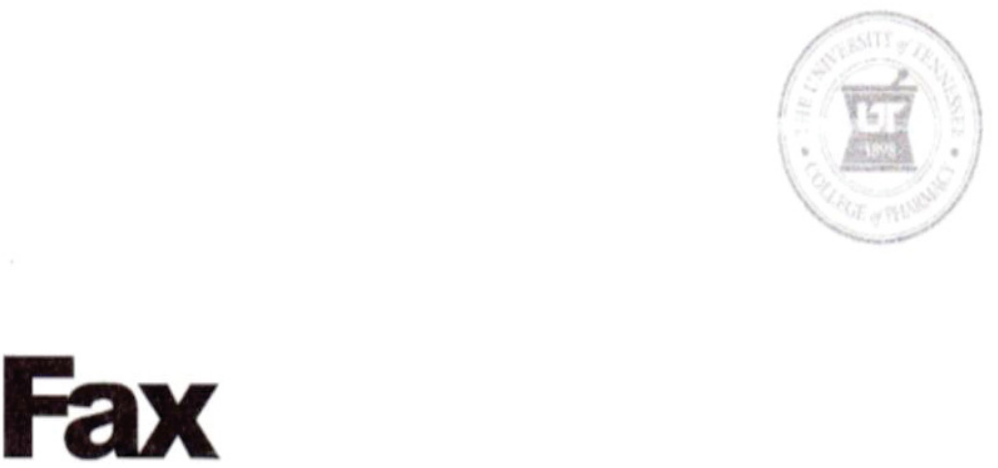

\begin{tabular}{lccl} 
To: & Donald Morisky & From: & Cynthia Crowe \\
\hline Fax: & $310-794-1805$ & Pages: & 3 (including cover) \\
\hline Phone: & Date: & December 17, 2012 \\
\hline Re: $\quad$ Yazed Al-Ruthia & CC: & \\
\hline & & & \\
Q Urgent $\quad \square$ For Review & $\square$ Please Comment & $\square$ Please Reply $\square$ Please Recycle
\end{tabular}




\title{
FACTORS INFLUENCING PHYSICIAN-PATIENT COMMUNICATION (FIGURE 2-1) PERMISSION
}

\author{
ELSEVIER LICENSE \\ TERMS AND CONDITIONS \\ Feb 21, 2015
}

This is a License Agreement between Yazed Sulaiman AlRuthia ("You") and Elsevier ("Elsevier") provided by Copyright Clearance Center ("CCC"). The license consists of your order details, the terms and conditions provided by Elsevier, and the payment terms and conditions.

\begin{tabular}{|c|c|}
\hline \multicolumn{2}{|c|}{$\begin{array}{l}\text { All payments must be made in full to CCC. For payment instructions, please see } \\
\text { information listed at the bottom of this form. }\end{array}$} \\
\hline Supplier & $\begin{array}{l}\text { Elsevier Limited } \\
\text { The Boulevard,Langford Lane } \\
\text { Kidlington,Oxford,OX5 1GB,UK }\end{array}$ \\
\hline Registered Company Number & 1982084 \\
\hline Customer name & Yazed Sulaiman AlRuthia \\
\hline Customer address & 7879 Crescent Hill Drive \\
\hline & Memphis, TN 38133 \\
\hline License number & 3573780527234 \\
\hline License date & Feb 21, 2015 \\
\hline Licensed content publisher & Elsevier \\
\hline Licensed content publication & Social Science \& Medicine \\
\hline Licensed content title & $\begin{array}{l}\text { Physicians' communication and perceptions of patients: } \\
\text { Is it how they look, how they talk, or is it just the } \\
\text { doctor? }\end{array}$ \\
\hline Licensed content author & Richard L. Street,Howard Gordon,Paul Haidet \\
\hline Licensed content date & August 2007 \\
\hline Licensed content volume number & 65 \\
\hline Licensed content issue number & 3 \\
\hline Number of pages & 13 \\
\hline Start Page & 586 \\
\hline End Page & 598 \\
\hline Type of Use & reuse in a thesis/dissertation \\
\hline Portion & figures/tables/illustrations \\
\hline $\begin{array}{l}\text { Number of } \\
\text { figures/tables/illustrations }\end{array}$ & 1 \\
\hline Format & both print and electronic \\
\hline $\begin{array}{l}\text { Are you the author of this Elsevier } \\
\text { article? }\end{array}$ & No \\
\hline Will you be translating? & No \\
\hline
\end{tabular}


Original figure numbers

Title of your thesis/dissertation

Expected completion date

Estimated size (number of pages)

Elsevier VAT number

Permissions price

VAT/Local Sales Tax

Total

Terms and Conditions

\section{Figure 1}

The Value of Online Medication Rating Systems to Older Adults and Their Association with Self-Reported Outcomes

Apr 2015

220

GB 494627212

0.00 USD

$0.00 \mathrm{USD} / 0.00 \mathrm{GBP}$

$0.00 \mathrm{USD}$ 


\title{
STAGED MODEL OF TRUST (FIGURE 2-4) PERMISSION
}

\author{
ELSEVIER LICENSE \\ TERMS AND CONDITIONS
}

Feb 21, 2015

This is a License Agreement between Yazed Sulaiman AlRuthia ("You") and Elsevier ("Elsevier") provided by Copyright Clearance Center ("CCC"). The license consists of your order details, the terms and conditions provided by Elsevier, and the payment terms and conditions.

All payments must be made in full to CCC. For payment instructions, please see information listed at the bottom of this form.

Supplier

Registered Company Number

Customer name

Customer address

License number

License date

Licensed content publisher

Licensed content publication

Licensed content title

Licensed content author

Licensed content date

Licensed content volume number

Licensed content issue number

Number of pages

Start Page

End Page

Type of Use

Intended publisher of new work

Portion

Number of figures/tables/illustrations

Format

Are you the author of this Elsevier article?
Elsevier Limited

The Boulevard,Langford Lane

Kidlington,Oxford,OX5 1GB,UK

1982084

Yazed Sulaiman AlRuthia

7879 Crescent Hill Drive

Memphis, TN 38133

3573801136816

Feb 21, 2015

Elsevier

Social Science \& Medicine

How do patients evaluate and make use of online health information?

Elizabeth Sillence,Pam Briggs,Peter Richard Harris,Lesley Fishwick

May 2007

64

9

10

1853

1862

reuse in a thesis/dissertation

other

figures/tables/illustrations

1

both print and electronic

No 
Will you be translating?

Original figure numbers

Title of your thesis/dissertation

Expected completion date

Estimated size (number of pages)

Elsevier VAT number

Permissions price

VAT/Local Sales Tax

Total

Terms and Conditions
No

Fig. 1.

The Value of Online Medication Rating Systems to Older Adults and Their Association with SelfReported Outcomes

Apr 2015

220

GB 494627212

0.00 USD

$0.00 \mathrm{USD} / 0.00 \mathrm{GBP}$

0.00 USD 


\title{
MODEL OF TREATMENT DECISION-MAKING (TABLE 2-1) PERMISSION
}

\author{
RE: Obtain Permission - Book request \\ Jones, Jennifer (ELS-OXF) [J.Jones@elsevier.com] \\ Sent:Tuesday, December 23, 2014 4:15 AM \\ To: yalruthi
}

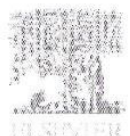

Dear Dr Yazed Al-Ruthia

We hereby grant you permission to reproduce the material detailed below at no charge in your thesis, in print and on the University of Tennessee Health Science Center's web site subject to the following conditions:

1. If any part of the material to be used (for example, figures) has appeared in our publication with credit or acknowledgement to another source, permission must also be sought from that source. If such permission is not obtained then that material may not be included in your publication/copies.

2. Suitable acknowledgment to the source must be made, either as a footnote or in a reference list at the end of your publication, as follows:

"This article was published in Publication title, Vol number, Author(s), Title of article, Page Nos, Copyright Elsevier (or appropriate Society name) (Year)."

3. Your thesis may be submitted to your institution in either print or electronic form.

4. Reproduction of this material is confined to the purpose for which permission is hereby given.

5. This permission is granted for non-exclusive world English rights only. For other languages please reapply separately for each one required. Permission excludes use in an electronic form other than as specified above. Should you have a specific electronic project in mind please reapply for permission.

6. This includes permission for UMI to supply single copies, on demand, of the complete thesis. Should your thesis be published commercially, please reapply for permission.

Yours sincerely

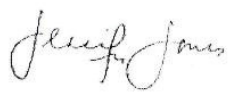


Jennifer Jones

Permissions Specialist

Elsevier Limited, a company registered in England and Wales with company number 1982084 , whose registered office is The Boulevard, Langford Lane, Kidlington, Oxford, OX5 1GB, United Kingdom.

From: yalruthi@uthsc.edu [mailto:yalruthi@uthsc.edu]

Sent: 13 December 2014 20:05

To: Rights and Permissions (ELS)

Subject: Obtain Permission - Book request

Title:

First name:

Last name:

Institute/company:

Address:

Post/Zip Code:

City:

Country:

Telephone:

Email:

Please select the type of

publication:

Book - Title:

Book - ISBN:

Book - Author(s):

Book - Year:

Book - Pages from:

Book - Pages to:

Book - Chapter Num:

Book - Chapter Title:
DR

Yazed

Al-Ruthia

University of Tennessee Health Science Center

7879 Crescent Hill Drive \#205

38133

Memphis

United States

617-755-9170

yalruthi@uthsc.edu

Book

Sociology as Applied to Medicine

9780702040252

Graham Scambler and Myfanwy Morgan

2003

58

58

4

The Doctor-Patient Relationship

I would like to use (please select one of the following options):

Table(s)

If using figures/tables or

illustrations please specify the

quantity:
Table 4.3 in chapter \# 4 in page \# 58 
Are you the author of the material?:

No

If not, is the author involved with your project:

No

In what format will you use the

material?:

Print and Electronic

Will you be translating the

material?:

Information about your proposed

use:

No

Proposed use text:

thesis

The University of Tennessee Health Science Center school of Graduate Studies will publish my dissertation after approving it in their website.

Elsevier Limited. Registered Office: The Boulevard, Langford Lane, Kid lington, Oxford, OX5 1GB, United Kingdom, Registration No. 1982084, Registered in England and Wales. 
APPENDIX B. INSTITUTIONAL REVIEW BOARD DOCUMENTS 


\section{UT IRB APPROVAL}

\begin{tabular}{lr}
\hline THE UNIVERSITY OF TENNESSEE \\
Health Science Center \\
\hline \\
Institutional Review Board \\
& 910 Madison Avenue, Suite 600 \\
Memphis, TN 38163 \\
Tel: (901) 448-4824
\end{tabular}

April 15, 2013

Song Hee Hong, Ph.D.

UTHSC - COP - Clinical Pharmacy

219 Pharmacy Building

Re: 13-02442-XM

Study Title: The Value of Patient Reviews of Medication Experiences (PROMEX)

Dear Dr. Hong:

The Administrative Section of the UTHSC Institutional Review Board (IRB) has received your written acceptance of and/or response dated April 10, 2013 to the provisos outlined in our correspondence of March 22, 2013 concerning the application for the above referenced project.

The IRB determined that your application is eligible for exempt review under 45CFR46.101(b)(2) in that the study/project involves eligible research using educational tests, surveys, interview procedures, or observation of public behavior. In accord with 45 CFR 46.116(d), informed consent may be altered with the cover statement used in lieu of an informed consent interview. The requirement to secure a signed consent form is waived under 45 CFR 46.117(c)(2). Willingness of the subject to participate will constitute adequate documentation of consent. Your application has been determined to comply with proper consideration for the rights and welfare of human subjects and the regulatory requirements for the protection of human subjects. Therefore, this letter constitutes full approval of your application (version 1.1), consent cover statement and survey [stamped approved by the IRB on April 15, 2013] for the above referenced study.

This study may not be initiated until you receive approval from the institution(s) where the research is being conducted.

In the event that volunteers are to be recruited using solicitation materials, such as brochures, posters, webbased advertisements, etc., these materials must receive prior approval of the IRB.

Any alterations (revisions) in the protocol, consent cover statement, or survey must be promptly submitted to and approved by the UTHSC Institutional Review Board prior to implementation of these revisions. In addition, you are responsible for reporting any unanticipated serious adverse events or other problems involving risks to subjects or others in the manner required by the local IRB policy.

Sincerely,

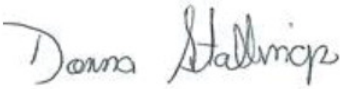

Signature applied by Donna L Stallings on 04/15/2013 01:20:05 PM CDT

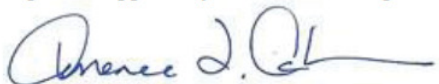

Signature applied by Terrence F Ackerman on 04/15/2013 01:22:00 PM CDT

Donna Stallings, CIM

Terrence F. Ackerman, Ph.D 


\section{STUDY COVER LETTER (CONSENT FORM)}

\section{Patient Reviews of Medication Experience (PROMEX)}

You, the patient, achieve the best health outcomes when you are involved in the treatment decision making process. You are more motivated to adhere to medication treatment when your physician considers your experiences and preferences while making the treatment decision. Thus, we would like to know what it has been like for you to take your medications.

First, we will ask you how valuable patient reviews of prescribed medicines (PROMEX) would be, if available. We will then ask you about your beliefs about prescribed medicines, as well as your experience of communicating with your doctor. If you have high blood pressure, we will further ask you to provide a review based on your own experience of taking each high blood pressure medication. The information you provide will help health care providers receive feedback on medication therapy decisions. It will facilitate communication between you and your prescribers about the best medication therapy options that work for you.

We are visiting senior centers in and around the Memphis area to invite people like you to participate in the survey, because as a senior, you are most likely to have taken a prescribed medicine, especially for high blood pressure. The survey will take approximately 25 minutes to complete. If you have any questions or concerns about the survey, we encourage you to talk to one of our research assistants. As a token of our appreciation, you will receive a $\$ 20$ Kroger gift card for completing the survey.

The survey does not involve any physical risks. However, at times, you may be tired after answering a series of questions. If that is the case, we absolutely encourage you to take a break for a couple of minutes, and then come back and finish the rest of the survey. Through your participation in this study, you will become aware of current trends of patient care as well as different drug therapy options for high blood pressure. Your participation in this study is absolutely voluntary. You have the right to stop answering questions at any time and withdraw from this study with no penalty or loss of rights to which you are entitled.

In order to keep your responses confidential, we will not ask for your name during the survey. Your record will be labeled with a code number. Hard copies of surveys will be kept in a secure place. If you have any questions about the research, you may contact Song Hee Hong, $\mathrm{PhD}$ at $901-448-5140$ (daytime M-F) or 901-850-8416 (nights \& weekends). If you have any questions about your rights as a research subject or concerning a research related injury, you can contact Dr. Terrence F. Ackerman, Ph.D., UTHSC IRB Chairman at 901-448-4824.

Sincerely,

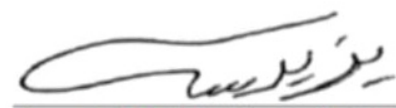

Yazed Al-Ruthia, PharmD, PhD student

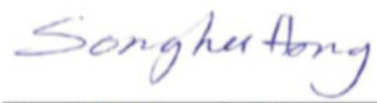

Song Hee Hong, Ph.D., Associate Professor College of Pharmacy

University of Tennessee Health Science Center 


\section{VITA}

Yazed Sulaiman AlRuthia was born in Riyadh, Saudi Arabia in 1983. He completed his bachelor degree in pharmaceutical sciences from King Saud University in Riyadh, Saudi Arabia, in 2007. After receiving his degree, he worked as a teaching assistant in the college of pharmacy at King Saud University from year 2007-2008. In fall 2008, he received a scholarship from the Saudi Arabian ministry of higher education to pursue his doctor of pharmacy from Massachusetts College of Pharmacy and Health sciences in Worcester, MA. In May 2011, he completed his doctor of pharmacy degree and joined the $\mathrm{PhD}$ program at the University of Tennessee (Major: Health Outcomes and Policy Research). 